\title{
Le rituel des cérémonies
}

\section{Jean Duma (dir.)}




\section{Le rituel des cérémonies}

Jean Duma (dir.)

DOI : $10.4000 /$ books.cths. 1545

Éditeur : Éditions du Comité des travaux historiques et scientifiques Année d'édition : 2015

Date de mise en ligne : 13 novembre 2018

Collection : Actes des congrès nationaux des sociétés historiques et scientifiques

ISBN électronique : 9782735508693

\section{Sbooks}

http://books.openedition.org

\section{Édition imprimée}

Nombre de pages : 150

\section{Référence électronique}

DUMA, Jean (dir.). Le rituel des cérémonies. Nouvelle édition [en ligne]. Paris : Éditions du Comité des

travaux historiques et scientifiques, 2015 (généré le 10 décembre 2020). Disponible sur Internet: <http://books.openedition.org/cths/1545>. ISBN : 9782735508693. DOI : https://doi.org/10.4000/ books.cths. 1545 .

(C) Éditions du Comité des travaux historiques et scientifiques, 2015

Conditions d'utilisation:

http://www.openedition.org/6540 
COMITÉ DES TRAVAUX HISTORIQUES ET SCIENTIFIQUES

\section{Le Rituel des cérémonies}

Sous la direction de

Jean DUMA

ÉDITIONS DU CTHS

2015 
Ministère de l'Éducation nationale,

de l'Enseignement supérieur et de la Recherche

Congrès national des sociétés historiques et scientifiques

139e, Nîmes, 2014

Collection Actes des congrès des sociétés historiques et scientifiques,

Version électronique

ISSN 1773-0899 


\section{Cérémonies et pouvoir}

Nicole BOELS-JANSSEN

Les multiples langages du rituel nuptial à Rome

Françoise BAYARD

Faire, dire, montrer : la communication $d u$

consulat lyonnais lors des entrées princières (1656-1789)

p. 23

Sandrine KRIKORIAN

De l'entremets médiéval aux festins

louis-quatorziens : propagande politique et faste royal

p. 34

Fernando SUAREZ GOLAN

Conflit et mise en scène du pouvoir : les entrées

des archevêques dans la ville de Saint-Jacques-de-Compostelle aux XVII et XVIII siècles

\section{Gestes, mise en scène et représentation}

Éric TEYSSIER

Pollice verso ou comment communiquer

dans l'amphithéâtre?

Chrystel LUPANT

Jeux de mains et jeux de regards.

Nouvelle lecture du manuscrit de saint Maur

Philippe CHAREYRE

Pasteur caché, pasteur devoilé. Le rituel des assemblées du Désert en Béarn

Jean-Pierre BAT et Émeline SEIGNOBOS

Le président face à ses discours (1932-2014) 


\section{Lieux}

Sabine TEULON LARDIC

Communiquer sur la citoyenneté et la latinité

par le spectacle dans l'amphithéâtre de Nîmes (1900-1939)

p. 106

Sonia ZERBIB

De l'apologie à l'apothéose médicéenne:

le «Salon des Cinq Cents » et «San Lorenzo » (1564-1587)

p. 122

Blandine SILVESTRE

La représentation départementale en

ses murs : l'hémicycle du Conseil général de Vaucluse (1875-2013)

p. 133 


\title{
Introduction
}

\author{
Jean DUMA \\ Professeur émérite des universités, \\ président de la commission des publications du CTHS \\ Extrait de : Jean DUMA (dir.), Le Rituel des cérémonies, Paris, \\ Extrait de : Jean DUMA (dir.), Le Rituel des cérémonies, Paris,
des congrès des sociétés historiques et scientifiques), 2015. \\ Cet article a été validé par le comité de lecture des Éditions du CTHS dans le cadre de la publication \\ des actes du $139^{\mathrm{e}}$ Congrès national des sociétés historiques et scientifiques tenu à Nîmes en 2014.
}

Dire que les formes de communication sont extrêmement diverses, c'est énoncer une évidence, voire émettre une banalité ou une platitude. Elles utilisent différents vecteurs. L'écrit ou la parole y apparaissent comme des éléments fondamentaux et l'image également joue un rôle précoce. Mais la communication non verbale, surtout dans les sociétés qui ne maîtrisent que partiellement l'écrit et qui sont peu alphabétisées, a une très grande importance et prend des chemins très divers : association du geste, volontaire ou non, à la parole; usage des codes: couleurs, musique, bruits, gestes, signaux à distance; usage des symboles dont il est intéressant de suivre à la fois l'origine et le devenir et comment ils ont pu être réappropriés par des sociétés différentes de celles qui les ont mises en circulation.

Parmi les formes de communication, les cérémonies occupent une place particulière. Lorsque Furetière, dans son dictionnaire, les définit en 1690 comme un " assemblage de plusieurs actions, pompes \& manières d'agir, qui servent à rendre une chose plus magnifique et plus solennelle », il met d'emblée l'accent sur un double aspect qui les caractérise.

Tout d'abord leur dimension rituelle qui se manifeste aussi bien dans leur forme, avec un assemblage de règles invariables, que dans leur fonction, donner à voir une certaine image du pouvoir, de son détenteur, une image lisible et souvent immédiatement compréhensible par ceux à qui elle est destinée. Ces pratiques réglées donnent aux phénomènes concernés un caractère sacré et symbolique fort.

Ensuite, c'est une pratique que l'on pourrait qualifier de globale. Les cérémonies concernées sont aussi bien politiques que religieuses. Mais la ritualisation cérémonielle peut aussi concerner fêtes et jeux. Ce rituel met en œuvre toutes les techniques déjà évoquées, usage des images et des symboles, recours à des codes de toutes sortes y compris vestimentaires, communications non verbales, usage de lieux spécifiques ou mise en scène dans des lieux usuels.

Les cérémonies contribuent à donner une certaine image et du pouvoir et de leurs détenteurs. Ce sont des discours qui se déclinent dans des lieux divers, des lieux de la parole publique, de l'affirmation de l'autorité mais aussi de sa contestation. Elles jouent un rôle important dans les comportements individuels et collectifs. Elles sont investies de significations symboliques variables selon les sociétés. Tantôt elles sont accessibles à tous, tantôt seulement à des élites, seules capables de les « décrypter ».

Le congrès de Nîmes du CTHS a consacré une session au rituel des cérémonies et les communications présentées à cette occasion couvrent un champ chronologique très large, de l'Antiquité à aujourd'hui et ont exploré, de façon très diverse et à travers des sources nombreuses, quelques-unes de ces questions. Trois grands axes se dégagent de leur présentation. 


\section{Cérémonies et pouvoir}

Un certain nombre de contributions se sont intéressées aux cérémonies et à leur rituel de façon globale en s'interrogeant sur les rapports qu'elles entretiennent avec le ou les pouvoirs.

Nicole Boëls-Janssen, en analysant le rituel nuptial dans la Rome antique a une approche globale de la cérémonie avec ses dimensions privée, religieuse, festive. Elle souligne les multiples langages utilisés lors de ce rite d'intégration, parole juridique et religieuse, mais aussi images signifiantes, gestuelle théâtrale, cris, acclamations, chants qui se succèdent ou s'associent à cette occasion changeant selon les lieux privés ou publics investis et les publics auxquels s'adressent ces messages.

En présentant la communication du consulat lyonnais lors des entrées princières (16561789), Françoise Bayard met en évidence une spécificité lyonnaise : la persistance, après 1656, sous la responsabilité des autorités municipales de la réception des souverains et des princes français ou étrangers et des ambassadeurs. Dans ces cérémonies, organisées à l'image des entrées royales, se manifeste l'affirmation, parfois coûteuse, des élites urbaines.

Sandrine Krikorian analyse comment propagande politique et faste royal sont étroitement imbriqués à l'occasion de certains repas royaux organisés à la fin du Moyen Âge et à l'époque moderne. Les banquets officiels des rois et des princes constituent un lieu privilégié de cette propagande. Elle souligne les mutations qui se manifestent dans ce qui est aussi un discours sur le pouvoir et met notamment en évidence, comment, à travers la typologie très variée de ces repas, on assiste à un dédoublement des langages, et on passe du souverain serviteur de Dieu aux représentations allégoriques des Dieux qui servent les souverains.

Fernando Suárez Golán se penche sur les entrées des archevêques dans la ville de SaintJacques-de-Compostelle aux XVII ${ }^{\mathrm{e}}$ et $\mathrm{XVIII}{ }^{\mathrm{e}}$ siècles et montre qu'elles constituent une mise en scène du pouvoir. Les différentes procédures mises en œuvre par la communauté urbaine visent à perpétuer et, éventuellement, modifier l'ordre de gouvernement établi dans la ville. Elles sont un reflet des conflits sociaux et politiques dans l'espace urbain.

\section{Gestes, mise en scène et représentation}

D'autres contributions sont davantage centrées sur des aspects plus spécifiques et abordent la question des gestes et de la théâtralisation des cérémonies.

Ainsi Éric Teyssier s'attache aux formes de communication dans l'arène lors des combats de gladiateurs. Il montre, à travers de multiples exemples, que tous les moyens sont bons pour communiquer : en amont par des «affiches » peintes sur les murs, des "produits dérivés ", des graffitis, des programmes sans doute sur papyrus ; pendant les combats, avec les couleurs de certains combattants et le décor de leur bouclier. Des pancartes, sans doute rédigées à l'avance, sont présentées par les ministri. Des sonneries connues du public annoncent chaque moment fort à grand renfort de cuivres. Le praeco, crieur officiel à mi-chemin entre le monsieur Loyal et le "chauffeur de salle» délivre lui aussi les informations importantes. Mais surtout, la communication s'opère au moyen d'une gestuelle très codifiée des arbitres et des gladiateurs. Le public intervient également, par les cris ou par les gestes en agitant notamment sa mappa pour demander, plus souvent qu'on ne le pense, la grâce du vaincu. Il montre que, loin des stéréotypes forgés au XIX siècle, la gestuelle des gladiateurs est à la fois plus variée et moins rigide qu'on ne le pense et il apparait que la gladiature constitue une sorte de dialogue entre les combattants, l'arbitre, le commanditaire et surtout le public.

Chrystel Lupant, de son côté, en se livrant à une nouvelle lecture du manuscrit de la Vie de saint Maur, examine les jeux de mains et les jeux de regards dans les enluminures du 
manuscrit. Cette mise en scène imagée des mains et des regards souligne l'importance des gestes et des attitudes qui sont autant de moyens d'expressions des corps, des sens et des émotions, lors des rites de passage d'intégration à ou de rupture avec la communauté. Cette approche s'intéressant à la communication non-verbale conduit à revisiter l'image hagiographique du manuscrit.

Philippe Chareyre étudie les grandes assemblées protestantes au Désert, de formidables théâtres où le pasteur est l'acteur principal et s'affiche comme le conducteur de la communauté. Bien que le message repose sur l'écrit, le geste et l'oralité jouent un rôle important à l'occasion des sermons. Le geste est peut-être le moyen le plus fort pour faire passer un message et le pasteur, usant de l'écrit, du geste et de l'oralité, apparaît surtout comme le maître d'œuvre d'une mise en scène au sein d'un cérémonial spécifique entièrement dédié à son service.

Enfin Émeline Seignobos et Jean-Pierre Bat, en interrogeant «Le président face à ses discours (1932-2014) » développent une réflexion qui croise approches archivistiques et mémorielles et dégage la fonction de la parole présidentielle, de la $\mathrm{III}^{\mathrm{e}}$ à la $\mathrm{V}^{\mathrm{e}}$ République, depuis le mandat d'Albert Lebrun jusqu'à celui de François Hollande, dans la construction et les mécanismes qui président à cette élaboration. On assiste alors à une véritable mise en scène du dire présidentiel

Lieux

Enfin un certain nombre de contributions se sont attachées à voir comment ces cérémonies s'inscrivent dans des lieux spécifiques et s'interrogent sur la place de cet ordre cérémoniel.

Les spectacles donnés dans l'amphithéâtre de Nîmes entre 1900 et 1937 sont analysés par Sabine Teulon Lardic. Elle montre qu'à la faveur de représentations ambitieuses (drame antique, opéra et création recensés) et d'une fréquentation populaire due aux dispositifs de l'administration municipale, un cycle de spectacles, inspiré par le militantisme de Romain Rolland, constitue un outil de communication territoriale au cœur des enjeux du spectacle de masse. Favorisant les échanges culturels et économiques entre Nîmes et Paris (Comédie-Française, Opéra de Paris), Nîmes et les grandes villes (orchestres de Marseille, de Lyon), il participe des processus de représentation et de structuration des idéologies marquantes durant l'entre-deux-guerres.

De son côté Sonia Zerbib étudie la politique festive mise en œuvre à Florence pour les noces de 1565, le baptême d'Éléonore de Médicis en 1567, les funérailles de Michel-Ange, de Cosme $\mathrm{I}^{\text {er }}$ et de Francesco $\mathrm{I}^{\text {er }}$. Cette politique donne du sens à des lieux bien particuliers, le «Salon des Cinq Cents » et la basilique «San Lorenzo » et contribue à leur métamorphose. Ces lieux, qui témoignent d'une théâtralisation de l'événement par une théâtralisation de l'espace, permettent à l'autorité ducale puis grand-ducale de lutter contre le « caractère imparfait » de son régime autoritaire.

Blandine Silvestre, présentant la salle des délibérations du Conseil général de Vaucluse construite au lendemain de la loi du 10 août 1871 mettant en place les Conseils généraux, montre que la conception de la salle participe des expériences architecturales conduites depuis la fin du $\mathrm{XVIII}^{\mathrm{e}}$ siècle. Le plan de cette dernière et son programme ornemental répondent aux objectifs des travaux de l'assemblée départementale et s'inscrivent dans une approche des espaces de la représentation politique.

Ces différentes contributions constituent en fin de compte un ensemble riche et divers par la multiplicité des approches retenues. Elles autorisent une réflexion comparatiste qui souligne bien la fécondité de ce thème. Permanences et ruptures caractérisent les cérémonies présentées et cela débouche sur des approches riches et nombreuses. 
Cérémonies et pouvoir 



\title{
Les multiples langages du rituel nuptial dans la Rome antique
}

\author{
Nicole BOËLS-JANSSEN \\ Professeur émérite, \\ Université de Bourgogne \\ Extrait de : Jean DuMA (dir.), Le Rituel des cérémonies, Paris,
Édition électronique du CTHS (Actes des congrès des sociétés historiques et scientifiques), 2015.
$\begin{array}{r}\text { Cet article a été validé par le comité de lecture des Éditions du CTHS dans le cadre de la publication } \\ \text { des actes du } 139^{\circ} \text { Congrès national des sociétés historiques et scientifiques tenu à Nîmes en } 2014 .\end{array}$
}

Le langage, sous toutes ses formes, est l'indispensable outil du lien social : il permet aux membres d'une communauté de communiquer entre eux. La cérémonie nuptiale, outre qu'elle crée un couple conjugal par l'engagement réciproque des nouveaux époux, doit faire connaître cette nouvelle structure familiale à la société. On ne se marie pas seulement pour soi, mais aussi pour les autres. Je voudrais analyser ici les différents langages auxquels avait recours la cérémonie nuptiale dans la Rome antique, à chaque étape de son déroulement : le rite nuptial proprement dit, qui officialise l'engagement des époux, le pittoresque cortège nuptial, qui accompagne la mariée jusqu'à la demeure de son nouvel époux, et enfin l'entrée de celle-ci dans la maison conjugale, prélude à l'acte qui concrétisera l'union sur le lit nuptial. Le langage parlé y tenait une place importante, alternant les formules juridiques, religieuses ou simplement traditionnelles. Mais d'autres moyens d'expression y figuraient, rituels ou spontanés, qui utilisaient d'autres formes, orales, comme les acclamations, les chansons et les plaisanteries, ou visuelles, images signifiantes et gestuelles variées. En identifiant ces différents langages je tenterai aussi de déterminer à quel public ils s'adressent.

\section{La cérémonie privée}

\section{La dextrarum iunctio}

Je passe sur les préparatifs de la toilette et de la coiffure de la mariée. Certes elles ont une signification mais elles ne font pas à proprement parler partie de la cérémonie nuptiale. Celle-ci commence par un rite religieux qui se déroulait en privé : une prise d'auspices ${ }^{1}$. Avant d'informer les hommes, il faut informer les dieux et demander leur approbation. Plus qu'un message, c'est un dialogue : les hommes demandent l'approbation divine, qui leur est donnée par l'intermédiaire des oiseaux dont ils observent l'apparition. Pour respecter les coutumes religieuses, un sacrifice était également nécessaire ${ }^{2}$, autre façon de communiquer avec les dieux. En ce qui concerne les hommes, la signature du contrat, acte juridique, qui met par écrit et valide l'engagement réciproque des deux parties, est l'indispensable préalable à la cérémonie. C'est un accord privé entre deux familles, mais qui doit être vu, entendu et reconnu par des témoins, représentants de la société.

Mais ce qui officialise l'union des époux, c'est la dextrarum iunctio, geste par lequel ils joignaient leurs mains droites; $c^{\prime}$ est un rite nuptial dont on trouve maint exemple dans des civilisations variées ${ }^{3}$. À Rome la main droite symbolisait la fides, c'est-à-dire à la fois l'engagement et la fidélité à cet engagement ${ }^{4}$. La dextrarum iunctio est une union

1. Val. Max. 2, 1, 1 ; Serv., Aen. 4, 45. À l'époque historique, elle n'est plus que symbolique mais on donne encore le nom d'auspices à ceux qui sont censés les avoir pris.

2. Serv., Aen. 3, 136.

3. E. Westermarck, Histoire du mariage, IV, p. $184 \mathrm{sq}$.

4. Boyancé, «La main de Fides », p.101-107. 
symbolique des nouveaux époux, et non plus de leurs familles, garantie par leur fides, devant les yeux des assistants. De nos jours l'échange des anneaux, qui a la même signification, est toujours public, lui aussi. Le geste rituel se faisait sous l'égide d'une femme que l'on appelait la pronuba ${ }^{5}$ : $c^{\prime}$ était une sorte de marraine, qui avait préparé la fiancée à son nouvel état d'épouse en lui enseignant le travail de la laine et la morale matronale $^{6}$; elle l'accompagnerait ensuite jusqu'à la maison conjugale où elle la remettrait définitivement à son mari. Elle joignait elle-même les mains des époux. Le geste suffisait à constituer l'union conjugale: la scène figure sur les monuments funéraires et elle est parlante en soi. Cependant la pronuba prononçait peut-être en même temps une formule rituelle. On peut le supposer d'après un passage de la comédie de Térence intitulée L'Andrienne. La courtisane Chrysis, sur son lit de mort, confie sa jeune pupille Glycère à l'amant de celle-ci, Pamphile ; il ne s'agit pas vraiment d'un mariage car la jeune fille n'est pas citoyenne: Pamphile ne peut pas l'épouser légalement. Chrysis accomplit donc un simulacre d'union conjugale, en espérant que geste et formule engageront les jeunes gens comme dans un véritable mariage; elle tient le rôle de la pronuba en disant à Pamphile :

«Par ta main droite et par ton Genius, au nom de ta loyauté (fides) et de la solitude où elle va se trouver, je te demande solennellement de ne pas l'abandonner et de ne pas la laisser sans protection. ${ }^{7}$

Et elle la lui remet en disant :

« Je te donne à elle en tant que mari. »

Le commentateur Donat écrit en note :

« Il apparaît qu'elle dit ces mots en joignant leurs mains droites. »

Chrysis prononce peut-être la formule rituelle de la dextrarum iunctio ${ }^{9}$. La référence à la main droite et à la fides plaident en ce sens. Le geste et la parole s'unissent donc pour matérialiser l'engagement réciproque des époux et le faire connaître aux témoins qui assistent à la scène (familles et proches) et dont la présence certifie la validité de l'union. Dans la pièce de Térence l'absence de témoins confirme que l'union ainsi scellée n'est que symbolique et n'a aucune valeur aux yeux de la société.

\section{Les trois modes de mariage}

La dextrarum iunctio est commune à tous les mariages mais c'est seulement une coutume signifiante. Légalement la procédure romaine reconnaissait trois modes de mariage, tous anciens. Le mariage par usus se fondait sur la durée patente d'un an de vie en couple. Il ne nécessitait aucun acte particulier et n'entre pas dans notre sujet sauf dans la mesure où une vie commune notoire est en soi un moyen de manifester l'union entre les deux protagonistes : $c^{\prime}$ est une sorte de langage permanent.

Le mariage par coemptio était une union civile, fondée sur une vente fictive de la fiancée. La scène reproduisait les gestes et les formules d'une procédure de vente. Évidemment, comme pour une véritable cession commerciale, la présence de témoins susceptibles d'attester la validité de la transaction et donc du mariage était indispensable.

Le mariage par confarreatio était une cérémonie religieuse, pratiquée seulement par les

5. Isid., Orig. 9, 8 .

6. Seules les épouses des citoyens romains avaient droit au titre de matrone. Le statut matronal exigeait d'elles la fidélité au mari et un comportement irréprochable. En échange, il les protégeait de toute agression sexuelle et leur assurait le respect de tous. Voir P. Grimal, Matrona ; N. Boëls-Janssen, « Majestas matronarum ».

7. V. 289-290.

8. Te isti uirum do (v. 295).

9. G. Williams, « Roman Marriage », p. 16-29. 
vieilles familles patriciennes ${ }^{10}$. Elle prenait à témoin de la nouvelle union le grand dieu de la cité, Jupiter, représenté par son prêtre, le flamen Dialis ${ }^{11}$. Il n'est pas étonnant que Jupiter patronne un rite nuptial, car il est le dieu des serments et il a des liens étroits avec Fides $^{12}$, la déesse de la bonne foi à laquelle se réfère implicitement la dextrarum iunctio.

L'union des nouveaux époux est symbolisée par une mise en scène signifiante de couleur archaïque. Les époux sont assis sur des sièges jumelés recouverts par une peau de mouton encore garnie de sa laine, celle de l'animal immolé lors du sacrifice qui précède la cérémonie nuptiale $^{13}$. La peau brute est encore imprégnée de sacré. C'est réunis matériellement par ce double siège qui n'en fait qu'un que les futurs procèdent au geste essentiel du rituel : ils partagent un gâteau de far qui donne son nom à la cérémonie. Dans toutes les sociétés, se partager un mets ou une boisson signifie que l'on s'engage à partager les aliments vitaux. C'est un geste social, symbole d'alliance ; A. Van Gennep le classait parmi les rites d'union des nouveaux époux, comme le fait de partager le même siège ${ }^{14}$. Le far est une céréale très ancienne et par là même réservée à l'usage religieux. C'est lui qui sert à fabriquer la mola salsa, ce mélange de farine et de sel que l'on versait sur les animaux sacrificiels avant de porter le coup fatal ${ }^{15}$. La nature de l'aliment partagé dans le rite nuptial sacralise l'engagement, d'autant plus que la confarreatio se célèbre devant Jupiter, dieu des serments. Des formules consacrées complétaient la cérémonie.

La présence comme témoin de Jupiter, représenté par son flamine, et l'usage du far donnent une garantie religieuse à la nouvelle union mais le rite a aussi une signification sociale: la cérémonie exigeait la présence de dix témoins car l'alliance n'est pas seulement celle des deux époux, c'est celle de deux gentes (familles) patriciennes; elle concerne donc l'ensemble de la caste des patriciens, représentée par ces dix témoins. Il ne faut pas oublier que la vie politique romaine était en grande partie fondée sur les relations d'amitié entre les clans que représentaient les grandes familles de l'aristocratie et leurs alliés. Les mariages scellaient des unions politiques autant que conjugales. La sanctification de l'union apportée par la confarreatio garantissait cette alliance que les témoins pouvaient attester. La cérémonie s'adresse à la fois aux dieux et aux hommes, au roi des dieux et à l'élite de la société.

\section{Le cortège nuptial}

Quel que soit le mode de mariage utilisé, la partie festive en était le banquet de noces. Un repas pris en commun est toujours à l'origine un geste religieux. Certes, c'était aussi l'occasion pour les invités de classe sociale inférieure de participer à la liesse générale et de profiter largement de la générosité de leur hôte mais, dans un registre différent, le repas de noces a le même but que la confarreatio : publier l'union des nouveaux époux et la célébrer par un acte social et religieux. Les assistants y étaient plus nombreux et d'une origine sociale plus variée que lors de la dextrarum iunctio ou de la confarreatio et il se déroulait dans un lieu semi-public : les pièces de réception de la maison. L'atmosphère y était beaucoup moins solennelle que dans les rites précédents et la jeune mariée n'y assistait sûrement pas.

Le rituel nuptial à proprement parler reprend au moment où elle quitte la maison de son père pour se rendre chez son nouvel époux. Tout ce deuxième acte du mariage se déroule dans l'espace public. Les témoins n'en sont plus les quelques représentants des familles et de la caste concernée, ni les amis et clients conviés au banquet : c'est la cité qui va prendre connaissance de la nouvelle union. Pour imaginer l'ambiance qui y régnait, la littérature

10. Gaius, Inst., 1, 112 ; Ulp., Reg., 9, 1, où sont cités la plupart des éléments commentés ici.

11. Serv., G. 1, 31.

12. P. Boyancé, «Fides et le serment », p 339-341.

13. Serv., Aen. 4, 374.

14. A. Van Gennep, Les rites de passage, p. 187.

15. C'est le sens premier du verbe «immoler ». 
latine nous offre deux textes précieux, l'un sur le mode poétique (l'épithalame mise en scène par Catulle dans la Pièce 61), l'autre sur le mode parodique (la comédie de Plaute, Casina).

\section{La sortie de la mariée}

Après le banquet de noces, à la nuit tombante, les amis du marié se rassemblent devant la porte. Ils réclament la mariée à grands cris. Chez Catulle, chaque strophe s'achève par le refrain :

«Sors, nouvelle épouse. ${ }^{16}$

Dans Casina le chœur, composé du futur époux et de son patron, s'égosille grotesquement à chanter le chant d'hyménée ${ }^{17}$. Dans les deux cas la mariée tarde à apparaître : chez Catulle le chœur réitère plusieurs fois son appel; dans Casina le futur s'impatiente :

«Mais qu'est-ce qu'elle fabrique si longtemps ? Ma parole elle le fait exprès ! ${ }^{18}$

Cet ostensible manque d'empressement est un message : il signifie que la fiancée est chaste. Plus elle tarde à se montrer, plus elle affiche sa vertu :

«Une noble pudeur la retient. » ${ }^{19}$

Quand enfin elle apparait, les acclamations qui la saluent informent tout le voisinage de l'événement ${ }^{20}$. Le caractère spectaculaire de cette sortie tant attendue était renforcé par son apparence: elle était tout entière enveloppée dans le flammeum, un grand voile couleur de feu qui dissimulait son corps et cachait au moins le haut de son visage. La toilette de la mariée est chargée de sens mais les spectateurs ne voient que le voile qui la couvre. Ce voile transmet cependant un message essentiel puisque c'est lui qui donne son nom aux noces : nuptiae vient de nubere, qui signifie pour une jeune fille "se voiler pour (un homme)», c'est-à-dire "se marier». Et ce message est double. La couleur du flammeum est un présage de féconditée ${ }^{11}$; il promet que la fiancée remplira son devoir d'épouse : donner à son mari une descendance légitime ; car la fécondité fait partie des qualités qu'on loue chez une matrone, souvent associée à sa vertu ${ }^{22}$, et on l'inscrit même sur sa pierre tombale ${ }^{23}$. Mais la nature du vêtement transmet un autre message. Le voile proclame qu'au moment où elle se montre à l'extérieur de la maison de son père, elle est invisible. Cette invisibilité traduit concrètement l'idéal conjugal qu'elle s'engage à incarner. La matrone parfaite est celle $\mathrm{qu}^{\prime}$ on ne voit pas et $\mathrm{qu}^{\prime}$ on n'entend pas: la discrétion et la modestie sont ses vertus majeures, qui garantissent qu'elle restera l'épouse chaste d'un seul homme et ne suscitera la convoitise $\mathrm{d}^{\prime}$ aucun autre que lui ${ }^{24}$. La morale conjugale répartit les rôles entre les sexes: l'homme appartient au domaine public, la femme à la sphère privée : sa fonction est limitée à la domus, d'où elle est censée ne sortir que dûment voilée et escortée. Horace compare l'environnement des dames à un véritable rempart. La loi protège d'ailleurs l'intégrité des matrones et punit tout homme qui ose lui porter atteinte, en gestes ou en paroles ${ }^{25}$. L'épousée voilée du flammeum revendique publiquement ce statut.

16. V. $95,100,110,120$

17. V. 737-740.

18. V. 735-736 ; Catulle $(61,94)$ emploie le même verbe morari, tarder, que Plaute.

19. Cat. 61,83 .

20. Cat. $61,121-125$

21. N. Boëls-Janssen, « La fiancée embrasée », passim.

22. Par exemple, Valère Maxime loue une épouse dont la vertu et la fécondité étaient remarquables : uxorem pudicitia et fecunditate conspicuam $(7,1,1)$.

23. L'épitaphe précise souvent le nombre d'enfants qu'elle a mis au monde.

24. N. Boëls-Janssen, La vie religieuse des matrones, p. 229-232.

25. Hor., Sat., 1, 2, v. 96-99. Le costume matronal et l'escorte qui entoure la matrone en public sont un message proclamant qu'elle est intouchable. Le poète conseille de se tourner plutôt vers les prostituées qui montrent leurs charmes et dont la fréquentation est sans risque. Voir note 6. 
Une autre apparition était saluée par des acclamations: celle du panier de laine de la mariée, accompagné de son fuseau et de sa quenouille, qui témoignait qu'elle avait été initiée au lanificium (travail de la laine) et qu'elle serait une bonne lanifica ${ }^{26}$. Le statut matronal que Romulus est censé avoir fondé exemptait les matrones de tout travail domestique à l'exception du travail de la laine. Autrement dit la tâche première de la matrone était de filer et de tisser à l'intérieur de la maison, où était confinée toute son activité, et cette tâche était le symbole de sa vertu ${ }^{27}$. L'habileté au travail de la laine figure sur les épitaphes à côté de la chasteté et de la fidélité pour faire l'éloge de la défunte ${ }^{28}$ : même si à l'époque historique la matrone ne file ni ne tisse plus, l'adjectif lanifica est resté symbole de vertu. On reconnaît le mythe de Pénélope, à la fois tisserande exemplaire et modèle de fidélité. À Rome, cet idéal est incarné par Lucrèce, l'hérö̈ne de l'époque royale qui se suicide parce que, souillée par un viol, elle ne peut plus donner à son mari des enfants de pure race; la tradition la montre occupée au travail de la laine lorsque son séducteur la voit et s'éprend d'elle. Comme le flammeum, qui manifeste la vertu de l'épousée par sa nature et présage sa fécondité par sa couleur, le panier de laine, accompagné des outils du lanificium, annonce qu'elle sera une bonne épouse, répondant à l'idéal matronal. Les acclamations qui saluaient son apparition en criant son nom «Talassio ! Talassio ! ${ }^{29}$ le faisaient savoir à tout le voisinage.

\section{Le rapt nuptial simulé}

À l'image muette mais signifiante de l'apparition de la mariée sur le seuil succède une scène théâtrale, qui fait partie des rites de séparation. Les amis du marié se saisissent de force de la fiancée qui résiste et pleure en se cramponnant à sa mère ${ }^{30}$. Catulle évoque deux fois la scène ${ }^{31}$. L'enlèvement simulé est fréquent parmi les rites nuptiaux : comme le fait qu'elle tarde à sortir de la maison paternelle, il exprime visuellement la pureté et la pudeur de la vierge ${ }^{32}$. À Rome, la scène est censée rappeler l'ancienne coutume du rapt nuptial, dont l'enlèvement des Sabines est resté l'archétype. Mais Romulus avait ensuite sanctifié le rapt en créant le statut matronal, qui donnait aux Sabines un statut d'épouses légitimes. De sorte que dans la mémoire mythique cette scène de rapt simulé proclame publiquement à la fois que la fiancée est chaste et que le prétendu enlèvement aboutira à faire d'elle une matrone, comme ce fut le cas pour les Sabines. Il donne aux spectateurs une justification sociale au « transfert » de la jeune fille d'une maison à l'autre.

\section{Le cortège nuptial}

Le cortège qui escorte la fiancée jusqu'à la demeure de son mari est le moment le plus visible de toute la cérémonie, car son itinéraire traverse la ville : c'est un événement public. Jusqu'ici les différents rites ne concernaient que les familles et les proches; même la sortie de la fiancée et son enlèvement simulé sont un message aux seuls voisins; le cortège nuptial, lui, transmet le message à toute la cité. Il ne doit surtout pas passer inaperçu : son caractère public garantit la légitimité de l'union. C'est pourquoi il offre un spectacle coloré et bruyant, attirant l'attention générale.

Il est précédé de torches. Elles ont sans doute une fonction apotropaïque. Westermarck les compare aux cris et coups de fusil que l'on retrouve avec cette fonction dans de nombreux rites nuptiaux ${ }^{33}$. Mais en outre elles rendent le mariage visible, au propre, car les torches éclairent la scène, qui se déroule de nuit, et au figuré, car elles attirent

26. Pl., NH 8, 194 ; Cic., De or. 2, 68, 277

27. L. Larsson Loven, «Lanam fecit », p. 85-95 ; N. Boëls-Janssen, « La déesse au fuseau », p. 55-62.

28. La plus célèbre est celle de Claudia, CIL I, 2, 1211 ; voir aussi VI, 10230, qui associe pudicitia, lanificium et fides ; l'Éloge funèbre d'une matrone romaine (éd. par M. Durry aux Belles Lettres) cite aussi pudicitia et lanificium.

29. Plut., QR $271 \mathrm{f}$; sur le sens du mot, N. Boëls-Janssen, La vie religieuse des matrones, p. 174-180.

30. Fest. p. 364 L.

31. 62 , v. $21-23 ; 61$, v. 56-59.

32. E. Westermarck Histoire du mariage, IV, p. 302 sq.

33. Ibid. p. $252 s q$. 
l'attention sur lui. Une torche particulière, en aubépine, était portée devant l'épousée ${ }^{34}$. L'aubépine, signe de fécondités5, renforçait l'effet du flammeum dont elle était enveloppée. Le message transmis aux spectateurs est indirect mais clair : le but du mariage célébré est de donner une descendance au mari : la mariée met toutes les chances de son côté pour accomplir cette mission.

Elle était encadrée par les garçons d'honneur du marié, qui la tenaient chacun par un bras, continuant à mimer le rapt. Mais ce qui attirait surtout l'attention c'étaient les chants licencieux et les plaisanteries grivoises que lançait la troupe des jeunes gens. On les appelait vers fescennins (fescennina iocatio). Ils occupent une grande partie de l'épithalame de Catulle ${ }^{36}$ et visent surtout le mari. On s'accorde à donner à ces lazzi improvisés, qui sont toujours d'ordre sexuel, une valeur apotropaïque: ils sont censés écarter magiquement le danger qu'implique la défloration d'une vierge pour le mari. L'obscénité des vers fescennins, les rires qu'ils provoquent le protègent de ce danger mais en même temps ils proclament la pureté de l'épousée puisque s'unir à elle présente un tel risque.

Pendant le trajet, elle répétait comme une incantation le nom de Gaia Caecilia: cette déesse passait pour avoir été une matrone modèle, tant par ses vertus conjugales que par ses talents de filandière ${ }^{37}$. Elle avait sa statue, avec son fuseau encore garni de laine, dans le temple de Dius Fidius ${ }^{38}$, dieu de la fides, ce qui la met en relation à la fois avec le lanificium et avec le mariage. Effectivement elle avait été assimilée à la reine Tanaquil : celle-ci avait présidé à l'union d'une servante avec le dieu phallique apparu dans le foyer du palais royal ; cette union devait aboutir à la naissance du futur roi Servius Tullius ${ }^{39}$. Elle était ainsi l'archétype de la pronuba, la marieuse modèle. L'image de la corbeille à laine garnie des outils du lanificium et l'incantation convergeaient vers le même effet: proclamer que la mariée avait été initiée à la double fonction d'épouse et de lanifica et serait une autre Gaia Caecilia ${ }^{40}$. Enfin, comme Gaia Caecilia semble avoir eu des liens avec la symbolique du feu ${ }^{41}$, on peut penser qu'en l'invoquant l'épousée s'assurait aussi un présage de fécondité. On doit donc conclure que le patronage de Gaia Cecilia met la mariée sous le signe, non seulement de la mystique du travail de la laine, que symbolisent, dans le culte, la statue accompagnée des outils de filandière de la déesse, et dans le cortège nuptial, la quenouille et le fuseau de la uirgo nubens, mais aussi du feu fécondant qui précède la mariée sous la forme de la torche d'aubépine, qui l'enveloppe sous la forme du flammeum et qu'elle invoque en répétant le nom de Gaia Caecilia ${ }^{42}$. Chaque élément du cortège nuptial, visuel ou oral, fait savoir à tous le but du mariage et la perfection de la future épouse.

\section{L'arrivée à la maison conjugale}

L'arrivée à la maison conjugale change totalement le ton de la cérémonie. Le cortège s'arrête. Les chansons, les cris et les rires cessent : c'est le silence. Les scènes qui vont se dérouler seront statiques et graves.

34. Non. p. 161 L ; Pl., NH 16, 75.

35. Cette valeur est confortée par le fait que la torche était consacrée à Cérès (P. Fest. p. 77 L) ; voir H. Le Bonniec, Le culte de Cérès, p. 82-83.

36. V. 126-155.

37. P. Fest. p. 85 L.

38. Plut., QR 30, 272 e ; Pl., NH 8, 194.

39. Liv. 1, 39, 5-6 ; Pl. NH 36, 204 ; Den. Hal. 4, 2 sq.

40. N. Boëls-Janssen, « De Gaia Caecilia aux fées-marraines », p. 79-81.

41. N.Boëls-Janssen, La vie religieuse des matrones, p. 182.

42. Ibid., p. 181. 


\section{Gaius et Gaia}

D'abord le mari accueillait la fiancée devant la porte de la maison conjugale en lui demandant solennellement qui elle était. Et elle répondait par une formule de type juridique : «Où tu es Gaius je suis Gaia » ${ }^{43}$. En même temps qu'un engagement public, c'est une revendication de son identité nouvelle. Elle proclame que pour devenir l'épouse d'un homme elle renonce à tout ce qui était sa vie précédente. Il n'est pas anodin que la formule soit prononcée devant la maison et non à l'intérieur. D'abord il faut qu'elle ait changé d'identité pour pouvoir entrer dans la maison conjugale mais surtout la scène se déroule dans l'espace public : le voisinage de sa nouvelle demeure est informé à son tour du mariage.

\section{Les rites de la porte}

Avant de pénétrer dans la maison elle devait encore se livrer à quelques rites superstitieux : elle ornait de rubans de laine les montants de la porte et les graissait avec de la graisse de loup ${ }^{44}$. La porte, qui sépare deux mondes mais permet aussi de passer de l'un à l'autre, est sacralisée dans beaucoup de civilisations. Passer une porte pour la première fois exige des précautions magiques. Les bandelettes de laine (uittae) manifestaient la sacralité de la porte ${ }^{45}$. La graisse de loup, animal dangereux, devait protéger la mariée à son passage: on utilise souvent les forces maléfiques en les retournant contre les menaces éventuelles. En accomplissant ces rites la nouvelle mariée exprime sa volonté d'entrer dans sa nouvelle demeure, créant une symétrie avec sa résistance au moment du rapt simulé ; la situation est inversée : comme les Sabines elle va passer du statut de vierge enlevée par la violence, dont la résistance prouvait la pureté, à celui d'épouse légitime. En opérant ces rites d'entrée elle accepte et même revendique publiquement son entrée dans sa nouvelle demeure et dans sa nouvelle vie.

Le moment essentiel était le franchissement du seuil. Les témoignages des auteurs anciens divergent sur ce rite ${ }^{46}$. Mais qu'on l'ait portée à l'intérieur ou qu'elle ait pris soin de ne pas heurter le seuil, comme le conseille la pronuba à Casina ${ }^{47}$, le sens est le même : le seuil sépare l'espace public de l'espace privé. Il constitue une barrière sacrée, plus symbolique encore que la porte qui, elle, permet l'accès en s'ouvrant. Toucher cette ligne sacrée en entrant serait un dangereux sacrilège et un présage désastreux.

Bien entendu cette scène théâtrale, même si elle est muette, transmet un message clair aux voisins. Elle montre concrètement l'entrée solennelle de la nouvelle mariée dans la demeure conjugale et l'irréversibilité de son intégration dans la demeure. La gestuelle du franchissement du seuil vient confirmer la proclamation orale de la formule prononcée par la fiancée. L'un comme l'autre disent au voisinage qu'elle passe d'un monde à l'autre, d'une maison à l'autre, de l'état de vierge au statut de matrone.

\section{L'accueil dans la maison}

Une fois franchi le seuil, d'autres rites consacraient l'intégration de l'épousée dans la maison conjugale. Son mari l'accueillait «avec l'eau et le feu ${ }^{48}$. On ne sait pas exactement comment se déroulait le rite mais son sens ne fait aucun doute : aqua et igni accipere est exactement l'inverse de la formule de l'exil : aqua et igni interdicere. L'exilé est privé des deux éléments qui symbolisent la vie domestique. Aucune maison ne

43. Plut., $Q R$ 30, $271 \mathrm{~d}$.

44. Serv. Aen. 4, 458.

45. Les uittae séparaient visiblement le sacré du profane : les Vestales les portaient ; on en mettait aux portes des temples et sur les animaux sacrificiels.

46. N. Boëls-Janssen, La vie religieuse des matrones, p. 190-192.

47. Plut., QR 29, 271 d ; Luc., Phars. 2, 359 (on porte la mariée) ; Pl., Cas. 815 ; Serv. Buc. 8, 29 ; Isid. Orig. 9, 8 (elle ne doit pas toucher le seuil).

48. Varr., LL 5, 61 ; Dig. 24 ; Serv., Aen. 4, 167. 
l'accueillera. La nouvelle épouse au contraire reçoit à son arrivée une preuve de son intégration à la vie domestique. Les spectateurs du rite sont maintenant limités aux membres de la maisonnée; ce sont eux qui devront désormais considérer la nouvelle mariée comme la maîtresse de maison.

Les dieux ne sont pas oubliés. La mariée apportait trois pièces de monnaie ; elle donnait la première à son mari, déposait la seconde sur le foyer et allait jeter la troisième au carrefour le plus proche ${ }^{49}$. La valeur magique de l'argent est connue. La mariée se concilie d'abord la faveur du Genius de son mari : le Genius était un dieu attaché à la personne de chaque homme; vu sa racine (même famille qu'engendrer) il incarnait son pouvoir fécondant ${ }^{50}$. La nouvelle épousée achetait symboliquement la faveur du Genius pour qu'il l'accepte comme épouse du maître de maison et pour que son union soit heureuse et féconde. La pièce déposée sur le foyer était destinée au Lare Domestique, qui protégeait la maison ${ }^{51}$. Lui offrir cette piécette revenait à lui demander de bien vouloir la considérer comme faisant partie désormais de la maison sur laquelle il veillait. Quant à la troisième pièce, si l'épousée allait la jeter au carrefour le plus proche, c'est qu'à chaque carrefour il y avait un autel dédié aux Lares des Carrefours. Ces Lares recevaient un culte de la part des habitants du quartier car les croisements étaient des endroits dangereux; il fallait se concilier la faveur des divinités qui y résidaient. La mariée se mettait ainsi sous leur protection. Ces trois offrandes signifiaient donc son intégration religieuse à un couple, à une maison et à un quartier.

\section{Dans la chambre nuptiale}

Les rites d'accueil et d'intégration de la mariée une fois accomplis devant l'ensemble de la maisonnée, la pronuba la conduisait à la chambre nuptiale. Les autres assistants ont disparu; elle reste seul témoin des derniers instants avant l'acte décisif ; elle installait la jeune fille sur le lit nuptial et lui prodiguait les ultimes conseils : elle devait lui rappeler son devoir de soumission (obsequentia) et la préparer à ce qui l'attendait, comme le suggère la fameuse peinture dite des « Noces Aldobrandines »: sur cette scène empreinte de gravité la pronuba, assise sur le lit nuptial à côté de la jeune mariée, dont le visage exprime une tristesse résignée, l'encourage avec compassion. Plaute fait une joyeuse parodie de ces dernières recommandations dans Casina ${ }^{52}$. Puis la pronuba appelle le mari et lui remet solennellement sa nouvelle épouse :

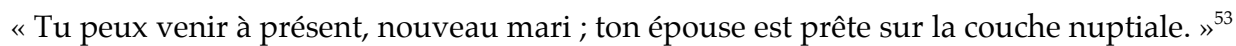

Il est probable qu'une dernière formule confirmait oralement la remise de l'épouse à l'époux. On trouve peut-être une allusion à celle-ci lorsque la pronuba qui accompagne Casina dit au mari :

«Allons, Olympion, puisque tu le souhaites, reçois de mes mains cette femme comme épouse. $»^{54}$

Une autre phrase de cette pronuba invite le mari à ne pas être trop brutal avec la jeune fille :

«S'il te plaît, elle est pure et innocente, vas-y doucement ! » ${ }^{55}$

49. Non. p. 852 L.

50. N. Boëls-Janssen, La vie religieuse des matrones, p. 209-215, où on trouvera un résumé de la controverse qui a opposé H. Le Bonniec à G. Dumézil sur la fonction du Genius, avec les références.

51. Le prologue de l'Aululaire de Plaute, prononcé par le Lare, montre qu'il réside dans le foyer de la maison.

52. V. 746-747. Tout est inversé. C'est quand la mariée sort de chez elle que la fausse pronuba l'invite à ne pas heurter le seuil et elle enchaîne sur des conseils qui sont exactement le contraire de la morale matronale qu'elle est censée lui avoir enseignée: "Sois toujours la maîtresse de ton mari ». Catulle insère ces conseils dans la fescennina iocatio : « Jeune épouse, ne refuse pas non plus ce que demande ton mari » $(61,151-153)$.

53. Cat., 61, 191-192.

54. Cas. v. 754-755

55. Cas. v. 756-757. 
Il est vrai que la mariée était souvent très jeune ${ }^{56}$ : le conseil n'était pas superflu. Dans Casina il est destiné à faire rire car le spectateur sait que sous le voile de la mariée se dissimule un solide gaillard qui rossera le mari. Mais la comédie parodie peut-être une formule rituelle qui garantissait au mari la virginité de la future, confirmant oralement ce qu'affirmait au départ, dans un autre langage, la comédie du rapt simulé. Les épitaphes précisent souvent, comme une des vertus de la défunte, qu'elle est arrivée vierge au mariage.

Sa mission accomplie la pronuba quittait la scène, elle aussi. Le rituel nuptial n'était pas fini pour autant mais désormais tout se déroulait sans témoin humain. C'est à un dieu que l'épousée adressait une prière : au Genius de son époux, auquel le lit nuptial, appelé lectus genialis, était consacrés7. Cette prière orale venait compléter le geste du don de la pièce de monnaie : l'un comme l'autre cherchent à obtenir la faveur de la divinité qui veille sur la virilité du mari. Le reste se passait sans témoins, dans l'obscurité : les protagonistes eux-mêmes ne voyaient pas la consommation de leur union. La cérémonie nuptiale était terminée. Il faudrait attendre le lendemain pour qu'un sacrifice le matin et un nouveau repas, où cette fois l'épousée serait présente dans son costume de matrone, rendent manifeste son nouvel état.

Il nous reste à tirer les conclusions de cette analyse des différents actes de la cérémonie nuptiale. Je choisis volontairement le terme "actes », qui évoque le monde du théâtre car, c'est la première constatation, les différentes étapes du rituel sont visiblement des scènes théâtrales, destinées à adresser un message aux spectateurs. Mais les modes d'expression varient. Une simple image peut suffire, comme l'apparition de la mariée drapée dans son flammeum ou celle du panier de laine. Le plus souvent c'est une gestuelle signifiante qui porte le message, comme le partage du gâteau de far, l'enlèvement simulé ou le franchissement de la porte. Mais souvent la parole formulaire vient confirmer la signification du geste et lui apporter sa garantie, car la parole possède une valeur performative aussi efficace que celle du geste. Les mots de la pronuba «doublent» en quelque sorte le geste d'union de la dextrarum iunctio ; la formule « Où tu es Gaius je suis Gaia » justifie le franchissement de la porte en lui donnant son sens. La prière au Genius a le même but que l'offrande de la pièce de monnaie. L'incantation de l'épousée qui répète le nom de Gaia Caecilia s'ajoute à l'apparition du flammeum et l'exhibition du panier de laine. Même les cris, les chansons, les interpellations, les rires, le bruit en général, transmettent un message.

La deuxième constatation est que le rituel nuptial est orienté ; il se déplace de la maison de la fiancée à celle du mari. Ce déplacement est déjà signifiant en soi car il manifeste de façon visible que le mariage fait passer l'épousée du monde dans lequel elle vivait en tant que vierge, chez son père, dans celui de son mari où elle sera une matrone. Son changement de statut est rendu visible aux yeux de tous par son passage d'un lieu à l'autre. En conséquence, les différents moments de la cérémonie se font dans des endroits différents et avec un public différent et le ton de chaque scène, ses modes d'expression dépendent de l'endroit où elle se déroule et du public auquel elle s'adresse. On pourrait diviser l'ensemble en trois phases :

- Première phase : dans puis devant la maison paternelle

On passe de l'intimité de la toilette de la mariée à la semi intimité des rites qui concluent le mariage : signature du contrat, dextrarum iunctio, confarreatio se font devant un public limité : famille, proches, témoins choisis. On prend comme garants de grandes divinités comme Jupiter et Fides. Les rites se célèbrent avec gravité dans des scènes statiques; les gestes signifiants sont complétés par un langage formulaire, juridique ou religieux. La 
sortie de la mariée marque un changement de ton car on est désormais dans la sphère semi-publique ; les témoins sont les gens du quartier. Les scènes sont plus théâtrales, avec davantage de mouvement et un langage moins formel: cris réclamant la mariée, acclamations saluant son apparition et celle du panier de laine, comédie du rapt simulé.

- Deuxième phase : de la maison paternelle à la maison du mari

Enfin la mariée quitte la maison paternelle. Son changement de résidence et de statut est matérialisé et proclamé par le bruyant déplacement du cortège qui l'escorte d'un point à l'autre. Cette fois le public s'élargit à la cité tout entière et, dans le mouvement général, les modes d'expression se font plus libres, mélangeant le visuel (torches, mariée dans son flammeum, cortège animé) et le sonore, où le spontané l'emporte sur le rituel (chansons grivoises, lazzi, acclamations). Tout est fait pour attirer l'attention des éventuels spectateurs, tant par la visibilité des acteurs que par le bruit qu'ils font. Il faut donner le maximum de publicité à l'événement. De nos jours encore, à défaut de cortège nuptial à l'ancienne, ce sont des cortèges de voitures qui traversent la ville en klaxonnant sans discontinuer, au son d'une musique tonitruante: le but de ce véritable spectacle est d'attirer l'attention sur des mariages qui, sans cela, demeureraient limités à la sphère privée et manqueraient de la publicité indispensable pour les valider aux yeux de la société. Ces bruyantes manifestations s'adressent à un public humain plus large, plus populaire que celui du rituel nuptial; il faut l'interpeller pour l'informer quasiment malgré lui. Sur le plan divin, le bruit, les torches, les chansons obscènes ne s'adressent plus à des grands dieux mais cherchent à éloigner des forces obscures: les pratiques magiques se substituent aux rites religieux. Même l'invocation à Gaia Caecilia prend la forme d'une incantation et non d'une prière. Le langage est adapté aux circonstances et au public.

- Troisième phase : devant puis dans la maison du mari

Dans la dernière phase du processus, une fois l'épousée arrivée à destination, le nombre des témoins diminue progressivement et les modes d'expression changent au fur et à mesure. Le cortège s'arrête et l'agitation se calme. Le voisinage est informé de l'arrivée de la nouvelle épouse par les rites qui matérialisent le passage du public au privé : échange préalable de paroles formulaires puis gestuelle codée du franchissement de la porte. On passe ensuite à la relative intimité de l'atrium de la maison conjugale où la nouvelle épouse est accueillie rituellement dans sa nouvelle demeure : le message s'adresse aux gens et aux dieux de la maison; le ton est grave et solennel. Puis il ne reste plus sur le plan humain que la pronuba, dont les propos s'adressent successivement à l'épouse et à l'époux, préparant leur union proche ; et elle s'efface enfin pour laisser les laisser seuls dans la chambre nuptiale, sous le seul regard des dieux. Le rituel referme progressivement l'éventail des témoins jusqu'à l'intimité totale, renforcée par l'obscurité : le geste final ne concerne plus que les époux. Les modes d'expression changent à mesure : scènes théâtrales de l'entrée solennelle de l'épousée dans la maison ; à l'intérieur rites, formules, prières sur un ton de gravité, avant qu'hommes et dieux laissent enfin les nouveaux époux seuls dans l'obscurité.

Au total, au fur et à mesure que s'ouvre l'éventail des destinataires du message que délivre la cérémonie nuptiale, les différents langages changent, de plus en plus animés, de plus en plus bruyants, passant peu à peu de la gravité à l'exubérance, du statique au mouvement, du formulaire au spontané. Bruit et mouvement culminent dans le cortège nuptial. Puis, en sens inverse, les différents modes d'expression du message redeviennent plus statiques, plus mesurés, plus graves au fur et à mesure que le public diminue en nombre, jusqu'à l'acte final où il n'y a plus de témoins. Les différents langages s'adaptent à chaque fois au public, proches ou inconnus, hommes ou dieux.

On voit donc qu'à Rome le rituel nuptial a pour intention de faire savoir successivement à toutes les sphères de la société qu'une nouvelle union se conclut. Nul ne pourra l'ignorer: ni les dieux de la cité ni les dieux de la maison conjugale, ni les hommes, citoyens, famille, proches, voisins, membres de chaque maisonnée, tous sont informés d'une façon ou d'une autre. C'est pourquoi les langages du rituel nuptial romain sont 
multiples, adaptés aux différents publics auxquels ils s'adressent. Et le message se prolonge sous d'autres formes encore puisque le lit nuptial restera exposé dans l'atrium, à côté des toiles tissées par la maîtresse de maison, attestant la présence d'une bona matrona dans la demeure ${ }^{58}$. Même au-delà de la mort le message survit grâce aux scènes de dextrarum iunctio représentées sur les monuments funéraires. L'art est le plus durable des langages; il montre aux passants et même à la postérité le geste qui avait fait des époux un couple uni jusque dans l'au-delà et les épitaphes attesteront que la défunte avait dès le mariage toutes les qualités d'une bonne épouse. Des siècles plus tard, le message s'adresse encore à nous : il nous prend à témoin des unions passées et sert même encore de modèle aux rites nuptiaux de notre temps car le sens de la cérémonie du mariage ne change pas: il a pour but de publier l'union d'un couple qui sera reconnu comme tel par la société et tous les langages sont bons pour le proclamer.

\section{Résumé}

Grâce aux témoignages antiques, source essentielle de cette étude, nous connaissons bien le déroulement de la cérémonie nuptiale à Rome. Son but est d'unir les époux mais aussi de proclamer leur union. Un certain nombre de rites scellent d'abord le mariage en privé mais en présence de témoins, humains et divins. Le départ théâtral de la fiancée informe les voisins de l'événement. Le bruyant cortège nuptial publie ensuite cette union à la cité entière. L'entrée solennelle de la mariée dans la maison conjugale prévient le quartier de l'arrivée de la nouvelle épouse. À l'intérieur son accueil rituel informe la maisonnée, qu'une nouvelle matrone fait désormais partie de la maison. Pour transmettre le message la parole formulaire, juridique ou religieuse, joue un rôle essentiel, mais d'autres langages sont utilisés : images signifiantes, gestuelle théâtrale, cris, acclamations, chants se succèdent ou s'associent, complétant ou remplaçant la parole formulaire. À chaque étape du rituel le langage change selon le lieu et le public auquel s'adresse le message. 


\section{Bibliographie}

BOËLS-JANSSEN Nicole

- «Maiestas matronarum », Latomus 67, 1, mars 2008, p. 37-55.

- «La déesse au fuseau et la sacralisation du lanificium matronal », dans CHAMPEAUX J. et Chassignet M. (dir.), Aere Perennius, Hommage à Hubert Zehnacker, Paris, PUPS, coll. Roma Antiqua, 2006, p. 55-70.

- «De Gaia Caecilia aux fées marraines: la survie du lanificium initiatique », dans H. DuCHÊNE (éd.), Survivances et métamorphoses, Journée d'études de l'EA 1865, Dijon, 2005 p. 73-93.

- La vie religieuse des matrones dans la Rome archä̈que, Coll. De l'École Française de Rome, $\mathrm{n}^{\circ} 176$, Rome, 1993.

- «La fiancée embrasée », dans D. Porte et J.P. NÉRAudAu (éd.) Hommages à H. Le Bonniec, Bruxelles, coll. Latomus, 1988, p. 19-30.

BOYANCÉ Pierre

- «Fides et le serment », dans Hommages à Albert Grenier, Bruxelles, 1962, p. 329-341.

- «La main de Fides », dans Hommages à Jean Bayet, (coll. Latomus LXX), Bruxelles, 1964, p. 101-113. Les 2 articles sont repris dans P. BOYANCÉ, Études sur la religion romaine, Coll. de l'École française de Rome, Rome, 1972, p. 91-103 et 121-133.

LARSSON-LOVÉN Lena, "Lanam fecit. Woolworking and Female Virtue », dans L. LARSSONLOVEn et A. Stromberg (éd.), Aspects of Women in Antiquity, Jonsered, Sweden, 1998, p. 85-95.

GRIMAL Pierre, "Matrona », dans R. BRAUN (ed.) Hommage à J. Granarolo, publ. de la faculté des Lettres de Nice, 1985, p. 195-203.

Le BONNIEC Henri, Le culte de Cérès à Rome. Des origines à la fin de la République, Paris, Klincksieck, 1958.

VAN GENNEP Arnold, Les rites de passage, réimpr. de l'éd. de 1909, augmentée en 1969, Paris, Picard, 2011.

WeStERMARCK Edward, Histoire du mariage, trad. Van Gennep, Paris, Payot, 1935.

WiLliamS Gordon, "Some aspects of Roman Marriage ceremonies and ideals », JRS 48, 1958, p. 16-29. 


\title{
Faire, dire, montrer : la communication du consulat lyonnais lors des entrées princières (1656-1788)
}

\author{
Françoise BAYARD \\ Professeur honoraire d'histoire moderne, \\ Université Lumière Lyon 2 \\ Extrait de : Jean DumA (dir.), Le Rituel des cérémonies, Paris, \\ Extrait de : Jean DuMA (dir.), Le Rituel des cérémonies, Paris,
des congrès des sociétés historiques et scientifiques), 2015. \\ Cet article a été validé par le comité de lecture des Éditions du CTHS dans le cadre de la publication \\ des actes du $139^{\mathrm{e}}$ Congrès national des sociétés historiques et scientifiques tenu à Nîmes en 2014.
}

Au début de l'époque moderne, Lyon, deuxième ville du royaume, a reçu 18 rois, princes, cardinaux, ministres auxquels une "entrée ", avec force décors éphémères et défilé de toute la population, a été réservée ${ }^{1}$. De 1656 à 1788, les registres de délibérations et de comptabilité municipales permettent d'identifier 44 visites dont 23 seulement ont donné lieu à des comptes rendus ${ }^{2}$. 20 sont réalisées par des femmes, 20 par des hommes et 4 par des couples. 7 sont des ambassadeurs ; 22 des souverains ou des enfants de monarques étrangers ; 13 des princes et des princesses français, certains étant des enfants de France. Le maréchal de Villars est gouverneur de Provence. M. et Mme Woronzov n'ont pu être identifiés. Seuls la reine de Sardaigne et Monsieur et Madame voyagent incognito.

Quand elles sont connues, les raisons de leur séjour sont assez variées. Cinq des 10 femmes vont ou viennent épouser des princes étrangers ou français. Les hommes se rendent sur les lieux de leurs fonctions ou en reviennent. Les ducs de Bourgogne et de Berry rentrent d'Espagne où ils ont accompagné leur frère Philippe $\mathrm{V}$.

Les visiteurs ne sont que de passage. Sur les 29 visites pour lesquelles on connaît la durée du séjour, 5 restent un jour voire une nuit ; 4 , deux ; 1 , trois ; 8, quatre ; 4, cinq ; 1 , six ; 1 , huit ; 5 plus de trois semaines.

Les réceptions sont beaucoup plus modestes que par le passé : seules les entrées du cardinal Chigi et de l'infant d'Espagne donnent lieu au défilé des corps de la ville et seule la première voit se dresser des arcs de triomphe. Toutes se déroulent de la même manière. Après préparation de l'événement, le Prévôt des marchands et les quatre échevins, dûment vêtus, accueillent la personnalité attendue, avec la milice et au bruit des canons, à une des portes de la ville. Ils la conduisent dans les établissements religieux ou administratifs où ils doivent résider - sur les 24 qui sont connus, 8 logent à l'Archevêché ; 4 à l'abbaye d'Ainay ; 3 à l'hôtel du gouvernement ; 2 à l'intendance - dans des hôtels - 2 vont au logis du Parc et 1 à l'Hôtel de Malte - ou dans des habitations privées - 3 (dont le roi) résident chez Mascrany place Bellecour et l'infante d'Espagne dans deux maisons du même lieu. Ces habitations sont constamment gardées. Des cadeaux leur sont offerts. Des visites de lieux ou de monuments sont organisées et diverses réjouissances mises en place. Lors de leur départ, les autorités les accompagnent. Par la suite, ayant été « délibéré et résolu qu'il en sera fait mention dans les registres de la ville », le secrétaire de la cité est chargé de rédiger une "relation » ou un "procèsverbal » de ces séjours qu'il place dans le registre des délibérations municipales. Parallèlement, à certaines périodes, des auteurs relatent les événements.

1. On en trouvera les récits dans l'ouvrage publié sur les ordres du Consulat en 1752 Relation des entrées solennelles dans la ville de Lyon de nos rois, reines, princes, princesses, Reprint Horvath, 1979. Deux expositions leur ont été en partie consacrées : Entrées royales et fêtes populaires à Lyon du XVe au XVIII siècle, Bibliothèque de la ville de Lyon, 1970 ; Voyages officiels à Lyon. Des entrées royales aux voyages présidentiels, Musées Gadagne, 2012.

2. L'annexe 1 en donne la liste ainsi que leurs références archivistiques. Il a paru inutile de les répéter dans les notes de bas de page. 
Au-delà des aspects factuels que révèlent ces récits, les manières de faire, de dire, de montrer du Consulat lyonnais attestent sa volonté de donner « une juste idée de cette grande ville » : une cité obéissante, fidèle, attachée à la monarchie, fière, dynamique et riche.

\section{Une ville obéissante, fidèle, attachée à la monarchie}

Une seule fois, en 1788, le Consulat n'est « informé que par les nouvelles publiques » de l'arrivée des notabilités. En temps normal, même si l'annonce est tardive (la veille pour Charlotte-Adélaïde d'Orléans), la ville est prévenue et dans 15 cas «le roi a donné des ordres » par lettre de cachet (1664) ou un mémoire du secrétaire d'État à la guerre (1741) prévoyant la conduite à tenir par les autorités civiles et militaires. Il ne faut donc qu'exécuter ce qui a été décidé à Versailles. Le prévôt des marchands réunit alors les échevins «pour déterminer tout ce qu'il convenait de faire». Pour les visites les plus importantes, le gouverneur $(1701)$ ou le lieutenant général $(1656 ; 1658 ; 1664)$ dirigent les débats. La cour peut aussi envoyer des aides: le sieur de l'Esseing pour la reine de Suède ; Monsieur de Joinville pour l'ambassadeur de la Porte ; le Comte de ClermontTonnerre pour Clotilde de France. La tâche des autorités est facilitée à partir de 1680 : le cérémonial public de l'Hôtel de ville de Lyon $^{3}$ réglemente tous les actes de la municipalité, notamment, dans son chapitre VII, toutes les cérémonies d'entrée ${ }^{4}$. Tout doit être prévu pour que les différents moments du séjour se déroulent sans heurt et que les accidents et les troubles à l'ordre public soient évités. Les dispositions sont ensuite divulguées par des ordonnances lues et affichées. Reviennent constamment, entre autres, la nécessité de libérer les espaces publics $(1656,1658,1664)$, les restrictions de circulation sur terre $(1701,1773)$ et sur la Saône (1773), l'enfermement ou l'expulsion des «vagabonds et gens sans aveu » (1701, 1773) et l'interdiction des jeux (1773). Quand le Consulat est livré à lui-même, le Prévôt des marchands en réfère après coup au Secrétaire d'État en charge de Lyon et au gouverneur.

Au-delà de l'exécution des ordres royaux, l'obéissance et la soumission de la cité sont constamment rappelées dans les discours d'accueil et de départ par les prévôts des marchands $(1658,1696,1706)$. Au roi, fait bien compréhensible après la Fronde, le prévôt affirme "l'inviolable fidélité dans laquelle nous protestons de vivre et mourir pour le service de sa Majesté et le bien de son État ». Par la suite, cinq autres visiteurs entendent les mêmes serments.

Car les Lyonnais sont attachés à la monarchie et à ses représentants comme le montre la dédicace d'un lieu à un représentant du roi ou à un membre de sa famille, les termes employés dans les discours, les devises et les tableaux affichés à l'Hôtel de ville ou sur les supports des feux d'artifice. En 1740, la municipalité attribue le nouveau quai créé le long du Rhône au duc de Retz, gouverneur de Lyon, et en 1775, son prolongement à Monsieur «pour perpétuer à jamais le souvenir de ses bontés et le bonheur que ses habitants ressentaient de l'avoir vu et gardé dans l'enceinte de leurs murs ». 16 discours parlent de la joie ou de la satisfaction de recevoir ces hôtes de marque ; 7 de l'honneur qu'ils font à la ville. Par 4 fois on ressent de l'admiration; par 6 de la vénération. Ces personnes sont sacrées :

«Il serait bien difficile d'exprimer par des paroles toute la joye qu'apporte dans nos cœurs la présence de votre sacrée majesté. »

3. Arch. Mun. Lyon BB 237 fol. 203-244 ; P. Rochex. (éditeur), « Cérémonial public de l’Hôtel de Ville de Lyon $1680 »$ p. $64-77 ; 142-159 ; 223-245$.

4. Arch. Mun. Lyon BB 237, fol. $220 v^{\circ}-222 v^{\circ}$; P. Rochex. (éditeur), «Cérémonial public de l'Hôtel de Ville de Lyon $1680 »$, p. $155-157$. 
Si 8 discours vantent les qualités des visiteurs, ainsi la douceur et la grâce de MarieThérèse de Savoie ou les dons de navigateur du duc de Penthièvre, c'est avant tout leur ascendance qui est mise en avant : on rappelle ainsi au jeune prince de Conti « l'idée du héros qui (lui) a donné le jour ». L'affection confine à la tendresse en certaines circonstances malheureuses - en 1666, la princesse de Conti reçoit quelques paroles de réconfort -, heureuses - Françoise de Valois est « félicitée par un beau discours sur son mariage» - ou incertaines - «les Lyonnais feront de continuels vœux pour la conservation de la santé et des jours de votre Altesse royale si précieux et si nécessaires » dit-on lors du départ du duc d'Orléans. Cet attachement transparaît dans les écrits éphémères. Pour l'infant d'Espagne :

«Au perron de l'Hôtel de ville, on lisoit ces mots : Heureuse elle s'enorgueillit de son hôte ${ }^{5}$ et l'emblème représenté en peinture sur la charpente (du feu d'artifice) étoit un ciel étoilé avec la comète, au-dessous un peuple nombreux qui observe ce phénomène et pour devise Les astres peuvent rester s'ils veulent, quand tu viens le jour ne saurait manquer au peuple. $»^{6}$

Les attitudes de l'échevinage attestent le respect qu'il accorde à ces personnalités. C'est à genoux que l'on s'adresse au roi et à la reine avant de leur faire une révérence. Mais seule cette dernière est faite à la reine de Suède, à Mademoiselle et au duc de Savoie et on leur parle debout. Une inclination profonde suffit pour le cardinal Chigi et un salut pour Mazarin et Monsieur. Les autres récits ne mentionnent pas la manière dont on les accueille. En revanche, ils n'oublient pas de préciser que, quand elles sont reçues à l'Hôtel de ville, le prévôt et les échevins viennent les attendre au bas du perron et qu'elles sont raccompagnées jusqu'à la porte de leur carrosse. Cette soumission est symbolisée par de nombreuses images: en 1773, sur le balcon de l'Hôtel de Ville on voyait «la princesse et le génie de la Savoie recevant les hommages respectueux de la ville qui, un genou en terre lui présentait des fleurs dans un bassin et parmi lesquelles elle choisissait un lis » et lors du feu d'artifice, des lions, attributs de la ville, sont au bas du piédestal d'un obélisque sur lequel figurent les bustes du comte et de la comtesse d'Artois. Quand les ducs de Bourgogne et de Berry quittent la ville sur un bateau, « le grand mât portoit un pavillon blanc orné de trois fleurs de lys et le mât d'arrière un pavillon bleu avec un lion d'or »: la fidélité aux souverains s'accompagne de la fierté d'être une ville importante.

\section{Une ville fière}

Accueillir une personnalité procure une grande fierté à la ville, surtout si, en raison de la géographie, elle est la première du royaume à le faire : « heureuse la ville qui la première aura réuni pour toi les peuples dispersés ${ }^{7}$ » peut lire Marie-Thérèse de Savoie. C'est pourtant son site, son antiquité, sa vie intellectuelle, religieuse et artistique, sa gouvernance, ses privilèges et son modernisme qu'elle souligne. La princesse de Conti est seule en 1730 à se rendre à Fourvière d'où elle admire la vue. Elle apprécie aussi les remparts qui surplombent le Rhône comme le font Marie-Adélaïde de Savoie, le duc d'Orléans et Charlotte-Adélaïde d'Orléans. Les ducs de Bourgogne et de Berry sont les seuls à voir, après vêpres, «les deux colonnes du temple d'Auguste » réutilisées dans l'abbaye d'Ainay et les tables de bronze de l'empereur Claude placées alors à l'entrée de l'hôtel de ville. Pour conforter leur amour de l'Antiquité, ils reçoivent le livre du père Colonia sur les principales antiquités et les singularités les plus remarquables de cette ville. En 1754, on montre les archives du consulat au duc de Penthièvre. Les ducs de Bourgogne et de Berry visitent le collège de la Trinité où ils admirent les livres de la bibliothèque, les médailles ainsi que la collection des empereurs romains en bronze, or et argent et les statues égyptiennes, grecques et romaines. La bibliothèque est également

5. Santeuil, Hospite laeta superbit.

6. Martial, Stent astra, licebit, non deerit populo te veniente dies.

7. Urbs felix quae prima tibi testatim amorit gentes. 
vue par 8 autres visiteurs dont l'ambassadeur de la Porte qui y découvre les manuscrits arabes. La princesse de Conti, son fils et Philippe d'Espagne y apprécient aussi le médailler. Mais c'est celui de l'Hôtel de ville que l'on montre au duc de Penthièvre. En 1701, 1730, 1744, 1775 les visiteurs rencontrent des élèves qui leur récitent « des poésies françoises et latines que le collège avoit composées à leur honneur » ou leur font des compliments (en vers en 1744). Au XVIII siècle, la ville dispose d'une académie: la comtesse d'Artois en reçoit certains membres.

En matière religieuse le premier arc de triomphe élevé pour le Cardinal Chigi rappelle que Lyon est le premier siège des Gaules ${ }^{8}$. La relation vante «le nombre considérable d'établissements religieux qui s'y sont installés ». Le cardinal souligne aussi « le nombre des martyrs » de la cité. Les visiteurs suivent souvent des offices. Outre le cardinal Chigi et les ducs de Bourgogne et de Berry qui y sont solennellement reçus, quatre femmes vont à la cathédrale Saint Jean. Clotilde de France y assiste au mariage de dix couples dont les femmes ont été dotées par le consulat. Marie-Adélaïde de Savoie et les ducs de Bourgogne et de Berry se rendent au couvent des carmélites édifié par la famille de Neuville dont une des descendantes est alors supérieure. Les ducs vont également «au grand monastère de la Visitation Sainte Marie où ils virent le cœur de Saint François de Sales que la feue reine mère étant à Lyon fit proprement enchâsser dans un grand reliquaire d'or », à la maison Saint Antoine pour y assister plus commodément au feu d'artifice donné sur la Saône et au couvent des Célestins proche de leur habitation. L'abbaye royale de Saint Pierre est visitée par Marie-Adélaïde de Savoie, les ducs de Bourgogne et de Berry et Charlotte-Adélaïde d'Orléans. Seuls le prince et la princesse de Conti se rendent «dans l'église de la congrégation des prêtres missionnaires de Saint Joseph fondée par feu Monsieur le prince de Conti ».

Dans le domaine artistique, la musique est la première fierté du Consulat. Lors de l'arrivée des visiteurs, ce sont essentiellement les trompettes et les timbales, parfois accompagnées de tambours, qui jouent. Par la suite, la musique se fait plus douce. La reine de Suède est ainsi accueillie dans la grande salle de l'hôtel de ville par « la grande bande du sieur La Violette de dix-huit violons étant dans la tribune » et dans la chambre de la collation par «une autre bande de violons ». Le deuxième jour de leur séjour, les ducs de Bourgogne et de Berry entendent «le bruit des tambours, des hautbois et des tymbales » puis « un beau concert de voix et d'instruments ». En 1744, Dom Philippe se rend à la salle de concert ; en 1773, Marie-Thérèse de Savoie écoute « plusieurs morceaux de symphonie de la musique de Monsieur de Brancas ». C'est cependant à l'Opéra qu'à partir de 1701, le Consulat convie ses hôtes, les ducs de Bourgogne et de Berry, le prince et la princesse de Conti, l'ambassadeur de la Porte et Dom Philippe y allant tous les jours pour des représentations de Phä̈ton, l'Europe galante, Philomène, Armide, les Indes galantes, Ajax et Thésée. Le consulat lui-même ne dédaigne pas de composer un prologue. Six bals sont offerts $(1714 ; 1744 ; 1773 ; 1788$ et 2 en 1721). Dom Philippe y danse le menuet et la contredanse de minuit 30 à 8 heures alors que la comtesse d'Artois n'y reste qu'une heure.

La comédie attire Charlotte-Adélaïde d'Orléans qui y assiste quatre jours de suite mais elle triomphe surtout à la fin du siècle: Marie-Thérèse de Savoie, Clotilde de France, Monsieur et Madame s'y rendent. Les ambassadeurs indiens suivent le deuxième jour un opéra-comique (Mélomanie) et un ballet hérö̈que (Aetius et Fulvie) et le quatrième, deux comédies (Rose et Colas; Annette et Lubin) et un grand ballet.

Le consulat n'hésite pas à montrer des jeux populaires typiques de la ville. Trois soirées des ducs sont consacrées en partie à des joutes de 100 bateliers sur la Saône. Le duc de Mantoue et la reine douairière de Pologne en voient aussi. Lors de la deuxième soirée des ducs, « le divertissement de l'oye et des canards dont les bateliers rompoient en passant les cages à coups de marteau et se plongeoient à l'envi dans la rivière pour y prendre les canards qui s'y étaient jetés » est présenté. Ils participent activement au tir à l'arc organisé

8. Lugdunum prima sedes Galliarum. 
« par la compagnie des Chevaliers de l'Arc, fort ancienne dans Lyon » et au prix du jeu de l'Arquebuse mis en place par les Chevaliers de la Butte.

Cependant, la plus grande fierté du Consulat réside dans les illuminations et les feux d'artifice qui sont d'ailleurs loin d'être réservés aux hôtes de marque ${ }^{9}$. Par 8 fois, le consulat demande aux Lyonnais de garnir leurs fenêtres de lampions durant le séjour de ses hôtes. Quelques lieux sont privilégiés : la place Bellecour $(1696,1749,1775)$, l'Hôtel de ville (1744, 1773), les nouveaux quais où sont disposés des pots à feu (1749). Les plus belles ont lieu en 1701 :

\begin{abstract}
« La montagne de Fourvière et celle des Chartreux parurent dans un instant éclairées d'un nombre prodigieux de pots à feu d'une invention particulière et arrangés avec beaucoup de symétrie. Les maisons des communautés et les maisons des Bourgeois dont ces collines sont couvertes accompagnoient cette illumination générale par des illuminations particulières et l'on distinguoit avec plaisir sur ces montagnes en feu, des pyramides ardentes, des clochers embrasés et des galeries rayonnantes. »
\end{abstract}

Dix feux d'artifice - œuvre commune de concepteurs (Ménestrier), de peintres (Blanchet et Panthot en 1658 ; Nonotte en 1773 et 1775) qui fixent les thèmes et les décors, de charpentiers (Bergerat en 1773; Forobert en 1775) qui exécutent les substructions et d'artificiers (Bergeret en 1658 ; Devillard en 1773 et 1775) ${ }^{10}$ - sont organisés. 2 ont lieu place Bellecour (1749, 1775), 1 place des Terreaux (1741), 1 aux Brotteaux. Les 6 qu'on tire sur la Saône $(1656,1658,1714,1744,1773,1775)$ et que les hôtes observent de leur lieu de résidence sont les plus grandioses: "de cette structure qui semble sortir de l'eau», émerge en 1744, « nombre de gerbes et de fusées en l'air et d'autres fusées lancées à l'eau qui formaient un étang de feu qui parut aussi singulier qu'amusant pendant un assez long espace de temps ». Ceux de 1744, 1773 et 1775 sont décrits ; celui de 1701 est gravé.

Aucune relation ne mentionne la gastronomie de la cité : les princes permettent «qu'on les voit manger " mais on ignore de quels mets ils se régalent et les collations données par 10 fois par le Consulat sont composées, pour la plupart, de fruits et de confitures $\left(1656\right.$; 1663) auxquels s'ajoutent des gelées, viandes et pâtés (1664) et au XVIII ${ }^{\mathrm{e}}$ siècle des pâtisseries (1741), des eaux glacées $(1720)$, des glaces $(1749,1754)$ et du café $(1741)$.

Ces réjouissances émanent d'un Consulat fier de montrer les apparences de sa gouvernance et ses privilèges. C'est généralement en tenue de cérémonie que le Prévôt et les échevins accueillent et accompagnent leurs hôtes, mais le duc de Chaulnes est reçu en tenue ordinaire et certains demandent qu'ils ne s'habillent pas pour leur départ. Pour tous les autres, ils portent une robe violette, couleur de la ville depuis 1580, en satin pour le Prévôt et en damas pour les autres. Ils sont "précédés de leurs deux mandeurs " portant «la livrée violette de la ville, avec sur la manche droite le grand écusson en broderie des armes de la ville et leur coadjuteur le petit écusson, chacun d'eux ayant en main leur baguette", "accompagnés de leurs trois officiers en robe de damas violette et suivis de Messieurs les exconsuls », depuis 1614, en robe noire ${ }^{11}$. Ils ne manquent pas de recevoir 16 de leurs hôtes à l'Hôtel de ville qui, jusqu'en 1696, est le seul lieu visité. La milice bourgeoise, constamment mise en avant et félicitée dans les récits, est de 21 entrées. On en célèbre le nombre - « trente-cinq quartiers et qui étoient tous composés de deux cens hommes choisis »-, la discipline - soigneusement organisée rue par rue de manière à ce que chaque quartier sache parfaitement où s'installer - les vêtements - « on vit même avec une vraye admiration dans la Place de Bellecour plusieurs penonnages entiers dont tous les soldats, voulant à l'envi marquer leur zèle dans cette glorieuse occasion, avoient des juste-au-corps d'écarlate ou de velours ou d'un drap des plus fins et tous galonés d'or ou d'argent» - et son expérience - «encore que la plupart de cette soldatesque et de ces troupes fussent tirées des boutiques, elles ne laissoient pas de faire

9. E. Vial, « Les réjouissances publiques à Lyon », p. 245-258.

10. Arch. Mun. Lyon, BB 213, fol. 610, 28 décembre 1658 ; fol. 639, 29 décembre 1658 ; CC 3512, frais de passage de Madame la Comtesse d'Artois ; CC 3548, dépenses extraordinaires pour le passage de Clotilde de France.

11. E. Vial, «Costumes consulaires », p. $55 ; 134-136$. 
parfaitement connoître dans leurs marches et dans leurs postes qu'elles sçavoient fort bien manier l'épée, le mousquet et la pertuisane » (1664).

La ville possède aussi une compagnie du guet également sollicitée lors des entrées. Elle ne manque pas de faire tirer les mousquets $(1664,1720)$, les canons et les boîtes ${ }^{12}$ en plus ou moins grand nombre (100 en 1696 et $1701 ; 12$ en 1788) à l'arrivée - sauf en 1701 pour " épargner aux dames la frayeur qu'elles auroient pu avoir si on avoit tiré le canon tandis que leurs carrosses passoient sur le pont du Rhône» - et au départ de chaque personnalité et parfois au cours du séjour - ainsi en 1744, au matin du bal donné en l'honneur de Philippe d'Espagne -, ce qui ne manque pas de donner un aspect militaire parfois ordonné par le roi, relevé en 1775 - «la ville ressemblait alors à une ville de guerre »- à ces réceptions que certains, comme le Cardinal Chigi qui désire passer les troupes en revue, ne détestent pas.

La garde bourgeoise est nécessaire puisque les « habitans jouissent de temps immémorial du privilège de se garder eux-mêmes, de garder leurs princes et de n'admettre aucunes troupes étrangères ». Elle se fait donc un devoir de monter la garde jour et nuit devant le lieu de leur résidence (1730) et veille à faire respecter la tradition ainsi en 1788 où elle montre "le plus vif désir de pourvoir exclusivement à la sureté » des ambassadeurs indiens « et de tout ce qui leur appartenait pendant la durée du séjour ». Des problèmes de préséance peuvent ainsi surgir du non-respect de « l'usage de tout temps introduit »: en 1658, alors que le consulat vient présenter ses devoirs à la reine, le doyen de Saint Jean et d'autres ecclésiastiques veulent le devancer, contrairement à l'habitude. C'est pourquoi lors de 8 entrées, le prévôt demande la conservation des privilèges de la ville (roi), la protection (Mazarin ; duc d'Orléans ; Marie-Adélaïde de Savoie ; Charlotte-Adélaïde de Savoie ; prince et princesse de Conti), la bienveillance (Mademoiselle) ou la bénédiction (cardinal Chigi) des autorités.

Enfin, le Consulat est fier de montrer son modernisme. S'il accueille ses visiteurs à l'Hôtel de Ville c'est qu'il a été récemment construit entre 1647 et 1655 par Simon Maupin et repris après l'incendie de 1674 par Robert de Cotte puis Mansart (on montre les plans des réparations aux ducs de Bourgogne et de Berry). Si la Place Bellecour est le lieu de passage presque obligé de leurs hôtes, c'est qu'elle est progressivement aménagée depuis l'entrée de Henri IV en 1600 et l'ordonnance de Louis XIV de 1658, l'achèvement se réalisant après l'érection en 1713 de la statue du souverain (dont on montre les plans à ses petits-fils), fort appréciée par les Conti en 1730. On fait aussi découvrir la salle de concert édifiée en 1724, place des Cordeliers, et le théâtre de Soufflot construit entre 1754 et 1756. Les itinéraires sont modifiés, de façon à faire découvrir les nouveaux quais : la rive droite de la Saône est délaissée pour la rive gauche où les quais d'Halincourt et de Sainte-Marie-des-Chaînes sont terminés au début du XVIII ${ }^{\mathrm{e}}$ siècle et où l'on prend les coches d'eau entre Lyon et Chalon-sur-Saône au Port Neuville ; les rues étroites du centre sont abandonnées pour les quais du Rhône ${ }^{13}$.

Au-delà de ce qu'il montre et défend, le Consulat est également fier de son dynamisme et de sa richesse.

\section{Une ville dynamique et riche}

Les récits des entrées montrent le dynamisme démographique de la cité. Les personnalités sont toujours accueillies par une «multitude innombrable de gens de la ville et d'étrangers » (1775), leur participation aux entrées ne se limitant pas à l'accueil enthousiaste (peut-être contraint ${ }^{14}$ ) : des fontaines de vin sont installées aux Terreaux

12. Projectiles d'artillerie comprenant de nombreuses balles placées dans une enveloppe de tôle. 13. E. Pariset, Souvenirs lyonnais, p. 56-60.

14. D. Vaillancourt, « La ville des entrées royales : entre transfiguration et défiguration », p. 507. 
(1658) ou sur les places de la cité avec des orchestres (1773) ; 12 prisonniers sont libérés en 1701 et 6 déserteurs et 6 prisonniers civils en 1775. De sorte que toute la population est heureuse :

«Les enfants éblouis du brillant de toutes les grandeurs qui vous environnent ont ardemment désiré de vous voir ; les jeunes y ont couru et vous ont montré, les vieillards vous ont admiré et les malades malgré leurs faiblesses s'y sont traînés. » (1664)

Cette population est jeune. Depuis 1737, 50 à 800 jeunes hommes de l'Académie militaire de la ville - «des riches négociants ou leurs enfants » - sont régulièrement envoyés audevant des visiteurs et chargés de les accompagner lors de leurs départs. Ils montent très bien (1775) "des chevaux de prix très bien harnachés » (1744, 1749). Ils portent des uniformes rouges soignés. Conduits par un chef (1775), ils savent manœuvrer : en 1737,

«Les uns et les autres entrèrent dans la ville deux à deux, l'épée à la main et surent se ranger en ordre de bataille au-devant des prisons de l'Archevêché et sur la place qui est à l'entrée du pont de bois. »

L'importance de la population conduit le Consulat à faire œuvre d'urbanisme. L'équipe dirigeante montre alors les réalisations récentes et les chantiers à ses visiteurs. En 1775, le consulat présente au frère du roi «une collection de différents plans dont le plan géométral de cette ville ». Monsieur va visiter les travaux Perrache visant à repousser le confluent du Rhône et de la Saône pour agrandir la ville au sud et ceux de Morand dans la plaine des Brotteaux, à l'est du Rhône. Les ambassadeurs indiens ont aussi droit à la visite des Brotteaux, jouissant de la beauté de la promenade et du coup d'œil, s'installant dans le café d'Antoine Spréafico et assistant, preuve supplémentaire du modernisme et du dynamisme de la ville, à l'envol de deux ballons « aérostatiques construits en papier à Annonay et apportés en cette ville par M. de Monneron, les opérations étant dirigées par Fontaine l'un des aéronautes qui monta le grand ballon Montgolfier en janvier 1784 ».

Ce dynamisme démographique et urbain s'explique par la richesse de la cité qui transparaît dans les cadeaux offerts à ses hôtes. Le cérémonial précise ce qu'ils doivent être: du vin pour les hommes; des confitures pour les dames, donc des " gourmandises », à l'instar des « victuailles » données "pour stimuler la bonne volonté des fonctionnaires de qui dépend la ville ${ }^{15}$. Les consignes sont respectées. Toutefois, la qualité des vins est soignée: le duc d'Orléans reçoit des vins de Bourgogne et de Champagne. Les quantités sont importantes : on donne 12 grands coffrets de confitures et de dragées à la princesse de Conti et «trois caisses de sirops étrangers et six coffrets de confitures » à l'ambassadeur de la Porte. On outrepasse volontiers les consignes : on attribue «des bêtes fauves et des poissons des lacs de Genève et du Bourget » à l'infant d'Espagne. Dès 1701, des étoffes (surtout des brocarts), des corbeilles doublées de drap d'argent brodé d'or, des fleurs artificielles (entre 1730 et 1759) et des habits s'ajoutent à ces présents ordinaires. Ces cadeaux sont tellement somptueux que les ducs de Bourgogne et de Berry les envoient (sauf le vin) à Versailles pour les faire apprécier, ainsi que leur présentation, par le roi.

Les réceptions données à l'hôtel de ville témoignent aussi de la prospérité de Lyon. Déjà somptueuses en elles-mêmes par le décor peint de Thomas Blanchet qu'ont admiré Louis XIV, Charlotte-Adélaïde d'Orléans, la comtesse de Toulouse et le duc de Penthièvre, les salles sont ornées de tapisseries $(1744,1749)$ que le Consulat prête volontiers pour embellir d'autres lieux, ainsi le couvent des franciscains de la Guillotière lors de la venue du cardinal Chigi, ou loue comme en 1658. Des tableaux enrichissent les murs : en 1701, chez les Antonins :

«On voyoit des peintures de prix et en grand nombre : une Judith d'Hannibal Carrache, un Seneque du Guide, des originaux du Padoüan, du Correge, d'André del Sarto, de Leonard Vinchi, Maître de Raphaël d'Urbin, etc. »

15. E. Vial, « Présents d'honneur et gourmandises », p. 138. 
Les loges de l'Opéra sont également tendues d'étoffes chatoyantes: celle de l'infant d'Espagne était « tapissée de velours cramoisi, galonnée en or ».

Les lieux qui les accueillent sont somptueusement éclairés. À l'hôtel de ville, l'infant gravit « le grand escalier garni d'une infinité de lustres et de flambeaux de cire blanche » avant d'arriver dans «la salle de bal éclairée d'un grand nombre de bougies dans des lustres et des girandoles ». Dans le couvent de Saint Antoine en 1701, « la galerie et les sales (sic) voisines avec l'escalier qui y conduit étoient embellies de quantité de lustres et de candélabres de cristal » et les loges, les corridors et la salle de l'Opéra «étoient éclairés de bougies » et de «très gros lustres » en 1788.

Les femmes de la ville, particulièrement habillées et parées de bijoux précieux font - aux dires des rédacteurs - partie du décor à tel point qu'en 1773, on fait sortir les hommes du milieu de la salle de bal " pour que le coup d'œil des amphithéâtres » où se tenaient " six à sept cents femmes placées sur cinq rangs de gradins » " put avoir tout son effet ». Aussi n'est-on pas étonné que l'ambassadeur de la Porte reçoive le soir même de son arrivée et le lendemain matin "toutes les dames et personnes de considération » et "demande aussi les dames » quand il rend visite au Prévôt des marchands et à l'intendant deux jours plus tard.

Les fondements économiques de cette richesse sont montrés et expliqués à la plupart des visiteurs au XVIII ${ }^{\mathrm{e}}$ siècle. Montés dans une salle de l'Hôtel de ville (pour 7) ou vus dans des ateliers (dont celui de Pernon pour 2) des métiers à tisser et à lire les dessins ainsi que des pièces de tissus, des plus modernes sont présentés. À partir de 1720, s'y ajoute pour 8, le travail des tireurs d'or, "soit pour dorer ou dégrossir les lingots, soit pour écacher (aplatir) l'or et l'argent et le mettre en filé pour les différents ouvrages où ils peuvent être employés » et plus tard, celui des guimpiers consistant à recouvrir un fil d'un ou de plusieurs autres. Tous, comme Charlotte d'Orléans qui «donna grande attention à ce travail et se fit expliquer jusqu'au plus petit détail de cette fabrique » sont intéressés. Mais l'essentiel est dévoilé dans le compte-rendu de la visite de Clotilde de France : il s'agit de faire connaître les étoffes «les plus belles du monde », les visiteurs devant s'en faire les propagandistes à leur retour chez eux, d'autant que ces activités qui « entretiennent les trois quarts de la ville » sont fragiles. Si lors des démonstrations « on avait fait habiller très magnifiquement les ouvriers » (1749), en 1750, la comtesse de Toulouse constate « la misère générale des ouvriers qui la suivaient partout pendant son séjour dans cette ville et en ayant demandé la cause, Monsieur le Prévôt des marchands lui dit que cette misère provenoit de la cessation totale de nos manufactures ».

Par ses actions, ses gestes et ses paroles, le Consulat lyonnais a sans doute réussi à capter un temps l'attention de ses visiteurs et à faire oublier les révoltes de la première ville ouvrière de France. Mais il a dû pour cela dépenser beaucoup d'argent. Sur les 37 dont les montants sont connus, 29 sont inférieures à 15000 livres. Mais il a fallu débourser 40118 livres pour le cardinal Chigi, 50943 livres pour Philippe d'Espagne, 64061 livres pour Clotilde de France, 77744 livres pour la comtesse d'Artois et 119476 livres pour les ducs de Bourgogne et de Berry. Fonctions du temps passé dans la ville, ces dépenses le sont aussi des réjouissances offertes : le prince électoral de Saxe a séjourné trois mois à Lyon mais il n'a bénéficié que d'une réception à l'Hôtel de Ville et d'un régal ; l'infant de Portugal, malade, est demeuré trois semaines mais on lui a offert seulement des pièces d'étoffes en dorure et du vin pour sa table. En revanche, la comtesse d'Artois a vu deux feux d'artifice, des illuminations durant trois nuits, un spectacle, a participé à un bal paré et a reçu, ainsi que ses dames d'honneur, une corbeille décorée et brodée et deux pièces d'étoffes tandis que Brancas, venu préparer sa visite, a bénéficié de vins d'honneur et d'un habit « riche ». Ces sommes ne sont en rien négligeables : entre 1680 et 1699, les recettes annuelles de la cité s'élèvent en moyenne à 1614000 livres ${ }^{16}$, entre 1725 et 1730 à

16. N. Neyret, « Les budgets municipaux à Lyon de 1680 à 1699 », p. 76. 
2647998 et entre 1775 et 1780 à $3505616^{17}$. Elles ont donc contribué à faire croire à la monarchie et à ses représentants (dont ses gouverneurs) qu'ils pouvaient puiser indéfiniment à cette source et finalement à accroître le déficit budgétaire constant de la ville.

\begin{abstract}
Résumé
Après 1656, Lyon connaît peu de cérémonies analogues aux entrées royales de la première modernité. Pourtant, elle continue de recevoir des souverains et des princes français ou étrangers et des ambassadeurs. Les registres de délibérations et de comptabilité municipales en portent une double trace. Pour 21 de ces passages ne figure que le coût de la réception. Pour 23 autres, une "relation » ou un " procès-verbal » des cérémonies organisées précède le montant financier. Sont ainsi révélés les préparatifs de la visite, les costumes arborés par le Consulat et son escorte, les logements choisis pour leurs hôtes, les réjouissances mises en place, les discours prononcés, les itinéraires suivis pour montrer les agrandissements de la ville, ses nouveaux bâtiments et ses nouvelles activités, «le faire», "le dire» et «le montrer » étant évidemment différents selon les voyageurs et l'époque de leur périple mais toujours coûteux pour la cité.
\end{abstract}

\title{
Bibliographie
}

ADLA Fabien, «L'endettement de la ville de Lyon au XVIII ${ }^{\mathrm{e}}$ siècle », Études et documents, IX, CHEFF, 1997, p. 195-229.

NEYRET Norbert, «Les budgets municipaux à Lyon de 1680 à 1699 », Études et documents, III, 1991, CHEFF p. 71-85.

PARISET Ernest, Souvenirs lyonnais de 1496 à 1896. Les entrées solennelles à Lyon et les embellissements de la ville, 1897.

Rochex P., (éditeur), "Cérémonial public de l'Hôtel de Ville de Lyon 1680 », Revue d'Histoire de Lyon, 1903, II p. 64-77 ; 142-159 ; 223-245.

VAILlANCOURT Daniel, «La ville des entrées royales: entre transfiguration et défiguration », XVII ${ }^{\mathrm{e}}$ siècle, $\mathrm{n}^{\circ}$ 212, juillet-septembre 2001, p. 491-508.

VIAL Eugène, "Costumes consulaires », Revue d'Histoire de Lyon, 1904, Tome 3, p. 43$60 ; 127-145 ; 288-305$.

VIAL Eugène, «Les réjouissances publiques à Lyon », Revue d'histoire de Lyon, 1907, Tome 6, p. 240-264.

VIAL Eugène, «Présents d'honneur et gourmandises », Revue d'Histoire de Lyon, 1910 Tome 9 , p. $122-148 ; 277-300 ; 377-401$.

17. F. Adla, « L'endettement de la ville de Lyon au XVIII ${ }^{e}$ siècle », p. 215-216. 


\section{Annexe 1 - Sources}

\begin{tabular}{|c|c|c|c|c|c|c|}
\hline Dates & Noms & Qualités & $\begin{array}{l}\text { Délibérations } \\
\text { municipales }\end{array}$ & $\begin{array}{l}\text { Recueil } \\
\text { des } \\
\text { entrées }\end{array}$ & Autres & Montants \\
\hline $\begin{array}{l}14-23 / 8 \\
1656\end{array}$ & Christine de Suède & Souveraine & $\begin{array}{l}\text { BB 211 } \\
\text { fol. 285-302 }\end{array}$ & $\begin{array}{l}\text { p. } 207- \\
212\end{array}$ & & $\begin{array}{l}\text { BB } 211 \\
\text { fol 305, 307, } 367 . \\
2737 £\end{array}$ \\
\hline $\begin{array}{ll}24 / 11 & \\
1658-\quad 13 / 1 \\
1659\end{array}$ & Louis XIV & Souverain & $\begin{array}{l}\text { BB } 213 \\
\text { fol. } 481-488 \\
\text { BB } 214 \text { fol. } 51\end{array}$ & $\begin{array}{l}\text { p. 213- } \\
222\end{array}$ & & $\begin{array}{l}\text { BB } 213 \\
\text { fol. } 472-657 \\
48645 £\end{array}$ \\
\hline $\begin{array}{l}28 / 11-8 / 12 \\
1658\end{array}$ & Duchesse de Savoie & Souveraine & $\begin{array}{l}\text { BB } 213 \\
\text { fol. } 492-508\end{array}$ & $\begin{array}{l}\text { p. 223- } \\
228\end{array}$ & & Idem \\
\hline $\begin{array}{l}23-29 / 3 \\
1663\end{array}$ & Françoise de Valois & $\begin{array}{l}\text { Princesse } \\
\text { française }\end{array}$ & $\begin{array}{l}\text { BB 218 } \\
\text { fol. } 116-120\end{array}$ & $\begin{array}{l}\text { p. 229- } \\
231\end{array}$ & & $\begin{array}{l}\text { BB } 218 \text { fol. } 126 \\
2358 £\end{array}$ \\
\hline $\begin{array}{l}31 / 5-7 / 6 \\
1664\end{array}$ & Cardinal Chigi & Ambassadeur & $\begin{array}{l}\text { BB 219 } \\
\text { p. 303-319 }\end{array}$ & $\begin{array}{l}\text { p. } 233- \\
248\end{array}$ & $\begin{array}{l}\text { B.M.Lyon } \\
119 \quad 069 \\
\text { Res. }^{18}\end{array}$ & $\begin{array}{l}\text { BB } 220 \text { fol. } 27 \\
40118 £\end{array}$ \\
\hline $26 / 41666$ & Princesse de Conti & $\begin{array}{l}\text { Princesse } \\
\text { française }\end{array}$ & $\begin{array}{l}\text { BB 221 } \\
\text { fol. } 80-80 v^{\circ}\end{array}$ & & & \\
\hline $\begin{array}{l}2 / 6 \\
1666 \\
\end{array}$ & Duc de Chaulnes & Ambassadeur & $\begin{array}{l}\text { BB 221 } \\
\text { fol. } 129\end{array}$ & & & \\
\hline mai 1684 & $\begin{array}{l}\text { Madame royale } \\
\text { de Savoie }\end{array}$ & Souveraine & $\begin{array}{l}\text { BB } 241 \\
\text { fol. } 54\end{array}$ & p. $232^{19}$ & & $\begin{array}{l}\text { BB } 241 \text { fol. } 86 \\
3985 £\end{array}$ \\
\hline 1692 & $\begin{array}{l}\text { Reine douairière } \\
d^{\prime} \text { Angleterre }\end{array}$ & Souveraine & & & & $\begin{array}{l}\text { BB } 250 \text { fol. } 143 \\
2030 £\end{array}$ \\
\hline 1692 & Prince de Monaco & Souverain & & & & $\begin{array}{l}\text { BB } 250 \text { fol. } 143 \\
1025 £\end{array}$ \\
\hline $\begin{array}{l}18-21 / 10 \\
1696\end{array}$ & $\begin{array}{l}\text { Marie-Adélaïde } \\
\text { de Savoie }\end{array}$ & Souveraine & $\begin{array}{l}\text { BB } 254 \\
\text { fol. } 103\end{array}$ & $\begin{array}{l}\text { p. } 249- \\
254\end{array}$ & $\begin{array}{l}\text { BM Lyon } \\
\text { Res } \\
354277^{20}\end{array}$ & $\begin{array}{l}\text { BB } 254 \text { fol. } 144 \\
11033 £\end{array}$ \\
\hline $\begin{array}{l}9-13 / 4 \\
1701\end{array}$ & $\begin{array}{l}\text { Ducs de Bourgogne } \\
\text { et de Berry }\end{array}$ & $\begin{array}{l}\text { Princes } \\
\text { français }\end{array}$ & $\begin{array}{l}\text { BB 260 } \\
\text { fol. } 59-70\end{array}$ & $\begin{array}{l}\text { p. } 255- \\
277\end{array}$ & $\begin{array}{l}\text { BM } \\
354 \text { Lyon } \\
354214 \text {; } \\
215^{21}\end{array}$ & $\begin{array}{l}\text { BB } 260 \text { fol. } 230 \\
119476 £\end{array}$ \\
\hline $\begin{array}{l}1704 \\
3 \text { semaines }\end{array}$ & Duc de Mantoue & Souverain & & & & $\begin{array}{l}\text { BB } 264 \text { fol. } 123 \text { et } \\
175 \\
5177 £\end{array}$ \\
\hline $4-5 / 71706$ & Duc d'Orléans & Prince français & $\begin{array}{l}\text { BB 266 } \\
\text { fol. } 92-95\end{array}$ & & & $\begin{array}{l}\text { BB } 266 \text { fol. } 103 \\
2869 £\end{array}$ \\
\hline août 1706 & $\begin{array}{l}\text { Princesse de } \\
\text { Monaco }\end{array}$ & Souveraine & & & & $\begin{array}{l}\text { BB } 266 \text { fol. } 102 \\
2548 £\end{array}$ \\
\hline 1709 & Duc de Vendôme & Prince français & & & & $\begin{array}{l}\text { BB } 266 \text { fol. } 102 v^{\circ} \\
1488 £\end{array}$ \\
\hline $\begin{array}{l}18 \text { août et } \\
\text { sq } 1714\end{array}$ & $\begin{array}{l}\text { Reine douairière de } \\
\text { Pologne }\end{array}$ & Souveraine & & & & $\begin{array}{l}\text { BB } 275 \text { fol. 217- } \\
217 \mathrm{v}^{\circ} \\
14865 £\end{array}$ \\
\hline 1716 & Maréchal de Villars & Gouverneur & & & $\begin{array}{l}\text { BM Lyon } \\
111688^{22}\end{array}$ & $\begin{array}{l}\text { BB } 278 \text { fol. } 184 \\
1548 £\end{array}$ \\
\hline $\begin{array}{l}1716 \\
3 \text { mois }\end{array}$ & $\begin{array}{l}\text { Prince électoral de } \\
\text { Saxe }\end{array}$ & Souverain & & & & $\begin{array}{l}\text { BB } 278 \text { fol. } 184 \\
2863 £\end{array}$ \\
\hline
\end{tabular}

18. C.F. Ménestrier, L'entrée solennelle dans la ville de Lyon de Monseigneur l'Éminentissime cardinal Flavio Chigi, neveu de sa sainteté et son légat a latere en France, 1664, Fumeux; Description de l'arc de triomphe dressé à la porte du Rhône par les soins de M. le Prévôt des marchands et échevins, 1664, Julliéron.

19. Seule figure l'ordonnance d'organisation.

20. Relation de ce qui s'est passé à l'arrivée de Madame la princesse de Savoye en France au mois d'octobre 1696, 1696, Martin.

21. Relation de ce qui s'est fait à Lyonau passage de Monseigneur le duc de Bourgogne et de Monseigneur le duc de Berry, 1701, Louis Pascal; Dessin du feu d'artifice dressé sur la rive de la Saône pour l'heureuse arrivée du duc de Bourgogne et du duc de Berry, Louis Pascal, 1701.

22. À Mgr le maréchal duc de Villars à son passage à Lyon allant ouvrir et présider aux États de Provence en qualité de gouverneur de la province, 1716, Molin. 


\begin{tabular}{|c|c|c|c|c|c|c|}
\hline 1719 & $\begin{array}{l}\text { Grand prieur de } \\
\text { Malte }\end{array}$ & Prince français & & & & $\begin{array}{l}\text { BB 281 fol. } \\
180 v^{\circ}-181 \\
1454 £\end{array}$ \\
\hline $\begin{array}{l}16-23 / 5 \\
1720\end{array}$ & $\begin{array}{l}\text { Charlotte-Adélaïde } \\
\text { d'Orléans }\end{array}$ & $\begin{array}{l}\text { Princesse } \\
\text { française }\end{array}$ & $\begin{array}{l}\text { BB 282 } \\
\text { fol. } 81-86\end{array}$ & $\begin{array}{l}\text { p. } 279- \\
286\end{array}$ & & $\begin{array}{l}\text { BB } 282 \text { fol. } 125 \\
12128 £\end{array}$ \\
\hline 1721 & $\begin{array}{l}\text { Ambassadeur de la } \\
\text { Porte }\end{array}$ & Ambassadeur & & & & $\begin{array}{l}\text { BB } 284 \text { fol. } 104 v^{\circ} \\
9877 £\end{array}$ \\
\hline $\begin{array}{l}1726 \\
3 \text { semaines }\end{array}$ & Infant de Portugal & Souverain & & & & $\begin{array}{l}\text { BB } 289 \text { fol. } 118 v^{\circ} \\
5275 £\end{array}$ \\
\hline $\begin{array}{l}1726 \\
3 \text { mois }\end{array}$ & Duc de Retz & Prince français & & & & $\begin{array}{l}\text { BB } 289 \text { fol. } 148 \\
12890 £\end{array}$ \\
\hline $\begin{array}{l}28 / 4-1^{\text {er }} / 5- \\
1730\end{array}$ & $\begin{array}{l}\text { Prince et princesse } \\
\text { de Conti }\end{array}$ & $\begin{array}{l}\text { Princes } \\
\text { français }\end{array}$ & $\begin{array}{l}\text { BB 294 } \\
\text { fol. } 67-71\end{array}$ & $\begin{array}{l}\text { p. 287- } \\
294\end{array}$ & & $\begin{array}{l}\text { BB } 294 \text { fol. } 134 \\
7051 £\end{array}$ \\
\hline 1730 & $\begin{array}{l}\text { duc de } \\
\text { Saint-Aignan }\end{array}$ & Ambassadeur & & & & $\begin{array}{l}\text { BB } 295 \text { fol. } 147 v^{\circ} \\
3680 £\end{array}$ \\
\hline 1732 & $\begin{array}{l}\text { Cardinal } \\
\text { de Polignac }\end{array}$ & Ambassadeur & & & & $\begin{array}{l}\text { BB } 296 \text { fol. } 142 \\
3293 £\end{array}$ \\
\hline $\begin{array}{l}1734 \\
3 \text { mois }\end{array}$ & $\begin{array}{l}\text { Prince et princesse } \\
\text { de Modène }\end{array}$ & Souverains & & & & $\begin{array}{l}\text { BB } 299 \text { fol. } 170 \\
3793 £\end{array}$ \\
\hline 1735 & $\begin{array}{l}\text { Princesse } \\
\text { de Modène }\end{array}$ & Souveraine & & & & $\begin{array}{l}\text { BB } 300 \text { fol. } 148 v^{\circ} \\
2743 £\end{array}$ \\
\hline $\begin{array}{l}27-30 / 3 \\
1737\end{array}$ & Reine de Sardaigne & Souveraine & & $\begin{array}{l}\text { p. } 295- \\
298\end{array}$ & & $\begin{array}{l}\text { BB } 302 \text { fol. } 118 \\
10966 £\end{array}$ \\
\hline 1739 & $\begin{array}{l}\text { Princesse } \\
\text { de Modène }\end{array}$ & Souveraine & & & & $\begin{array}{l}\text { BB } 304 \text { fol. } 124 \mathrm{v}^{\circ} \\
6926 £\end{array}$ \\
\hline $\begin{array}{l}22-26 / 11 \\
1741\end{array}$ & Ambassadeur turc & Ambassadeur & $\begin{array}{l}\text { BB 306 } \\
\text { fol. 138-145 }\end{array}$ & & & $\begin{array}{l}\text { BB 306, fol. } \\
180 v^{\circ} \\
\text { BB } 307 \text { fol. } 160 \\
24359 £\end{array}$ \\
\hline 1743 & $\begin{array}{l}\text { Duchesse } \\
\text { de Modène }\end{array}$ & Souveraine & & & & $\begin{array}{l}\text { BB } 309 \text { fol. } 166 \\
4090 £\end{array}$ \\
\hline $\begin{array}{ll}17-20 & / 2 \\
1744 & \end{array}$ & $\begin{array}{l}\text { Dom Philippe } \\
\text { d'Espagne }\end{array}$ & Souverain & $\begin{array}{l}\text { BB 310 } \\
\text { fol. } 50-54 v^{\circ}\end{array}$ & $\begin{array}{l}\text { p. } 299- \\
308\end{array}$ & & $\begin{array}{l}\text { BB } 310 \text { fol. } 58 v^{\circ} \\
50943 £\end{array}$ \\
\hline 1746 & $\begin{array}{l}\text { M. et Mme } \\
\text { de Woronzov }\end{array}$ & $?$ & & & & $\begin{array}{l}\text { BB } 312 \text { fol. } 208 \\
8894 £\end{array}$ \\
\hline $\begin{array}{l}12-14 / 10 \\
1749\end{array}$ & Infante d'Espagne & Souverain & $\begin{array}{l}\text { BB 315 } \\
\text { fol. } 150-154 v^{\circ}\end{array}$ & $\begin{array}{l}\text { p. 309- } \\
317\end{array}$ & & $\begin{array}{l}\text { BB } 315 \text { fol. } 192 v^{\circ} \\
\text { BB } 316 \text { fol. } 18-19 \\
86589 £\end{array}$ \\
\hline $\begin{array}{l}29 / 9-3 / 10 \\
1750\end{array}$ & $\begin{array}{ll}\text { Comtesse } & \text { de } \\
\text { Toulouse } & \end{array}$ & $\begin{array}{l}\text { Princesse } \\
\text { française }\end{array}$ & $\begin{array}{l}\text { BB } 316 \\
\text { fol. } 152 v^{\circ}-155\end{array}$ & $\begin{array}{l}\text { p. } 318- \\
322\end{array}$ & & $\begin{array}{l}\text { BB } 316 \text { fol. } 174 \\
\text { collectif }\end{array}$ \\
\hline $\begin{array}{ll}15-18 & / 9 \\
1754 & \end{array}$ & Duc de Penthièvre & Prince français & $\begin{array}{l}\text { BB 321 } \\
\text { fol. } 164-166 v^{\circ}\end{array}$ & & & $\begin{array}{l}\text { BB } 322 \text { fol. } 76 v^{\circ} \\
3722 £\end{array}$ \\
\hline 1758 & Duchesse de Parme & Souveraine & & & & $\begin{array}{l}\text { BB } 325 \text { fol. } 53 \\
\text { collectif }\end{array}$ \\
\hline $\begin{array}{l}22-23 / 3 \\
1759\end{array}$ & $\begin{array}{l}\text { Princesse } \\
\text { de Modène }\end{array}$ & Souveraine & $\begin{array}{l}\text { BB } 326 \\
\text { fol. } 48 v^{\circ}-50 v^{\circ}\end{array}$ & & & $\begin{array}{l}\text { BB } 326 \text { fol. } 108 \\
\text { collectif }\end{array}$ \\
\hline $\begin{array}{l}5-8 / 11 \\
1773\end{array}$ & Comtesse d'Artois & Souveraine & $\begin{array}{lr}\text { BB } 341 & \text { fol. } \\
171-177 & \end{array}$ & & $\begin{array}{l}\text { BM Lyon } \\
354284^{23}\end{array}$ & $\begin{array}{l}\text { CC } 3512 \\
77744 £\end{array}$ \\
\hline $2-5 / 91775$ & Clotilde de France & $\begin{array}{l}\text { Princesse } \\
\text { française }\end{array}$ & $\begin{array}{l}\text { BB 343 } \\
\text { fol. } 160 v^{\circ}-164\end{array}$ & & & $\begin{array}{l}\text { CC } 3548 \\
\text { CC } 3549 \\
64061 £\end{array}$ \\
\hline $\begin{array}{l}5-7 / 9 ; 26- \\
28 / 9 \\
1775\end{array}$ & M. et Mme & $\begin{array}{l}\text { Princes } \\
\text { français }\end{array}$ & $\begin{array}{l}\text { BB } 343 \\
\text { fol. } 164 \quad 164 \mathrm{v}^{\circ}- \\
166 ; 166-168 \mathrm{v}^{\circ}\end{array}$ & & & $\begin{array}{l}\text { CC } 3549 \\
10753 £\end{array}$ \\
\hline $3-7 / 71788$ & $\begin{array}{l}\text { Ambassadeurs } \\
\text { indiens }\end{array}$ & Ambassadeurs & $\begin{array}{l}\text { BB } 348 \text { fol. } \\
157 \mathrm{v}^{\circ}-162 \mathrm{v}^{\circ}\end{array}$ & & & \\
\hline
\end{tabular}




\title{
De l'entremets médiéval aux festins louis-quatorziens : propagande politique et faste royal
}

\author{
Sandrine KRIKORIAN \\ Docteur en histoire de l'art
} Extrait de : Jean DuMA (dir.), Le Rituel des cérémonies, Paris,
Édition électronique du CTHS (Actes des congrès des sociétés historiques et scientifiques), 2015.

Cet article a été validé par le comité de lecture des Éditions du CTHS dans le cadre de la publication des actes du $139^{\mathrm{e}}$ Congrès national des sociétés historiques et scientifiques tenu à Nîmes en 2014.

Les banquets officiels des rois et des princes constituent un lieu privilégié de communication propagandiste. En effet, que ce soit dans les différentes cours de l'Europe médiévale sur le «territoire français » ou bien dans le royaume unifié sous l'égide du souverain qui a régné le plus longtemps sur la population française, le faste est un puissant outil de communication propagandiste.

L'iconographie et les sources écrites contemporaines (manuscrites ou imprimées) sont un précieux support d'analyse. Cependant, ces relations et/ou images conservées des banquets apportent des informations qu'il est difficile de mettre totalement sur un pied d'égalité, car ces repas sont différents. En effet, la typologie est variée : visite d'un souverain étranger, banquet précédent une croisade, collation lors du sacre de la reine ou encore fêtes dans les jardins du château de Versailles sont les festins dans lesquels on peut trouver un langage propagandiste. Par ailleurs, il n'y a pas qu'une seule cour, mais plusieurs durant le Moyen Âge, tandis qu'à l'époque moderne, surtout sous Louis XIV, nous avons affaire à un royaume unifié. L'intention pour laquelle les banquets sont faits n'a pas la même portée selon les repas et les messages diffèrent donc. Il n'est donc pas possible de retracer de façon linéaire une évolution chronologique de ce lieu de communication. Aussi, le choix a été fait de réaliser des effets de loupe sur les principaux festins dont nous conservons un souvenir, du XIV siècle au XVII ${ }^{\mathrm{e}}$ siècle, afin de noter les éléments les plus importants pour chaque période et de voir les aspects convergents et divergents qui sont notables au fil du temps. Il s'agit ici non pas d'une étude exhaustive, mais seulement d'un aperçu général permettant d'envisager le sujet dans une vision globale pouvant être par la suite développée et approfondie.

Lors d'un repas public, il existe de nombreuses codifications et de nombreux rituels pouvant faire appel à un langage précis dans une volonté de communication particulière. En effet, chaque élément des banquets officiels étant à lui seul un outil de communication, car tout est soumis à codification, à un rituel et donc à un langage. Dans les repas les plus officiels, le cérémonial et l'étiquette en sont un exemple. L'ensemble de ces éléments ne pouvant être abordé ici, la question a été centrée uniquement sur les repas dans lesquels rentrent en compte un langage visuel décoratif et des divertissements joués entraînant donc une représentation scénique.

Dans cet enjeu de communication propagandiste, on peut noter l'importance de la destination des témoignages que nous conservons. La plupart sont justement officiels et destinés à conserver en mémoire le souvenir du déroulement des repas. La seule exception ici est le repas du faisan relaté par Olivier de la Marche, maître d'hôtel de Charles le Téméraire. Cette question de la destination de ces témoignages est importante car elle est au cœur de la problématique de communication et du langage utilisé pour 
communiquer : le discours (textuel ou visuel) utilisé n'est pas le même selon qu'il s'agit d'un témoignage destiné à être conservé et/ou lu par un public large ou d'un témoignage à usage privé voire strictement personnel.

\section{L'entremets médiéval}

\section{Charles V reçoit Charles IV et son fils Venceslas (6 janvier 1378)}

Monarque important, du point de vue qui nous concerne, car il est à l'origine du cérémonial qui va influencer la cour de France et la cour de Bourgogne, Charles V (13381380) est l'un des premiers souverains de la dynastie des Valois. En novembre 1377, il reçoit son oncle, l'empereur germanique Charles IV en compagnie de son fils Venceslas IV, roi de Bohème, fils de l'empereur et donc cousin du roi de France. Le 6 janvier 1378, jour de l'Épiphanie, un festin a été organisé dans la grande salle du Palais de la Cité à Paris et le souvenir en est conservé dans l'un des volumes des Grandes Chroniques de France qui relatent et illustrent cet événement. Deux enluminures représentant le même sujet ont été réalisées à un siècle d'intervalle; la première, contemporaine de l'événement (manuscrit français 2813) ${ }^{1}$ et la seconde réalisée au XVII ${ }^{\mathrm{e}}$ siècle par Jean Fouquet (manuscrit français 6465$)^{2}$.

Correspondant à la problématique de cette présentation, seule l'analyse de l'enluminure $\mathrm{du}$ manuscrit le plus ancien (et du texte qu'elle illustre) est pertinente ici ; la seconde occultant totalement la figuration de l'entremets.

Les convives, assis à une table, sont en train de discuter. Si au premier plan, des gentilshommes servants sont debout, les bras croisés, ou à genoux, affairés au service, le reste des personnages composent l'entremets. En bas à gauche de la composition, Pierre l'Ermite est debout dans une nef, alors que la droite de la composition est occupée par la représentation d'une bataille avec les croisés à l'assaut de Jérusalem défendue par les Sarrasins.

La description suivante peut être lue dans le manuscrit des Grandes Chroniques de France :

«L'ystoire et l'ordenance fu comment Godefroy de Buillon conquist la sainte cité de Jherusalem. Et fist le Roy faire à propos ceste hystoire, que il li sembloit que devant plus grans en la Chrestienté ne povoit on ramentevoir, ne donner exemple, de plus notable fait, ne à gens qui mieulx peussent, deussent et fussent tenus tele chose faire et entreprendre, ou service de Dieu. Et, pour mieulx figurer la besoigne et plus plainement la cognoistre, fu fait ce qui s'ensuit. Ou bout de la sale du Palais, qui estoit entreclos telement que on n'en povoit riens veoir par dehors, avoit une nef bien façonnée, à forme d'une nave de mer garnie de voille et de mast, chastel devant et derrière, et de tous autres abillemens et ordenances, qui appartiennent à nef pour aler sur mer, et estoit si joliement painte et abilliée, et très richement et plaisanment. Et dedenz estoit garnie de genz par semblance armez bien joliement, et estoient leurs cotes d'armes, leurs escuz et banieres des armes de Jherusalem, que Godefroy de Buillon portoit; et jusques à douze estoient, corne dit est, armez des armes des notables chevetaines, qui furent à la dite conqueste de Jherusalem, avecques le dit Godefroy. Et estoit au devant, sur le bout de la dite nef, Pierre l'Ermite, en l'ordenance et manière et au plus près qu'il se povoit faire, selon ce que l'ystoire raconte. Et fu la dite nef mise hors à gens qui couver- tement estoient dedenz, et fu menée très legierement par le costé senestre du dit Palais, et si legierement tournée, que il sembloit que ce fust une nef flotant sur l'eaue, et ainsi fu amenée jusques au grant dayz, ou dit costé de l'autre part, qui fu le destre costé de la dite sale. Et après ce, fu mis, hors de la place d'encosté où la dite nef

1. L'empereur Charles IV et le roi de France Charles $V$ assistent à la représentation d'une croisade, vers 1380, Grandes Chroniques de France, Paris, BnF, manuscrit français 2813, fol. 474.

2. Jean Fouquet, Les Grandes Chroniques de France, Banquet offert par Charles V à l'empereur Charles IV en la grande salle du Palais, vers 1455-1460, Paris BnF, manuscrit français 6465, fol. 444v. 
estoit partie, un entremés fait à la façon et semblance de la cité de Jherusalem, et y estoit le temple bien contrefait selon l'espace, et là avoit une tour haulte, assise delez le temple, ainsi comme les Sarrazins ont de coustume, où ilz crient leur loy. Là avoit un vestu en habit de Sarrazin très proprement, et qui, en langue arrabique, crioit la loy, en la manière que font les Sarrazins. Et estoit la dite tour si haute que celui qui estoit dessus joignoit bien près des trefs de la dite sale. Et le bas, tout entour de la dite cité, où il avoit forme de créneaux et de murs et de tours, estoit garny de Sarrazins, armez à leur manière, et banieres et panons, et ordenez à combatre pour deffendre la cité. Ainsi fu amené à force de gens, qui estoient dedenz si couvers que on ne les povoit veoir, jusques devant le dit grant dayz, à la destre partie. Et lors se mistrent les deux entremés l'un contre l'autre et descendirent ceuls de la nef, et par belle et bonne ordenance vindrent donner assault à la dite cité et longuement l'assaillirent, et y ot bon esbatement de ceuls qui montoient à l'assault à eschielles, qui en estoient ravalez et abatuz à terre. Et fînablement montèrent des- sus ceuls de la nef et conquistent la dite cité, et getoient hors ceuls qui estoient en habit de Sarrazins, en mectant sus les banieres de Godefroy et des autres. Et mieulx et plus proprement fu fait et veu que en escript ne se puet mectre. Et, quant l'esbatement fu parfait, les diz entremés furent remenez tous entiers en leurs places premières. »

Avec cette dernière phrase, on voit que si, généralement, on parle d'un seul entremets, en réalité il y a deux entremets qui se rejoignent et qui, à la fin, regagnent leurs places respectives.

La figuration de l'entremets sur l'enluminure ainsi que la longue description qui en est faite montre son importance lors du repas dans les esprits contemporains. En effet, si l'on observe l'enluminure que Fouquet a réalisée un siècle plus tard, l'entremets n'est aucunement présent et l'accent est plutôt mis sur le service du rôt en lui-même, autour duquel a généralement lieu l'entremets à l'époque médiévale, montrant ainsi une diminution de l'intérêt porté pour celui-ci d'un point de vue artistique, alors que dans la réalité, son importance est toujours là.

Mais plus importante encore est l'utilisation, à travers l'entremets, d'un langage visuel scénique en tant qu'outil de communication propagandiste représenté à travers la commémoration d'un événement, permettant ainsi une certaine continuité chronologique et une filiation avec les périodes antérieures.

\section{Le banquet du faisan (17 février 1454)}

Le 17 février 1454, le duc de Bourgogne Philippe le Bon et son fils, le futur Charles le Téméraire, réunissent la cour et les chevaliers de la Toison d'or pour le banquet du faisan, banquet précédant une croisade (qui n'eut finalement jamais lieu) afin de délivrer Constantinople que les Turcs avaient prise l'année précédente.

Ce banquet, sans doute le plus réputé de cette période de par son faste, était composé d'un gigantesque entremets. Dans cet entremets, ou dans ces entremets regroupés plus exactement, on note nombre de constructions éphémères, que l'on peut considérer comme les ancêtres des spectaculaires surtouts et dormants des XVIII ${ }^{\mathrm{e}}$ et XIX ${ }^{\mathrm{e}}$ siècles, ainsi que des jeux scéniques animés par des acteurs qui racontent et/ou participent à une histoire. Son souvenir est conservé dans les Mémoires d'Olivier de La Marche, maître d'hôtel de Charles le Téméraire ${ }^{3}$.

Trois tables composaient ce banquet : une grande, une moyenne et une petite. Sur la plus grande des trois tables étaient neuf entremets : un pâté avec des personnages jouant d'instruments de musique, un château "à la façon de Lusignan », un moulin à vent, un tonneau "mis en vignoble", un désert dans lequel se trouve un tigre combattant un serpent, un homme "sauvage monté sur un chameau », un verger avec une dame et un chevalier et à côté un homme battant un buisson rempli d'oiseaux, un fou sur un ours et enfin un lac environné de plusieurs villes et châteaux sur lequel voguait une nef. 
Sur la deuxième table, d'une taille moyenne, on pouvait voir une église avec une cloche sonnante et quatre chantres, un deuxième entremets composé d'un "petit enfant tout nu sur une roche, qui pisssoit eaue rose continuellement » et un troisième entremets qui était « une caraque ancree, garnie de toute marchandise, et de personnages de mariniers ».

Sur la dernière et la plus petite des tables, enfin, se trouvaient également trois entremets. Le premier était une forêt avec des animaux ; le deuxième était un lion attaché et, devant lui, un homme battant un chien ; le troisième était un marchand de merceries.

On constate donc, à travers ces différents éléments, la profusion d'un langage visuel qui est notable, le vœu du faisan semblant être l'apogée de ce type de banquets.

En dehors de ces entremets décoratifs, néanmoins mouvants, a eu lieu une sorte de pièce de théâtre, mise en scène et du même type que la prise de Jérusalem par Godefroy de Bouillon dans l'entremets du 6 janvier 1378, lors de la réception de l'empereur Charles IV et son fils Venceslas par le roi de France Charles V. La différence, ici, se situe dans le fait que les convives participent également à la mise en scène. Une femme, allégorie de l’Église prononce les paroles suivantes :

«Loué soit Dieux que je suis cy venue :

Car avis m'est que $j^{\prime}$ ay fait le voyage

Pour racheter mon ennuyeux dommage.

O toy, ô toy, noble duc de Bourgongne,

Fils de l'Eglise, et frére à ses enfans,

Enten à moy, et pense à ma besongne.

Pein en ton cueur la honte et la vergongne,

Les friefs remords, qu'en moy je porte et sens

Infidelles, par milliers et par cens,

Sont triomphans en leur terre damnee ;

Là où jadis souloye estre honnoree.

Et vous, princes puissants et honorés,

Plorez mes maux, larmoyez ma douleur.

Ma joye n'est, s'emprendre ne voulez,

En moy vengeant (ce que faire devez),

En servant Dieu, et acquerant honneur.

Par mes enfants je suis en ce mesheur :

Par eux seray (si Dieu plaist) secourue ;

Si requier Dieu, de conseil estre acreue.

Vous, chevalier qui portez la Toison,

N'oubliez pas le très divin service :

Et vous aussi, nés de bonne maison,

Gentilshommes, voicy belle ochasion

Pour acquerir de los le bénéfice. »

Une fois, ces paroles prononcées, relate toujours Olivier de La Marche :

«Mondict signeur le duc (qui savoit à quelle intention il avoit fait ce banquet) regarda $l^{\prime}$ Eglise : et ainsi comme ayant pitié d'elle, tira de son seing un brief contenant qu'il vouloit qu'il secourroit la chrestienté, comme il sera dict cy-apres: dont l'Eglise fit maniére de soy réjouir : et voyant que mondict signeur avoit baillé à Toison d'or son voeur, et que ledict Toison d'or le lisit, elle s'escria tout haut, et dît :

Dieu soit loué, et servi hautement

De toy, mon fils, doyent des pers de France!

Ton treshaut vœu m'est tel enrichiment,

Qu'il me semble que je suis clérement,

De tous mes maux à peint délivrance.

Par tout m'en vois requerir aliance,

Et prie à Dieu qu'il te donne la grâce

Que ton desir à son plaisir se face.

$\mathrm{O}$ vous princes, chevaliers, nobles hommes,

Voyez patron pour hauts faicts entreprendre.

Rompez votre aise, acoursissez vos sommes, 
Levez vos mains, tandis que nous y sommes.

Offrez à Dieu ce que luy devez rendre.

Je prend congé : car cy ne puis descendre,

Mais vois tirant la terre chrestienne,

Pour Dieu servir et abreger ma peine. »

On le constate donc, ce qu'on appelle un entremets à l'époque médiévale se décompose en deux aspects : celui décoratif, dans lequel le langage visuel est de prime importance et celui, plus expressif, fait de pièces de théâtre avec des tableaux dont la musique entrecoupe souvent les scènes jouées, comme cela est indiqué dans le témoignage que présente Olivier de La Marche pour le banquet du faisan.

Dans les deux entremets présentés, se manifestent une volonté de mise en scène du pouvoir ainsi qu'une volonté de propagande. Si pour l'entremets de 1378 les convives royaux sont seulement des spectateurs de la scène qui se joue sous leurs yeux, pour le banquet du faisan le duc participe pleinement à cette mise en scène, visant à valoriser l'image du pouvoir.

\section{Les XVI et XVII siècles : transition et dédoublement}

\section{L'entrée à Paris d'Élisabeth d'Autriche au retour de son sacre et couronnement}

Le 29 mars 1571, Élisabeth d'Autriche, reine de France entre dans Paris. Plusieurs manifestations ont eu lieu. Celle particulièrement intéressante pour le sujet est la collation qui a eu lieu le lendemain de l'entrée. Elle est relatée dans le Cérémonial françois de Godefroy ${ }^{4}$ :

«Ladite Dame fut suppliée par lesdits Prevost des Marchands \& Eschevins prendre la collation en une autre salle prochaine, où elle se rendit avec les Princesses susdites \& Dames de sa suite, comme aussi il plût au Roy de s'y trouver, avec Messeigneurs ses freres, \& plusieurs Princes \& grands Seigneurs, lesquels admirerent toute la nouveauté de cette collation. »

Cette collation présentait une histoire réalisée :

«Le tout de sucre, si bien ressemblant le naturel que plusieurs y furent trompez, mesmes les platz \& escuelles esquels ilz estoient faitz de sucre. Davantage pour plus grande decoration, furent estremelez parmy six grandes pieces de relief aussi sucre, dont n'a semblé impertinent faire quelque mention. »

Les six histoires évoquaient la naissance de Minerve, sa nourriture, « l'apparition de Minerve, quand elle se monstra pres du palus, ou lac Tritonien avec sa hache, \& targue comme preste a executer quelque grand ouvrage, \& exploit de sa main »; deux histoires étaient consacrées, l'une, à Minerve armée avec Persée tuant la Gorgone, et l'autre, toujours avec Persée, faisant son entrée dans Athènes. La dernière des six histoires avait pour thème Neptune et Minerve débattant sur le nom de la ville.

Dans cette collation, le sens allégorique est primordial et, pour chaque histoire, d'ailleurs, Godefroy en explique le sens : Élisabeth d'Autriche, reine de France, est représentée en Minerve pour montrer les qualités de la souveraine (vertu, justice, etc.)

Il est intéressant de noter que, contrairement aux banquets médiévaux, surtout celui du vœu du faisan, où on avait un mélange entre entremets décoratif et entremets joué, dans cette entrée, le langage, à la fois décoratif, historié et propagandiste se trouve prioritairement dans cette collation qui n'est pourtant pas le repas le plus important de

4. T. Godefroy, Le cérémonial françois, tome 1, p.551-555. 
ceux qui se sont déroulés durant l'entrée de la reine à Paris lors du retour de son sacre, marqué par un degré moindre de solennité.

\section{Les Plaisirs de l’Isle enchantée}

En 1664, voulant offrir une fête somptueuse, Louis XIV a fait organiser dans les jardins du château de Versailles, qui allait devenir son lieu résidence en 1682. Il s'agit de la première journée des Plaisirs de l'Isle enchanté, dont on conserve deux gravures d'Israël Sylvestre, ainsi qu'une description officielle.

Les quatre Saisons chargées des mets pour le roi et la reine et les douze Signes du zodiaque dansèrent une entrée de ballet. Puis avancèrent le cortège des Saisons et leur suite composée de quarante-huit personnes. Ils portaient les bassins pour la collation. Il y avait douze personnes qui portaient des fleurs (printemps), douze moissonneurs (été), douze vendangeurs (automne) et douze vieillards (hiver). Puis venait le cortège de Pan et de Diane, suivi d'une machine en forme de montagne mouvante ombragée d'arbres. Suivaient des pages devant servir les Dames à table. Et des vers furent adressés à la reine, en commençant par le Printemps. Une fois les récits terminés, une table en forme de croissant fut découverte et derrière apparurent trente-six violonistes, tandis que les Contrôleurs Généraux, sous les allégories de l'Abondance, de la Joie, de la Propreté et de la Bonne-Chère firent couvrir la table par les Plaisirs, les Jeux, les Ris et les Délices.

Les rôles des quatre Saisons sont joués par des acteurs de la troupe de Molière: Mademoiselle du Parc incarne le Printemps, René Berthelot, dit Monsieur du Parc, l'Été, François Lenoir, dit Monsieur de la Thorillière, l'Automne) et Louis Béjart interprète l'Hiver. Molière et Madeleine Béjart, quant à eux, incarnent respectivement Pan et Diane. En voici le récit détaillé ${ }^{5}$ :

«Pendant que les Saisons se chargeoient des mets délicieux qu'elles devoient porter, pour servir devant leurs Majestez la magnifique collation qui estoit préparée, les douze Signes du Zodiaque, \& les quatre Saisons danserent dans le rond une des plus belles entrées de Ballet qu'on eût encore veûë.

Le Printemps parut ensuite sur un Cheval d'Espagne, représenté par Mademoiselle du Parc, qui avec le sexe \& les avantages d'une femme, faisoit voir l'adresse d'un homme. Son habit estoit vert en broderie d'argent, \& de fleurs au naturel.

L'Esté le suivoit, représenté par le Sieur du Parc, sur un Elephant, couvert d'une riche housse.

L'Automne aussi avantageusement vestuë, représentée par le Sieur de la Thorilliére, venoit après monté sur un Chameau.

L'Hyver suivoit sur un Ours, représenté par le Sieur Béjard.

Leur suite estoit composée de quarante-huit personnes, qui portoient toutes sur leurs testes de grands bassins pour la collation.

Les douze premiers couverts de fleurs, portoient, comme des Jardiniers, des Corbeilles peintes de vert \& d'argent, garnies d'un grand nombre de porcelaines, si remplies de confitures \& d'autres choses délicieuses de la Saison, qu'ils estoient courbez sous cét agréable faix.

Douze autres, comme Moissonneurs, vestus d'habits conformes à cette procession, mais fort riches, portoient des bassins de cette couleur incarnate, qu'on remarque au Soleil levant, \& suivoient l'Esté.

Douze autres vestus en vendangeurs, estoient couverts de feuilles de vignes \& de grappes de raisins, \& portoient dans des paniers feuille-morte, remplis de petits bassins de cette même couleur, divers autres fruits \& confitures à la suite de l'Automne.

Les douze derniers, estoient des Vieillards gelez, dont les fourrures \& la démarche marquoient la froideur, la foiblesse, portant dans des bassins couverts d'une glace \& d'une neige si bien contrefaites, qu'on les eust pris pour la chose même, ce qu'ils devoient contribuër à la Collation, \& suivoient l'Hyver.

Quatorze Concertans de Pan \& de Diane précedoient ces deux Divinitez, avec une agréable Harmonie de Flûtes \& de Musettes.

5. Les plaisirs de l'Isle enchantée, p. 15-18. 
Elles venoient en suite sur une machine fort ingenieuse en forme d'une petite montagne ou roche ombragée de plusieurs arbres ; mais ce qui estoit plus surprenant, c'est qu'on la voyoit portée en l'air, sans que l'artifice qui la faisoit mouvoir se pûst découvrir la veûë.

Vingt autres personnes les suivoient, portant des viandes de la Mênagerie de Pan, \& de la Chasse de Diane.

Dix-huit Pages du Roy fort richement vestus, qui devoient servir les Dames à table, faisoient les derniers de cette troupe ; laquelle estant rangée, Pan, diane \& les Saisons se presentant devant la Reine, le Printemps luy adressa le premier ces vers [...].

Ces Récits achevez, une grande Table en forme de Croissant, où l'on devoit couvrir \& garnir de fleurs le costé où elle estoit creuse, vint à se découvrir.

Trente-six Violons tres-bien vestus parurent derriére sur un petit Théâtre pendant que Messieurs de la Marche \& Parfait Pere, Frere \& Fils, Contrôlleurs Géneraux, sous les noms de l'Abondance, de la Joye, de la Propreté, \& de la Bonne-Chere, la firent couvrit par les Plaisirs, par les Jeux, par les Ris, \& par les Délices. »

On le voit donc, le langage est à la fois expressif et scénique, mis d'ailleurs en valeur par le mécanisme de la table elle-même. On peut donc constater que, dans cette collation au sein d'un événement officiel auquel se mêle néanmoins un certain divertissement, la présence de figures allégoriques est notable. Par ailleurs, ces allégories sont incarnées par des acteurs de la troupe de Molière, qui est sous la protection du roi.

La présence de récits adressés à la reine n'est pas sans rappeler le banquet du faisan dans lequel nous avons pu noter une interaction entre acteurs et convives, bien que ces derniers ne participent pas de manière active à la « représentation théâtrale ». Le banquet du faisan vu précédemment semble donc être une exception en cela, et les convives semblent être plus volontiers spectateurs qu'acteurs. Il est également intéressant de noter que les Dieux et les allégories des Saisons servent le souverain et les Dames.

En réalisant ces effets de loupe sur ces repas officiels, on constate des convergences dans l'utilisation d'un langage visuel, les mises en scène théâtrales, le lien entre acteurs et convives, ainsi que dans l'utilisation de représentations allégoriques.

Néanmoins, des divergences sont notables : la typologie de ces repas est variée, on assiste à un dédoublement des langages, et à une inversion de celui-ci dans certains cas : du souverain serviteur de Dieu, on passe aux représentations allégoriques des Dieux qui servent les souverains.

De plus, si l'intention affichée est différente, l'intention officieuse reste peu ou prou identique (propagande et/ou mise en valeur du souverain bien que de façon plus ou moins directe) avec néanmoins, une attention de plus en plus importante apportée au souverain (envoyé de Dieu sur terre) mais les formes des langages utilisés varient et évoluent.

On peut également noter que les repas dans lesquels on trouve le langage visuel à travers des réalisations décoratives historiées et le langage expressif et scénique, au fur et à mesure que l'on avance dans le temps, sont de moins en moins officiels. Ce n'est que dans les repas à caractère très officiels, comme les repas de sacre par exemple, que l'on observe une permanence un peu plus présente. 


\begin{abstract}
Résumé
Les repas sont depuis très longtemps un lieu de communication par excellence, d'ailleurs souvent ritualisé. En France, les banquets officiels des princes et rois en sont un exemple : sur un même territoire, à l'époque médiévale composé de plusieurs cours puissantes (France, Berry, Bourgogne), et qui, sous le règne des Bourbons, était devenu un royaume unifié, on constate une certaine permanence dans une volonté communication propagandiste.

L'époque médiévale est celle des entremets, a priori scènes de divertissement jouées devant les convives, qui animent le repas, dont les XIV et $X^{e}$ siècles marquent l'apogée. Quant au $\mathrm{XVII}{ }^{\mathrm{e}}$ siècle, avec le règne de Louis XIV qui en est le point culminant, on assiste à des repas de fêtes somptueux dans lesquels le faste est prépondérant.

Le but est donc ici de montrer l'évolution du discours dans ces repas officiels entre le $\mathrm{XIV}^{\mathrm{e}}$ siècle et le XVII ${ }^{\mathrm{e}}$ siècle, quels sont les points convergents et les aspects divergents ainsi que les outils et les langages employés.
\end{abstract}

\title{
Bibliographie
}

Grandes Chroniques de France, Paris, BnF, manuscrit français 2813.

Grandes Chroniques de France, Paris BnF, manuscrit français 6465.

Mémoires d'Olivier de La Marche, maître d'hôtel et capitaine des gardes de Charles le Téméraire, publié pour la Société de l'histoire de France par Henri Beaune et J. d'Arbaumont.

GODEFROY Théodore, Le cérémonial françois contenant les ceremonies observées en France aux Sacres \& Couronnemens de Roys, \& Reynes, \& de quelques anciens Ducs de Normandie, d'Aquitaine, \& de Bretagne : Comme aussi à leurs Entrées solennelles : Et à celles d'aucuns Dauphins, Gouverneurs de Provinces, \& autres Seigneurs, dans diverses Villes du Royaume. Recueilly par Théodore Godefroy, Conseiller du Roy en ses Conseils. Et mis en lumière par Denys Godefroy, Advocat en Parlement \& Historiographe du Roy, chez Sébastien Cramoisy, Paris, 1649.

Les plaisirs de l'Isle enchantée, Paris, 1664. 


\title{
Conflit et mise en scène du pouvoir : les entrées des archevêques dans la ville de Saint-Jacques-de-Compostelle aux XVII ${ }^{e}$ et XVIII ${ }^{e}$ siècles
}

\author{
Fernando SUÁREZ GOLÁN \\ Enseignant en histoire moderne \\ Université de Saint-Jacques-de-Compostelle
}

Extrait de : Jean DUMA (dir.), Le Rituel des cérémonies, Paris, Édition électronique du CTHS (Actes des congrès des sociétés historiques et scientifiques), 2015.

Cet article a été validé par le comité de lecture des Éditions du CTHS dans le cadre de la publication des actes du $139^{\mathrm{e}}$ Congrès national des sociétés historiques et scientifiques tenu à Nîmes en 2014.

Cet article tente d'analyser le développement de l'entrée solennelle de l'archevêque de Saint-Jacques-de-Compostelle dans son diocèse et sa ville épiscopale. L'historiographie est restée presque muette sur le thème des entrées des évêques venus prendre possession de leur siège épiscopal ; à signaler tout de même les contributions récentes de Stéphane Gomis pour la France et l'étude comparative de José Pedro Paiva pour l'Europe moderne, publiées en $2009^{1}$, mais le sujet a été peu étudié surtout en comparaison avec l'attention retenue par les entrées royales ${ }^{2}$. Toutefois, l'entrée solennelle des évêques dans les villes épiscopales de l'époque moderne fournit un contexte où l'ordre public, la hiérarchie sociale et le pouvoir ne sont pas seulement représentés et confirmés, mais où ils ont également été négociés ${ }^{3}$.

En effet, j'ai donc travaillé essentiellement à partir des collections de règlements et témoignages notariés du chapitre cathédral ${ }^{4}$. Celles-ci se sont révélées assez riches parce que les relations décrivent en détail l'entrée d'un nouvel archevêque. D'autre part, ce sont les procès-verbaux et les relations des contemporains et des travaux d'érudits du $\mathrm{XIX}^{\mathrm{e}}$ siècle ${ }^{5}$, mais également du siècle dernier ${ }^{6}$, qui ont consacré quelques pages à cette question. Au total, cette documentation permet une connaissance approfondie des entrées des archevêques, en particulier pour les XVII ${ }^{\mathrm{e}}$ et XVIII ${ }^{\mathrm{e}}$ siècles.

Pendant l'Ancien Régime, le Royaume de la Galice était formé par quatre petits diocèses peu riches, et l'archevêché métropolitain de Saint-Jacques-de-Compostelle, l'un des plus importants dans la couronne de Castille et seigneur juridictionnel de sa ville. Une relation étroite lie les cérémonies d'entrée des évêques avec les sociétés urbaines. L'entrée

1. S. Gomis, «Les entrées solennelles des évêques dans la France des XVII et ${ }^{\mathrm{e}}$ eVIII ${ }^{\mathrm{e}}$ siècles », p. 509-523. J. Paiva, "Les entrées des évêques dans leurs diocèses dans l'Europe moderne : une vision comparée ", p. 495-508.

2. J. Paiva, « Public ceremonies ruled by the ecclesiastical-clerical sphere : a language of political assetion (16th18th centuries) », p. 415-425.

3. M. A. Visceglia, « Il ceremoniale come linguaggio politico : su alcuni conflitti di precedenza alla corte di Roma tra cinquecento e seicento ", p. 117-176.

4. Archivo Catedralicio de Santiago, IG 292, «Competencias con el Concejo Compostelano. Cuestiones sobre precedencia (entrada pública de los arzobispos)».

5. E. Álvarez Carballido, « Reminiscencias históricas, el Concejo de Santiago, y el Cabildo de la misma ciudad en el siglo XVII », p. 155-157. B. Barreiro de Vázquez Varela, « Actas consistoriales, competencias, pleitos y decretos reales sobre ceremonial, para el recibimiento de los señores arzobispos », p. 173-174, et p. 183-185. A. López Ferreiro, Historia de la Santa A. M. Iglesia Catedral de Santiago de Compostela, plusieurs volumes. B. Fernández Alonso, "Conflicto entre el obispo don Juan de la Torre y el Ayuntamiento de Orense desde Sejalvo a la Ciudad ", p. 1-2. B. Fernández Alonso, El Pontificado gallego : su origen y vicisitudes : seguido de una crónica de los Obispos de Orense, p. 550-640.

6. J. Carro, « Las entradas solemnes de los arzobispos compostelanos », p. 7-8. M. Murguía, «De los regocijos públicos con que se celebra en Santiago la recepción de sus prelados », p. 11-12.

7. M. Barrio Gozalo, « Perfil socio-económico de una élite de poder (III) : Los obispos del Reino de Galicia (16001840) », p. 11-107. 
solennelle dans une ville était très importante parce que, alors que d'autres parties de la cérémonie de prise de possession de l'évêque n'étaient accessibles qu'au clergé ou à l'élite, tous les habitants de la ville pouvaient contempler l'entrée de l'évêque ${ }^{8}$. Les cérémonies d'entrée solennelle d'un évêque dans sa ville étaient l'occasion de révéler la structure sociale mise en mouvement à l'occasion, avec ses hiérarchies et ses préséances, et de remarquer aussi l'intervention des autorités municipales et du chapitre cathédral comme garants de l'ordre ${ }^{9}$. La tension était donc inhérente aux cérémonies d'entrée des archevêques de Saint-Jacques-de-Compostelle parce qu'ils étaient seigneurs temporels de plusieurs vassaux et gouverneur d'une seigneurie étendue dans laquelle la ville était l'espace de l'autorité et du gouvernement. Le protocole essayait de chercher l'harmonie et l'équilibre entre des organismes qui sont membres d'une communauté particulière, mais aussi de maintenir un certain ordre hiérarchique.

L'ordre de préséance et le désir d'être le centre d'attention dans certaines étapes significatives de la cérémonie dérivaient souvent en conflit. Ces disputes étaient assez communes à Saint-Jacques-de-Compostelle, plus que dans les autres villes galiciennes ${ }^{10}$. Donc, les positions occupées par les divers participants étaient fixées par un protocole strict qui exprimait et négociait les conditions de domination ou subordination.

Cet article vise à étudier comment la surveillance de l'ordre hiérarchique de la ville et les tentatives de modification sont les deux principes qui ont guidé l'action des différents secteurs ou des institutions opérants dans les cérémonies d'entrée des archevêques de Saint-Jacques-de-Compostelle. Les différentes procédures mises en scène par les différents secteurs de la communauté urbaine pour maintenir et perpétuer, ou même, pour modifier l'ordre de gouvernement établi dans la ville, ont été recueillies dans les textes examinés (les règlements du chapitre cathédral, des procédures, des rapports, des procès-verbaux, des documents des institutions civiles et ecclésiastiques, etc.). À cet égard, cette étude propose d'analyser, aussi, les raisons des tentatives de modification de la cérémonie, lesquelles reflètent les désordres dans la ville et son gouvernement.

Puisque dans les diocèses galiciens l'évêque était aussi seigneur temporel de sa ville respective, l'entrée du nouvel évêque-seigneur se déroule en deux temps : une " entrée séculière » dans la ville et une « entrée spirituelle » dans la cathédrale. Dans les diocèses les plus petits, l'effort se centrait principalement sur «l'entrée » spirituelle dans la cathédrale. Dans ces cas-là, l'entrée ne durait que quelques heures et elle se développait de façon identique au modèle profilé par le Caeremoniale Episcoporum publié en $1600^{11}$. Notons qu'une cérémonie aussi brève et hautement réglée ne favorisait pas l'apparition de signes de tension, même s'il y en avait (par exemple à Mondoñedo et Ourense) ${ }^{12}$. Par contre, dans l'archevêché de Saint-Jacques-de-Compostelle, la partie la plus élaborée était l'entrée séculière. À Saint-Jacques-de-Compostelle, comme à Olomouc, Palencia, Siguënza, Vence et autres villes d'évêques-seigneurs, pour lesquelles il y a des études, cet événement soulignait les fonctions civiles de l'archevêque ${ }^{13}$.

Tout le cérémonial qui accompagne la prise de possession du nouvel archevêque de Saint-Jacques-de-Compostelle était assez différent du modèle officiel dicté par le

8. M. Elbel, «Bishop's secular entry : power and representation in inauguration ceremonies of the eighteenthcentury bishops of Olomouc », p. 48 .

9. M. Boiteux, « Parcours rituels romains à l'époque moderne », p. 27-28.

10. F. Suárez Golán, «Todo es cuydar de las zeremonias. Imagen y representación del poder en el episcopado gallego », p. 197-219.

11. J. P. Paiva, "O cerimonial da entrada dos bispos nas suas dioceses : uma encenação de poder (1741-1757) », p. 137.

12. B. Fernánde Alonso, «Conflicto entre el obispo don Juan de la Torre y el Ayuntamiento de Orense desde Sejalvo a la Ciudad », p. 1-2. F. Rodríguez Martínez, "Fray Sebastián de Arévalo y Torres, OFM (el obispo limosnero). Obispo de Mondoñedo y Osma (1616-1704)», p. 351-352.

13. M. Elbel, « Bishop's secular entry : power and representation in inauguration ceremonies of the eighteenthcentury bishops of Olomouc », p. 54. A. Polanco Pérez, "Ceremonias de recibimiento y despedida a los obispos en la tradición palentina (s. XV et XVIII) », p. 401-4078. A. Blazquez, "Les ceremonies de prise de posssession du diocèse et de la seigneurie de Sigüenza par ses evêques-seigneurs à l'epoque moderne », p. 61-85. S. Gomis, «Les entrées solennelles des évêques dans la France des XVII ${ }^{\mathrm{e}}$ et XVIII" ${ }^{\mathrm{e}}$ siècles », p. 514. 
Caeremonial Episcoporum. La morphologie du rituel peut être divisée en plusieurs étapes. José Pedro Paiva a identifié, par exemple, six étapes : organisation, rencontre, réception, cortège, consécration spirituelle et fête ${ }^{14}$. Du point de vue méthodologique, je soutiendrais que l'entrée solennelle dans la ville faisait partie d'une cérémonie d'institution dans laquelle on peut distinguer deux phases successives, chacune ayant plusieurs étapes : d'une part, le « recibimiento » (ou réception dans le diocèse) et, d'autre part, «l'entrée publique» (ou entrée solennelle dans la ville et ensuite dans la cathédrale).

Le premier moment du rituel, ce que les sources appellent « recibimiento », qui avait lieu hors de la ville, comprenait les actes de rencontre et de réception de l'archevêque dans le diocèse par les différents représentants de la ville et du chapitre cathédral, puis l'assistance et transfert de l'archevêque des confins du diocèse jusqu'à la ville de SaintJacques-de-Compostelle. On peut constater que les célébrations de l'entrée débutaient non pas au moment où l'archevêque arrivait devant la porte de la ville, mais à l'endroit même où il commençait le trajet vers ses territoires, d'habitude le monastère de SainteMarie de Sobrado des Moines, situé à environ 45 kilomètres de la ville ${ }^{15}$.

Le deuxième moment, c'est-à-dire l'entrée publique dans la ville, se déroulait (depuis le milieu du XVII ${ }^{\mathrm{e}}$ siècle) quelques jours, semaines ou mois plus tard, puisque la première entrée dans la ville était une entrée privée ${ }^{16}$. Cette deuxième phase peut se diviser, à son tour, en plusieurs étapes avec quelques actes principaux. Le moment central de cette entrée se déroulait à l'extérieur de l'entrée principale de la ville, quand le chanoine le plus ancien offrait au nouvel archevêque les clés symboliques de la ville qui faisaient partie de la dignité archiépiscopale ${ }^{17}$. C'est alors que commençait le deuxième temps fort de cette cérémonie d'entrée. Après quelques mots de bienvenue en honneur du nouveau prélat, auxquels l'archevêque répondait, la procession rentre dans la ville pour se rendre à la cathédrale où avait lieu "l'entrée spirituelle », c'est-à-dire la prise de possession ecclésiastique de la cathédrale et du diocèse ${ }^{18}$.

Il y avait beaucoup de spécificités locales révélatrices d'un caractère plus politique de la cérémonie lorsqu'il s'agit de se rendre à la cathédrale. Ainsi, dans son entrée solennelle, l'archevêque de Saint-Jacques-de-Compostelle ne se présente jamais paré des ornements pontificaux, contrairement à ce qui est prescrit dans le Ceremoniale episcoporum de Clément VIII. Au lieu de cela, il portait la mosette, avec rochet et mantelet ${ }^{19}$. Il importe également de signaler que, si les archevêques de Saint-Jacques-de-Compostelle étaient seigneurs temporels de la ville, il n'y avait pas de serment, ni la reconnaissance mutuelle de privilèges.

Toutefois, avant ce moment-là, un autre acte important avait déjà eu lieu. L'archevêque devait se rendre au couvent de la Merci de Conxo, situé à quelques lieues, pour effectuer son entrée solennelle ${ }^{20}$. Peu après son départ avait lieu la rencontre entre le cortège formé par l'archevêque, les membres de sa famille et la délégation du chapitre, avec le doyen, dignités et chanoines de la cathédrale, et avec les représentants du pouvoir urbain. La réunion avait lieu normalement dans une chapelle à mi-chemin du parcours. Le membre le plus digne du chapitre devait présenter à l'archevêque chacun des chanoines en signe

14. J. P. Paiva, «Les entrées des évêques dans leurs diocèses dans l'Europe moderne : une vision comparée ", p. 496-500.

15. Archivo Catedralicio de Santiago, IG 292, «Ceremonial original de la Entrada Pública solemne de los Señores Arzobispos ».

16. Archivo Histórico Diocesano de Santiago, FG 219, « Entrada del Sr. Arzobispo el Illmo. D. Francisco Alexandro Bocanegra y Xivaja ».

17. Archivo Catedralicio de Santiago, IG 292, «Ceremonial original de la Entrada Pública solemne de los Señores Arzobispos ".

18. Archivo Histórico Diocesano de Santiago, FG 219, « 1610-1796. Documentación relativa al ceremonial de la entrada pública de los Sres. Arzobispos en la capital de la diócesis ».

19. Archivo Catedralicio de Santiago, IG 292, «Ceremonial original de la Entrada Pública solemne de los Señores Arzobispos».

20. R. J. López, «Las entradas públicas de los arzobispos compostelanos en la Edad Moderna », p. $199-201$. 
de respect et soumission; cependant, ce privilège n'était pas autorisé aux échevins, et cela a provoqué des émeutes ${ }^{21}$.

Il s'agit donc d'une série de cérémonies qui représentent sous l'Ancien Régime bien plus que de simples actes protocolaires. Organisées autour de deux ou trois actes centraux, réunissant les civils et les ecclésiastiques, elles soulignent la complexité des rapports canoniques et juridico-administratifs entre le nouveau prélat, le clergé et les vassaux. Les différentes cérémonies qui composaient cette entrée solennelle étaient imprégnées d'actes symboliques à forte connotation juridique. La meilleure preuve que les cérémonies d'entrée étaient envisagées par ses protagonistes comme des actes avec une importance politique et sociale est que de nombreuses disputes se sont produites pendant leur déroulement.

À Ourense, ce type de conflits sur la possession de la seigneurie de la ville entre l'évêque et les magistrats municipaux fut très habituel jusqu'au début du XVII ${ }^{\mathrm{e}}$ siècle. En 1622, la tension éclata à cause d'une dispute juridico-administrative entre le corregidor et l'évêque ${ }^{22}$. À Mondoñedo, la question du serment demeure la plus sensible, comme l'illustre cet épisode survenu en 1672: lors de l'entrée de Sebastián de Arévalo, qui n'avait pas prêté serment à cause des pluies, la ville refusa de reconnaître l'évêque s'il ne répétait pas l'entrée selon l'usage habituel ${ }^{23}$.

À Saint-Jacques-de-Compostelle, les tensions à l'occasion des cérémonies publiques d'intronisation des nouveaux archevêques n'étaient pas seulement le résultat de conflits de préséance ou de protocole, mais aussi d'une affaire se poursuivant pendant plus d'un siècle entre l'archevêque, le conseil municipal et le chapitre métropolitain concernant l'ordre et le déroulement des cérémonies et, indirectement, ce qui appartenait à la seigneurie temporelle de la ville.

En 1717, puis en 1723, les échevins arrivèrent en retard pour rencontrer le nouvel archevêque, et puisque le chapitre cathédral ne les avait pas laissés passer pour saluer le prélat, ils partirent sans prendre part à cette étape du défilé. Ils réapparurent aux portes de la ville où ils essayèrent d'offrir les clés au prélat à la place du représentant du chapitre cathédral. Comme ils n'avaient pas atteint non plus cet objectif, les échevins, en colère, quittèrent la cérémonie ${ }^{24}$. Mais, le plus gros conflit se déroule en décembre 1728, lors de l'entrée de José del Yermo Santibáñez (étudiée par Roberto Javier López) ${ }^{25}$. Ce prélat accepta de recevoir le salut des échevins avant les chanoines mais, plus grave, les échevins formèrent un cortège derrière l'archevêque et sa famille ${ }^{26}$. Le chapitre, qui croyait que la hiérarchie protocolaire devait être rigoureusement respectée, jugea irrecevable ces faits et il quitta le cortège en ordonnant que les portes de la cathédrale soient fermées ${ }^{27}$.

Le corps des chanoines était le plus soucieux pour s'approprier la cérémonie et, par conséquent, il était celui qui avait plus de possibilités de gagner dans cette dispute particulière, chaque fois qu'il prenait une bonne partie du potentiel légitimateur de la cérémonie. Il s'agit, en effet, de bien souligner que la co-puissance seigneuriale n'appartenait pas aux autorités civiles, mais que l'archevêque la partageait avec le chapitre métropolitain. Généralement, l'historiographie sur ce sujet a considéré l'entrée publique de l'évêque comme un des rituels les plus évidents d'institution, légitimation,

21. Archivo Catedralicio de Santiago, IG 292, « Resume del Zeremonial de Entradas de señores Arzobispos ».

22. F. Suárez Golán, "Todo es cuydar de las zeremonias. Imagen y representación del poder en el episcopado gallego », p. 208-209.

23. F. Rodríguez Martínez, «Fray Sebastián de Arévalo y Torres, OFM (el obispo limosnero). Obispo de Mondoñedo y Osma (1616-1704)», p. 351-352.

24. Archivo Catedralicio de Santiago, IG 292, « Protestas que hubo entre el Cavildo y la Ciudad sobre pretender esta entrar por el centro de el Cauildo a complimentar a Su Ill.ma en su entrada pública ».

25. R. J. López, Ceremonia y poder a finales del Antiguo Régimen. Galicia 1700-1833, p. 60-68.

26. Ibid, p. 62

27. Ibid, p. 63-64. 
consécration et propagande du pouvoir épiscopal ${ }^{28}$. À mon avis, à Saint-Jacques-deCompostelle cette cérémonie devait être abordée comme le moment essentiel de l'affirmation du pouvoir du chapitre, pas de l'archevêque, au regard de tout le clergé local et surtout des autres pouvoirs qui coexistaient dans la ville ${ }^{29}$.

On pourrait multiplier les exemples significatifs non seulement de la difficulté que les autorités civiles urbaines avaient pour trouver une place dans les cérémonies publiques pendant les $\mathrm{XVII}^{\mathrm{e}}$ et $\mathrm{XVIII}^{\mathrm{e}}$ siècles, mais aussi d'une création cérémonielle dirigée par et pour le chapitre cathédral.

D'après la documentation générée par les chanoines, il semblerait que les archevêques soient relégués à un niveau secondaire, soumis à la volonté du chapitre. En contrepartie, les causes de la plupart des conflits furent les prétentions des échevins et des maires, qui souhaitaient obtenir la puissance que le chapitre leur niait: une place à gauche de l'archevêque dans sa réception ou pendant l'entrée, le privilège d'offrir les vraies clés de la ville au lieu des fausses clés offertes par le chapitre; c'est-à-dire un lieu protocolaire dans la cérémonie, mais aussi un lieu réel dans la structure socio-politique de la ville. Dans ce contexte, la participation marque l'adhésion, l'intégration ou l'exclusion d'un groupe ; et le rite accompli apparaît comme signe de reconnaissance ${ }^{30}$.

L'entrée de Cayetano Gil Taboada en 1745 fut la première entrée pacifique du $\mathrm{XVIII}^{\mathrm{e}}$ siècle $^{31}$. Malgré cela, l'édit royal du 20 novembre 1784 fut cependant nécessaire pour mettre fin à un procès qui semblait ne jamais en finir. Cependant, le Conseil de Castille déclarait en même temps que cet « acte purement politique » ne causait ni dénotait droit de préséance quel $\mathrm{qu}^{\prime} \mathrm{il} \mathrm{soit}^{32}$. Cette déclaration fut un petit échec pour le chapitre qui pendant des siècles avait utilisé la cérémonie d'entrée des archevêques comme instrument pour laisser libre cours à sa prétention concernant la juridiction civile sur la ville de Saint-Jacques-de-Compostelle. On pourrait dire qu'un des buts du chapitre était de laisser au conseil municipal à la vue de tous, sans aucun type de représentation à l'égard de la politique urbaine. Mais le grand échec, c'est pour le conseil de la ville, qui s'est vu supprimer son ancienne demande pour obtenir un lieu digne dans la cérémonie qui reflète et ratifie le lieu qu'il recherchait dans la société et dans le gouvernement de la ville ${ }^{33}$.

En somme, ces moments particulièrement solennels (comme l'entrée dans la ville du nouvel évêque-seigneur) montrent à la fois la valeur profonde et la double nature temporelle et spirituelle - du complexe normatif compris dans les cérémonies. En ce qui concerne les entrées des évêques galiciens de l'Ancien Régime, tout du moins jusqu'en 1784, nous pouvons considérer le cérémonial comme l'image et la représentation du pouvoir, et les tensions intrinsèques des cérémonies comme l'émergence évidente des conflits cachés entre les divers corps urbains. Il s'agit dans notre cas, non seulement de solenniser et fêter l'arrivée d'un nouvel évêque-seigneur (étant donné l'étendue de son pouvoir sur la ville, on doit se soumettre) mais également d'établir clairement et publiquement les droits et privilèges aussi bien du conseil municipal que, surtout, du chapitre cathédral.

28. J. P. Paiva, «Les entrées des évêques dans leurs diocèses dans l'Europe moderne : une vision comparée », p. 495.

29. F. Suárez Golán, «Todo es cuydar de las zeremonias. Imagen y representación del poder en el episcopado gallego », p. 219.

30. Archivo Catedralicio de Santiago, IG 219, « Razón que se dio a Su Ilustrísima de los papeles que existen en este Archivo ».

31. F. Lozano, El Iris de la paz : justa parentacion que a la memoria de el Illmo. Señor D. Cayetano Gil Taboada Arzobispo, $i$ señor de Santiago, ofrece en eterno monumento de su filial gratitud, su mas reverente familia, p. 17-18.

32. Archivo Histórico Diocesano de Santiago, FG 219, s.n.

33. Archivo Catedralicio de Santiago, IG 292 «Razón que se dio a Su Ilustrísima de los papeles que existen en este Archivo ». 


\begin{abstract}
Résumé
Cette étude vise à analyser comment la surveillance hiérarchique de la ville et les tentatives de modification sont les deux principes qui ont guidé l'action des différents secteurs des municipalités ou des institutions opérant dans les cérémonies d'entrée des archevêques de Saint-Jacques-de-Compostelle. On étudie les différentes procédures mises en œuvre par les différents secteurs de la communauté urbaine pour maintenir et perpétuer, ou même, pour modifier l'ordre de gouvernement établi dans la ville. À cet égard, l'article propose d'approfondir les raisons des tentatives de modification de la cérémonie qui reflète les désordres dans la ville et son gouvernement. L'analyse de ce processus historique, étroitement lié à l'espace urbain, donne un aperçu de l'importance politique des cérémonies reflétant les structures hiérarchiques, et c'est également un reflet des conflits sociaux et politiques dans l'espace urbain.
\end{abstract}

\title{
Bibliographie
}

Álvarez CARBALlido Eduardo, «Reminiscencias históricas, el Concejo de Santiago, y el Cabildo de la misma ciudad en el siglo XVII », Galicia Diplomática, vol. 20, mai 1888, p. $155-157$.

BARREIRO de VÁZqueZ VAREla Bernardo, «Actas consistoriales, competencias, pleitos y decretos reales sobre ceremonial, para el recibimiento de los señores arzobispos ", Galicia Diplomática, vol. II, $\mathrm{n}^{\mathrm{o}} 23$, décembre 1883, pp. 173-174, et vol. II, nº 25, décembre 1883, p. $183-185$.

BARRIo Gozalo Maximiliano, «Perfil socio-económico de una élite de poder (III) : Los obispos del Reino de Galicia (1600-1840) », Anthologica Annua, vol. 32, 1985, pp. 11-107.

BLAZQUEZ Adrian, «Les cérémonies de prise de possession du diocèse et de la seigneurie de Sigüenza par ses évêques-seigneurs à l'époque moderne ", dans PAIVA José Pedro (éd.), Religious ceremonials and images : power and social meaning (1400-1750), Coimbra, Éd. Palimage, 2002, p. 61-85.

BOITEUX Martine, «Parcours rituels romains à l'époque moderne », dans VISCEGLIA Maria Antonietta et CATHERINE Brice (éd.), Cérémonial et rituel à Rome (XVI - XIX siècle), p. 27-87.

CARRO Jesús, "Las entradas solemnes de los arzobispos compostelanos », La noche. Suplemento del sábado, vol. 9, 1949, p. 7-8.

ElBEL Martin, “Bishop's secular entry: power and representation in inauguration cérémonies of the eighteenth-century bishops of Olomouc" dans PAIVA José Pedro (éd.), Religious ceremonials and images: power and social meaning (1400-1750), Coimbra, Éd. Palimage, 2002, p. 47-60.

FERNÁNDEZ AlONSO Benito, "Conflicto entre el obispo don Juan de la Torre y el Ayuntamiento de Orense desde Sejalvo a la Ciudad", Album Literario. Revista Semanal de Literatura, Ciencias y Arte, anné II, no 80, aout 1889, p. 1-2, et nº 82, aout 1889, p. 1-2.

FernÁNDeZ Alonso Benito, El Pontificado gallego : su origen y vicisitudes : seguido de una crónica de los Obispos de Orense, Orense, Imp. de «El Derecho », 1897.

GOMIS Stephan, "Les entrées solennelles des évêques dans la France des XVII et XVIII ${ }^{\mathrm{e}}$ siècles ", dans DOMPNIER Bernard (dir.), Les cérémonies extraordinaires du catholicisme baroque, Clermont-Ferrand, Presses Universitaires Blaise-Pascal, 2009, p. 509-523. 
LÓPEZ FERREIRO Antonio, Historia de la Santa A. M. Iglesia Catedral de Santiago de Compostela, Santiago de Compostela, Imprenta del Seminario, 1898-1909, 11 vol.

LÓPEZ ROBERTO Javier, "Las entradas públicas de los arzobispos compostelanos en la Edad Moderna », dans RomANí MARTínEZ Miguel et NovOA GÓMEZ María de los Ángeles (éds.), Homenaje a José García Oro, Santiago de Compostela, Éd. Universidade, Servicio de Publicacións e Intercambio Científico, 2002, p. 193-209.

LÓPEZ ROBERTO Javier, Ceremonia y poder a finales del Antiguo Régimen. Galicia 1700-1833, Santiago de Compostela, Universidade, Servicio de Publicacións e Intercambio Científico, 1994.

LOZANO Francisco, El Iris de la paz : justa parentacion que a la memoria de el Illmo. Señor D. Cayetano Gil Taboada Arzobispo, $i$ señor de Santiago, ofrece en eterno monumento de su filial gratitud, su mas reverente familia, Santiago, Éd. Buenaventura Aguayo, 1751.

MURGUía Manuel, « De los regocijos públicos con que se celebra en Santiago la recepción de sus prelados ", Suevia, année 2, vol. 30, décembre 1912, p. 11-12.

PAIVA José Pedro, «O cerimonial da entrada dos bispos nas suas dioceses: uma encenação de poder (1741-1757) », Revista de História das Ideias, vol. 15, 1993, p. 117-146.

PAIVA JosÉ Pedro, «Les entrées des évêques dans leurs diocèses dans l'Europe moderne : une vision comparée ", dans DOMPNIER Bernard (dir.), Les cérémonies extraordinaires $d u$ catholicisme baroque, p. 495-508.

PAIVA JosÉ Pedro, "Public cérémonies ruled by the ecclesiastical-clerical sphere: a language of political assetion (16th-18th centuries)», dans PAIVA José Pedro (éd.), Religious ceremonials and images: power and social meaning (1400-1750), Coimbra, Éd. Palimage, 2002, p. 415-425.

POlANCO PÉREZ Arturo, "Ceremonias de recibimiento y despedida a los obispos en la tradición palentina (s. XV-XVIII) », Publicaciones de la Institución Tello Téllez de Meneses, vol. 69, 1998, pp. 401-478.

RodríGuez MARTínez Felipe, "Fray Sebastián de Arévalo y Torres, OFM (el obispo limosnero). Obispo de Mondoñedo y Osma (1616-1704) », Archivo ibero-americano, vol. 60, 2000, p. 337-381.

SUÁREZ GOLÁN Fernando, "Todo es cuydar de las zeremonias. Imagen y representación del poder en el episcopado gallego », Obradoiro de Historia Moderna, vol. 20, 2011, p. 197219.

VISCEGLIA Maria Antonietta, « Il ceremoniale come linguaggio politico : su alcuni conflitti di precedenza alla corte di Roma tra cinquecento e seicento ", dans VISCEGLIA Maria Antonietta et CATHERINE Brice (éd.), Cérémonial et rituel à Rome (XVI et XIX siècle), Rome, Éd. École Française de Rome, 1997, p. 117-176. 

Gestes, mise en scène et représentation 


\title{
Communiquer dans l'amphithéâtre sous le Haut Empire
}

\author{
Éric TEYSSIER \\ Maître de conférences Université de Nî̀mes \\ Extrait de : Jean DuMA (dir.), Le Rituel des cérémonies, Paris, \\ Édition électronique du CTHS (Actes des congrès des sociétés historiques et scientifiques), 2015. \\ Cet article a été validé par le comité de lecture des Éditions du CTHS dans le cadre de la publication \\ des actes du $139^{\circ}$ Congrès national des sociétés historiques et scientifiques tenu à Nîmes en 2014.
}

Nous avons tous en tête le fameux tableau du peintre Gérôme «Pollice Verso » $(1872)^{1}$. Alors que sur le sable rougi de l'arène un rétiaire tend désespérément la main vers un empereur indifférent, des vestales surexcitées assises au premier rang des gradins demandent sa mort en tournant le pouce vers le sol. Le geste de la mise à mort en ellemême est un des moments les plus représentés de la gladiature... à l'époque contemporaine. Fondé sur une seule source contemporaine, le fameux pouce abaissé symboliserait à lui seul le sadisme supposé des Romains. Les péplums ont maintes fois contribué à rendre célèbre cette image. Depuis Laurence Olivier en consul Crassus insensible et calculateur dans Spartacus jusqu'au plus récent Gladiator où Joaquin Phoenix incarne un empereur Commode, maniaque et sanguinaire, en passant par le célèbre Quo Vadis où Peter Ustinov campe un Néron veule et débauché, tous ont levé ou plus souvent abaissé le pouce fatal.

En fait, force est de constater qu'aucune source iconographique ne représente ce geste pourtant légendaire. De plus la simple logique devrait avoir eu raison depuis longtemps de ce mythe. En effet, comment peut-on imaginer que le fait de lever le pouce dans une arène qui compte jusqu'à 45000 spectateurs pourrait déterminer la mort du vaincu. En effet, comment pourrait-on compter cette multitude de pouces levés ? Comme souvent pour le monde des gladiateurs, les idées reçues ont la vie dure.

La question de la communication dans l'amphithéâtre ne concerne pas seulement les gladiateurs qui s'entretuent. En plus des gladiateurs, se trouvent aussi des porteurs de pancartes, deux arbitres qui suivent le combat au plus près. Des musiciens qui jouent de différents instruments à vents et de l'orgue hydraulique, directement sur la piste. Un praeco qui a sans doute le rôle de notre monsieur Loyal dans le cirque, en annonçant les combattants. Le public sur les gradins et l'éditeur, l'empereur à Rome, ou un notable en province qui suit le spectacle depuis sa tribune réservée. Tous ces acteurs interagissent entre eux pour orienter la décision finale de l'éditeur qui décide de la vie ou de la mort $\mathrm{du}$ vaincu. Il est donc intéressant de tenter d'y voir plus clair sur les moyens de communication qui sont alors utilisés.

1. Ce tableau peint en 1872 est conservé au Phoenix Art Museum (Arizona). Cette œuvre célèbre est représentée dans la plupart des ouvrages sur les gladiateurs avec si peu d'esprit critique qu'elle doit apparaître comme une source authentique pour nombre de lecteurs. E. Teyssier, « Regard critique sur la représentation des gladiateurs dans quelques romans historiques du XIX siècle », pp. 185-203. Il est intéressant de constater que le tableau de Gérome continue à faire de l'effet. C'est en présentant cette œuvre que les producteurs de Dreamworks ont convaincu Ridley Scott de réaliser le fameux Gladiator (2000). 


\section{Communiquer autour et dans l'amphithéâtre}

La communication dans l'arène ne se résume pas à ce pouce retourné. En effet, la demande de la mort ou de la vie du vaincu n'est que l'aboutissement d'un processus marqué par d'autres gestes et d'autres moyens de communiquer. En effet, cette communication débute avant même le jour du combat. Pompéi nous a ainsi laissé pas moins de 27 «affiches » peintes (edicta) sur les murs de la ville ${ }^{2}$. Cet affichage permet de connaître le jour du munus, le nombre de combattants, leur armatura, leur école, le nombre de leurs victoires, la présence ou non du vellum et surtout le nom du généreux magistrat qui offre ce spectacle de choix à ses concitoyens. Lorsque le jour tant attendu est arrivé, la ville est traversée par le défilé des gladiateurs. Comme le montre le monument funéraire du duumvir Cn. Clavatius à Pompéi ${ }^{3}$, cette pompa est ouverte par les magistrats de la cité qui sont suivis par des musiciens. Ces derniers soufflent dans de longues trompettes afin que nul ne puisse ignorer l'événement. Viennent ensuite un porteur de palme et un porteur de pancarte ${ }^{4}$. Cette pancarte devait certainement comporter les mêmes informations que celles affichées sur les murs de la ville depuis plusieurs jours. Enfin, des ministri portent les casques et les boucliers des combattants.

À l'intérieur et à l'extérieur de l'amphithéâtre d'autres informations sont également données aux spectateurs qui achètent un libellus munerarius avant le spectacle. Il s'agit certainement de feuilles volantes réalisées sur papyrus où le programme des réjouissances est indiqué. Ovide évoque d'ailleurs l'utilisation de ces feuilles pour engager la conversation avec une spectatrice ${ }^{5}$. Sur ces programmes, le palmarès de chaque gladiateur est probablement rappelé. De même, lors de la pompa, des crieurs publics professionnels doivent eux aussi contribuer à l'information des spectateurs. Ainsi, Claude fait annoncer les jeux séculaires de cette manière comme le rapporte Suétone.

«On se moqua de l'annonce du crieur public (praecones) qui invitait, dans les termes consacrés à des jeux. ${ }^{6}$

À ce stade du spectacle, chacun peut encourager son champion préféré ou son armatura favorite. L'éditeur et même l'empereur à Rome peuvent, et sans doute doivent, participer à ces échanges afin de montrer leur proximité vis-à-vis du peuple. C'est ce que nous dit Suétone à propos de Titus quand il affirme que l'empereur affiche « ouvertement sa préférence pour l'armatura des thraces et il en plaisanta souvent avec le peuple de la voix et du geste ${ }^{7}$.

\section{Distinguer les gladiateurs pendant le combat}

Alors que les gladiateurs entrent dans l'arène, le nom des combattants est annoncé au moyen de pancartes portées par des ministri. Cet usage est mis en évidence par le médaillon de Cavillargues conservé au musée archéologique de Nîmes qui figure deux ministri porteurs de ces pancartes ${ }^{8}$. Sur la gauche, la pancarte indique tout près du rétiaire «XANTUS CAES(ARI). XV, tandis que la pancarte de droite placée au-dessus du secutor mentionne «EROS CAES(ARI). XVI» (Figure $\mathrm{n}^{\circ} 1$ ). Ainsi, les spectateurs peuvent connaître le nom et l'école des combattants. Il s'agit ici de l'école des Césars, un prestigieux ludus impérial. Il importe de préciser cette origine comme un gage de qualité,

2. P. Sabbatini Tumolesi, Gladiatorum Paria, annunci di spettacoli gladiatori a Pompei, p. 38.

3. Musée archéologique de Naples inv. 6704. Bas-relief du monument funéraire du duumvir Cn. ou N.

Clovatius, provenant de la nécropole de Pompéi de la porte de Stabie. Deuxième quart du I ${ }^{\text {er }}$ siècle ap. J.-C.

4. E. Teyssier, La mort en face. Le dossier gladiateur, p. 244. Toutes les représentations qui sont évoquées sans être reproduites dans cet article le sont dans cet ouvrage.

5. Ovide, L'art d'aimer, I, 167.

6. Suétone, Vie des douze Césars, Claude, XXI.

7. Suétone, Vie des douze Césars, Titus, VIII.

8. E. Teyssier, «Le médaillon de Cavillargues », p. 36-41. 
car ces gladiateurs doivent couter fort cher à l'éditeur. Ces combattants sont d'autant plus onéreux qu'ils sont expérimentés et de force égale avec un palmarès prestigieux de $\mathrm{XV}$ et XVI victoires. En soulignant le palmarès flatteur des combattants, l'éditeur tient à rappeler sa générosité au moyen de ces pancartes. Si le nom et le palmarès constituent des informations importantes à rappeler, il est inutile de préciser à quelles armaturae appartiennent Xantus et Éros, puisqu'il est facile de distinguer un rétiaire d'un secutor.

Par contre, distinguer deux provocatores ou deux equites, une fois que le combat a commencé, s'avère plus délicat. En effet, la particularité de ces deux armaturae est de faire s'opposer deux gladiateurs identiques. C'est sans doute pour cette raison que ces gladiateurs sont alors équipés de boucliers de couleurs différentes. C'est ce que laisse apparaître plusieurs mosaïques polychromes représentant ces armaturae spécifiques ${ }^{9}$. Cette distinction peut même être renforcée pour les equites qui sont les seuls gladiateurs à ne pas combattre torse nu mais en étant vêtus de tuniques qui sont systématiquement de différentes couleurs permettant de les distinguer.

\section{La musique dans l'arène}

La musique constitue un autre élément important qui doit également être pris en compte dans la communication et la scénographie complexe de l'amphithéâtre. Ces musiciens, très bien représentés sur de nombreuses images, sont toujours placés au plus près des combattants et des arbitres, ce qui indique leur présence sur le sable même de l'arène. Ainsi, sur un graffiti de la nécropole de la Porta Nocera à Pompéi, six musiciens accompagnant le combat $d^{\prime} u n$ hoplomaque et $d^{\prime} u n$ mirmillon (Figure $n^{\circ} 2$ ). Il semble que les musiciens accompagnent l'action ou du moins l'instant de son dénouement. Dans le cas présent, les musiciens figurés à droite soufflent dans des tubae et des flutes, tandis que ceux de gauche sont maladroitement représentés avec leurs cornus enroulés autour d'eux. Alors que le combat est encore en train de se jouer, les musiciens de droite ont toute leur attention captée par les combattants et sont en train de jouer alors que les joueurs de cornu demeurent inactifs. Il semble bien que la musique soit destinée à accompagner l'action, sans doute lorsque celle-ci est particulièrement digne d'intérêt. Si telle est le cas, nous retrouverions alors un schéma qui existe toujours dans la tauromachie lorsque le président fait signe à l'orchestre de jouer pendant le combat.

La mosaïque de Zliten, conservée au musée archéologique de Tripoli présente à deux reprises quatre musiciens jouant ensemble. Il s'agit dans les deux cas d'un joueur de tuba, de deux joueurs de cornu et d'une femme placée derrière un orgue hydraulique. Dans l'une de ces scènes musicales, le lien entre l'orchestre et l'arbitre est particulièrement souligné par l'artiste. En effet, le vainqueur d'un combat d'equites semble ne pas vouloir entendre l'arbitre qui lui a sans doute intimé l'ordre de cesser le combat contre son adversaire couché sur le dos. Désespérant de pouvoir arrêter sa fureur meurtrière, l'arbitre, tout en retenant le bras de l'eques se retourne vers les musiciens qui semblent répondre à son appel en jouant tous ensemble de leurs instruments.

Incontestablement, les musiciens sont présents pour rythmer les moments forts du spectacle. Cette pratique, qui est peut-être aussi ancienne que la gladiature ${ }^{10}$, correspond certainement à une codification précise qui nous échappe largement. Parmi les rares indices, les reliefs de Fiano Romano présentent à deux reprises des musiciens placés au plus près des combattants. Sur cet exemple daté des débuts du principat, un tubicen joue au moment où un Thrace lève le doigt pour reconnaître sa défaite (Figure $n^{\circ} 3$ ). Sur un autre panneau qui orne le même monument funéraire, c'est un cornicen aux joues gonflées qui fait sonner son instrument au moment où un provocator s'apprête à tuer son adversaire vaincu. Faut-il voir dans cette répartition une mission spécifique donnée à

9. C'est le cas de la mosaïque de Zliten conservée au musée archéologique de Tripoli ou de la mosaïque d'Augst.

10. Rappelons que des musiciens sont déjà présents lors des combats représentés sur les tombes de Paestum du $\mathrm{IV}^{\mathrm{e}}$ siècle av. J.-C. De même, le plus ancien témoignage figuré de la gladiature à Pompéi met également en scène un tubicen avec deux samnites et deux equites au milieu du $\mathrm{I}^{\mathrm{er}}$ siècle av. J.-C. 
chaque instrument suivant le type d'action en train de se dérouler ? Cette hypothèse est plausible mais les témoignages sont trop rares pour permettre de donner une réponse définitive à cette question.

\section{Les arbitres}

Jamais représentés dans les péplums mais très présents dans le corpus iconographique de la gladiature, les arbitres participent eux aussi à la communication dans l'arène. Intervenant généralement par paire, le summa et le secunda rudis sont là pour témoigner de l'absence de fraude pendant le combat. Munis d'un bâton (rudis), l'arbitre peut intervenir au cœur même du combat. Ainsi, une carafe en verre découverte en Égypte à Ismant el-Kharab ${ }^{11}$ montre un arbitre en train d'interrompre l'assaut d'un rétiaire qui vient d'amener son adversaire à terre (Figure $n^{\circ} 4$ ). Sur un bas-relief d'Éphèse, un autre arbitre retire ostensiblement le bouclier d'un secutor en l'engageant à reprendre le combat sans cet équipement (Figure $\left.\mathrm{n}^{\circ} 5\right)^{12}$. Dans d'autres circonstances, l'arbitre ou l'éditeur peuvent communiquer leur décision au public et aux combattants au moyen de pancartes. C'est ce que montre un petit vase de bronze découvert à Reims. Sur une pancarte assez grande pour être portée sur les épaules de deux ministri, est indiquée en gros caractères "PERCEVERATE " ${ }^{13}$. Cette injonction doit sans doute manifester la volonté de l'éditeur de voir le combat se poursuivre. De même sur un graffiti découvert à Rome, le rétiaire Antigonus affronte le secutor Superbus en présence d'un arbitre (Figure $n^{\circ} 6$ ). Ce dernier tend sa baguette avec sous ses pieds un cartouche portant la mention "Casuntius dira: Avance", (Casuntius dicet accede). Ces deux exemples, ainsi que le médaillon de Cavillargues, confirment l'usage sans doute important des pancartes pour communiquer dans l'amphithéâtre.

En dehors de ces mentions, certaines représentations laissent deviner l'existence d'une gestuelle très codifiée qui devait certainement être évidente aux Romains mais dont le sens exact nous échappe souvent. Ainsi, sur l'autre face de la carafe en verre d'Ismant elKharab, l'arbitre pointe clairement son index à l'horizontal et semble ainsi encourager le secutor à poursuivre son effort contre le rétiaire. De même sur la mosaïque de Nennig en Allemagne, l'arbitre est représenté en train de faire un geste de la main droite dont $l^{\prime}$ interprétation n'est pas assurée (Figure $n^{\circ} 7$ ). Tenant sa baguette de la main gauche, il tend sa main droite au-dessus des combattants en pointant son index replié et en rétractant ses autres doigts. D'après la direction du regard, l'arbitre semble bien s'adresser aux combattants et non pas à l'éditeur placé dans les gradins. Peut-être encourage-t-il les combattants (Perceverate!) ? Ou bien ce geste particulier est-il en corrélation avec l'action en train de se dérouler. En effet, sur cette mosaïque de grande qualité, le rétiaire semble crocheter le bas du bouclier de son adversaire. L'arbitre veut-il alors signaler cette action particulière en accordant un quelconque avantage à son auteur? Il n'est pas possible de le dire mais sur une mosaïque aussi détaillée que celle de Nennig, ce geste a sans aucun doute une signification très précise.

\section{La gestuelle des gladiateurs}

Quoiqu'il en soit, c'est semble-t-il à la fin du combat que la communication par gestes prend tout son sens dans l'amphithéâtre. Les gladiateurs eux aussi peuvent user d'une gestuelle particulière liée au combat. Ainsi dans de nombreux cas et sur différents supports, des gladiateurs sont représentés en train de pointer l'index vers le haut ${ }^{14}$. On remarque que sur tous ces bas-reliefs, ces peintures murales, ces gobelets, ces lampes à

11. C. A. Hope, H. V. Whitehouse, “The gladiator Jug from Ismant el-Kharad. The Oasis Papers 3", pp. 291-310. 12. Musée de Selçuk. Bas-relief conservé provenant d'Ephèse. L'arbitre tenant sa rudis empêche le secutor de récupérer son bouclier. Il doit alors faire face au rétiaire en se protégeant de sa seule manica.

13. Musée du Petit Palais, Inv. DUT 89. Petit vase de bronze, découvert à Reims. Ht $59 \mathrm{~mm}$ sans le couvercle. Une scène de combat rétiaire secutor et deux porteurs de pancartes. Deux autres faces présentent un autre moment du même duel et un organiste derrière son instrument. E Teyssier, La mort en face. Le dossier gladiateur, p. 341.

14. C'est ce geste qui est évoqué par Martial avec l'expression « ad digitum ». Martial, Des spectacles, XXXII. 
huile et ces mosaïques, le doigt tendu est toujours celui de la main gauche. Cette main qui porte ordinairement le bouclier est utilisée pour manifester que le gladiateur, qu'il soit debout ou agenouillé, veut cesser le combat. En effet, en levant cette main il doit abandonner son bouclier qui est souvent représenté à ses côtés. De plus, la main droite étant souvent pourvue d'un gantelet de cuir qui prolonge la manica du bras, l'usage de la main droite aurait pu dissimuler ce geste. Ce geste tragique signifie la fin du combat et le moment crucial qui va déterminer le sort du vaincu.

Lever le doigt constitue sans doute une référence au même geste qui dans la lutte et le pancrace grecs signifie l'arrêt du combat et la reconnaissance de la défaite. Ce geste commun constitue un élément de convergence très net entre l'athlétisme de combat grec et les gladiateurs. Au-delà du geste lui-même, il semble que ce soit l'attitude qui détermine la fin du combat. Ainsi, le fait de jeter ostensiblement ses armes à terre doit également entrainer l'intervention de l'arbitre et la désignation explicite du vainqueur. Dans une anecdote rapportée par Suétone, un rétiaire a repris ses armes après les avoir jeté à terre pour échapper au verdict fatal ${ }^{15}$. C'est sans doute ce type de mésaventure que les organisateurs veulent éviter afin d'assurer la "bonne tenue» du spectacle. Ainsi par ce geste du doigt levé, le vaincu s'engage formellement auprès du public et de l'éditeur, vers qui il se tourne, à ne plus reprendre les armes.

Lorsque l'un des gladiateurs reconnaît sa défaite et qu'il a demandé l'arrêt du combat, l'acte suivant consiste à demander sa grâce au public et surtout à l'éditeur. Le public intervient alors en communiquant son choix en donnant de la voix. Un texte important de Martial souligne que le public ne baisse certainement pas le pouce pour demander la « grâce » (missio) et pour demander son renvoi (vivant) mais donne plutôt de la voix.

«Quand Priscus, quand Vérus traînaient leur affrontement en longueur sans que Mars enfin se décidât pour l'un ou pour l'autre, le renvoi (missio) fut réclamé maintes fois à grands cris par l'assistance pour les champions. ${ }^{16}$

Dans le même temps ceux qui sont mécontents du combat expriment leur verdict par des cris tels que, «frappe!», (verbera), «brule-le!», (vre), lorsque le gladiateur manque de vaillance. Lorsqu'un des gladiateurs est blessé et que le dénouement est proche l'expression, «il en a! », « cette fois il en tient!», (Habet, hoc habet) s'élève des gradins. Enfin, quand les spectateurs exigeants jugent que le vaincu n'a pas assez bien combattu pour espérer continuer sa carrière, ils crient alors, « égorge-le! » (Iugula) ${ }^{17}$. Il est à noter que ces cris sont souvent repris dans les ouvrages sur la gladiature mais n'apparaissent pas directement dans les sources. Même s'ils ont certainement retenti dans l'amphithéâtre, ils ont été extrapolés à partir de différents passages tirés de Cicéron et de Suétone. Forgés pour la plupart par Jérôme Carcopino qui voulait dénoncer la cruauté des Romains, ils ont été repris ensuite par de nombreux auteurs sans plus de vérification.

Quoiqu'il en soit, ces cris engendrent une belle cacophonie et mis à part les cas où le combattant vaincu a très bien ou très mal combattu, il doit être souvent difficile pour l'éditeur de déterminer la tendance du public par les seuls cris. Certes, les arbitres, témoins directs du combat peuvent certainement donner leur avis par signe sur la valeur de l'engagement. C'est ce qu'indique une mosaïque du III $^{\mathrm{e}}$ siècle provenant de Rome et conservée au musée archéologique de Madrid, un secutor vient de l'emporter sur un rétiaire qui rend les armes (Figure $\mathrm{n}^{\circ} 8$ ). Cette image présente deux arbitres faisant cesser le combat. Dans ce cas, la fin du combat est manifestée par le rétiaire. Malgré l'avantage qu'il a pu emporter en enroulant son filet sur le casque du secutor, ce dernier n'a pas faibli jusqu'à parvenir à jeter son adversaire à terre. Face à un adversaire supérieur, le rétiaire Kalendio présente sa dague posée dans sa main. À cet instant, l'arbitre de droite lève la main droite ouverte et le bras dressé. Il regarde en direction du secutor sans doute pour l'arrêter dans son élan ou pour manifester son triomphe. Simultanément, l'arbitre de

15. Suétone, Vie des douze César, Caligula, XXX.

16. Martial, Des spectacles, XXXII.

17. J. Carcopino, La vie quotidienne à Rome, à l'apogée de l'Empire, pp. 278-279. 
gauche, sans doute le summa rudis, lève lui aussi sa main ouverte mais avec le bras allongé et regarde en dehors de la scène, sans doute en direction de l'éditeur. Ce signe particulier de la main accompagne par deux fois le nom de Kalendio suivi du thêta. Cette lettre, symbole de la mort (thanatos), semble indiquer que le rétiaire Kalendio n'a pas été renvoyé mais qu'il a été tué par son vainqueur à l'issue du combat.

Une autre mosaïque retrouvée et conservée à Vérone (Figure $n^{\circ}$ 9) représente un Thrace vainqueur d'un mirmillon. Ce dernier, allongé face contre terre semble déjà mort ou du moins inconscient. Comme sur la mosaïque de Madrid l'arbitre lève la main droite ouverte. Dans le cas présent, le combat est de toute évidence terminé. Il est cependant difficile de dire si le vaincu a déjà été tué, s'il va l'être ou s'il peut encore être gracié.

Un détail d'un bas-relief aujourd'hui fragmentaire pourrait, peut-être, indiquer une autre piste. Cette sculpture conservée à la Glyptothèque de Munich, représente la fin d'un combat entre equites. Alors que les cuivres résonnent, le vainqueur s'apprête à frapper le vaincu qui est à ses pieds. Passant entre les deux joueurs de tuba une main gauche apparaît sur la scène. La main est ouverte à l'horizontale, le pouce levé, l'index et le majeur tendu et les deux doigts suivants repliés. La partie gauche du relief ayant disparu, il est impossible de dire à qui appartient cette main. S'il est peu probable qu'il s'agisse de l'éditeur, il est beaucoup plus plausible que cette main soit celle du summa rudis qui serait placé derrière les musiciens. Manifestement, cette main a un rôle à jouer dans la composition. Étant donné l'instant représenté, il pourrait bien s'agir de la main de l'arbitre transmettant au vainqueur la décision fatale de l'éditeur. Si l'on accepte cette proposition, force est de constater que ces trois doigts tendus en direction du vaincu correspondraient bien au «pollice verso » le «pouce dirigé vers » de Juvénal.

En dehors du cas classique de la demande de missio, une autre issue est possible lorsque les deux adversaires sont de même force. Ce cas de figure est connu sous la dénomination de stantes missi. Si la bravoure des deux hommes dans le combat est parvenue à séduire le public et à donner satisfaction à l'éditeur, ce dernier peut, sans doute sur proposition de l'arbitre ou à la demande de la foule, accepter de «renvoyer debout» les gladiateurs méritants. Dans ce cas l'arbitre, qui est là pour juger en professionnel de la qualité et de la réalité du combat, a un rôle crucial. Sur le médaillon de Cavillargues (Figure $\mathrm{n}^{\circ} 1$ ), la mention " renvoyés debout " (stantes missi) est effectivement inscrite en haut à droite audessus d'un personnage qui est très certainement le summa rudis. De fait, cet arbitre tient une place importante dans le médaillon. En effet, l'artiste le représente tête levée et de profil. L'arbitre semble alors se détourner du combat et tourne ses yeux en direction de l'éditeur, comme toujours absent de la composition, pour lui donner une indication. Si l'on regarde sa main droite, qu'il brandit en direction d'une tribune ici invisible, il est possible de constater qu'il effectue un geste bien déterminé. Ce geste, qui semble ne rien devoir au hasard, présente le pouce clairement replié sur les quatre autres doigts de la main qui sont eux aussi rétractés sans pour autant figurer un poing fermé. Il est remarquable de constater que l'artiste a placé ce geste juste au-dessous de l'inscription stantes missi comme pour indiquer un lien entre les deux. Ce lien semble d'ailleurs renforcé par un trait vertical bien souligné qui ne semble pas avoir d'autre utilité que de relier la main de l'arbitre à l'inscription. Au sommet du médaillon, à gauche de l'inscription, quatre petits personnages sont encore représentés. Il s'agit du secutor et du rétiaire, sans armes, qui semblent saluer la foule. De part et d'autre de ces deux silhouettes, deux musiciens soufflent dans leurs instruments. De toute évidence ce petit groupe illustre concrètement le signe de l'arbitre et la mention « renvoyés debout ».

\section{Le geste final des combats de gladiateurs}

Mille fois représenté dans les péplums, les séries télé, les tableaux pompiers ou les romans historiques, le geste de la mort n'est pas aussi évident qu'on ne le pense. Parfois, c'est le gladiateur lui-même qui peut refuser sa grâce comme en témoigne Cicéron.

«J'ai vu un gladiateur vraiment courageux... qui après avoir été blessé, s'est retourné vers 
la foule qui demandait sa grâce pour son courage, en faisant signe du bras qu'il n'avait rien fait et qu'il ne voulait être recommandé par personne. ${ }^{18}$

Il ne fait pas de doute que dans ce cas le gladiateur fait un choix stratégique. En refusant sa grâce malgré sa blessure il marque son professionnalisme et son mépris de la mort. Il sait parfaitement que c'est ce que le public attend d'un gladiateur et la foule sera ainsi d'autant mieux disposée envers lui.

Lorsque le public, les arbitres et les gladiateurs se sont exprimés, c'est à l'éditeur de trancher et d'indiquer le verdict final. Malgré un corpus iconographique de près de 1600 images répertoriées, un seul éditeur est représenté en train de faire ce geste qui semble tellement passionner les Modernes ${ }^{19}$. Cette distorsion entre «notre » représentation de la gladiature et «les » représentations qu'en ont laissées les Anciens n'est pas sans intérêt. Elle semble indiquer que ce qui est important pour nous ne l'est pas pour les Romains. $\mathrm{Au}$ fond, au risque d'être un peu provocateur, il se pourrait que nous soyons plus avides de sang que nos lointains ancêtres...

Qui plus est, cette unique image représentant un munerarius en train de faire un geste est un graffiti peu exploitable de ce point de vue (Figure $\mathrm{n}^{\circ} 10$ ). Il semble bien que pour l'habitant de Pompéi qui a dessiné cette scène, l'essentiel ne porte pas sur le geste de l'éditeur qui est tellement schématisé qu'il se réduit à lui faire lever l'avant-bras gauche. Geste qu'il fait peut-être pour demander le silence. En revanche, la posture de l'arbitre tourné vers lui montre bien le lien qui existe entre ces deux personnages dans la mise en scène de la mort du gladiateur vaincu. Effectivement, le graffiti mentionne que le mirmillon Herrenius est mort $(P($ erit $))$. À en croire cet unique témoignage iconographique, faut-il comprendre que l'éditeur exprime sa sentence de mort simplement en levant la main gauche (sinistra), tandis que l'arbitre tend lui aussi la même main comme s'il répétait le signe aux combattants?

Même s'il n'est jamais représenté dans le corpus iconographique ${ }^{20}$, le personnage du praeco doit alors jouer un grand rôle pour transmettre au public, aux arbitres, aux musiciens et aux gladiateurs la décision de l'éditeur des jeux.

«Un jour où, dans un combat de gladiateurs, on lui demandait une grâce avec insistance, il (Hadrien) ne l'accorda pas, et, de plus, donna l'ordre au praeco de répéter le mot de Domitien : «Faites silence ». Cette parole ne fut pas prononcée, car le praeco ayant étendu la main et obtenu le calme par ce seul geste, comme c'est la coutume dit lorsque le silence régna « Voilà ce que veut l'empereur ». » ${ }^{21}$

Par cette anecdote, Dion Cassius montre bien que le geste se substitue souvent à la parole afin d'être compris par tous. Ce témoignage indique également que le praeco se tient tout près de l'éditeur. À la tempête des cris et de l'agitation du public doit succéder un silence absolu. Un silence qui permet d'accueillir une décision lourde de sens puisque la vie d'un homme est alors en jeu. Une fois la décision prise, la gestuelle du public demeure surtout importante pour l'éditeur. Ce dernier reste seul maître de la décision finale et doit donner son verdict en s'appuyant sur l'avis de spectateurs qui sont aussi ses concitoyens. Pour cela, l'avis du public doit pouvoir être pris en compte. Comptabiliser, sans aide électronique, le vote manifesté par des dizaines de milliers de mains exprimant des avis divers semble peu crédible. Aucun texte ni aucune image ne nous montre le public dans une telle attitude. Il importe également de souligner que le seul et unique témoignage

18. Cicéron, Tusculannes, II, 17.

19. Un autre éditeur est représenté entouré par du public et des musiciens sur le bas-relief funéraire de Lucius Storax à Chieti. Malheureusement, le mauvais état de ce monument ne permet pas de tirer des conclusions de la gestuelle utilisée. M. Junkelman, Gladiator das spiel mit dem tod, pp. 36-37.

20. Alors que les musiciens, les arbitres voire les porteurs de pancartes sont souvent représentés, le praeco ne figure jamais sur aucun support. Peut être que cette absence est due à un statut indigne qui l'exclue au même titre que les proxénètes ou les propriétaires de gladiateurs de toutes magistratures publiques comme en témoigne les tables d'Italica.

21. Dion Cassius, Histoire romaine, LXIX, 6. 
que nous possédons sur le signe de la main est donné par Juvénal et encore concerne-t-il uniquement l'éditeur.

«Naguère sonneurs de cor et habitués de l'arène des villes de province... ils financent maintenant des jeux de gladiateurs (munera) et quand le peuple l'ordonne en tournant le pouce (verso pollice), ils tuent pour se faire bien voir... $»^{22}$

Dans cette satire, Juvénal s'en prend aux nouveaux riches des provinces qui font oublier l'origine douteuse de leur fortune en s'attirant les bonnes grâces de la plèbe. La seconde mention de verso pollice se trouve dans un texte beaucoup plus tardif sous la plume de Prudence. Dans ce passage du Contre Symmaque, Prudence veut dénoncer les pulsions sanguinaires des prêtresses païennes que sont les Vestales.

«... Et la poitrine de celui qui est à terre, l'honnête vierge, en retournant le pouce (converso pollice), ordonne de la briser. ${ }^{23}$

Comme on le voit, ces deux témoignages ne traitent pas directement des gladiateurs mais veulent dénoncer, à travers l'instant crucial de la mort du vaincu, l'attitude de certains contemporains qui la réclament. Au passage, il est intéressant de souligner que le témoignage de Prudence peut, à bon droit, être mis en doute. En effet, en tant que chrétien, Prudence n'a pas pu assister à ce genre de spectacle interdit à ses coreligionnaires par tous les Pères de l'Église. De plus, on ne saurait trop insister sur le caractère tardif du témoignage de Prudence. En effet, le Contre Symmaque a été rédigé au tout début $\mathrm{du} \mathrm{V}^{\mathrm{e}}$ siècle alors que la gladiature a pratiquement disparu à cette époque. Enfin, cet ouvrage est une charge virulente contre les ultimes manifestations du dernier carré des païens de Milan alors que le christianisme a déjà triomphé. Ainsi, le témoignage de Prudence constitue avant tout une charge violente contre les païens et leur religion. En présentant les vierges païennes que sont les Vestales sous un jour criminel, l'auteur cherche avant tout à valoriser la douceur et l'innocence des vierges chrétiennes. Dans un tel contexte, la réalité gladiatorienne importe peu à ses yeux. Prudence se contente donc pour assoir son argumentation de puiser dans les sources littéraires anciennes, en l'occurrence Juvénal, pour présenter les combats à sa façon.

Ainsi, la nature exacte du fameux geste fatal est fondée sur une seule référence littéraire qui, comme le démontre brillamment Michel Dubuisson, a sans doute été mal comprise.

«Le vertere de Juvénal, que Prudence jugeait déjà utile de préciser en convertere, est loin d'avoir toujours été interprété de cette façon-là. Pour les commentateurs du début de l'avant-dernier siècle, il allait de soi, au contraire, que pollice verso signifiait ici 'pouce tendu vers' un objet (...) La simple lecture du Gaffiot nous apprendra, ou nous rappellera, que le complément de vertere, quand il en a un, est constamment introduit par in ou ad suivis de l'accusatif ('vers' quelqu'un ou quelque chose, représentant une direction ou un but à atteindre); il n'y a donc aucune raison de supposer que ce même verbe, employé absolument, se mette soudain à désigner une direction de haut en bas. Pollice verso ne pourrait dès lors signifier que « pouce tourné vers, tendu vers. $»^{24}$

Mais ce qui compte avant tout pour l'éditeur est de savoir quelle est la volonté de la majorité des spectateurs. L'expression d'un choix, outre les cris que nous venons d'évoquer, doit prendre une forme plus visible afin de dégager une impression d'ensemble. Sur ce point Martial, qui est un habitué des amphithéâtres, donne une indication précieuse.

«Il y a peu, comme on demandait le renvoi (missio) de Myrinus blessé, Hermogène a réussi à voler quatre serviettes (mappas). ${ }^{25}$

22. Juvénal, Satires, III, 36.

23. Prudence, Contre Symmaque, XI, 1098-9.

24. M. Dubuisson, "Et pourquoi pas les langues anciennes?»

25. Martial, Epigrammes, XII, 28. 
La seule façon de comprendre cette épigramme, est qu'Hermogène a volé les serviettes ou les morceaux de tissus que ses voisins de gradins utilisent pour manifester leur volonté de voir gracier le gladiateur Myrinus. Ce dernier n'ayant pas démérité du fait de sa blessure, les voisins de l'indélicat personnage n'ont pas pu manifester leur verdict. Les serviettes de Martial constituent une solution pratique qui est d'ailleurs encore utilisée dans le monde de la tauromachie. Lorsque le toréro a enchainé une suite de passes remarquables, le président fait signe à l'orchestre qu'il peut jouer en agitant son mouchoir. De même, le public des corridas utilise ce même procédé pour demander l'attribution d'un trophée au toréro.

Plus que des pouces levés, baissés ou dans toute autre position, plus que les cris qui servent surtout d'exutoire à la violence des foules, le fait d'agiter une serviette blanche permet certainement à l'éditeur de jauger la tendance du public à chaque demande de missio. Ce point est important, car la décision de l'éditeur, si elle est souveraine, se doit d'être en conformité avec la volonté du peuple. S'il fait égorger un gladiateur que le public veut sauver il est taxé de cruautée ${ }^{26}$. S'il renvoie un homme condamné par la foule, il peut être accusé d'avarice. Dans les deux cas son verdict sera ressenti comme une grave injustice aux yeux de la foule qui se voit ainsi privée du pouvoir qu'elle est fermement convaincue de détenir.

Comme on peut le constater dans ces exemples, tous les moyens sont bons pour communiquer autour des gladiateurs. En amont par les « affiches » peintes sur les murs, les "produits dérivés", les graffitis, des programmes sans doute sur papyrus. Pendant les combats, les couleurs de certains combattants et le décor de leur bouclier jouent également leur rôle pour distinguer deux gladiateurs portant la même armatura. Des pancartes, sans doute rédigées à l'avance, sont présentées par les ministri. Des sonneries connues du public annoncent chaque moment fort au public à grand renfort de cuivres. Le praeco, crieur public à mi-chemin entre le monsieur Loyal et le «chauffeur de salle» délivre lui aussi les informations importantes. Mais surtout, la communication s'opère au moyen d'une gestuelle très codifiée des arbitres et des gladiateurs.

Enfin, le public ne manque pas d'intervenir, par les cris ou par les gestes en agitant notamment sa mappa pour demander, plus souvent qu'on ne le pense, la grâce du vaincu. D'autres moyens de communiquer existent également qui nous échappent, mais il semble assuré que jamais le pouce levé tel que nous l'imaginons a pu avoir le rôle que nous lui prêtons. Loin des stéréotypes forgés au XIX ${ }^{\mathrm{e}}$ siècle, la gestuelle des gladiateurs est à la fois plus variée et moins rigide qu'on ne le pense. Il apparaît clairement que la gladiature constitue une sorte de dialogue entre les combattants, l'arbitre, l'éditeur et surtout le public. 


\section{Résumé}

«Le pouce retourné ». Interprété d'après un texte de Juvénal (Satires, III, 36) puis illustré par Gérôme (1872) et dans de nombreux péplums, ce geste semble universellement connu. Pourtant, ce signe de mort n'a jamais été utilisé par les Romains. En effet, comment serait-il possible de compter rapidement les pouces levés ou baissés des 45000 spectateurs au Colisée?

Contrairement aux idées reçues, l'amphithéâtre est un lieu de communication. En effet, il est nécessaire que le public, l'éditeur des jeux et les protagonistes du spectacle qui évoluent sur la piste puissent interagir. Grâce aux témoignages des auteurs anciens (Juvénal, Suétone, Martial, Prudence), aux inscriptions et graffiti de Pompéi et aux nombreuses représentations de gladiateurs, il est possible de comprendre les différents moyens de communiquer autour et dans l'amphithéâtre. Il apparaît ainsi que, par la voix, la musique, les pancartes et une gestuelle particulière, le public et l'éditeur pouvaient interagir sur les combattants et sur la conclusion des combats.

\section{Bibliographie}

CARCOPINO Jérôme, La vie quotidienne à Rome, à l'apogée de l'Empire, Paris, Hachette, 1939.

DUBUISSON Michel, «Et pourquoi pas les langues anciennes? ».

http : www.ulg.ac.be. Université de Liège. Septembre 2003.

Hope C. A., Whitehouse H. V., The gladiator Jug from Ismant el-Kharad. The Oasis Papers 3. Third International Conference of the Dakhleh Oasis project, Oxford, Oxford Books, 2004, pp. 291-310.

JUNKELMAN Marcus, Gladiator das spiel mit dem tod, Mayence, PHZ, 2008.

SABbAtini Tumolesi Patrizia, Gladiatorum Paria, annunci di spettacoli gladiatori a Pompei, Rome, Tituli I, 1980, p. 38.

TEYSSIER Éric, «Regard critique sur la représentation des gladiateurs dans quelques romans historiques $\mathrm{du} \mathrm{XIX}^{\mathrm{e}}$ siècle ", dans La plume et la pierre, l'écrivain et le modèle historique au XIX siècle, Nîmes, Lucie Éditions, 2007, pp. 185-203.

TEYSSIER Éric, «Le médaillon de Cavillargues », Dossier Nîmes ville antique, Histoire Antique, ${ }^{\circ} 32$, juillet 2007, p. 36-41.

TEYSSIER Éric, La mort en face. Le dossier gladiateur, Paris, Actes Sud, 2009.

VILLE Georges, La gladiature en Occident. Des origines à la mort de Domitien. Rome, École française, 1981. 


\section{Illustrations}

Figure 1: Médaillon de Cavillargues, musée archéologique de Nîmes. Combat rétiaire secutor. Début du I ${ }^{\text {er }}$ siècle ap. J.-C. Photo Vincent Chambon. (dans TEYSSIER Éric, Nîmes la Romaine, Nîmes, Éditions Alcide, 2014).

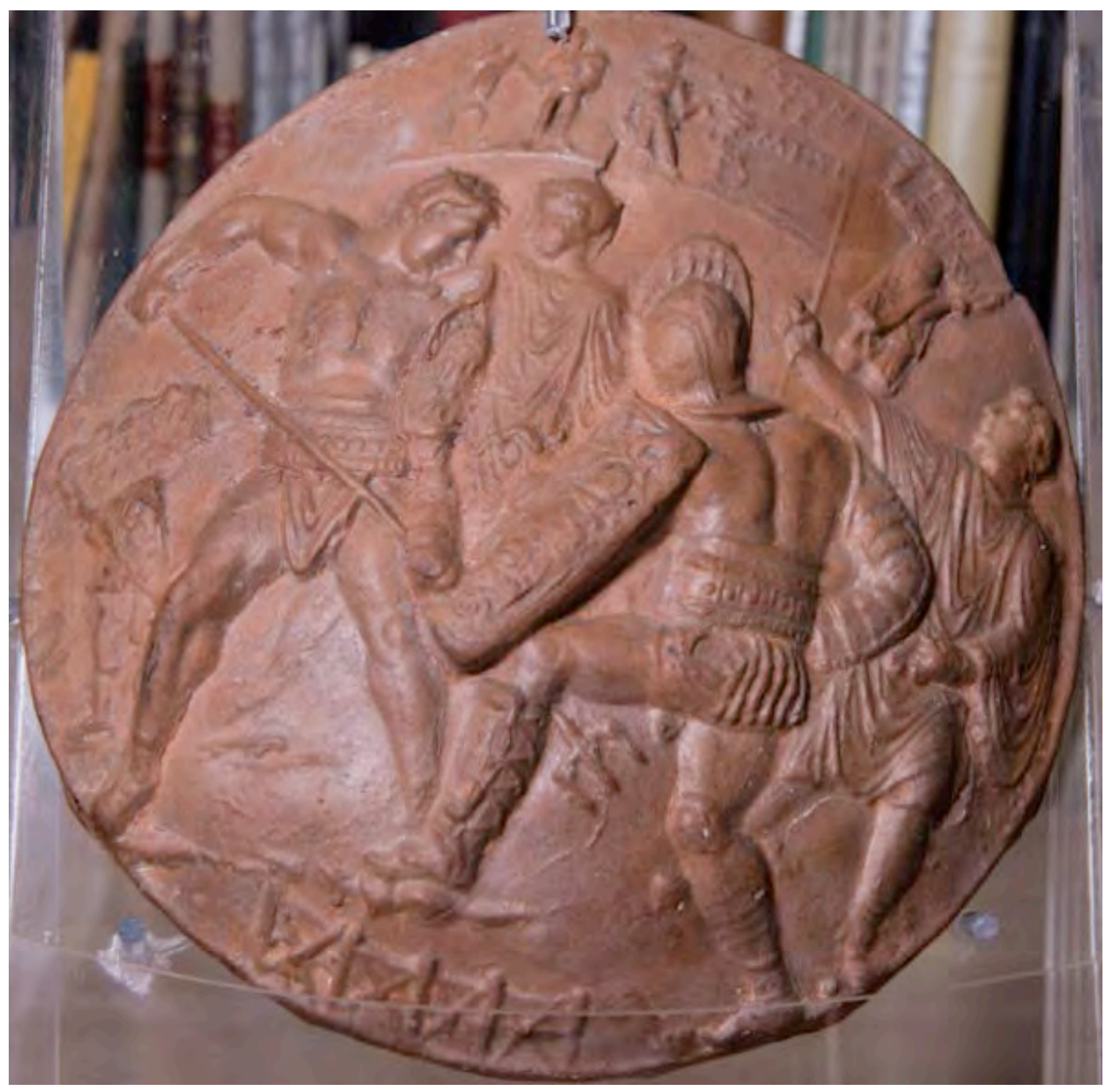


Figure 2: Graffiti de la nécropole de la Porta Nocera, Pompéi. Des musiciens accompagnant le combat d'un hoplomaque et d'un mirmillon. $\mathrm{d}^{\text {er }}$ siècle ap. J.-C. (TEYSSIER Éric, Le dossier gladiateur, Paris, Actes sud, 2009, p. 358).

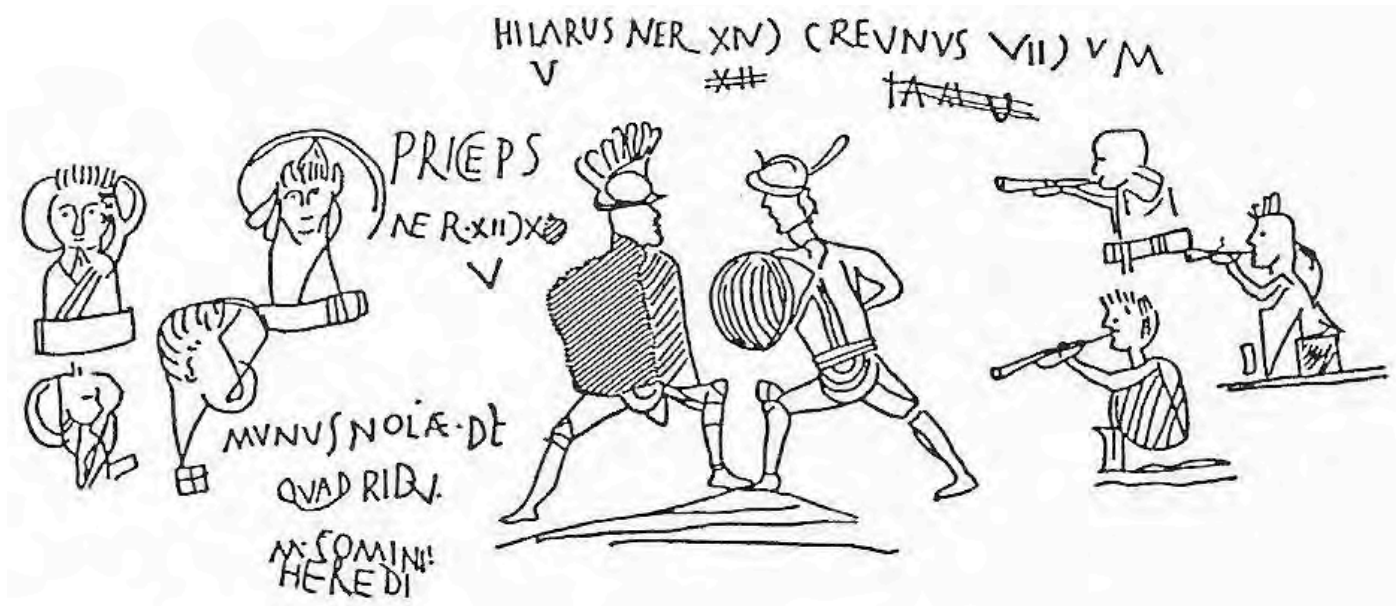

Figure 3 : Détail d'un bas-relief funéraire de Fiano Romano. Fin du I ${ }^{\mathrm{er}}$ siècle av. J.-C. La mort en face. Teyssier Éric, Le dossier gladiateur, Paris, Actes sud, 2009, p. 48. (TEYSSIER Éric, Le dossier gladiateur, Paris, Actes sud, 2009).

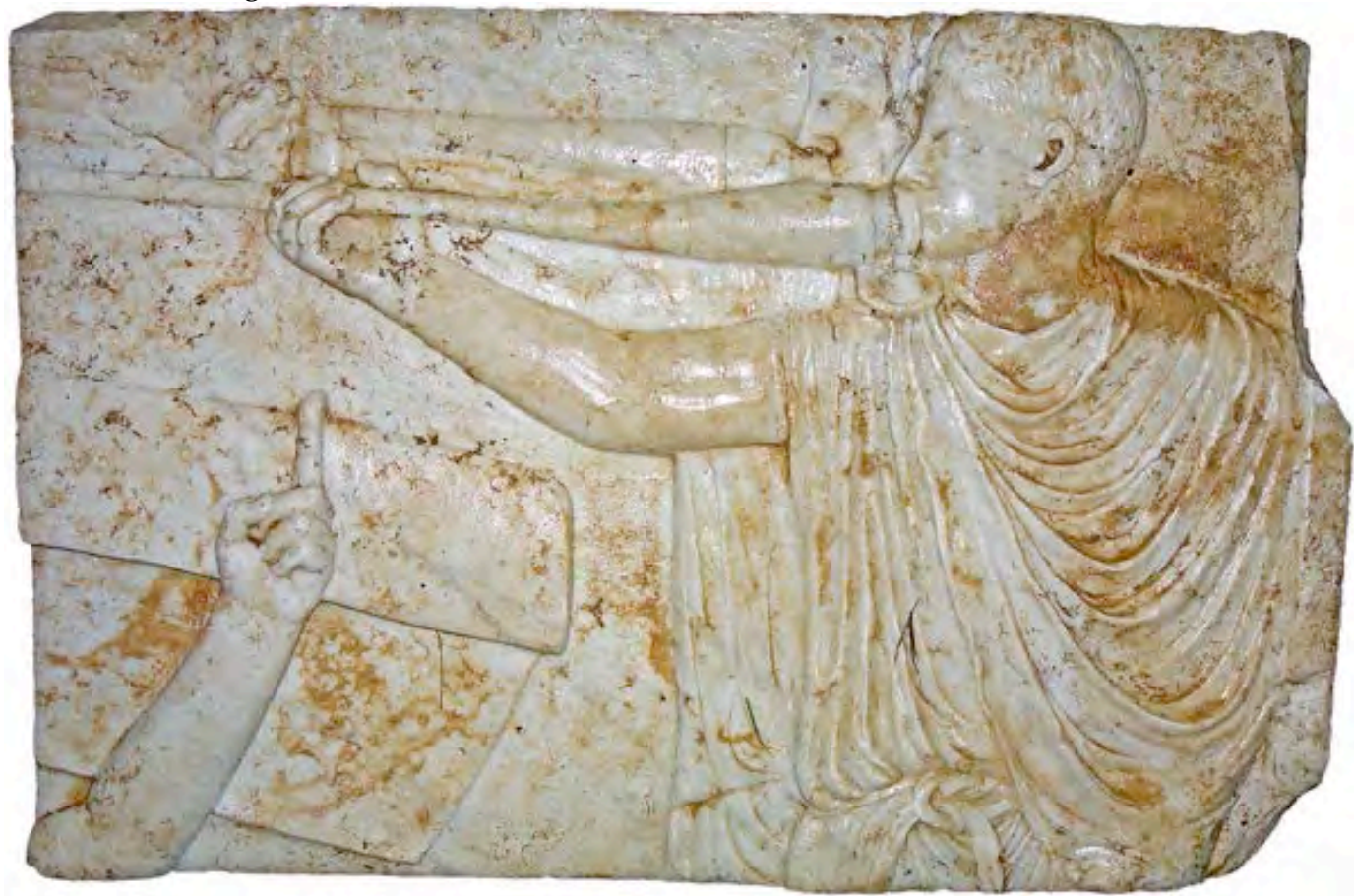


Figure 4 : Carafe en verre découverte en Égypte à Ismant el-Kharab. Un arbitre arrête un combat rétiaire secutor. II $^{\mathrm{e}}$ siècle. (TEYSSIER Eric, Le dossier gladiateur, Paris, Actes sud, 2009, p. 315).
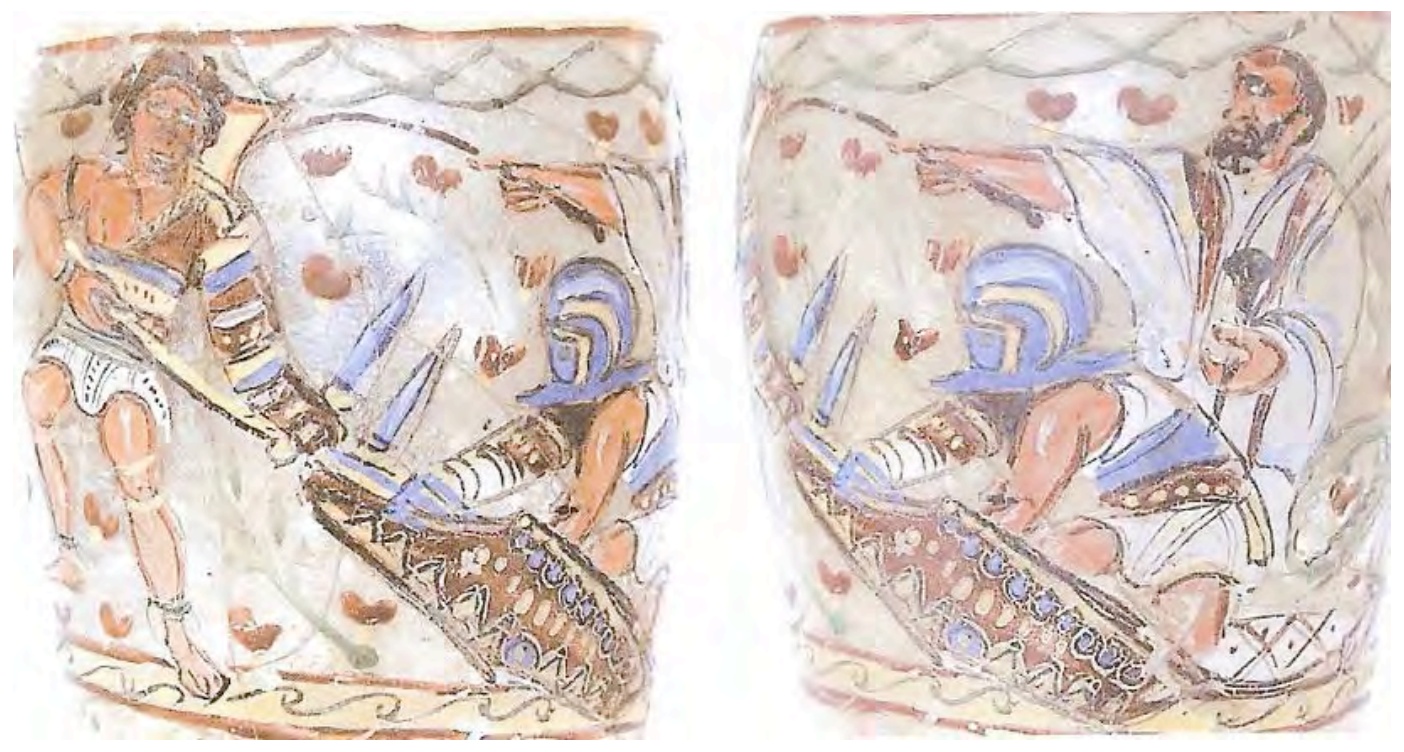

Figure 5 : Bas-relief d'Éphèse. Musée archéologique de Selcuk. Intervention d'un arbitre dans un combat rétiaire secutor. II ${ }^{\mathrm{e}}$ siècle. Photo de l'auteur.

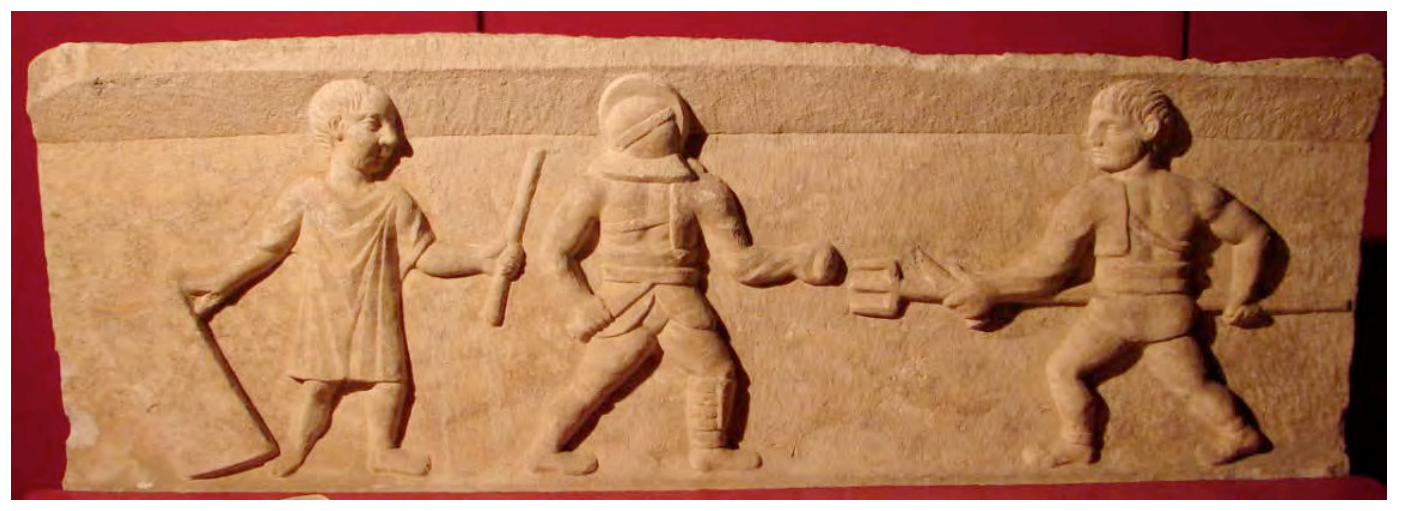


Figure 6: Graffiti découvert à Rome. Intervention d'un arbitre dans un combat rétiaire secutor. II ${ }^{\mathrm{e}}$ siècle. (TEYSSIER Éric, Le dossier gladiateur, Paris, Actes sud, 2009, p. 339).
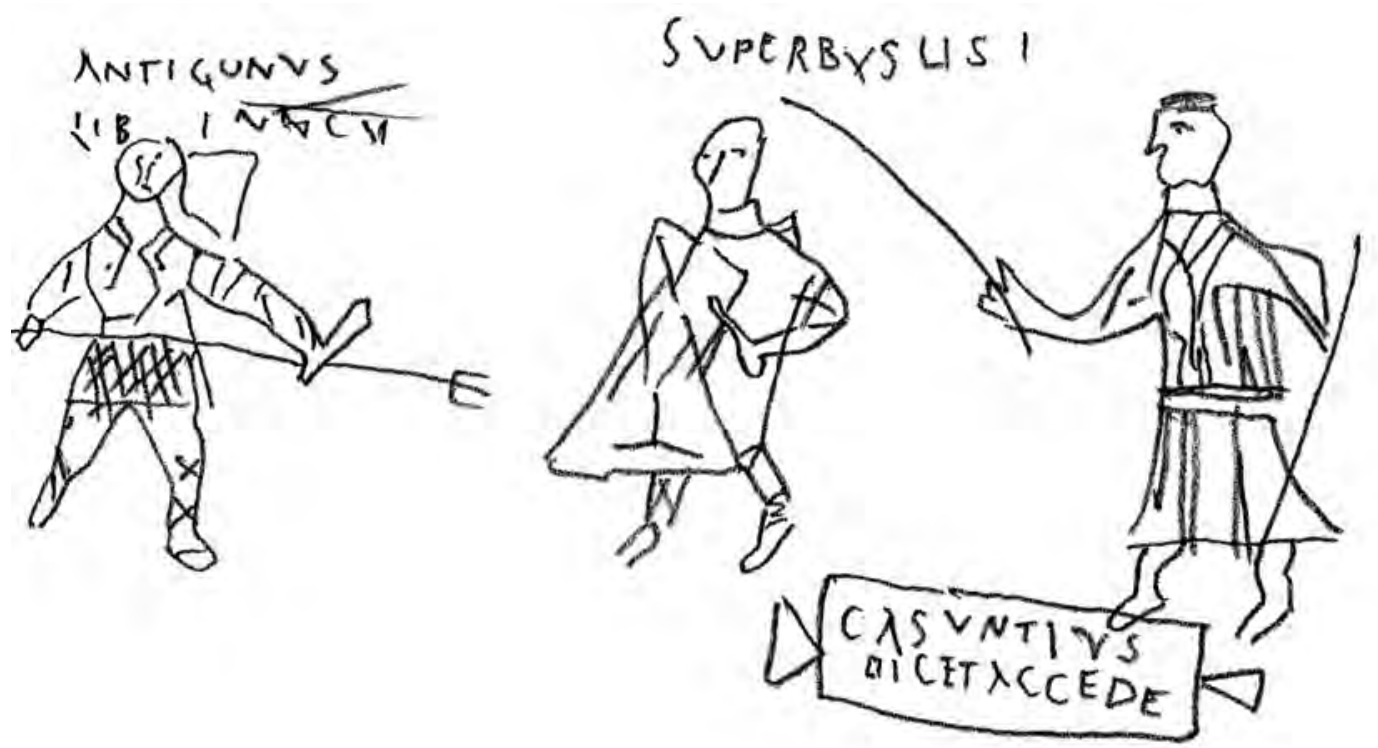

Figure 7 : Villa de Nennig. Intervention d'un arbitre dans un combat rétiaire secutor. Fin du II siècle. Photo de l'auteur.

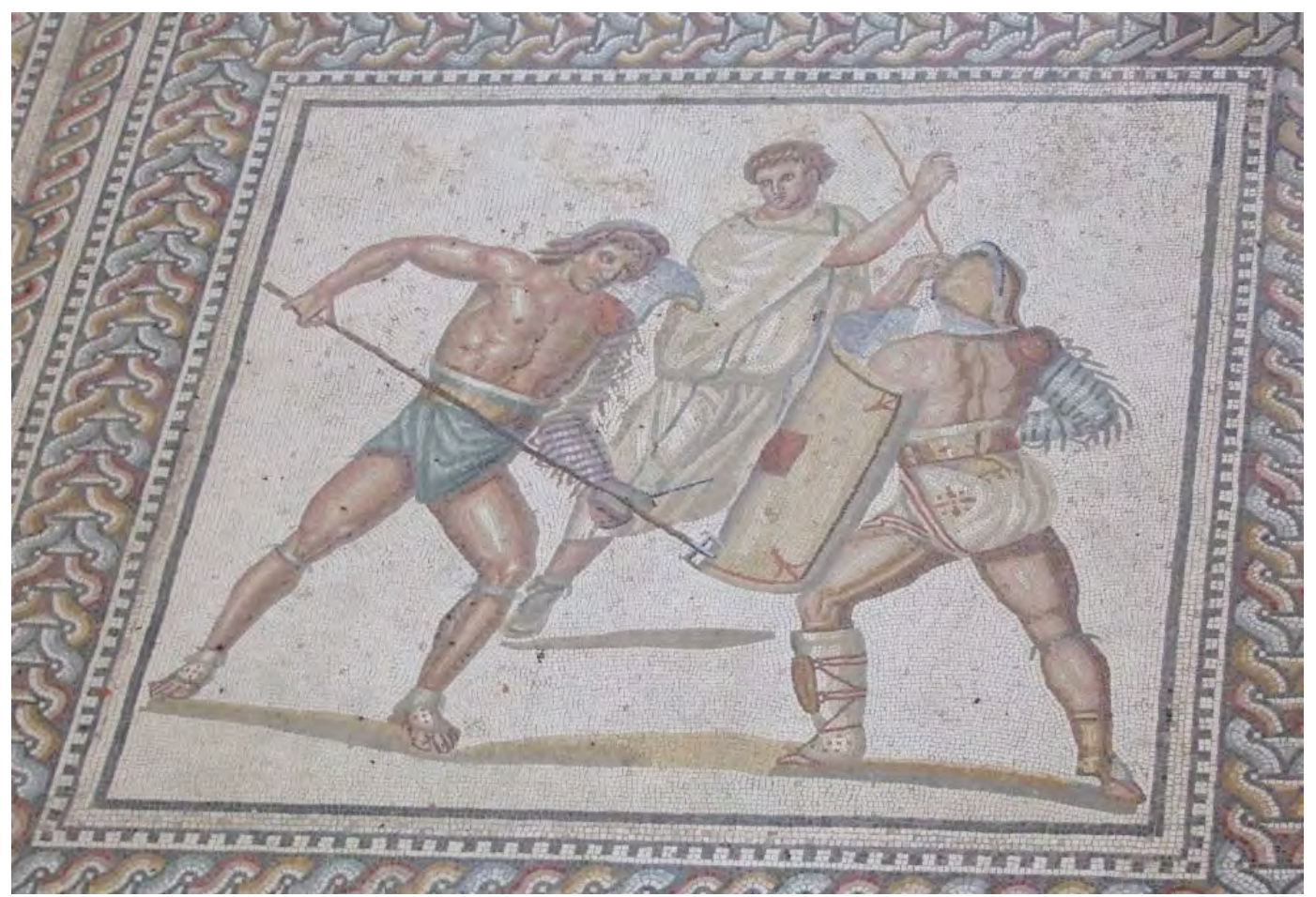


Figure 8: Détail d'une mosaïque conservée au musée archéologique de Madrid. Provenance Rome. Intervention de deux arbitres à la fin d'un combat rétiaire secutor. III' ${ }^{\mathrm{e}}$ siècle. (TEYSSIER Éric, Le dossier gladiateur, Paris, Actes sud, 2009, 286).

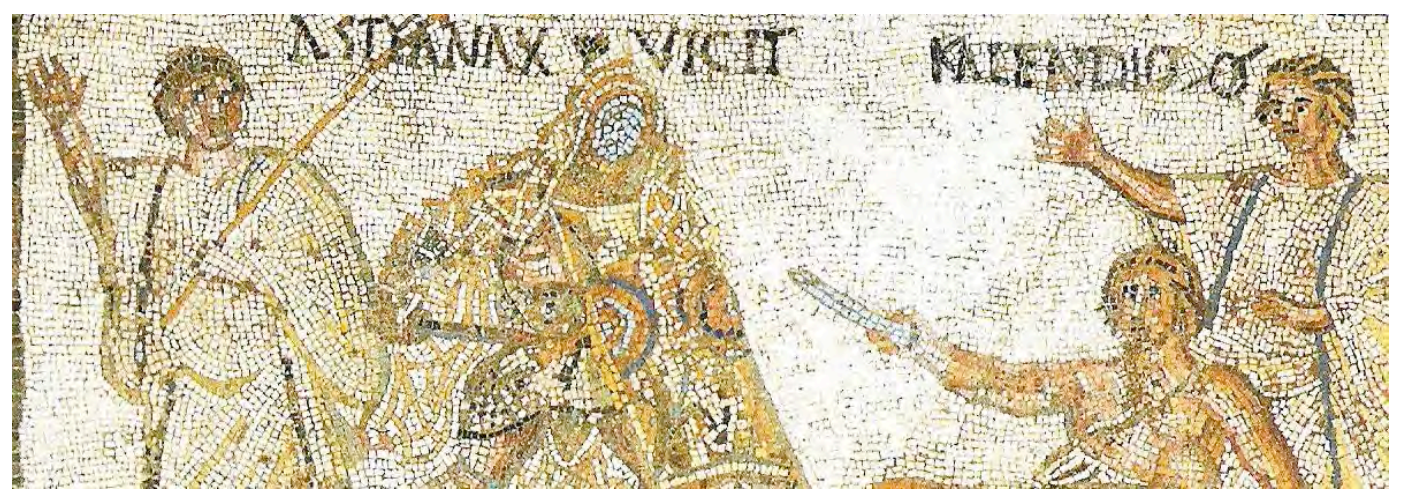

Figure 9: Mosaïque du musée archéologique de Vérone. Intervention d'un arbitre à la suite de la défaite d'un mirmillon. IIIe siècle. Photo de l'auteur.

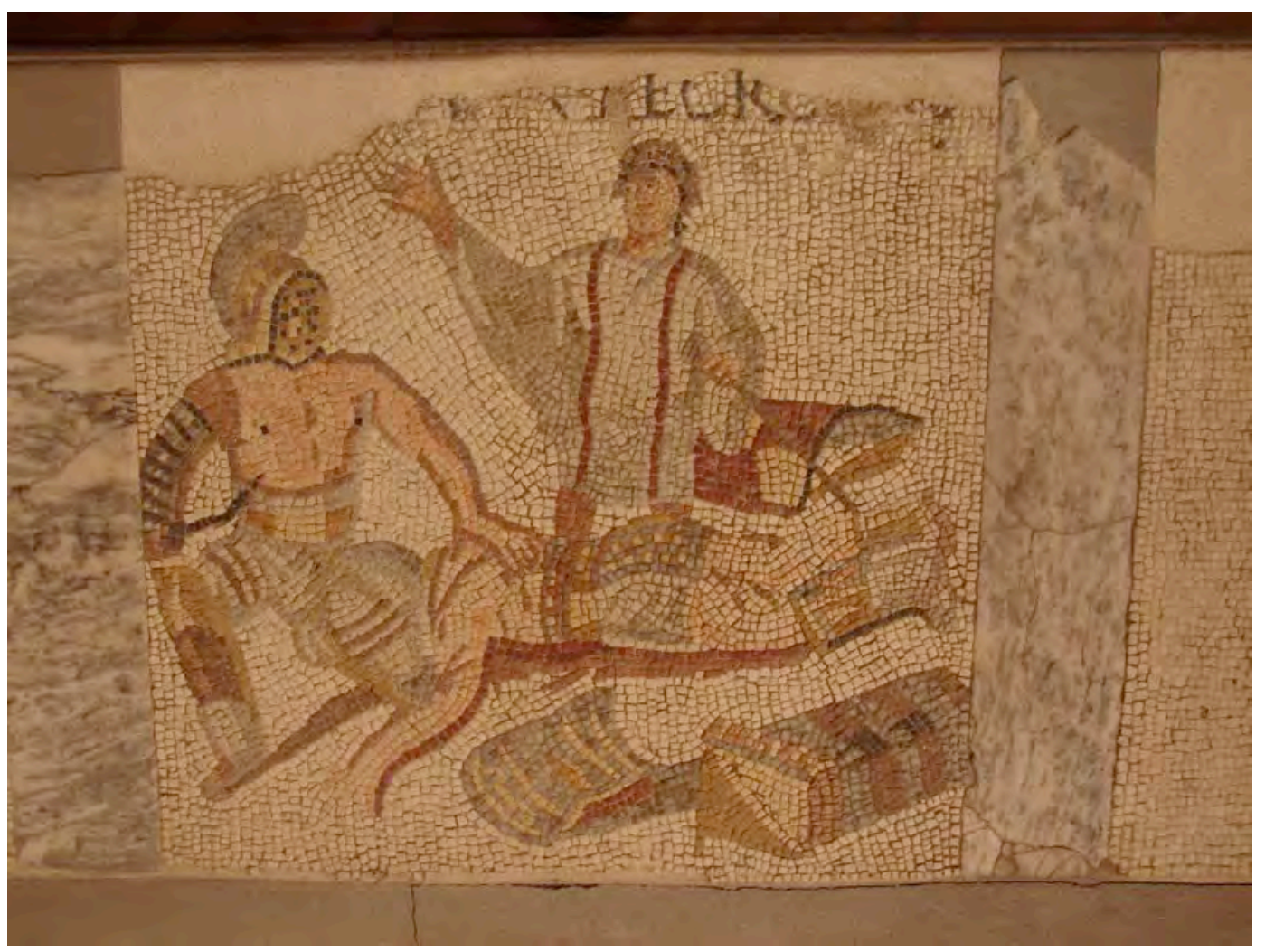


Figure 10: Graffiti de Pompéi. Le mirmillon Priscus contre le thrace. Deux arbitres attendent la décision de l'éditeur représenté à droite. $\mathrm{I}^{\mathrm{er}}$ siècle ap. J.-C. (TEYSSIER Éric, Le dossier gladiateur, Paris, Actes sud, 2009, p. 134).

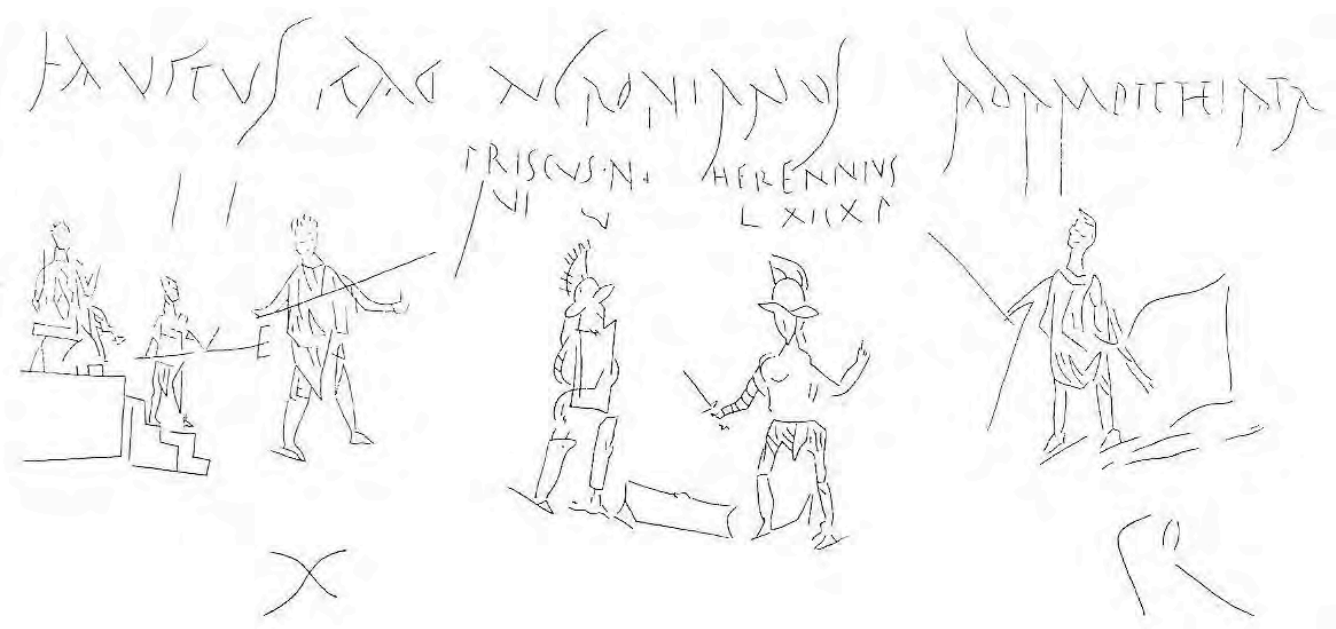




\title{
Jeux de mains et jeux de regards Nouvelle lecture du manuscrit de la Vie de saint Maur
}

\author{
Chrystel LUPANT \\ Docteur en histoire de l'art \\ Extrait de : Jean DuMA (dir.), Le Rituel des cérémonies, Paris,
Édition électronique du CTHS (Actes des congrès des sociétés historiques et scientifiques), 2015. \\ Cet article a été validé par le comité de lecture des Éditions du CTHS dans le cadre de la publication \\ des actes du $139^{\text {e }}$ Congrès national des sociétés historiques et scientifiques tenu à Nîmes en 2014.
}

L'étude s'inscrit dans une recherche d'actualité menée sur la conception iconographique et sur l'expression des domaines sensoriels dans les représentations de type hagiographique, où le voir et le toucher, le regard et le geste, sont les outils d'une communication non-verbale.

Elle porte sur deux scènes cérémonielles d'un manuscrit conservé à la Médiathèque de l'Agglomération de Troyes sous la cote 2273. L'intérêt codicologique et iconographique de ce manuscrit a fait l'objet d'une étude détaillée par Charlotte Denoë $1^{1}$, conservatrice des bibliothèques à la Bibliothèque nationale de France, au département des manuscrits médiévaux. L'angle d'approche proposé ici s'en inspire certes, mais s'en distingue également en analysant plus précisément les aspects cités précédemment.

\section{Un ouvrage de Trésor}

Ce manuscrit est l'un des nombreux libelli produits à partir de l'époque romane et dédié à la vie et aux miracles d'un saint. Bien que le dossier hagiographique le plus important soit consacré à saint Maur de Glanfeuil, le lectionnaire renferme en réalité un ensemble assez hétéroclite de documents hagiographiques sur les trois principaux saints de l'abbaye de production. Le codex sur parchemin est composé de 125 feuillets + III ff de $285 \mathrm{~mm}$ sur $190 \mathrm{~mm}$ (fig. 1). Il s'ouvre, tel qu'il se présente aujourd'hui, par le second livre des Dialogues de Grégoire le Grand relatif à Benoît de Nursie (f. 1-18v, partie originellement indépendante) et un texte anonyme (Pauca de questionibus Albini, f. 18v$20 \mathrm{v})$. La vie et des miracles de saint Maur et son cycle iconographique (f. 21-107v), dont il sera question ci-après, est suivi du récit rédigé vers le milieu du $\mathrm{XI}^{\mathrm{e}}$ siècle de la vie et des miracles de Babolein (f. 108-125v), moine originaire de Luxueil et fondateur de SaintMaur-des-Fossés sur le terrain d'un vieux château des Bagaudes sur les bords de la Marne, donné par l'archidiacre de Paris, Blidégisilde, vers $639-641^{2}$. Tous les textes ont été copiés dans la première moitié du $\mathrm{XII}^{\mathrm{e}}$ siècle. Révélateur des usages liturgiques de l'abbaye pour laquelle il était destiné, l'ensemble forme un témoin capital de l'activité du scriptorium de Saint-Maur-des-Fossés et des talents artistiques de l'atelier monastique. Il est une des gloires de la production manuscrite de Saint-Maur-des-Fossés à l'époque romane ${ }^{3}$, réalisé dans un contexte de production mouvementé marqué par la rénovation

1. C. Denoël, «La Vie de saint Maur. Médiathèque de Troyes, manuscrit 2273 », p. 4-51. Voir aussi M. Baudot, Histoire de l'abbaye des Fossés des origines à l'année 925, 1925; L. Morel-Payen, Les plus beaux manuscrits et les plus belles reliures de la Bibliothèque de Troyes, 1935 ; Vie et miracles de saint Maur (CD-Rom), 2005.

2. M. de Bréquigny, F. J. G. de La Porte du Theil et J.-M. Pardessus, Diplomata, chartae, epistolae, leges, aliaque instrumenta ad res Gallo-Francicas spectantia, 1843.

3. Le sanctoral propre à l'abbaye et la décoration indiquent que le manuscrit a été produit dans cette même abbaye, ce qui est confirmé par un ex-libris des Fossés datant du XIII ${ }^{\mathrm{e}}$ siècle. 
et l'exaltation du culte des saints tutélaires de Saint-Maur-des-Fossés, Pierre, Paul et Maur. L'enjeu du codex était également de rattacher le culte au monastère possesseur de reliques depuis l'époque carolingienne, en justifiant par là même ses prétentions sur Glanfeuil $^{4}$.

Ce contexte explique la qualité de l'ouvrage et l'abondance des textes relatifs à saint Maur. Le dossier hagiographique (f. 21-107v) comprend divers textes ${ }^{5}$, le principal étant la Vita et les Miracula (f. 40-96), dont l'observation paléographique et stylistique autorise une datation des années 1100 . Le texte et l'iconographie retracent la vie et les miracles du fondateur légendaire de Glanfeuil, selon Odon de Glanfeuil ${ }^{6}$, abbé de Glanfeuil avant 863 puis de Saint-Maur-des-Fossés en 869. Il présente l'œuvre comme celle d'un certain Faustus du Mont-Cassin, compagnon de Maur et témoin oculaire de ses gesta. En réalité, le «biographe" réunit sous un seul et même individu deux personnages : Maur, le disciple de Benoît de Nursie évoqué par Grégoire le Grand dans ses Dialogues II, et son homonyme, fondateur légendaire du monastère de Glanfeuil. Ainsi, selon Odon, saint Maur naît vers 512, dans une riche famille patricienne de Rome. Encore enfant, il entre au monastère du Mont-Cassin. Montrant rapidement des signes d'élection et de dons, engagé dans une obéissance sans borne, il devient rapidement le disciple de Benoît de Nursie, fondateur de l'abbaye cassinienne et législateur de l'ordre bénédictin. Quelques années plus tard, l'abbé l'envoie en mission en Gaule afin d'y diffuser la Règle bénédictine et c'est après un long voyage ponctué de miracles que Maur établit une communauté à Glanfeuil, en Anjou, avec l'aide d'un seigneur local. Quelques siècles plus tard, face aux menaces des invasions normandes et après six années de pérégrinations, les moines de Glanfeuil trouvent refuge au monastère de Saint-Pierre-desFossés. Celui-ci prendra le nouveau vocable à l'arrivée des reliques et devient le centre principal d'une dévotion. Largement inspiré des célèbres Dialogues du pape Grégoire le Grand relatant la vie et les miracles de Benoît de Nursie, la Vita sancti Mauri contenue dans ce manuscrit retrace l'histoire de la quête spirituelle de Maur, doué de vertus thaumaturgiques et capable de miracles, même posthumes.

Constituant le corps du manuscrit, ce module est l'œuvre d'un seul copiste et d'un enlumineur anonyme dénommé communément le «Maître de la Vie de saint Maur »", lequel a fourni une iconographie riche (scènes de dédicace, portrait d'auteur, peintures en pleine page, enluminures de dimensions variables, initiales ornées, figurées ou historiées) $)^{8}$ et une ornementation à effet décoratif dans un style harmonieux et homogène. Le cycle narratif comprend 23 peintures et 4 initiales historiées en rapport avec la Vita, exception faite du folio 77 qui se rattache au Miracula. La plupart des images sont accompagnées de tituli rubriqués, offrant un résumé de l'histoire.

Selon les topoi de l'hagiographie médiévale et leurs prolongations par les codifications iconographiques, le cycle valorise le mimétisme du saint au Christ. Accomplissant les

4. Outre les querelles opposant les moines du Mont-Cassin aux monastères bénédictins de France, les abbayes des régions angevines et parisiennes sont depuis l'époque carolingienne confrontées à des différends les opposants entre elles. Le monastère de Glanfeuil est au centre des revendications. Urbain II, dans la région vers 1096, contraint les moines de Saint-Maur-des-Fossés à présenter les preuves de leurs prétentions sur Glanfeuil. Les documents produits sont déclarés apocryphes et l'émancipation de l'abbaye fondée par saint Maur est proclamée par bulle pontificale le 31 mars 1096. Yves de Chartres, probablement présent lors du synode de Tours, prend la défense des moines de Saint-Maur-des-Fossés dans une lettre adressée au successeur d'Urbain II, Pascal II. Il accuse les angevins d'avoir fait disparaître les preuves de sujétion. Finalement, en 1133, Glanfeuil passe sous la dépendance du Mont-Cassin et échappe ainsi à la tutelle de l'évêque d'Angers. M. Lauwers, « La vie du seigneur Bouchard, comte vénérable: conflits d'avouerie, traditions carolingiennes et modèles de sainteté à l'abbaye des Fossés au XI ${ }^{\mathrm{e}}$ siècle », p. 377-378.

5. Le dossier comprend une vie métrique composée par Foulcoie de Beauvais, religieux poète formé à l'école cathédrale de Reims et décédé à Meaux vers 1110 (f. 21-36v), trois récits concernant la translation des reliques de Maur en 868, rapportés par l'abbé Odon de Glanfeuil (f. 38-40), la vita et les miracula à proprement parler (f. f. $40-74 \mathrm{v}$ et $74 \mathrm{v}-96)$, un sermon d'Eudes II de Saint-Maur sur les miracles à la suite de la nouvelle dédicace en 1030 (f. 96-102) et deux récits de miracles survenus en 1100 (f. 102-107v). 6. BHL 5773.

7. Y. Deslandres, « Les manuscrits décorés au XI $\mathrm{e}^{\mathrm{e}}$ siècle à Saint-Germain-des-Près par Ingelard », p. 3-10. 8. Les images sont numérisées et consultables gratuitement à l'adresse suivante : http: / / www.enluminures.culture.fr/ 
mêmes gestes thaumaturgiques, exorcisant et opérant des résurrections, Maur est présenté comme un saint doué de vertus multiples, disciple de Benoît mais surtout du Christ. Le double récit (textuel et imagé) s'inscrit pleinement dans la tradition apostolique d'évangélisation et d'expansion de la foi. Dans le domaine des images et afin que celles-ci soient compréhensibles et signifiantes pour tous ses destinataires, il est nécessaire d'avoir un langage commun, simple, constant et répétitif. Ce langage est constitué d'un ensemble d'éléments et de combinaisons iconographiques disposant d'un vocabulaire et d'une grammaire propres, organisés en un système destiné à la communication; la parole prononcée lors de la liturgie, les gestes et les regards en sont trois formes.

Comment les regards et les gestes de la main sont-ils valorisés dans l'image et par quels moyens permettent-ils d'augmenter l'effet de communication de l'image ? Comment l'un renforce-t-il la signification de l'autre? Cette présentation s'appuie sur deux images cérémonielles, constituées d'un ensemble de formes extérieures et de règles solennelles qui marquent la célébration du culte religieux. L'une inaugure le cycle iconographique, l'autre la termine.

\section{Gestes et regard convergeant vers le corps}

L'oblation de Maur est représentée au folio 45v (fig. 2). Le déroulement de la cérémonie est codifié au chapitre LIX de la Règle bénédictine. Sans utiliser le terme d' "oblation ", le texte décrit la procédure d'offrande des fils de notables ou de pauvres à Dieu, donc au monastère afin qu'ils y mènent une vie religieuse, et expose le rite de la déposition de la pétition rédigée par les parents en insistant sur le caractère irrévocable de la décision ${ }^{9}$ : l'enfant n'aura plus aucun droit de propriété ou de richesse. Le déroulement du rite est similaire à celui de l'entrée dans l'ordre d'un novice mais en diffère puisque ce dernier se donne par principe de sa propre initiative, contrairement à l'oblat, dont l'acte se déroule durant l'offertoire, cette partie de la messe au début de la liturgie eucharistique où une prière est faite sur les offrandes (le pain et le vin). La main de l'enfant est alors enveloppée dans la mappula, la nappe de l'autel, en même temps que la promesse écrite de la main de ses parents. L'autel joue ainsi parfaitement son rôle de table d'offrande, puisque la petitio transite par elle avant d'être archivée. L'acte est réalisé devant témoins attestant de l'offrande définitive, religieuse et juridique d'enfants parfois très jeunes.

L'enluminure se positionne sur toute la largeur de la pleine ligne. La dimension conséquente de l'image sur l'espace de la surface du feuillet indique l'importance accordée à l'épisode montrant la naissance des liens personnels et la filiation spirituelle

9. Le chapitre intitulé «De filiis nobilium aut pauperum qui offeruntur » prescrit le déroulement du rite Si quis forte de nobilibus offerit filium suum Deo in monasterio, si ipse puer minor aetate est, parentes eius faciant petitionem quam supra diximus et cum oblaturee ipsam petitionem et manum pueri involvant in palla altaris, et sic eum offerant. De rebus autem suis, aut in praesenti petitione promittant sub iureiurando quia numquam per se, numquam per suffectam personam nec quolibet modo ei aliquando aliquid dant aut tribuunt occasionem habendi; vel certe si hoc facere noluerint et aliquid offerre volunt in eleemosynam monasterio pro mercede sua, faciant ex rebus quas dare volunt monasterio donationem, reservato sibi, si ita voluerint, usufructu. Atque ita omnia obstruantur ut nulla suspicio remaneat puero per quam deceptus perire possit -- quod absit -- quod experimento didicimus. Similiter autem et pauperiores faciant. Qui vero ex toto nihil habent, simpliciter petitionem faciant et cum oblaturee offerant filium suum coram testibus ». («Il peut arriver qu'un notable offre son fils à Dieu en le donnant au monastère. Quand c'est un enfant très jeune, ses parents écrivent la promesse à sa place. [...] Ils enveloppent tout ensemble, dans la nappe de l'autel ! La promesse écrite et la main de l'enfant avec l'offrande du pain et du vin. C'est ainsi qu'ils offrent leur enfant à Dieu. Pour les biens que les parents possèdent, dans la promesse écrite, ils font le serment de ne jamais donner quelque chose à l'enfant. Ils promettent aussi de ne jamais lui fournir l'occasion de posséder quelque chose plus tard : que cela vienne d'eux-mêmes, ou d'une personne nommée par eux, ou de n'importe quelle autre façon. Ou bien, si les parents ne veulent pas faire cela, et s'ils veulent offrir une aumône au monastère pour obtenir de Dieu une récompense, ils donnent, par écrit, au monastère les biens qu'ils veulent offrir. Mais pendant leur vie, ils peuvent garder pour eux l'usage de ces biens, s'ils le veulent. Ainsi, on ferme tous les chemins, et l'enfant n'a plus à attendre aucun bien pour lui. En effet, cette attente peut seulement le tromper et le conduire à la mort. Voila ce que l'expérience nous a appris. Espérons que cela n'arrivera pas! Ceux qui sont plus pauvres feront la même chose. Et ceux qui n'ont rien du tout écrivent seulement la promesse et ils offrent l'enfant avec l'offrande du pain et du vin, devant des témoins »). 
s'instaurant entre Benoît et Maur. Le texte explique comment l'enfant, empreint de sagesse malgré son jeune âge, est conduit par sa famille biologique vers l'abbé. L'image montre comment se déroule son initiation monastique, au travers d'une cérémonie liturgique considérablement codifiée se déroulant dans une église évoquée par un bâtiment de belle taille et de belle facture, disposant d'une coupole et de deux chapelles avec abside en cul-de-four. Les perspectives non réalistes permettent au spectateur de l'image d'observer simultanément l'action se déroulant dans le chœur liturgique du monument et les personnages regroupés dans la nef. Loin d'une réalité architecturale anachronique pour cette période, la représentation matérialise les lieux dont l'autel marque l'endroit le plus sacré : c'est le lieu de l'offrande, où est posé le calice, réceptacle du sang du Christ présent réellement à cet instant selon la croyance chrétienne ${ }^{10}$. Le cloisonnement des différents espaces augmente la lisibilité de l'image et matérialise la dialectique entre la sphère sacrée et la sphère profane. D'une part, les moines sont représentés autour de l'autel, munis de divers objets liturgiques (comme le flabellum et le livre) dont la mise en scène rappelle bien que le rite a lieu durant l'offertoire. D'autre part, les membres de la famille de sang et les témoins profanes sont regroupés à droite de l'image et séparés de la communauté religieuse par un pilier, véritable axe de distinction entre les deux mondes. Les doubles arcs outrepassés insistent sur la bipolarité, tandis que le jeune Maur se trouve à la frontière entre ces deux mondes ${ }^{11}$. L'image montre ainsi trois rites d'une catégorisation établie par Arnold Van Gennep : le rite de séparation, le rite de marge et celui d'agrégation, illustrés par plusieurs actions et gestes. Ceux-ci opèrent une modification sur le milieu, sur celui qui l'exécute ou traduit une réaction, consciente ou non, voulue ou non, exprimant ce qui est ressenti ou pensé. Dans l'enluminure, le père biologique présente Maur en le tenant par l'épaule, la main posée sur son coude gauche. Le geste montre à la fois la finalité de l'acte et la nature de l'opération. Le geste des mains est efficace. Le géniteur et son enfant sont tous deux agenouillés face à Benoît, indiquant ainsi leur soumission au supérieur mais aussi au Christ symboliquement représenté par Benoît lui-même, prêtre officiant. L'autel rend le Christ aussi en quelque sorte physiquement présent, selon un principe déjà énoncé par Amalaire de Metz, archevêque de Trèves et grande figure de la Renaissance carolingienne († 850) : lieu du sacrifice, l'autel est le symbole de la table de la Cène, l'image de la Crucifixion et la représentation symbolique du Tombeau. C'est un « autel-corps du Christ».

Parmi les laïcs représentés, alors que les hommes restent impassibles, les deux seules femmes de l'enluminure sont caractérisées par la douleur marquée sur leurs visages. Leurs sourcils sont fortement arqués; l'une d'elles se tient le coude droit, tout en apposant la main refermée sur la joue. Ses yeux sont grands ouverts et ses pieds sont tournés dans le sens opposé, signifiant l'abandon définitif de l'enfant au monastère. Les codifications iconographiques utilisent la triade de la main sur le coude, l'autre sur la joue, les yeux ouverts, pour exprimer la douleur et la tristesse comme un sentiment durable et non pas une réaction émotionnelle éphémère. Le "geste » des larmes $\mathrm{s}^{\prime}$ exprime ici de manière silencieuse ${ }^{12}$. L'émotion de la séparation, qui s'apparente à un deuil, est contrôlée par la maîtrise de la peine et la mesure des gestes. La solennité du rite impose effectivement une certaine contenance, mais les sentiments familiaux ne sont pas pour autant niés. La présence de cette femme «pleureuse » participe ainsi à l'extériorisation des sentiments de la famille et double l'affect exprimé par le jeune Maur, dont la main droite est posée sur la joue tandis que la main gauche soutient le coude droit, dans un geste proche de celui de la résignation, évoquant en tout cas l'obéissance. L'affectivité est propre à l'image: aucun sentiment n'est décrit dans le texte. L'enlumineur a donc enrichi la scène par une représentation plus détaillée des effets de la séparation définitive.

10. Ce principe connu sous le terme de transsubstantiation, apparait chez Hildebert de Tours à la fin du XI siècle. La doctrine est fixée par Thomas d'Aquin. Il sera définit comme dogme au IVe Concile du Latran (1215) et confirmé par le Concile de Trente (1545-1563). J. Vijgen, The status of eucharistic accidents "sine subiecto »: an historical survey up to Thomas Aquinas and selected reactions.

11. A. Van Gennep, Les Rites de passage, étude systématique des rites, p. 13.

12. P. Nagy, Le Don des larmes au Moyen Âge. 
La transmission entre Eutichius, le père biologique, et Benoît, le nouveau père spirituel est signalée par les gestes et les positions. L'un comme l'autre touchent Maur. Il y a passation par le geste. L'un présente et donne, l'autre accepte et bénit dans un geste rituel. Le jeu des mains cautionne un lien particulièrement fort, un contact physique exprimant l'affectivité mais qui prend aussi la forme d'une promesse bilatérale. La proxémie est réduite, ce qui contribue à affirmer la qualité de la rencontre, confirmée par l'expressivité des yeux, grands ouverts. Ceux-ci donnent une intensité particulière à l'image. Le centre de l'image, où Maur se situe, est le point convergeant de tous les regards et de tous les gestes (fig. 3). Ainsi, si la dialectique sacré/profane est matérialisée par l'architecture et la césure entre les groupes, les regards constituent également un moyen d'augmenter la lisibilité de l'image. Ils se renvoient l'un à l'autre, de part et d'autre d'un axe constitué par la colonne et l'enfant agenouillé. L'enfant est tourné vers la communauté des moines, montrant ainsi son désengagement envers son ancienne vie. Son positionnement à la frontière des deux mondes est matérialisé par la distinction architecturale entre la nef et le chœur liturgique de l'église ; il est à la lisière de deux univers et n'appartient déjà plus à la sphère profane à qui il tourne le dos, mais n'est pas encore intégré à la communauté religieuse puisqu'il n'en porte ni la tonsure, ni encore le vêtement qu'un moine s'apprête à lui enfiler. L'entre-deux mondes, dans lequel se positionne l'oblat, joue le rôle de révélateur des différences entre deux sphères qui se rencontrent lors d'un rite. Ainsi, cette frontière unit-elle tout autant qu'elle sépare les laïcs des moines. Ceux-ci se tiennent dans le sanctuaire, où des lampes rappellent l'importance de la vue, celle qui permet de voir l'Invisible, mais surtout engagent Sa présence. Elles indiquent la bonne lumière et participent à l'activation du regard.

\section{Le glissement du regard vers un autre point focal}

Le cycle enluminé se termine par une autre célébration du culte, celui de la mort et des funérailles de saint Maur. L'image constitue, avec celle vue précédemment, un des points culminants dans le récit de la vie de Maur. Au f. 73v (fig. 4), la mort de Maur est l'occasion pour la communauté monastique symboliquement composée de douze moines affectés de se retrouver une dernière fois autour de leur abbé mourant, de lui administrer les derniers sacrements puis de célébrer ses funérailles. Le rituel s'inscrit dans un cadre architectural imposant et se déroule en deux temps. Sur la gauche, le moribond reçoit les derniers sacrements, un religieux tendant l'hostie consacrée au mourant, tout en tenant le calice bien en vue. Deux moines se tiennent derrière Maur, un posant une main sur l'épaule et l'autre sur la tête du saint. L'image a une construction évoquant la mort de la Vierge, entourée des apôtres. De l'autre côté, prenant la majorité de l'espace figuratif, les funérailles sont célébrées au pied de l'autel principal, recouvert d'un parement en tissu. Le calice y est posé, surmonté d'une lampe flanquée de deux croix. Dans l'axe se tient un religieux tonsuré, le livre ouvert tenu haut et l'index pointant la page ouverte en direction du nouvel abbé. Il y lit la prière de l'absoute, non intres in judicium bien lisible, tandis qu'autour de lui se tiennent d'autres moines participant à la cérémonie: un moine thuriféraire, d'autres tenant le poêle funéraire au-dessus du corps du défunt, entièrement revêtu de son habit monastique et la tête encapuchonnée. Deux moines le maintiennent et s'apprêtent à le poser dans le caveau dans lequel eux aussi ont pris place. Tous les personnages ont le visage marqué par la douleur, les sourcils froncés, les larmes coulant sur les joues, le rictus négatif, rappelant les gestes de tristesse de la femme présente dans l'oblation, au folio $45 \mathrm{v}$.

À nouveau, les jeux des mains des différents protagonistes et leurs regards attristés, focalisés sur un point central, conduisent le regard du spectateur vers ce qu'il faut observer (fig. 5). Contrairement à la représentation de l'initiation monastique dont elle fait le pendant, le pivot de l'image du folio 73v n'est plus saint Maur mais son successeur à l'abbatiat, lequel est déjà muni de la crosse. Maur ne concentre plus tous les regards, mais bien le nouvel abbé officiant. Comme lors de l'oblation où le vêtement allait englober le jeune enfant, le corps mortel de Maur disparaît sous les tissus de la coule, du 
capuchon et du poêle funéraire. Son corps physique n'est plus l'objet des regards. La personnalité du fondateur de Glanfeuil laisse place à sa communauté regroupée une dernière fois autour de sa dépouille ${ }^{13}$, concélébrant ses funérailles dirigées par le nouvel abbé. La transmission est assurée, la succession aussi.

Les gestes et les attitudes sont autant de moyens d'expressions des corps, des sens et des émotions, exacerbés lors des rites de passage. Qu'ils soient ceux de l'intégration à la communauté ou ceux de la rupture avec celle-ci, l'image du corps révèle les relations et donne à voir les sentiments. Les gestes des mains segmentent l'image et concentrent l'attention sur l'évènement majeur de la scène.

Dans la première image, l'intégration de l'oblat dans la sphère religieuse se fait par un rite d'agrégation, aux gestes bien codifiés. Cet instant est montré par la main de Benoît, placée presque sur la tête de Maur et par le don du vêtement par un moine ; imposition des mains, bénédiction et vêture constituant les véritables signes sensibles de l'entrée dans la communauté religieuse. Les mains positionnées de manière centrifuge vers le personnage central polarisent l'œil du spectateur/lecteur du manuscrit vers le point principal de la représentation: l'entrée en religion d'un homme promis à un destin remarquable, définit saint par et pour la société chrétienne médiévale. La scène de funérailles, bien que de contenu différent et faisant une sorte de pendant à l'image de l'oblation, reprend cette codification qui permet à nouveau au spectateur/lecteur du manuscrit de centrer son propre regard sur le point focal : l'autel, le calice, la lampe et particulièrement le nouvel abbé célébrant la liturgie funéraire.

Outre les nombreux détails qui confèrent un caractère pittoresque aux enluminures et audelà de la répétition formelle de modèles iconographiques ou de codifications typologiques, l'iconographie utilise les regards et les gestes, tous deux fonctionnant en interrelation. Leur étude révèle l'importance qui doit être accordée à la conception de l'image. Parce qu'ils sont uniques ou au contraire universels, les jeux de mains et les jeux de regards deviennent des outils de lecture efficients. Ils sont enjeu de la communication. Exactement comme dans le langage parlé où chaque parole ou intonation doit être prise en compte, dans l'image et son contexte figuratif, le moindre geste ou regard doit aussi être pris en considération.

\footnotetext{
Résumé

À partir de l'étude des jeux de mains et des jeux de regards, signaux de la communication non-verbale, est proposée une nouvelle lecture de l'image hagiographique du manuscrit consacré à la vie et aux miracles de saint Maur, produit au scriptorium de l'abbaye de SaintMaur-des-Fossés vers les années 1100 et aujourd'hui conservé à la Médiathèque de Troyes. L'attention est portée sur le concept de communication activant un des cinq sens, la vue, et la gestuelle, langage corporel loin d'être silencieux. Par une approche exploratoire fondée sur la conception visuelle des enluminures et la convocation des sources écrites, l'étude se propose d'observer les correspondances ou divergences dans l'image mettant le corps en scène, et donc de la sensibilité, par les jeux de mains et le regard posé, ou évité. Expression du corps, ils deviennent aussi, par leur truchement dans l'image hagiographique, enjeux de la communication.
} 


\section{Bibliographie}

BAUDOT Marcel, Histoire de l'abbaye des Fossés des origines à l'année 925, Paris, École Nationale des Chartes. Positions des thèses soutenues par la promotion de 1925, 1925.

De Bréquigny M., De La Porte du Theil François Jean Gabriel et PARdessus J.-M., Diplomata, chartae, epistolae, leges, aliaque instrumenta ad res Gallo-Francicas spectantia, Paris, Ex Tyopgrapheo Regio, 1843.

DESLANDRES Yvonne, "Les manuscrits décorés au XI $\mathrm{I}^{\mathrm{e}}$ siècle à Saint-Germain-des-Près par Ingelard », Scriptorium, IX, 1955, p. 3-10.

DenOËL Charlotte, «La Vie de saint Maur. Médiathèque de Troyes, manuscrit 2273 », Art de l'enluminure/12, 2005, p. 4-51.

LAUWERS Michel, « La vie du seigneur Bouchard, comte vénérable : conflits d'avouerie, traditions carolingiennes et modèles de sainteté à l'abbaye des Fossés au XI ${ }^{\mathrm{e}}$ siècle ", Guerriers et moines : conversion et sainteté aristocratique dans l'occident médiéval, IXe - XII siècle, Antibes, 2002, p. 377-378.

MOREL-PAYEN Lucien, Les plus beaux manuscrits et les plus belles reliures de la Bibliothèque de Troyes, accompagné de 52 planches en héliogravure, Troyes, Paton, 1935.

NAgy Piroska, Le Don des larmes au Moyen Âge, Paris, Albin Michel, 2000.

Donadieu-RIgaut Dominique, Penser en images les ordres religieux, XII - XV siècles, Paris, Éditions Arguments, 2005.

VAN GENNEP Arnold, Les Rites de passage, étude systématique des rites de la porte et du seuil, de l'hospitalité, de l'adoption, de la grossesse et de l'accouchement, de la naissance, de l'enfance, Paris, Picard, [1909] 2011, p. 13.

Vie et miracles de saint Maur, Paris, RMN, 2005 (CD-ROM).

VIJGEN Jörgen, The status of eucharistic accidents « sine subiecto »: an historical survey up to Thomas Aquinas and selected reactions, Berlin, Akademie Verlag, 2013 (Quellen und Forschungen zur Geschichte des Dominikanerordens, 20). 


\section{Illustrations}

Figure 1 : Tableau, description codicologique (C) Chrystel Lupant

\begin{tabular}{|c|c|}
\hline Cote & Troyes, Médiathèque ms. 2273 \\
\hline Langue & Latin \\
\hline Support & Parchemin \\
\hline Origine & Saint-Maur-des-Fossés \\
\hline Provenance & Saint-Maur-des-Fossés \\
\hline Date & Vers 1100 \\
\hline $\begin{array}{l}\text { Importance } \\
\text { matérielle }\end{array}$ & 125 + III ff. \\
\hline Dimension & $\begin{array}{l}285 \times 190 \mathrm{~mm}, 200 / 205 \times 130 / 135 \mathrm{~mm} \text { (justification, dossier } \\
\text { hagiographique Maur) }\end{array}$ \\
\hline Reliure & $\begin{array}{l}\text { Reliure du XV } \mathrm{XV}^{\mathrm{e}}-\mathrm{XVI}^{\mathrm{e}} \text { siècle, pleine peau blanchâtre sur ais de bois. } \\
\text { Traces de boulons et de fermoirs. Restaurée en } 1955 \text { (B. n. F.). }\end{array}$ \\
\hline Histoire & $\begin{array}{l}\text { Collection Pierre II Pithou (1539-1596), acquisition auprès de } \\
\text { l'abbaye ou d'un libraire. }\end{array}$ \\
\hline $\begin{array}{l}\text { Inscriptions } \\
\text { dans le manuscrit }\end{array}$ & $\begin{array}{l}. m \text {. (fin XII }{ }^{\mathrm{e}} \text { siècle) par le bibliothécaire de Saint-Maur ? } \\
\text { Ex-libris des Fossés (XIII }{ }^{\mathrm{e}} \text { siècle) } \\
\text { Note } \text { M. ongison Parisien. } 1418\left(\mathrm{XVI}^{\mathrm{e}} \text { ou XVII }{ }^{\mathrm{e}} \text { siècle) }\right.\end{array}$ \\
\hline Style & $\begin{array}{l}\text { Tradition du dessin, palette diversifiée, prédilection pour éléments } \\
\text { ornementaux et végétaux (initiales ; évocation du style normand) }\end{array}$ \\
\hline Contenu & $\begin{array}{l}\text { f.1-18v, Grégoire le Grand, Vita et miracula venerabilis Benedicti } \\
\text { abbatis } \\
\text { f.18v-20v, Pauca de questionibus Albini } \\
\text { f.21-36v, Mauri levita vita beati (BHL 5778) } \\
\text { f.36v-37v, Versus ad laudem Guidonis Oacrii } \\
\text { f.38-40, Odon de Glanfeuil, Epistola donni Odonis abbatis ad } \\
\text { Adalmodum Cenomannice sedis archidiaconum super inventione beati } \\
\text { levite Mauri (BHL 5772) } \\
\text { f.40-74v, Odon de Glanfeuil, Epistola Fausti monachi editoris vite beati } \\
\text { levite et abbatis Mauri (BHL 5773) } \\
\text { f.74v-96, Odon de Glanfeuil, Libellus seriem miraculorum presentis } \\
\text { temporis... ab Odone (BHL 5775) } \\
\text { f.96-102, Eudes de Saint-Maur, Item sermo domni Odonis abbatis de } \\
\text { eadem tranlatione legendus in dedicatione Fossatensis ecclesiae (BHL } \\
5779) \\
\text { f.102-104v, Altera miracula de beato Mauro abbate et levita (BHL 5780) } \\
\text { f.104v-107v, Item aliud miraculum de eodem sancto (BHL 5781) } \\
\text { f.108-120v, Vita sancti Baboleni confessoris atque abbatis (BHL 886) } \\
\text { f.120v-125v, Miracula que per eum Dominus operari dignatus est (BHL } \\
887 \text { ) } \\
\text { f.126-128, anciennes gardes, fragment manuscrit juridique glosé } \\
\text { (première moitié du XIII siècle) }\end{array}$ \\
\hline
\end{tabular}


Figure 2 : Troyes, Bibliothèque de l'Agglomération, ms. 2273, f. 45v. L'oblation de Maur. (c) IRHT et Troyes, Bibliothèque de l'Agglomération. Source : http://www.enluminures.culture.fr/

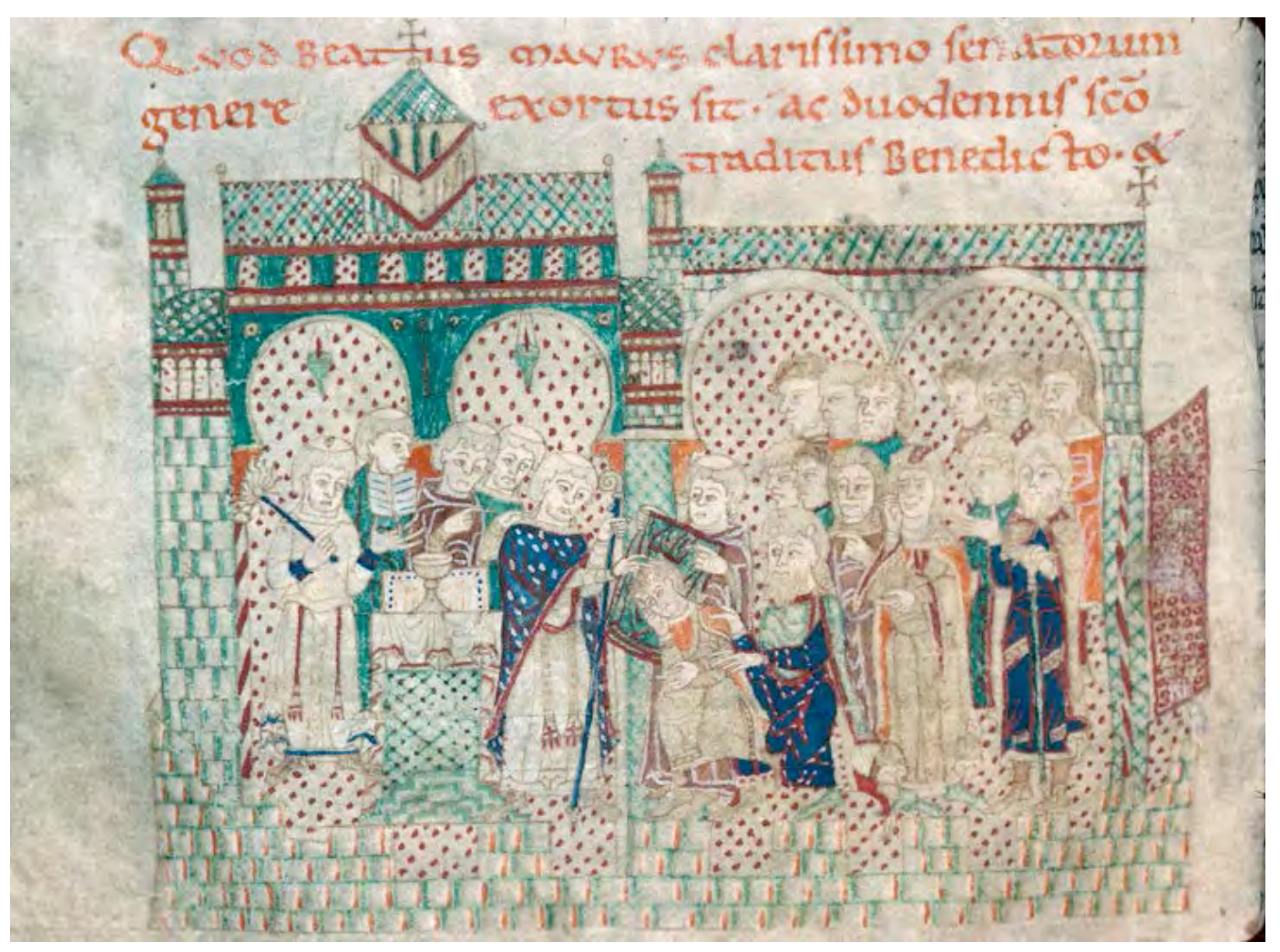


Figure 3 : Troyes, Bibliothèque de l'Agglomération, ms. 2273, f. 45v. Schématisations de la scène de l'oblation de Maur. (C) IRHT et Troyes, Bibliothèque de l'Agglomération.

Source : http:/ / www.enluminures.culture.fr /

Étude de la conception de l'image Chrystel Lupant

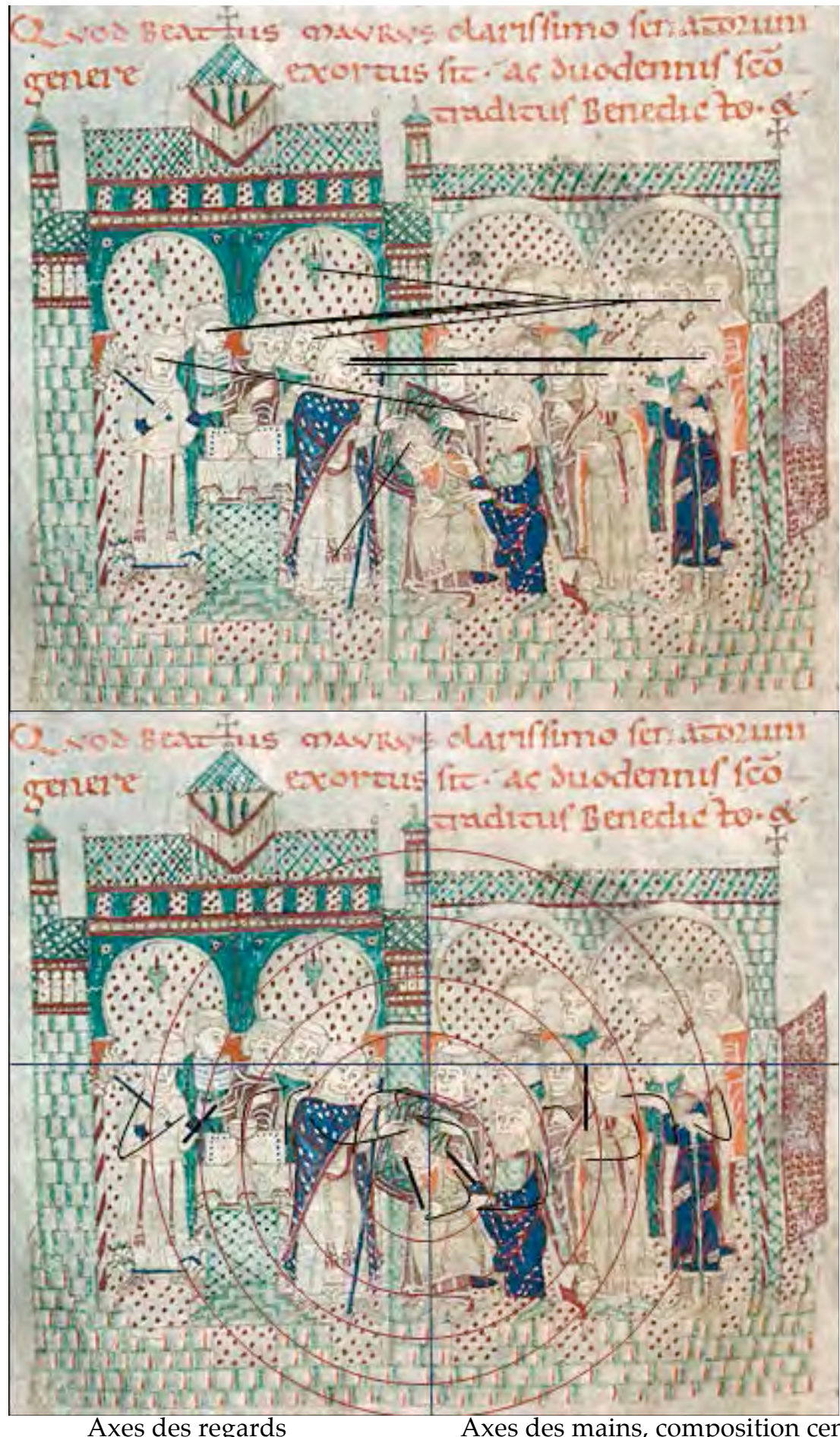

Axes des regards

Axes des mains, composition centrifuge 
Figure 4: Troyes, Bibliothèque de l'Agglomération, ms. 2273, f. 73v. La dernière communion et les funérailles de Maur. (c) IRHT et Troyes, Bibliothèque de l'Agglomération.

Source : http:/ / www.enluminures.culture.fr/

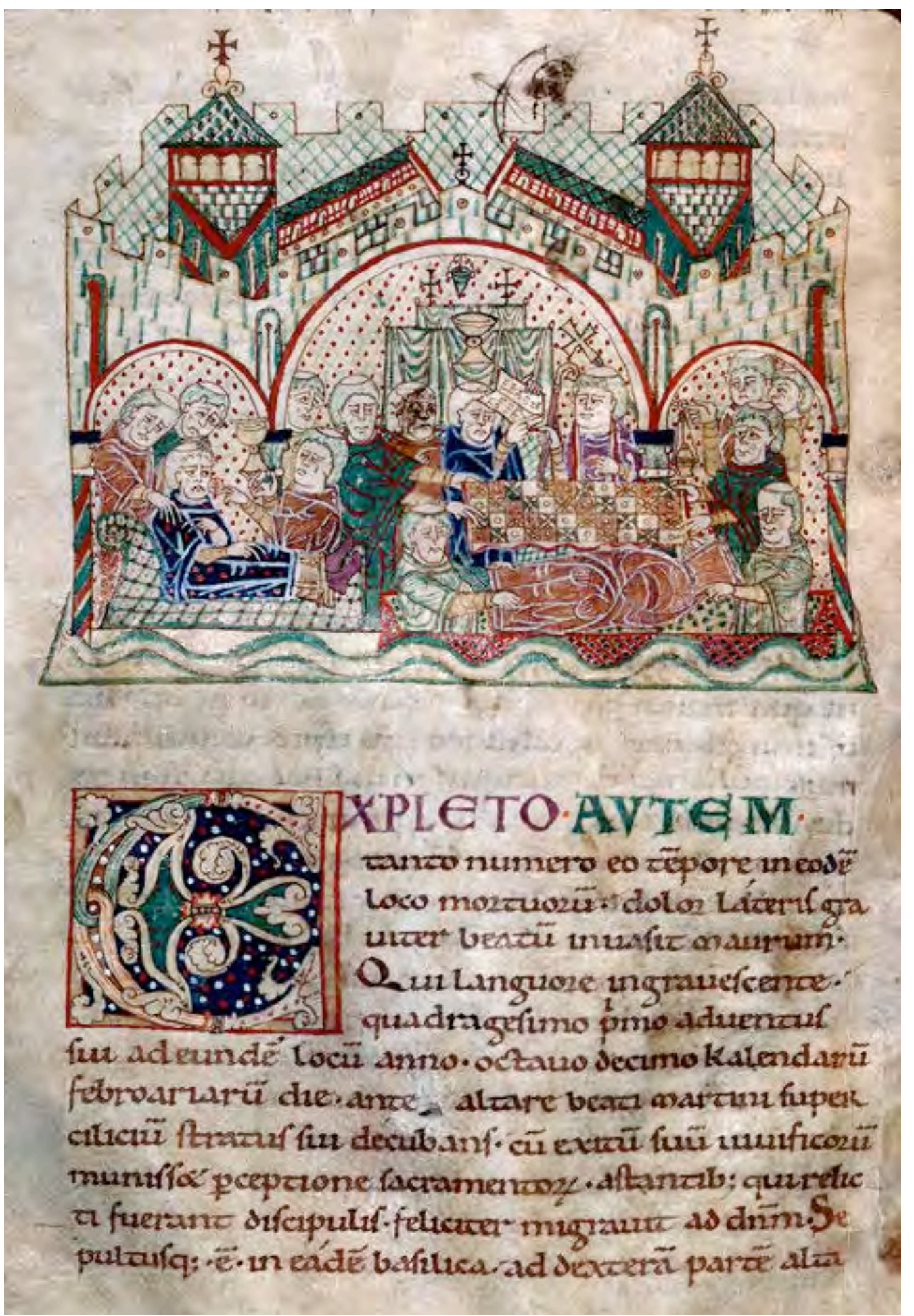


Figure 5 : Troyes, Bibliothèque de l'Agglomération, ms. 2273, f. 73v. Schématisation de la dernière communion et les funérailles de Maur. (C) IRHT et Troyes, Bibliothèque de l'Agglomération. Source : http:/ / www.enluminures.culture.fr/

Étude de la conception de l'image Chrystel Lupant

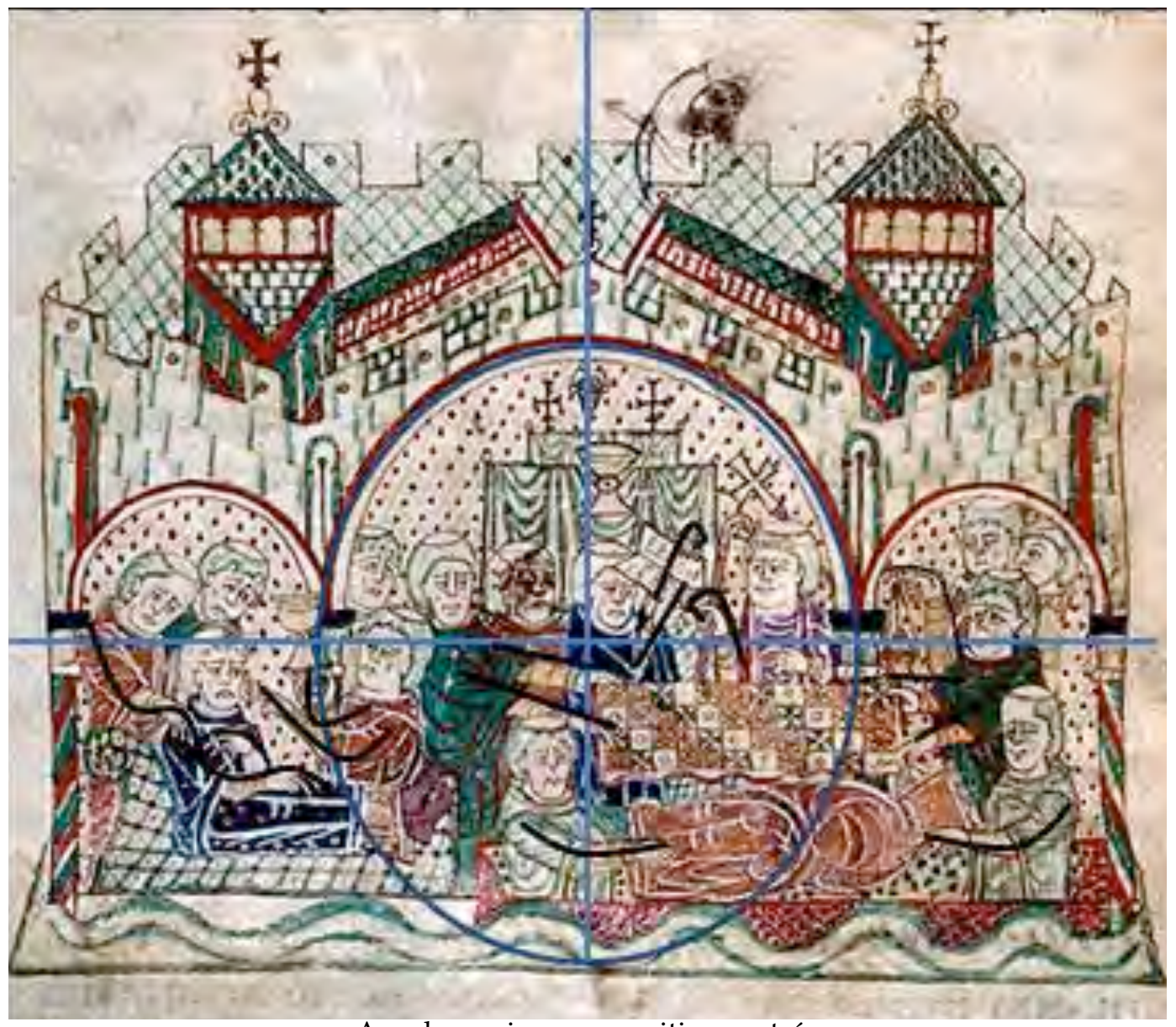

Axe des mains, composition centrée 


\title{
Pasteur caché, pasteur devoilé Le rituel des assemblées du Désert en Béarn
}

\author{
Philippe CHAREYRE \\ Professeur, \\ Université de Pau et des Pays de l'Adour
}

Extrait de : Jean DuMA (dir.), Le Rituel des cérémonies, Paris,
Édition électronique du CTHS (Actes des congrès des sociétés historiques et scientifiques), 2015.

Cet article a été validé par le comité de lecture des Éditions du CTHS dans le cadre de la publication des actes du $139^{\mathrm{e}}$ Congrès national des sociétés historiques et scientifiques tenu à Nîmes en 2014.

Le ministère pastoral consiste essentiellement en la prédication, ce qui très souvent, a relégué au second plan l'autre aspect de la communication entre le ministre et les fidèles qui passe par une mise en scène particulière et des gestes. Le rituel de la cène récemment étudié ${ }^{1}$ n'est que l'un des éléments de l'ensemble de ces gestes, le plus souvent observés au travers de l'organisation de l'espace cultuel, mais ceux-ci dépassent toutefois le simple cadre de la liturgie ${ }^{2}$. Ce fait est plus évident au temps du Désert alors que le pasteur vit clandestinement et que le culte est célébré en plein air dans des endroits écartés. Les temps de prédication durant lesquels il s'expose dans tous les sens du terme, sont des moments de communication intense où le sermon n'est qu'une composante du message délivré aux fidèles rassemblés autour de lui. La mise en scène reproduisant symboliquement la disposition cultuelle au sein des anciens temples place le pasteur au centre du dispositif, dans une composition bien structurée et hiérarchisée; son apparition, ses gestes ritualisés participent de cette mise en scène et confèrent au message oral une force particulière.

Cette étude s'appuie principalement sur une enquête menée sur les assemblées tenues " par des religionnaires » et les prédications, baptêmes et mariages célébrés par des " prétendus ministres de la RPR » dans les sénéchaussées d'Orthez et de Sauveterre-deBéarn. Elle a été confiée par le procureur général du parlement de Navarre au conseiller Ignace Tristan de Carrère qui, accompagné d'un greffier et d'un huissier, diligente l'instruction à Orthez et à Salies-de-Béarn du 27 juillet au 25 août 1757. Pour cela, le conseiller de Carrère rassemble tout d'abord les instructions préalables réalisées par les jurats des lieux concernés, puis les dépositions soigneusement numérotées de 225 témoins, signées lorsqu'ils le peuvent, et prononce à son terme 119 prises de corps et 102 convocations devant le parlement, consignées sur les dernières pages du cahier qui rassemble toutes les pièces de la procédure ${ }^{3}$. Il a ainsi essayé de reconstituer méthodiquement les faits, de repérer l'ensemble des suspects tout en prenant bien soin de faire recouper les témoignages afin de faciliter le travail répressif. Les propos qui sont plus ou moins développés selon la sensibilité religieuse des déposants donnent une vision certes conditionnée par le juge qui pose les questions de manière souvent répétitive ; toutefois, par les nombreux détails apportés, ces déclarations constituent une source très précieuse d'informations sur une population qui découvre ce que sont les grandes assemblées, voire ce qu'est la personne d'un pasteur, décrivant des gestes et des sentiments qui nuancent la vision parfois épique des rassemblements au Désert, notamment dans le contexte particulier du Béarn. Ce document est complété par des

1. C. Grosse, Les rituels de la Cène.

2. Y. Krumenacker, "La liturgie, un enjeu dans la renaissance des Églises françaises au XVIII siècle », p. 111-126.

3. Archives départementales des Pyrénées-Atlantiques (ci-après ADPA), B 5444. 
correspondances et des sources produites par les Églises clandestines, notamment de comptabilité ${ }^{4}$.

Depuis la révocation de l'édit de Nantes, le Béarn n'a pas connu de révolte armée et après quelques assemblées très durement réprimées tenues dans les premières années, s'est retranché dans une résistance silencieuse alliant un catholicisme de convenance à des réunions restreintes et un culte familial. La reconstitution d'Églises clandestines qui débute en Bas-Languedoc à la fin des années 1720 parvient tardivement en Béarn où le «relèvement» se produit en 1755-1756, sous l'impulsion d'un pasteur de l'entourage d'Antoine Court envoyé à cet effet, Étienne Defferre, bientôt rejoint par le cévenol Jean Journet. Ce sont les premiers pasteurs à y demeurer depuis 1685. C'est à eux qu'incombe la tâche de ce relèvement, qui consiste non seulement à établir des institutions clandestines mais également à pousser des populations qui vivaient jusque-là dans l'ombre, ou même dans un lointain souvenir familial de leurs origines protestantes, à renouer avec la religion de leurs ancêtres et à la pratiquer ouvertement au risque de s'exposer aux mesures de rétorsions prévues par la loi, et notamment de se placer en infraction à la législation sur les baptêmes et le mariage ${ }^{5}$.

Les premières grandes assemblées se tiennent dans les environs d'Orthez et de Salies-deBéarn en 1756. Leur soudaineté et leur importance surprennent les autorités, par ailleurs davantage préoccupées par le conflit généralisé de la guerre de Sept Ans qui prive l'intendant des moyens militaires d'une répression. Néanmoins, en 1757, dans un climat quasi insurrectionnel, alerté par les jurats des lieux, le parlement de Navarre lance une grande enquête qui a pour but de mettre un terme à ces assemblées en menaçant personnellement de poursuites pénales leurs principaux initiateurs. Cette enquête, qui semble être la seule de ce type, dresse un instantané exceptionnel de la restauration d'une Église, s'attachant principalement aux personnes des étrangers à la province et à ceux qui les soutiennent et les hébergent.

Dans ce contexte, l'action du pasteur pour convaincre les populations de sortir de la clandestinité ne se résume pas seulement au texte de ses sermons, mais à un langage symbolique et gestuel complémentaire voire indispensable de la parole qui s'inscrit dans un cadre cultuel original, au sein de vallons boisés, et plus largement dans le cadre privé de maisons particulières.

\section{Le «théâtre sacré » du Désert}

Les grandes assemblées réunies par Étienne Defferre reprennent le modèle pratiqué habituellement par les pasteurs dans le Bas-Languedoc et plus spécifiquement dans la région nîmoise et dans les Cévennes. Elles se déroulent dans un lieu écarté pour ne pas perturber l'ordre religieux urbain, se placer hors du regard des autorités comme de la communauté catholique, et pour pouvoir se disperser rapidement en cas de menace. Le lieu n'est ainsi pas choisi au hasard et la disposition spatiale de l'assemblée obéit à des règles strictes qui ressortent des dépositions.

\section{Espace clandestin}

Le lieu de réunion est donc un lieu caché, sous le couvert d'un bois et dans un vallon qui permet une disposition en amphithéâtre pour des raisons d'acoustique et d'organisation de l'assemblée. Ces vallons ne sont pas pour autant trop éloignés des principales agglomérations, afin d'éviter des temps trop importants de déplacement. Il s'agit pour

4. Fonds du Centre d’Etude du protestantisme béarnais déposés aux ADPA (ci-après CEPB), 60J 50/180, Cahier des réunions des assemblées 1756-1760; $60 \mathrm{~J}$ 300/ 40, Cahiers des réunions des assemblées 1756-1767; documents relatifs aux impositions, aux collectes et aumônes 1756-1767.

5. P. Chareyre, « De bois en granges... », p. 265-290. 
l'essentiel du bois de Castetarbe à l'ouest d'Orthez, à proximité également des communautés de Bellocq et Puyoô, puis de Salles-Mongiscard, et du bois de Saubade situé sur la rive gauche du Gave, entre Bérenx et Bellocq, plus facilement accessible par les communautés de Salies et de Lagor. Il ne s'agit pas non plus de lieux occultes car il est difficile de dissimuler leur emplacement lorsque la foule dépasse le millier de personnes ; certaines assemblées, selon les chiffres de l'époque, auraient atteint entre trois et six mille assistants ${ }^{6}$. Le secret n'en est pas vraiment un lorsque les lieux de rendez-vous sont si peu nombreux et deviennent de plus en plus réguliers, le plus souvent le dimanche. En 1765, l'assemblée réunie sur les hauteurs du Bugala à Osse-en-Aspe avait même allumé des feux pour se réchauffer. C'est donc essentiellement le temps de la réunion qui est tenu secret et qui est annoncé par une personne accréditée dénommée le «mande » :

«Ajoute le déposant avoir ouy dire publiquement que les deux ministres protestans ont logé souvent chés le nommé Marsou deu Bosq... réputé dans le publique pour faire les fonctions de mande, c'est-à-dire qu'il indique aux religionaires le jour et le lieu où les assemblées doivent se tenir. ${ }^{7}$

Parfois, cette annonce dépasse largement le cadre de la communauté, attirant même quelques catholiques curieux.

«Marie Dubosq, [...] dépose qu'un jour de dimanche pendant le Carême de l'année 1756, elle eut la curiosité de voir ce qui se passait dans les assemblées des religionaires, elle y alla avec Marie Laguilloune, $20^{\mathrm{e}}$ témoin, et la cadette de Manes, toutes trois faisant profession de la religion catholique. ${ }^{8}$

\section{Espace symbolique}

Le choix de l'espace comme son organisation ne sont pas laissés au hasard. Le périmètre de l'assemblée est délimité, il est destiné à rassembler les membres de la "véritable Église » et son accès est protégé contre toute présence hostile.

«Jean Gaston cadet, du lieu de Castetner, [...] dépose qu'il vit de fort loin, le 21 novembre 1756, une nombreuse assemblée au parsan appellé Congot ; les habitans de Castetner sortant de la messe coururent vers le lieu de laditte assemblée qu'il a ouy dire être de religionaires et qu'il y avait un prédicant ; à peine ceux de Castetner pouvaient-ils être aperçus des gens de laditte assemblée qu'il s'en détacha plusieurs arméz de bâtons, qui les obligèrent à se retirer bien vite. ${ }^{9}$

L'ordonnancement du lieu obéit enfin à des règles précises qui dressent le décor imposé au cœur duquel officie le pasteur. Les fidèles sont rassemblés autour d'un espace sacralisé, fermé, un enclos matérialisé par des pieux et une corde, au centre duquel se trouve une « espèce de chaire élevée au milieu de l'assemblée couverte d'une toile », dont un autre témoin dit qu'elle est "garnie de cadis avec des rideaux de la même étoffe » ${ }^{10}$. Dans cet enclos prennent place face à la foule, les anciens de l'Église et les chantres, les proposants et le pasteur.

« Il y a vu deux ministres de la R.P.R., l'un âgé de 30 ans, l'autre de 45 ans ou environ, qui ont prêché alternativement; ils se plassaient à une espèce de chaire couverte d'une toile ; plusieurs des assistans se tenaient auprés d'eux, séparés du reste de l'assemblée par une corde attachée à des piquets; on les appelle confrères, qui ont des fonctions distinguées parmy les protestans. »

6. ADPA, B 5444, témoins 32 et 38 . Le chiffre le plus haut paraît exagéré car il dépasse celui de la population protestante du Béarn à cette époque estimée à cinq mille individus. Voir S. Tucoo-Chala "Protestants et protestantisme en Béarn, du Désert à l'Après-Révolution. 1755-1804. », p. 209. Toutefois, la présence de catholiques, comme d'anciens protestants hésitants, a certainement contribué à accroître cet effectif.

7. ADPA, B 5444, témoin 5.

8. Ibid., témoin 25 .

9. Ibid., témoin 98 .

10. Ibid., témoins 25 et 225 .

11. Ibid., témoin 185 . 
La comptabilité clandestine mentionne que du mobilier de culte fut acheté très tôt. Deux coupes de communion en argent figurent dans les comptes de 1757 pour un montant de 236 L. 1 s. La chaire pourvue d'un ciel de toile, décrite par les témoins de l'enquête, est payée 24 L. le 15 janvier, et par la suite une seconde chaire propre au désert de Magret est mentionnée en août 1759. En décembre 1758, un Nouveau Testament provenant de Bordeaux est payé $14 \mathrm{~L}$.

Cet espace est le lieu où s'annonce la parole de Dieu, où se célèbrent la cène, les baptêmes, les mariages. Cet espace masculin, croisement du vertical et de l'horizontal est le cœur/chœur de l'Église, le lieu par excellence du sacré. Cette hiérarchie n'est pas sans rappeler la disposition de la communauté dans les anciens temples, mais sa localisation dans un bois, au sein de la nature glorifiée par les philosophes de cette seconde moitié du XVIII ${ }^{\mathrm{e}}$ siècle, lui apporte un surcroît de légitimité.

\section{La recomposition du religieux}

Le dictionnaire de l'Académie dans son édition de 1762, contemporaine de la « Profession de foi du vicaire savoyard » extraite du chapitre IV de la première édition de Émile ou de l'éducation de Jean-Jacques Rousseau, cite parmi les occurrences du mot nature, «toute nature nous prêche qu'il y a un Dieu ${ }^{\prime 2}$.

L'emplacement de l'assemblée est considéré comme un espace sacré par excellence: le culte est célébré dans la nature, œuvre de Dieu et non dans un bâtiment, œuvre des hommes. L'exaltation de la nature est clairement explicitée dans la littérature du Désert ; ainsi les Sonnets chrétiens sur divers sujets de Charles Drelincourt parvenus en Béarn dans leur édition de Jacques Desbordes à Amsterdam en 1758, comportent un livre premier intitulé «Sur la Nature et son Auteur ». Le quinzième sonnet chante les arbres qui sont le refuge naturel des premières assemblées. La Liturgie pour les protestans de France éditée pour la première fois en 1758, dont un exemplaire de 1761 a également été retrouvé en Béarn, contient une "Prière à Dieu sur la beauté du spectacle de la Nature, \& sur l'aveuglement de la plupart des hommes à n'y pas reconnaître la souveraine Intelligence » tout à fait édifiante ${ }^{13}$. Les textes produits par l'Église locale en reprennent les termes: l'en-tête des premiers synodes béarnais "Les églises du Béarn assemblées sous les yeux de Dieu... » ${ }^{14}$ souligne ce lien direct entre les fidèles rassemblés et leur créateur.

Cet espace est donc celui de la loi divine et non celui de la loi royale, un espace qui légitime la transgression de celle-ci, qui met le culte célébré par le pasteur en position d'expression de la religion naturelle. Cette sur-légitimation contribue à l'attractivité de l'assemblée.

Les dépositions évoquent rarement la peur que l'assemblée soit surprise. Ce sentiment réside plutôt dans l'idée de transgression de la loi royale, mais plus encore d'une sacralité admise, la catholique. Certains manifestent spontanément devant le juge leur horreur des propos tenus à l'encontre des prêtres et de l'Église romaine. Un tisserand d'Orthez témoigne de sa surprise devant les propos anti-romains du pasteur :

«Ce qui fit tant d'horreur au déposant qu'il se retira avec précipitation craignant que la terre ne s'entr'ouvrît sous ses pieds. ${ }^{15}$

12. $4^{\text {ème }}$ édition, p. 198.

13. D. de Superville, de Latreille, B. Pictet et J. Saurin, Liturgie pour les protestans de France ou prières pour les familles des fidèles privés de l'exercice public de leur religion, Marc-Michel Rey, Amsterdam, 1761, p. 342-346, (CEPB, BPr 7/37).

14. Formule initiale des actes des premiers synodes du Désert béarnais, 1757-1758, ADPA/CEPB, 60J 300/36.

15. ADPA, B 5444, témoin 32. 
L'expression de cette crainte est toutefois minoritaire. La protection armée de même que l'importance en nombre rendant toute tentative d'arrestation périlleuse et vaine, jouent pour beaucoup dans ce sens. La veuve d'un maçon de Bellocq déclare ainsi que :

«Depuis qu'elle a ouy dire que les protestans s'assemblaient au désert, presque toute la parroisse a changé de religion, ils vont presque tous aux assemblées et l'église du lieu, les dimanches et les jours de fêtes, est presque déserte. $»^{16}$

La foule enfin attire la curiosité, le nombre appelle le nombre; c'est un moyen de prosélytisme sur lequel table Defferre ainsi qu'il l'écrit à son arrivée en Béarn :

"Tout se prépare à une vaste moisson dans cette province, il y a un grand nombre de gens en balance qui n'attendent qu'un vent doux et favorable pour les jeter dans le port, de sorte que, pourvu que les choses continuent à être pacifiques comme elles sont pendant quelque temps, on verra les gens entrer en foule dans la bergerie du Seigneur. $»^{17}$

L'assemblée a pour but de reconstituer le périmètre de l'ancienne Église, comme Court de Gébelin l'écrit avec un grand enthousiasme en 1761 :

«On m'écrit des merveilles de Béarn : les catholiques courent en foule aux assemblées, mais quels catholiques s'il vous plaît! ce n'est pas uniquement du peuple, ce sont des seigneurs, des barons, des religieux même, oui, des religieux; et tous font mille politesses aux ministres. Ce sont de braves gens, ils se souviennent de leurs dignes ancêtres; ils montrent du moins que leur sang bout encore dans leurs veines... ${ }^{18}$

D'où l'importance de la célébration des baptêmes et des mariages devant l'assemblée, actes publics d'opposition à la loi royale et de rupture avec le culte catholique auxquels l'assemblée réunie consent et apporte son témoignage.

L'intendant D'Étigny n'est pourtant pas dupe de cette stratégie. Bien renseigné, il écrit à Saint-Florentin en décembre 1755 :

«Le prédicant n'a pas manqué d'entrer en matière sur les risques qu'il courait, en exagérant son zèle, et tout le peuple a promis de l'en garantir ».

Il préfère temporiser faute de troupes disponibles dans la région, en ce temps de guerre qui est un temps de grâce pour Defferre.

« Tout porte à croire -poursuit-il- que ces gens sont armés, et ce serait inutilement que l'on ferait marcher contre eux quelques brigades de la maréchaussée ; il n'en résulterait, selon toute apparence, que des événements fâcheux. ${ }^{19}$

Cette posture d'attente a très certainement favorisé l'œuvre du pasteur. Celui-ci peut alors jouer de cette situation, tantôt se cachant, tantôt se montrant pour annoncer à tous son message.

\section{Le ministre de Jésus-Christ}

Étienne Defferre, arrivé au début de l'année 1755 en Béarn pour rétablir les Églises, est un pasteur de choc. Il exerce depuis 1748 son ministère à Nîmes, ville clé du protestantisme français du XVIII ${ }^{\mathrm{e}}$ siècle où il est l'un des proches d'Antoine Court, qui lui propose de se rendre en Béarn où "se prépare depuis longtemps une moisson qui n'attend que la

16. Idem, témoin 112

17. C. Coquerel, Histoire des Églises du Désert, p. 233.

18. «Lettres inédites de Court de Gébelin et du pasteur Gal-Pomaret », B.S.H.P.F., 1854, p. 603. (12 octobre 1761).

19. P. Raymond, « Le protestantisme en Béarn (1755-1756)», p. 606. 
faucille d'un ouvrier zélé, prudent et habile $»^{20}$. Il exerce seul durant deux années, avant d'être rejoint par le cévenol Jean Journet. Defferre est l'un des très rares pasteurs à être issu d'une famille de la petite noblesse, gentilshommes verriers de la Vaunage, et a préféré le pastorat à la carrière des armes, contre l'avis de son père. De ses origines, il tire un militantisme actif, voire offensif et prend le titre de ministre de Jésus-Christ plutôt que de ministre de la Parole de Dieu comme ses confrères. Le portrait qu'en dresse le parlement de Navarre dans son décret de prise de corps est plutôt flatteur :

«Bel homme, bien carré, de taille de cinq pieds, trois, quatre ou cinq pouces, nez crochu, jambes menues, visage plein, joli de sa figure, portant perruque blonde, vêtu d'un habit bleu, veste et culotte rouge et d'âge de quarante-cinq à cinquante ans. $~^{21}$

Paul Rabaut évoquait en 1755 son «tempérament vif ${ }^{22}$, le pasteur Redonnel parle de « charbon de feu ». Le redressement des Églises de Béarn est lié à sa personnalité.

\section{Le pasteur caché}

Le pasteur vit dans la clandestinité car il est la cible privilégiée des autorités. Il ne faut pas oublier que non loin de là, en 1762 le pasteur Rochette qui officiait dans le Quercy et l'Agenais, est exécuté à Toulouse, au moment même où débute dans cette ville l'affaire Calas. Étienne Defferre est sans cesse en déplacement, à la fois pour aller de familles en familles en vue de reconstruire l'Église béarnaise, et pour échapper aux menaces d'arrestation. Il possède deux pistolets placés dans les fontes de sa selle, ainsi qu'une carabine et l'un de ses valets est armé d'un sabre. Très rapidement, il se charge de sa propre protection quitte à y perdre un peu d'anonymat, comme le révèle l'un des déposants :

«Dit aussy avoir vu passer sur le pont du Gave de cette ville, il y a environ 3 semaines ou un mois, où il était entre 9 ou 10 heures du soir, une troupe de gens à cheval et à pied, ceux qui étaient à cheval étaient environ une vingtaine, ceux qui étaient à pied environ une trentaine arméz de pistolets et de gros bâtons ; le déposant entendit que ces gens-là disaient "Ne craignés pas, Monsieur, jurent le saint nom de Dieu, nous vous deffendrons si quelqu'un oze entreprendre contre vous", ces propos persuadèrent le déposant qu'on parlait au ministre et que cette excorte n'était que pour sa sûreté, ainsy qu'on le dit dans le publiq que lesdits ministres ne marchent jamais que bien accompagnéz de personnes bien déterminées à les deffendre au besoin. ${ }^{23}$

Ces mesures de sécurité sont indispensables car très vite, toute la région est au courant de sa présence dans un périmètre relativement restreint. Ainsi, lorsque le fils de Hourty, tisserand, s'approche du lieu où vient de souper le pasteur :

«Il trouva quelque personnage qui sortait de la maison qui lui demanda ce qu'il venait espioner, que s'il ne se retirait promptement il lui donnerait du pied au cul, qu'il se retira promptement, crainte qu'on n'effectuat ce dont on l'avait menacé, le ton dont on lui parla lui en fit craindre davantage. »

Le pasteur semble même parfois se déplacer en toute impunité, comme en témoigne deux ans après son arrivée, un garçon tuilier venu le dénoncer en vain auprès de la maréchaussée, le capitaine lui ayant répondu que «n'ayant que 3 cavaliers à ses ordres, il yrait inutilement les exposer $»^{24}$.

Protégé et caché, le pasteur ne peut être aperçu qu'occasionnellement lors de ses déplacements. Pierre Casalis, tisserand de Puyoô, dépose ainsi que :

20. C. Dardier, et A. Picheral-Dardier, Paul Rabaut. Ses lettres à Antoine Court (1739-1755), 5 février 1755, p. 353355.

21. ADPA, B 4895.

22. C. Dardier, Paul Rabaut., t.2, p. 353, et C. Coquerel, Histoire des églises du Désert, p 236.

23. ADPA, B 5444, témoin 18

24. Ibid., témoins 52 et 62. 
«Le premier ou second dimanche du mois de novembre dernier... il vit un étranger, qu'il reconnut pour l'avoir vu souvent passer devant sa maison. »

Mais en certaines circonstances, il peut être approché de plus près ; c'est le cas par hasard pour Marie Perguilhem habitant sur la route entre Castetarbe et Orthez, qui vit venir cette troupe s'abriter d'une forte pluie dans sa grange et parmi eux :

«Un homme avec une redingote, le visage gravé de la petite vérole, cheveux châtains, de taille avantageuse, entra dans la chambre où elle était, ledit homme remarqua deux jambons pendus au plancher, dit que c'était une bonne provision pour le Carême ».

Pour la femme de Pierre Canton, c'est par curiosité, trouvant étrange que le valet de son parent Jean Lacarrère de Peirède, l'empêche de rentrer dans la maison, elle :

« regarda par le trou de la serrure, vit un homme à elle inconnu qui était à la fenettre en robe de chambre ; il luy parut âgé de 45 ans ou environ, de taille avantageuse, gravé de la petite vérole ; le portrait qu' on lui avait fait du ministre luy parut ressembler à cet étranger et est persuadée que c'est l'unique raison pour laquelle on porta obstacle lorsqu'elle voulut entrer. »

Pour Jean Capdevielle, visitant une maison de Salies, la vision est plus familière :

«Le matin, après qu'il fut levé, il vit ledit étranger dans la maison habillé d'un gilet, un bonnet de nuit à la tête, ce qui ne lui permit pas de douter qu'il n'y eut couché. ${ }^{25}$

\section{Le pasteur et ses familiers}

Seules quelques personnes de confiance peuvent bénéficier de la compagnie du pasteur, ceux qui l'hébergent, ceux qui le reçoivent à souper. Ceux qui peuvent le croiser et lui adresser la parole en ces circonstances sont peu nombreux, et font partie de l'élite dirigeante de la communauté, elle-même exposée aux poursuites. Les curieux sont soigneusement écartés, on l'a vu, par les valets de la maison. Cette semi-clandestinité contribue à renforcer le mystère autour du personnage qui ne fréquente que ceux qui sont admis dans le cercle étroit, matérialisé par des piquets, situé autour de la chaire lors des assemblées. D'un niveau social aisé, Defferre dut plaire à la bourgeoisie orthézienne dont il pouvait partager des instants privilégiés de sociabilité.

Le témoignage de ces moments privés dans les maisons particulières est rapporté par Jean Danglade de Castetarbe :

« Après la dernière assemblée qui se tint audit lieu de Castetarbe, le ministre de la R.P.R. se retira avec plusieurs personnes qui avaient assisté à ladite assemblée chés Marsau Croharé, dudit lieu, où il soupa avec sa troupe ; a ouy dire aussy qu'après souper ledit ministre prit par la main la fille de la maison nommée Sourine et dansa une danse ronde avec ceux de sa suite, après quoy ils passèrent au jardin pour chanter les pseaumes ; le déposant, qui est à portée, les entendit jusques après neuf heures du soir. »

De même, Marie Danglade dépose que :

« le $24^{\text {e }} \mathrm{du}$ mois de juillet dernier, elle vit arriver chés le nommé Arrout dudit lieu une vingtaine d'hommes à cheval ; étant entrés dans la cour, Arrout père et fils coururent, les bonnets à la main, aider un homme à descendre de cheval,... tous ces personnages entrèrent dans la grange où ils se mirent à table ; après le souper, la déposante vit le ministre qui prit Arrout aîné par la main et tous allèrent danser sur un pré proche la grange ; ensuite, ils chantèrent des cantiques jusques à 9 ou 10 heures que le ministre se retira avec toute sa troupe. ${ }^{26}$ 
Toutefois, si le pasteur évite de se montrer en temps ordinaire pour sa sécurité, c'est pour mieux se révéler au sein de son Église, dans l'accomplissement de son ministère. Le secret amplifie ainsi sa prise de parole publique, et il se dévoile sur la scène du lieu de l'assemblée.

\section{Le pasteur dévoilé}

L'organisation de l'assemblée est en effet théâtralisée autour du rôle principal du pasteur, mis en valeur par le décor et les figurants qui l'entourent. Dans cette mise en scène soigneusement orchestrée, il n'est pas impossible de retrouver les traits de la personnalité d'Étienne Defferre qui cherche à marquer les esprits dans le cadre de son œuvre de reconstruction de l'Église protestante locale, voire de reconquête. La pièce est précédée d'un temps préparatoire au cours duquel monte la tension jusqu'à l'arrivée du ministre. Elle se déroule ensuite en trois actes, la célébration des baptêmes et la bénédiction des mariages, le temps du sermon et dans certains cas, la célébration de la cène, suivis par la séparation de l'assemblée, chaque période étant rythmée par le chant des psaumes par les fidèles.

Le premier temps est décrit par les témoins de l'enquête du parlement de Navarre. Joseph Fargues, tisserand d'Orthez expose le déroulement de ce début d'assemblée :

«Il vit et entendit le cadet de Marsoulet deu bosq, de cette ville, assis sur le marchepied d'une chaire placée au milieu de cette troupe, qui faisait lecture un livre à la main, attendant le ministre, qui arriva monté sur un cheval gris, armé d'une carabine, deux pistolets à la scelle et un autre à la ceinture, habillé comme le sont ordinairement les négociants qui voyagent, homme assés bien fait de l'âge de 40 ans à ce qu'il croit. L'empressement qu'on eut à son arrivée luy fit croire que c'était le ministre, ce qui luy fut confirmé par plusieurs. $»^{27}$

Un autre témoin signale que cette lecture est accompagnée également d'un temps de catéchisme :

«Le cadet de Marsoulet, le cadet de Segalas, lecteurs [...] faisaient réciter le cathéchisme à ceux de l'assemblée avant que le ministre n'arriva. ${ }^{28}$

Une autre déposition décrit bien la gradation en intensité qui précède le sermon, le changement de vêtement, la montée en chaire puis l'adresse à l'assemblée :

«Il changea ensuite de décoration, il prit un rabat et une robe, monta en chaire environné desdits Labourdette, Larroque, des nommés Bareits, Marsoulet père et fils et Lacoste Titoy aîné et grand nombre d'autres de cette ville, gens très distingués et d'un grand crédit parmy les religionaires. Le ministre commança par regarder de tous cottés et s'adressant à ceux de l'assemblée il leur dit "Je m'expose pour vous, veillés qu'il ne soit fait aucune surprise" ; tous répondirent "Tranquilisés-vous, nous vous deffendrons contre tout venant". ${ }^{29}$

Cette entrée en matière destinée à entraîner l'adhésion de l'auditoire, repose sur une mise en scène de la personne du pasteur qui s'expose alors en dehors du cercle de ses fidèles, comme le Christ révélant son message en dehors du cercle de ses disciples. À l'occasion de l'assemblée du dimanche de carême de 1756 à Salles-Mongiscard, à ce même moment qui suit son arrivée, de façon très surprenante, les premiers mots prononcés furent pour chasser des « pauvres » assemblés près de la chaire, action justifiée de la bouche même du pasteur :

«Que si on avait chassé les pauvres, qu'ils n'en fussent point surpris, qu'on avait découvert qu'ils avaient formé le projet de l'arrêter ».

27. Ibid., témoin 32

28. Ibid., témoin 38

29. Ibid., témoin 32. 
Il s'agissait selon un autre témoignage d'un seul mendiant qui s'était vanté que «s'il eût été secouru de 4 autres personnes, il aurait arrêté ledit ministre ${ }^{30}$. Le régent Chéruques, ancien catholique converti, déclarera plus tard lors de son procès qui se terminera par une condamnation aux galères, avoir été de ce nombre, suspecté d'être espion et apostat $^{31}$.

Cette mesure spectaculaire permet de conditionner l'assemblée en marquant symboliquement la frontière spirituelle et matérielle entre élus et réprouvés, les véritables pauvres faisant partie des premiers et méritant d'être aidés, comme le montrent la comptabilité des sommes collectées lors des assemblées et leur distribution. Quant à la mise en scène, elle permet par un système de résonance de mettre en phase l'orateur et son auditoire.

Suit alors la célébration des baptêmes et des mariages qui dans l'ancienne Église prenait plutôt place à la fin de la prédication et qui a ce stade, souligne davantage l'importance de l'entrée dans la nouvelle communauté des fidèles et valorise le courage de ceux qui osent ainsi le faire devant témoins. Elle est une manifestation publique de la reconstruction de l'Église et plus symboliquement, elle affiche la volonté de passer outre l'édit de Fontainebleau et d'avancer vers son démantèlement par la reconnaissance d'un état civil aux non-catholiques. C'est cette question qui mobilise principalement l'opposition des prêtres et des évêques car elle s'inscrit contre leur prérogative et leur enlève le principal moyen d'action contre les crypto-protestants obligés de passer devant eux tout particulièrement au moment du mariage. C'est elle qui avait cristallisé les tensions au cours des années précédentes, poussant même des protestants d'Orthez à recourir à de faux certificats ${ }^{32}$.

Le temps de la prédication est le second temps essentiel de l'assemblée. Les sermons peuvent être recopiés et circuler ; quelques-uns de Defferre et plusieurs de Journet ont été recueillis localement ${ }^{33}$. Toutefois, leur contenu n'a pas fait l'objet de la curiosité du conseiller au parlement de Navarre, et les témoins s'attachent davantage à décrire la longueur de l'action:

«Ensuite, ledit ministre prêcha longtemps, suspendit par intervales sa prédication et, tendis qu'il reposait, l'assemblée chantait des cantiques. »

Cette longueur peut aussi être due au fait que Defferre et Journet officient en même temps, comme à Castagnède où l'on mentionne que « deux ministres de la R.P.R.... ont prêché alternativement", un autre témoin précise que "après que l'un avait prêché, l'autre prenait sa place pour chanter. » ${ }^{34}$ Court de Gébelin écrit en 1763 :

«On y est sept heures dans ces assemblées sans impatience, avec plaisir ; il est donc tard quand on en revient et on finit le reste du jour d'une manière qui leur fait beaucoup d'honneur... $\gg^{35}$

L'assemblée se termine avec la quête dont la comptabilité fournit également d'intéressants renseignements.

"Avant que l'assemblée ne se sépara, le déposant vit que lesdits Lagoardére, Davitou, Lechit, Labere et Joanhau firent la quette et amassèrent beaucoup d'argent dans leurs chapeaux $»^{36}$.

30. Ibid., témoins 27 et 21 .

31. A. Cadier, « Le protestantisme béarnais. Interrogatoire de D. Chéruques à Pau, 17 avril 1759 », p. 165-174.

32. M.-H. Grintchenko, Les baptêmes protestants au Désert en Béarn 1756-1778.

33. CEPB, 60J 50/186, 191/23-3, 262/12.

34. ADPA, B 5444, témoins 185 et 184 .

35. C. Coquerel, Histoire des églises du Désert, p. 239. Lettre adressée à Paul Rabaut, datée de septembre 1763.

36. Ibid., témoin 27. 
Chacun se retire alors mais dans certains cas, le pasteur et les anciens prennent leur repas sur le lieu de l'assemblée et ne repartent plus discrètement qu'à la nuit, après que la foule se soit dispersée. Ainsi, des habitants « avaient fait porter un jour d'assemblée un souper pour le ministre et pour plusieurs qui devaient manger avec luy au bois de Castetarbe ». Pierre Boileau, laboureur de Sainte-Suzanne, quant à lui court pour empêcher que l'on utilise son bois pour le repas, mais ne peut que constater « qu'on avait alumé du feu dans l'endroit où l'on avait soupé $»^{37}$. Lorsque l'assemblée s'est tenu près d'une maison, notamment dans le secteur le Castetarbe, le pasteur peut aussi y être accueilli comme il a été vu précédemment.

La mise en scène du personnage du pasteur a donc pour objectif de renforcer la portée de ses propos dans sa fonction de ministre de la Parole, mais son message passe également par des exhortations orales et par des gestes qui continuent à le mettre au centre de la communauté.

\section{Les paroles $d u$ ministre}

\section{La prédication}

Les dépositions des témoins comparaissant devant le juge civil apportent plusieurs renseignements sur les circonstances du sermon, mais aucun sur son contenu. Elles signalent en premier lieu son succès qui se manifeste par la satisfaction des auditeurs, indirectement rapportée à propos de ses maîtres par la servante de Loustet, négociant d'Orthez, ou encore plus ouvertement par Pierre Lauret, jurat de Bellocq :

«Qu'un jour du mois de décembre dernier il eut la curiosité d'aller à l'assemblée des religionaires qu'ils tinrent sur le territoire de Belloq, qu'il entendit prêcher le ministre de la R.P.R., qu'il eut tant de plaisir de l'entendre qu'il y est retourné 3 ou 4 fois. » ${ }^{38}$

Toutefois, plusieurs témoignages font état de difficultés à comprendre le sermon, non pas tant en raison de la langue puisqu'ici le français n'est pas la langue pratiquée quotidiennement par le plus grand nombre, qu'en raison de la configuration même de l'assemblée. Il n'est en effet pas toujours audible pour ceux qui sont les plus mal placés à la périphérie, comme l'indique Pierre Souviraa, de Puyoô :

«... il y avait tant de monde qu'il ne put se mettre à portée d'entendre le prédicant ny connaître ceux qui étaient auprès de luy $»^{39}$.

Ce propos pourrait être de sa part, une stratégie dilatoire face aux questions de l'enquêteur, mais on ne peut toutefois occulter les difficultés inhérentes à de telles assemblées qui rassemblent pêle-mêle, peut-être aussi de façon insidieuse en fonction de leur degré d'adhésion, des fidèles convaincus, des prosélytes potentiels et des assistants curieux. Les problèmes d'acoustique comme ceux de compréhension ont pu limiter la pénétration du message pastoral.

Les dépositions de trois habitantes d'Orthez semblent confirmer la hiérarchie concentrique. Marie Laguilloune expose :

« (qu'arrivées) au lieu de l'assemblée, elles cherchèrent contre un arbre à se mettre à l'abry du soleil ; cette place fut enviée par des femmes de l'assemblée..., qui prétendirent, comme huguenotes, en avoir la préférance. » 
La suite laisse mal augurer de la compréhension, Marie Manes déclarant:

« (qu')étant arrivées sur le territoire de Sales-Mongiscard, elles furent éblouies, voyant une assemblée aussy nombreuse, elles tachérent de prendre une place d'où elles pussent voir et entendre. [...] La déposante était si éblouie et sy troublée de tout ce qu'elle avait vu et entendu qu'elle ne peut rendre un compte aussy exact qu'elle aurait souhaité. »

Ce que confirme plus explicitement sa commère Marie Duboscq :

«La déposante, ainsy que ses camarades, donnèrent toute leur attention pour voir et pour entendre mais le mauvais accueil qui leur avait été fait, les mauvais propos qu'on tenait sur leur compte les troublèrent si fort qu'elles prirent le party de se retirer sans avoir pu satisfaire leur curiosité pour rendre compte de ce qu'elles auraient souhaité voir et entendre. $\gg{ }^{40}$

Un synode de Béarn déplore par ailleurs l'indiscipline qui peut régner dans ces assistances :

«On s'est aperçu qu'il règne dans nos assemblées religieuses pendant la lecture de l'Écriture sainte, du chant des psaumes et pendant la récitation du catéchisme, beaucoup d'irrévérence et d'indévotion. »11

La prédication peut être complétée par les propos des auxiliaires du pasteur ainsi que par la lecture, mais ces deux vecteurs ne touchent que les convaincus. Les deux pasteurs sont aidés par deux chantres qui les accompagnent, dont l'un d'eux est dit être le frère d'Étienne Defferre. Ils sont chargés de conduire le chant dans l'assemblée mais également d'aller par les maisons pour assurer le réapprentissage du chant des psaumes; ainsi Léonard Dufau, avocat et jurat de la ville d'Orthez déclare que «depuis 5 ou 6 mois qu' on dit que ces deux chantres sont en cette ville, il a entendu dans différents quartiers qu' on chantait les pseaumes, le jour ainsy que la nuit ${ }^{42}$, et ce chant des psaumes dans les maisons est attesté par de nombreux témoins.

Ce même Dufau indique également « avoir ouy dire publiquement qu'il était venu en la présente ville un étranger qui reliait les livres qu'on vendait aux religionnaires ». Il atteste ainsi du relais institutionnalisé de l'écrit comme prolongement de la prédication et comme support intellectuel et argumentatif du redressement de l'Église. L'enquête menée par les jurats de Labastide-Villefranche confirme le lien entre l'assemblée et la vente des livres:

«Un marchand de Pontac avoit vendu dans l'assemblée des calvinistes dud. jour 20 mars [1757]... pour plus de quatre mille livres des livres de la secte et qu'il en auroit vendu beaucoup plus sy sa boutique avoit été plus fournie. " $^{43}$

Ces livres sont des psautiers que plusieurs témoins déclarent avoir vu entre les mains de plusieurs personnes, mais aussi sans doute des bibles, des sermons et des ouvrages de controverse. Le livre qui circule désormais sous le couvert est en effet un vecteur complémentaire de la prédication, il peut même apporter l'argument décisif de la conversion comme le révèle un laboureur de Baigts à qui l'un de ses cousins a déclaré qu'il «luy prêterait un livre qui ne luy permettrait pas de douter que la religion protestante ne fût préférable à celle qu'il professait $\gg{ }^{44}$. Il peut aussi apparaître comme objet de légitimation de la contestation, ainsi qu'il ressort de l'algarade ayant opposé Lanusse de Peirède au curé $\mathrm{d}^{\prime}$ Athos au cours de laquelle le premier « un grand livre sous

40. Ibid., témoins 21, 25, 26.

41. E. Hugues, Les synodes du Désert, p. 288. Synode du 10 mars 1763.

42. ADPA, B 5444, témoin 1.

43. Archives communales de Labastide-Villefranche, FF15.

44. ADPA, B 5444, témoin 211. 
le bras ", affronte le prêtre venu faire cesser une assemblée, et l'aurait même bousculé parce que le curé avait voulu le lui arracher ${ }^{45}$.

\section{Un exhortateur}

La mission de Defferre consiste à « redresser » une Église dont une partie des membres pratiquait de manière fractionnée dans des cénacles, et était soumise à l'influence de prédicateurs passagers, dissidents du mouvement de restauration des Églises françaises lancé par Antoine Court. C'est donc à cette nouvelle communauté que le pasteur destine ses prédications, mais également plus quotidiennement, au cours de conversations privées, ses conseils et exhortations tirés de la Parole pour l'inciter à «sortir de Babylone ». Reposant en grande partie sur une argumentation anticléricale, ses propos sont rapportés à plusieurs reprises dans l'enquête du conseiller au parlement de Navarre, alors que le contenu des sermons en est totalement absent.

Les exhortations dénoncent l'illégitimité de l'Église catholique comme l'indiquent les propos du chirurgien Planté à un laboureur de Baigts :

« (qu')il était dans une très grande erreur de préférer la religion catholique à la protestante, que Rome était l'ancienne Babilone, que c'était un mélange de christianisme et de paganisme, bien différente de la protestante, qui était dans toute sa pureté. »

Ce même personnage se met en colère contre un paysan de Bérenx qui ne veut pas se rendre à l'assemblée et lui déclare :

«que tendis qu'il irait à l'église adorer les images et la croix comme font les catholiques, qu'ils seraient tous damnés. »

Quant au fils aîné de Gentiu, il déclare sarcastiquement à une femme d'un marchand d'Orthez après la Fête-Dieu «qu'on allait aux églises adorer les idoles et qu'à la procession on avait promené un marmouset ». Les propos peuvent même aller jusqu'aux menaces, comme celles qu'adresse le fils Domerc à un tisserand de Puyoô qu'il a sollicité à plusieurs reprises d'aller aux assemblées :

«Luy disant que la religion protestante soit la préférable ayant toujours résisté, il lui a fait querelle et menacé que s'il ne changeait, le temps allait venir que les catholiques seraient persécutés comme les protestans l'avaient été. ${ }^{46}$

C'est bien le pasteur qui donne le ton à cette animosité envers l'Église catholique, selon plusieurs témoignages convergents. Un apprenti de dix-neuf ans déclare que dans la maison de son maître :

«Il se fait souvent des assemblées de huguenots qui déchirent sans ménagement les ministres de l'Église romaine. »

Un maître tisserand d'Orthez dépose que le pasteur au début de l'assemblée,

«se déchaîna contre les ministres de l'Église romaine, damnant tous ceux qui comerceraient avec eux et fréquenteraient l'église, ce qui fit tant d'horreur au déposant qu'il se retira avec précipitation craignant que la terre ne s'entr'ouvrît sous ses pieds. »

On peut rappeler ici les propos tenus chez Marie Perguilhem lorsque Defferre se réfugie chez elle pour échapper à la pluie, et citer ceux qu'il adresse à sa fille Catherine âgée de dix-sept ans, il :

«prit le cathéchisme que la déposante lizait, aprés y avoir jetté les yeux il luy dit que l'évêque de Dax était un homme suspect. » ${ }^{47}$ 
Le pasteur fait aussi courir le bruit que le roi leur est favorable et qu'il est sur le point de reconnaître le protestantisme. Le procureur du sénéchal rapporte une conversation qu'il eut avec deux habitants de Baigts qui lui répondirent :

«qu'ils croyaient ne point contrevenir à la volonté du Roy, ce qui leur aurait été certifié par des personnes dignes de foy. »

Ainsi qu'une autre qu'il eut à Hagetmau à propos des assemblées, au cours de laquelle un habitant d'Orthez lui répondit:

«Qu'il continuerait d'y aller, que le Parlement aurait beau le deffendre, qu'il y irait jusques à ce qu'il vît un ordre bien précis du Roy et qu'il envoyât des troupes pour l'en empêcher et s'exalta en mauvais propos ».

L'origine de cette information est rapportée plus loin à l'occasion de l'audition de la femme d'un laboureur de Baigts qui entendit la lecture d'une gazette dans laquelle il était mentionné :

« une déclaration par laquelle les gouverneurs des provinces pouvaient permettre à ceux de leur Gouvernement de bâtir des prêches et le libre exercice de la R.P.R. »

Elle précise ensuite que :

"pendant que laditte Suson fit lecture de cette prétendue gazette, elle faisait des poses pour assurer que tout ce qu'elle disait était véritable et que, incessament, on verrait la religion protestante préférée, dans le Royaume, à la religion catholique. ${ }^{48}$

Ces citations renvoient à la place croissante que va jouer la bourgeoisie protestante béarnaise dans le combat plus général lancé par Court de Gébelin, en faveur de la reconnaissance civile et des libertés de conscience et de culte ${ }^{49}$, qui commence dès 1758 par la rédaction d'un Mémoire des protestants de Béarn ${ }^{50}$.

La fonction pastorale dépasse le cadre de la simple prédication dans les assemblées, le sermon seul ne suffit pas, même s'il est prononcé dans un temps cultuel éminemment symbolique. Organisateurs, controversistes, exhortateurs, Defferre et ses confrères dirigent et coordonnent la reconstruction en s'appuyant sur des élites locales qui découvrent un nouveau système ecclésiastique, en même temps que la personne d'un pasteur doté d'un caractère très affirmé.

\section{Le rituel transgressé}

L'enquête sur les assemblées révèle la mise en ordre quasi militaire de la nouvelle Église et l'établissement d'un rituel qui, se substituant au culte domestique ancien morcelé, place le pasteur en position incontournable de constructeur, voire de directeur d'une structure centralisée qui embrigade au service de la cause, les principales personnalités des Églises locales.

La puissance de ce personnage transparaît donc dans le cérémonial dont il est en fin de compte tout à la fois le premier personnage et le metteur en scène, au point que lui seul peut se permettre de le mettre à mal, voire de le transgresser. Un évènement intervenu

47. Ibid., témoins 36, 32, 60. Louis-Marie de Suarez d'Aulan, évêque trop zélé, à qui le secrétaire d'État Saint Florentin avait reproché les difficultés qu'il opposait au mariage des protestants par l'intermédiaire du curé d'Orthez.

48. ADPA, B 5444, témoins 58, 55, 207.

49. H. Bost, "Correspondance entre Court de Gébelin et les protestants d'Orthez (1763-1782) », et "Espoirs et déconvenues des protestants béarnais entre 1760 et 1787 ».

50. SHPF, ms. 362, pièces 10 et 11. 
quelques années plus tard en apporte la démonstration. S'il fit beaucoup de bruit en son temps, il n'a pas laissé de trace autre qu'une simple mention dans les comptes des collectes pour le jour de la cène de Pentecôte qui s'est tenue dans la châtaigneraie de Patran, le 2 juin 1765.

Le receveur des deniers choqué, ne put s'empêcher de noter de manière très inhabituelle cette brève mention :

«Le $2^{\mathrm{e}}$ juin, assemblée à Patran. Mr Montigny a presché et donné la communion. Il escandalisa la moitié des fidelles en donnant la communion, il tourna le dos à ceux qui se présentoit et au lieu de se mettre derrière la table comme c'est l'usage, il se acorté. ${ }^{51}$

Comment interpréter une telle posture à l'occasion de la célébration de l'un des deux sacrements du protestantisme? Une première interprétation qui tendrait à souligner la cléricalisation du pasteur marquant sa distinction vis-à-vis des fidèles ne peut être retenue car elle s'inscrit ouvertement contre le principe du sacerdoce universel. Pour cet homme qui a le sens du symbole, ce geste d'inversion est un geste parodique pouvant être interprété comme une dérision de la célébration eucharistique catholique, un prolongement en quelque sorte de ses propos à l'encontre de l'Église romaine, mais cela n'explique pas pour autant l'inscription sur la liste.

Il s'agit en fait d'un mouvement d'humeur puisque la semaine suivante, il donne à nouveau la communion dans une grange de Ségalas à Salles-Mongiscard, puis donne une prédication à nouveau à Patran le 7 juillet, sans que le comptable indique quoi que ce soit sur la liste des assemblées. Le message s'adresse donc à l'assistance, et peut-être même directement à ceux qui l'entourent de près. Il tourne le dos à la foule comme pour signifier en ce temps de Pentecôte qu'ils ne sont pas dignes de la descente de l'Esprit saint, au risque de compromettre la validité de l'acte. Il marque ouvertement son désaccord, s'écartant de la table et sans doute laissant les anciens distribuer la cène.

Ce n'est pas la première fois que Defferre manifeste son humeur. Alors que durant l'été 1762, l'intendant envoyait les dragons entre Orthez, Bellocq et Labastide-Villefranche pour réprimer les rassemblements et notamment celui du mois de juin qui avait vu le mariage du pasteur Jean-Jacques Fosse, que par précaution ce dernier avait quitté la région et que Journet se cachait, le consistoire avait décidé de suspendre les assemblées, mais Defferre s'obstina à les maintenir. Dans le cahier des assemblées, figure pour un rassemblement à Patran à la date du 8 août 1762 :

«Il n'y avoit presque personne. M. Montigny a presché contre le sentiment des notables et consistoire et malgré que l'on luy eut escrit de ne pas prescher. Il n'a pas fait de sermon mais une morale pour la persécution. » ${ }^{52}$

Il convient alors de replacer ce geste dans le contexte chronologique. Les anciens s'inquiètent des multiples procédures qui ont été lancées, la maréchaussée quadrille la région et l'intendant d'Étigny en profite pour tenter de faire cesser les assemblées trop voyantes qui défient l'ordre public, au détriment de Defferre qu'il tente de faire passer pour un ministre «venu pour les duper $»^{53}$. Après le départ de l'intendant, le marquis de Lons, lieutenant pour le roi en Béarn va charger Jean-Paul de Saint Cricq, lieutenantcolonel de cavalerie, apparenté à quelques familles de la bourgeoisie orthézienne bien placées au consistoire, les Paraige, les Dutilh, Poey et Lacoste, de conduire des négociations qui se déroulent désormais entre Béarnais (mars 1767-mars 1768) ${ }^{54}$. L'objet de ces négociations est clairement explicité dans la justification qu'en donnera plus tard l'un des principaux représentants de la communauté, l'avocat Vidal, dans une lettre adressée à Court de Gébelin :

51. CEPB, 60J 300/40.

52. Ibid.

53. H. Bost, « Correspondance... », p. 428. (1 $1^{\text {er }}$ août 1766$)$.

54. J. D. Robert, « Les assemblées du désert autour d'Orthez en 1767 », p. 143-148. 
« Je ne crois point que des assemblées publiques soient si essencièles à la religion, que des assemblées particulières ne puissent en remplir les veües et peut-être d'une façon plus parfaite. $»^{55}$

À partir de cette période, les réunions commencent à se dérouler dans des granges ; Defferre continue cependant à tenir de grandes assemblées qui cessent définitivement en avril 1767. Aux prisonniers détenus dans les geôles du parlement, il adresse sur un ton mystique, cet encouragement à la résistance :

«Vous combatés sous les étendars du prince de la vie et pour la cause la plus juste et la plus glorieuse qui fut jamais. [...] Ah réjouissés vous d'être injuriés et persécutés au sujet de J. Ch., faites éclater votre joye, parce qu'une grande récompense vous attant dans le ciel. $»^{56}$

Le pasteur a donc utilisé une fois de plus la scène des grandes assemblées pour manifester symboliquement, par un geste public et non par la parole, sa désapprobation vis-à-vis d'une divergence fondamentale sur la conduite de l'Église.

Étienne Defferre se plie néanmoins tant bien que mal à cet accommodement, qui par ailleurs met momentanément fin aux poursuites à son encontre et assure une certaine sécurité pour son épouse et ses deux enfants nés en avril 1766 et juin 1767. Néanmoins, son jugement a été clairvoyant, les autorités ont entravé efficacement, pour la première fois, le mouvement qu'il avait initié une dizaine d'années plus tôt. Le synode n'est plus réuni après sa dernière session du 19 mars 1766 ; la liste des assemblées commencée en 1756 n'est désormais plus tenue après le 12 avril 1767. En 1772, malgré l'accord passé, les poursuites reprennent contre les pasteurs. Defferre se sentant sans doute trop exposé et considérant ne plus pouvoir apporter aux Églises de Béarn, se retire en Bas-Languedoc au printemps 1773.

\begin{abstract}
Résumé
Les grandes assemblées protestantes au Désert constituent un formidable théâtre dont l'acteur principal est le pasteur qui dans les premiers temps du redressement des Églises de Béarn, s'affiche comme le conducteur de la communauté. Bien que le message repose sur l'écrit, le geste et l'oralité sont loin d'être secondaires et c'est par le geste que passe le message le plus fort. La prédication n'est en effet pas toujours bien comprise par l'ensemble de la foule comme le montrent les témoignages, $c^{\prime}$ est davantage le caractère extraordinaire de ce nouveau personnage, sa mise en scène et les propos tenus en dehors des prédications qui restructurent la communauté. La communication passe certes par le sermon, mais peut être encore davantage par sa mise en scène au sein d'un cérémonial spécifique entièrement dédié au service du pasteur qui en est le maître d'œuvre et en use jusqu'à le détourner, voire à le transgresser.
\end{abstract}

55. H. Bost, « Correspondance... », p. 436. (19 août 1768).

56. CEPB, 60J 258, Lettre du ministre Deferre aux protestants du Béarn emprisonnés pour la foi chrétienne en 1767. 


\section{Bibliographie}

BOST Hubert, « Correspondance entre Court de Gébelin et les protestants d'Orthez (17631782)», Bulletin de la Société de l'Histoire du Protestantisme Français, t. 140 (1994), et "Espoirs et déconvenues des protestants béarnais entre 1760 et 1787 », Revue de Pau et $d u$ Béarn, $\mathrm{n}^{\circ} 22$ (1995). Ces deux textes ont été repris dans Nouvelles pages d'histoire sur le protestantisme en Béarn, C.E.P.B., Pau, 1998, p. 211-236 et p. 297-351.

CADIER Alfred, « Le protestantisme béarnais. Interrogatoire de D. Chéruques à Pau, 17 avril 1759 », B.S.H.P.F., t. 26 (1877), p.165-174.

CHAREYRe Philippe, «De Bois en Granges : Les assemblées du Désert en Béarn de 1757 à 1767 », Mélanges en mémoire de Michel Péronnet, Publications de l'Université Paul-ValéryMontpellier III, tome 2, 2003, p. 265-290.

COQuerel Charles, Histoire des églises du Désert, tome 2, Cherbuliez, Paris, 1841.

« Lettres inédites de Court de Gébelin et du pasteur Gal-Pomaret », B.S.H.P.F., 1854.

DARdier Charles, Picheral-Dardier A., Paul Rabaut. Ses lettres à Antoine Court (17391755). Dix-sept ans de la vie d'un apôtre du Désert, tome 2, Grassart, 1884, t. 2.

GRINTCHENKO Marie-Hélène, Les baptêmes protestants au Désert en Béarn 1756-1778, vol. 1 : texte, vol. 2 : liste des actes, TER, UPPA, juin 2000, $178+168$ p.

GROSSE Christian, Les rituels de la Cène. Le culte eucharistique réformé à Genève, XVI"XVII ${ }^{e}$ siècles, Genève, Droz, 2008.

Hugues Edmond, Les synodes du Désert, seconde édition, Grassart, Paris, 1891, tome 2.

KRUMENACKER Yves, «La liturgie, un enjeu dans la renaissance des églises françaises au XVIII $I^{\mathrm{e}}$ siècle », Édifier ou instruire? Les avatars de la liturgie réformée du XVI au XVIII siècle, M. C. Pitassi (éd.), Champion, 2000, p. 111-126.

RAYMOND Paul, «Le protestantisme en Béarn (1755-1756), Lettres de l'intendant Mégret d'Étigny à M. le comte de Saint-Florentin », B.S.H.P.F., 1867.

ROBERT Jean-Daniel, "Les assemblées du désert autour d'Orthez en 1767 », Réforme et Révocation en Béarn, J\&D Éditions, Pau 1986, p. 143-148.

Tucoo-Chala Suzanne, "Protestants et protestantisme en Béarn, du Désert à l'Après Révolution: 1755-1804», Nouvelles pages du protestantisme en Béarn, CEPB, Pau, 1989, p. 197-209. 


\title{
Le président face à ses discours (1932-2014)
}

\author{
Jean-Pierre BAT \\ Chargé d'études documentaires, Archives nationales \\ Émeline SEIGNOBOS \\ Docteur de l'université Paris-Sorbonne (CELSA)
}

Extrait de : Jean DUMA (dir.), Le Rituel des cérémonies, Paris, des congrès des sociétés historiques et scientifiques), 2015.

Cet article a été validé par le comité de lecture des Éditions du CTHS dans le cadre de la publication des actes du $139^{\mathrm{e}}$ Congrès national des sociétés historiques et scientifiques tenu à Nîmes en 2014.

Si aujourd'hui les nombreuses anthologies réunissant les « grands discours politiques » sont légion et cherchent à s'imposer hic et nunc comme autant de nouveaux lieux de mémoire nationaux et de monuments littéraires, la patrimonialisation de la trace reste le cœur d'une communication qui dépasse l'immédiate action politique pour recouvrir une dimension historique. À partir du mandat d'Albert Lebrun, une première stratégie élyséenne de communication politique apparaît, avec Charles de Gaulle émerge un régime à vocation présidentielle: un lien original se construit au $\mathrm{XX}^{\mathrm{e}}$ siècle entre le président et les citoyens, sur un registre à la fois personnel et institutionnel. Au-delà de l'apparition d'une technique de communication inspirée de la campagne de Kennedy avec les élections de 1965, l'enjeu patrimonial se noue à partir de la décennie 1970 et de la « société de conservation » autour du devenir des manuscrits de discours et interventions présidentiels sous la $\mathrm{V}^{\mathrm{e}}$ République. Avec l'institutionnalisation à l'Élysée de la figure de la «plume» présidentielle dans les années 2000, se fait jour un nouvel enjeu communicationnel, mémoriel et archivistique.

C'est donc dans une double tension entre «société de la communication » et "société de la conservation » que cette étude, nécessairement diachronique, entend se développer, considérant que, à partir des années soixante-dix - et notamment la création d'un service d'archives à l'Élysée -, les archives deviennent un élément de la stratégie politique de communication, avec, désormais, la postérité comme horizon. À travers ce panorama se posent alors les termes d'une archéologie communicationnelle du verbe présidentiel et de ses incarnations matérielles comme autant de traces politiques, rhétoriques et stratégiques à mettre au jour.

Cet article, qui s'appuie essentiellement sur les fonds présidentiels conservés aux Archives nationales dans la série $\mathrm{AG}$ (sous sériés 1 à 5 , de la $\mathrm{III}^{\mathrm{e}}$ à la $\mathrm{V}^{\mathrm{e}}$ République), est le fruit de la collaboration scientifique établie entre les Archives nationales et le CELSA (Paris-Sorbonne). Il s'inscrit dans une perspective pluridisciplinaire entre sciences de l'information et de la communication, histoire des institutions et archivistique. 


\section{De l'art d'être grand-père: une préhistoire de la communication présidentielle de Lebrun à Coty (1932-1958)}

La fonction présidentielle, depuis 1870 et la refondation de la République, est marquée par une essence anti-bonapartiste. En d'autres termes, tout lien politique direct entre le chef de l'État et la nation doit être proscrit, pour empêcher toute potentielle dérive du pouvoir exécutif (la crise boulangiste a rappelé à la République naissante la menace bonapartiste)... Les présidents de la $\mathrm{III}^{\mathrm{e}}$ République, issus du cursus honorum parlementaire ${ }^{1}$, intègrent tous cette donnée fondamentale lors de leur mandat. À ce titre la figure d'Armand Fallières apparaît archétypale : on parle, pour son mandat, de la "France de Monsieur Fallières", synonyme d'une société républicaine de la Belle Époque, apaisée car dirigée par le plus tranquille des notables de province qui ne cherche surtout pas à interférer dans les affaires politiques. Certes, dans certaines circonstances exceptionnelles, le président peut être amené à investir pleinement sa fonction (comme Raymond Poincaré lors de la Première Guerre mondiale) : il n'en reste pas moins que le charisme et les talents d'orateur ne sont pas les qualités premières qui définissent l'ethos de la fonction présidentielle entre 1870 et 1958. Pourquoi, dans de telles conditions, considérer la présidence d'Albert Lebrun (1932-1940) comme un jalon de cette archéologie communicationnelle? Tout simplement parce qu'il a dû adapter sa parole aux innovations techniques et technologiques (notamment la TSF ${ }^{2}$ ), d'une part, et, d'autre part, parce qu'il a créé la médiatisation du président, « patriarche » de la République.

Avec l'aide d'André Magre, un de ses proches qu'il a nommé secrétaire général de l'Élysée, Albert Lebrun va chercher à établir une stratégie de communication sans sembler céder aux tentations bonapartistes. Ce n'est en réalité qu'à la fin de son mandat, en 1939, qu'aboutissent réellement ces efforts. Le 15 avril paraît dans L'Illustration «Les jeudis de l'Élysée ou l'art d'être grand-père » mettant en scène le président et sa famille, métonymie du grand-père de la nation; le 14 juillet, il est le premier chef d'État républicain à s'adresser directement à ses concitoyens par les ondes. Au-delà de la convocation des auspices de Victor Hugo ${ }^{3}$, Albert Lebrun dessine par sa «communication» les contours de la figure présidentielle comme l'aïeul de la nation, le sage qui peut ainsi se poser au-dessus des débats pour garantir la continuité républicaine, en somme le juge de paix de la famille républicaine. Il crée ainsi un espace politique qu'il peine toutefois à investir du fait de la guerre, et notamment des prises de décisions politiques du printemps 1940 - qui sera pleinement récupéré par ses successeurs sous la IV République.

Si la Seconde Guerre mondiale constitue par essence une parenthèse institutionnelle pour la fonction présidentielle, le maréchal Pétain comme le général de Gaulle ont imposé la parole du chef de l'exécutif (quelle qu'en soit sa légitimité) comme un fondement de la politique contemporaine. En effet, l'un et l'autre ont massivement eu recours à la radio (notamment de Gaulle avec Radio Londres et Radio Brazzaville) et ont inauguré les premiers enregistrements vidéo de discours (notamment le maréchal Pétain pour les diffusions aux Actualités filmées). Les présidents de la IV ${ }^{e}$ République - surtout après le passage du général de Gaulle à la tête du GRPF (1944-1946) - ne peuvent alors faire l'économie de ces évolutions, sans toutefois trahir les fondements anti-bonapartistes de leur fonction. Le point d'orgue est sans conteste atteint avec l'appel de René Coty " au plus illustre des Français » le 29 mai 1958, par lequel il rappelle au pouvoir le général de

1. Au fil des élections, la tradition veut que le président du Sénat ait vocation à prétendre aux fonctions de président de la République.

2. Une comparaison peut être établie avec la famille royale anglaise et les efforts du prince Albert. A King's Speech, film de Tom Hooper (2010), met au cœur de l'intrigue l'élocution (défaillante) du monarque. Le rôle assigné alors au «discours du roi » à l'entrée de la Seconde Guerre mondiale se pose comme le pivot d'une (re)construction héroïque du personnage. Quant à la parole souveraine, elle prend des accents éminemment épidictiques rappelant les valeurs communes dans lesquelles le peuple britannique doit se reconnaître.

3. V. Hugo, L'Art d'être grand-père, recueil de poèmes publié en 1877. 
Gaulle pour mettre un terme à la crise du 13 Mai - quitte à achever la IV République et à ouvrir la voie à une nouvelle constitution gaulliste, promise depuis le discours de Bayeux en 1946. Plus que jamais, à l'heure de l'agonie du régime, le président a entendu assumer son rôle de patriarche de la République en procédant à la solution qui lui paraît la plus sage. Aussi le rapport à l'écrit, à la trace, s'est-il décalé sous la plume présidentielle entre 1946 et 1958 : Vincent Auriol et René Coty n'écrivent pas pour l'actualité politique mais pour l'histoire de France. Vincent Auriol écrit moins qu'il n'enregistre, avec un magnétophone dissimulé, ses entretiens dans son cabinet élyséen, à l'insu de ses interlocuteurs ${ }^{4}$. René Coty tient, depuis au moins les années trente, un journal personnel de la vie politique française ${ }^{5}$. Les archives de son secrétariat personnel à la présidence conservent les versions manuscrites de ses discours. On y découvre la «fabrique » de la parole de cet héritier littéraire de la "République des avocats»; ses «textes », genre hybride entre oralité et écrit, portent la marque de scansions (sur le modèle latin et à la manière d'une partition de musique), qui doivent rythmer sa mise en scène lors de la prononciation du discours.

Toutefois, au-delà de cette question de la parole présidentielle qui accompagne durant les Trente Glorieuses l'éclosion de la «société de communication », se jouent en filigrane les prolégomènes de la "société de conservation». Vincent Auriol, par ses enregistrements mais aussi les documents qu'il emporte à son départ de l'Élysée en janvier 1954, et René Coty, avec la tenue de son journal privé, se font les chroniqueurs de l'histoire contemporaine depuis l'observatoire le plus élevé de la République. Le cap est franchi lorsque Vincent Auriol commence l'édition du Journal du septennat, avec le concours de Pierre Nora pour l'édition critique, à partir de 1970. Cette édition devient alors le baromètre, pour de longues années, de l'édition de mémoires politiques - rendant ainsi la voix au président de manière d'autant plus forte que le temps est (légèrement) différé entre l'action et le témoignage.

Il est en revanche permis de s'interroger sur l'ambition de René Coty qui, manifestement, ne souhaitait pas rendre son journal public de son vivant. Quoi qu'il en soit, un tel artefact demeure encore l'objet d'une épiphanie archivistique, quelques décennies plus tard... Les Archives deviennent, peu à peu, par touches impressionnistes, le lieu de la communication en temps différé, une communication pour la postérité délaissant l'instantanéité de l'action bassement politique au profit d'une construction mémorielle qui donnera au temps l'opportunité d'une nouvelle exégèse. Les archives se veulent ainsi un lieu de mémoire ${ }^{6}$ aussi bien matériel qu'intellectuel, qui fait donc l'objet de stratégies communicationnelles ${ }^{7}$. En 1971, Jacques Foccart, alors secrétaire général des Affaires africaines et malgaches, remet aux Archives nationales les manuscrits du général de Gaulle qu'il a collectés. Ces pièces olographes, trace de la «main du roi », deviennent le socle du fonds Foccart constitué à la fin de la décennie soixante-dix (1977-1980) ${ }^{8}$. L'amiral Philippe de Gaulle imitera simultanément son geste en remettant aux Archives nationales les différentes versions manuscrites des discours de son père, fondant ainsi la collection de pièces authentiques (au sens le plus littéral et archivistique du terme) du fonds de Gaulle ${ }^{9}$. Avec l'avènement de la $\mathrm{V}^{\mathrm{e}}$ République et du régime gaulliste, le verbe et l'action

4. L. Theis, « Le magnétophone d'Auriol», p. 21.

5. Arch. nat., 111 AJ, fonds René Coty collecté en 2013 auprès de son descendant Benoît Duteurtre. « René Coty, découverte d'un président méconnu à travers ses journaux ", conférence de Jean-Pierre Bat et Benoît Duteurtre dans le cadre du cycle « Trésors du Patrimoine écrit » (20 mai 2014).

https: / / www.archives-nationales.culture.gouv.fr/sia/web/guest/ connaissance-des-arts 6. P. Nora, Les lieux de mémoires.

7. Les archives et manuscrits de Raymond Poincaré, président de la IIIe République (1913-1920), ont fait l'objet d'une stratégie de communication/conservation mémorielle originale. Sa veuve donne ses papiers, contenant notamment les manuscrits de ses discours (1895-1930) et de ses mémoires Au service de la France, neuf années de souvenirs, à la Bibliothèque nationale de France. BnF, NAF 15992-16063.

8. Arch. nat., 5 AG F, fonds du secrétariat général des Affaires africaines et malgaches et de la Communauté.

J.-P. Bat, «Jacques Foccart, le mythe de l'homme sans papier », colloque du centenaire des Archives du Sénégal (à paraître avec le concours du SIAF).

9. N. Éven, Inventaire des archives de la présidence du général de Gaulle (1959-1969). Considérés comme les trésors patrimoniaux des archives présidentielles, les manuscrits du général de Gaulle conservés dans le fonds 
politiques vont désormais procéder d'une unité, dont témoigne le nouvel usage de la parole présidentielle, mais aussi de la politique de conservation qui se développe autour de cette parole - pourtant par essence éphémère...

\section{La voix présidentielle et sa plume}

La $V^{\mathrm{e}}$ République est ainsi profondément, institutionnellement, constitutionnellement, incarnée par la figure présidentielle dont le verbe, $\mathrm{d}^{\text {'abord }}$ rare et donc précieux ${ }^{10}$, se veut un moment historique de communion avec les citoyens. À travers la nature des traces laissées par les présidents successifs, les modalités de leur collecte, leurs lieux de conservation, leurs matérialités, peut se lire une histoire de l'appréhension de la mémoire politique et, si l'on s'arrête davantage sur les manuscrits de discours, rhétorique ${ }^{11}$.

Le corpus des manuscrits de discours de De Gaulle conservés aux Archives nationales se pose d'emblée, matériellement, comme une collection : les différentes versions de chaque discours, à la manière d'un palimpseste, sont soigneusement classées et reliées avec, sur la tranche, en lettres d'or, l'année durant laquelle il a été prononcé. Ces « annales » de la parole gaullienne, ces reliques de la fabrique rhétorique du président, se présentent comme des «textes » déjà ordonnés, prêts à l'exégèse historique et à l'analyse des différentes leçons. Le discours final se rempare, en creux, d'un possible apparat critique témoin d'une pensée première que le dire stratégique a occultée.

Pour Georges Pompidou, nul corpus organique : le président qui meurt d'une maladie secrète et rare au cours de son mandat ${ }^{12} \mathrm{n}^{\prime}$ a pas eu le temps de penser l'après-fonction ni les traces destinées à une relecture future. Le fonds conservé aux Archives nationales apparaît bien disparate au regard de l'exhaustivité ordonnée gaullienne. Reconditionnés dans des dossiers, chemises et sous-chemises, les manuscrits et annotations présidentiels ont été récupérés par ses collaborateurs, au premier chef desquels Édouard Balladur, secrétaire général de l'Élysée, qui se fait le gardien du temple mémoriel pompidolien ${ }^{13}$. Le fonds n'est plus ce marbre dans lequel s'est forgée la statue du commandeur (patrimoniale) que le lecteur des archives découvre en lisant, par exemple, les recueils de discours de De Gaulle: il invite surtout à la redécouverte fragmentée de la voix présidentielle tout à la fois intime et officielle.

C'est avec le septennat du jeune Valéry Giscard d'Estaing que se dessine une véritable volonté de constituer, à chaud, au cœur de l'actio politique, un fonds structuré et exhaustif de la présidence. Entre témoignage de "transparence » et désir de "laisser une trace dans l'histoire », le fonds Giscard est ainsi le résultat d'une collecte systématique et professionnelle qu'incarne la nomination le 18 juin 1974 (à la demande de Philippe Sauzay $^{14}$, chef de cabinet du président) de Perrine Canavaggio, à la tête d'un service inédit: celui des archives de l'Élysée. Cette même conservatrice assurera cette fonction jusqu'aux dernières années du deuxième mandat de François Mitterrand, dépolitisant ainsi ce poste dédié à la construction de la mémoire présidentielle in situ.

de Gaulle (5 AG 1) et dans le fonds Foccart (5 AG F) ont fait l'objet en 2014 d'un programme de numérisation intégrale.

10. En tout cas selon les préceptes du peu loquace conseiller en communication politique Jacques Pilhan dans l'un des rares entretiens qu'il a accordés, J. Pilhan « L'écriture médiatique ».

11. É. Seignobos, « Les discours présidentiels aux Archives nationales : l'urgence de la postérité ».

12. Le président Pompidou meurt le 2 avril 1974 de la maladie de Waldenström.

13. Son engagement est amorcé avec la constitution d'un fonds d'archives privées aux Archives nationales (543 $\mathrm{AP})$, véritable complément direct de 5 AG 2. Ce fonds s'ouvre sur la mémoire de Georges Pompidou et la compilation de ses notes et commentaires présidentiels. En 2011, à la faveur du centenaire de la naissance de Georges Pompidou, inscrit dans le programme des commémorations nationales, Édouard Balladur s'affirme comme l'exécuteur testamentaire de la mémoire archivistique de Georges Pompidou en remettant notamment les notes manuscrites de son ultime conseil des ministres conclu par les mots: "Alors on verra bien. J'ai le ferme espoir d'embêter tout le monde ». La retranscription se trouve dans P. Geneste (dir.) et J.-P. Bat, Georges Pompidou, 1911-2011, p. 101-103.

14. P. Sauzay, « La collecte exemplaire des archives présidentielles de Valéry Giscard d’Estaing ». 
Cette quête de la voix présidentielle tapie dans les cartons d'archives prend tout son sens quand le président est écrivain. On voudra alors y lire, comme dans les manuscrits littéraires dont on connaît la fortune patrimoniale et scientifique ${ }^{15}$, les errements de la pensée politique et les secrets de fabrication du verbe ; on y verra, derrière les volutes plus ou moins hésitantes de la plume, la main de ce personnage déjà historique au soir de son élection ; on y pressentira parfois un frisson d'intimité que tout autre retranscription ou captation vidéo ne saurait transmettre. "Écrivain », Charles de Gaulle le fut sans conteste; il se définissait lui-même de trois manières : militaire, politique et écrivain. Dans cette logique, son fils, l'amiral Philippe de Gaulle, a remis les manuscrits de ses ouvrages à la Bibliothèque nationale pour consacrer le littéraire derrière le politique ${ }^{16}$. Georges Pompidou, connu de l'opinion publique sous le titre d'« agrégé sachant écrire », citait des poètes dans ses conférences de presse, rappelant ainsi sa formation en lettres à l'École normale supérieure. Valéry Giscard d'Estaing et François Mitterrand ont aussi marqué la postérité de leur plume qui ne fut pas seulement logographique ${ }^{17}$. L'existence de $l^{\prime}$ « écrivant ${ }^{18}$ ", du «nègre ", de la "plume» n'a connu la lumière et les feux médiatiques que récemment, dressant une nouvelle cartographie archivistique et mémorielle du verbe présidentiel et de sa genèse.

\section{Le président et ses plumes}

Pour comprendre l'avènement de la figure politique de la "plume» présidentielle, il convient de renouer le fil des années soixante et, dans l'ombre du verbe gaulliste, les premiers pas du conseil en communication. Le référendum de 1962 fait tomber - au grand dam de la classe politique issue des $\mathrm{III}^{\mathrm{e}}$ et $\mathrm{IV}^{\mathrm{e}}$ Républiques - une digue traditionnelle de la République française avec l'élection du président au suffrage universel - acte fondateur de la prise du pouvoir de Louis-Napoléon Bonaparte en décembre 1848. Le général de Gaulle, considérant que depuis 1940 un lien particulier et absolu l'unit aux Français, dédaigne recourir à des agences de communication pour la campagne de 1965. Jean Lecanuet, candidat inconnu des électeurs, parvient au contraire à se créer une surface et une personnalité politiques en 1965 grâce à l'agence de communication de Michel Bongrand... dont de Gaulle avait préalablement refusé les services. Selon certains sondages, la stratégie de communication de Lecanuet l'aurait fait passer de 4 à $15 \%$, soit près d'une dizaine de points - qui feront défaut à de Gaulle au premier tour. Michel Bongrand s'est délibérément inspiré de la campagne de Kennedy, qu'il a suivie aux États-Unis. Il n'y a qu'à se référer aux affiches électorales pour s'en persuader : le sourire est franc, un brin séducteur ${ }^{19}$. La vie privée de l'homme politique se dessine sur tous les murs de France, pour la première fois, comme un argument de confiance publique.

Pour l'échéance des législatives de 1967, l'état-major gaulliste est soucieux de ne pas rééditer la même erreur: Jacques Foccart, ancien camarade parachutiste de Michel

15. M. O. Germain et D. Thibault (dir.), Brouillons d'écrivains, p. 38 : «L'importance accordée aux traces de leur travail par les écrivains eux-mêmes et le goût contemporain pour les signes précieux et instables de la création vont faire du manuscrit tout à la fois un "objet culte", un objet d'art et un objet d'étude. ”

16. BnF NAF 28590. Certains discours, datant notamment de la guerre (1943-1944), ont fait l'objet d'une politique d'acquisition de la Bibliothèque nationale de France. BnF, NAF 17596-17572.

17. Élu à l'Académie française en 2003 au fauteuil de Léopold Sédar Senghor, Valéry Giscard d'Estaing a notamment publié Le Passage chez Robert Laffont en 1994, La Princesse et le président chez De Fallois en 2009 et Mathilda chez XO en 2011. François Mitterrand sera également l'auteur de nombreux ouvrages, entre chroniques et réflexions politiques.

18. Nous reprenons ici la distinction faite par R. Barthes dans «Écrivains et écrivants », p. 152: «La parole de l'écrivain est une marchandise livrée selon des circuits séculaires, elle est l'unique objet d'une institution qui n'est faite que pour elle, la littérature ; la parole de l'écrivant, au contraire, ne peut être produite et consommée qu'à l'ombre des institutions qui ont à l'origine, une toute autre fonction que de faire valoir le langage: l'Université, et, accessoirement, la Recherche, la Politique, etc. [...] »

19. En 1974, l'équipe de campagne de Jacques Chaban-Delmas cherche à réactiver cette adaptation du mythe d'un Kennedy à la française. 
Bongrand, prend contact avec lui en accord avec Georges Pompidou pour organiser la campagne dès décembre $1966^{20}$. Le cabinet de Michel Bongrand, "Services et Méthodes » dont la devise est "Savoir faire savoir", prépare le vademecum des candidats. Des modèles de discours sont méthodiquement préparés suivant les contextes (députés sortants ou challengers) : il en ressort une véritable mallette électorale rhétorique, qui se veut une déclinaison pure et simple, mais sans risque de pastiche, du propos présidentiel assorti d'une explication de texte et d'une grille d'emploi pour éviter toute initiative malheureuse. En somme, se joue ici la fabrique d' «éléments de langage » avant la lettre, venant contrecarrer une circulation médiatique de la parole politique de plus en plus périlleuse. Avec le succès de cette expérience, Georges Pompidou, qui s'initiait au suffrage universel avec les législatives de 1967, décide de conserver une stratégie de mise en scène de son message politique. Celle-ci ne se résume pas à sa prise de parole: souhaitant incarner la modernité dans la tradition après Mai 68, il s'appuie sa communication sur l'ombre du général de Gaulle et l'emploi du «Bleu Pompidou ».

Cette période 1967-1969, caractérisée par les orientations tactiques et communicationnelles de Georges Pompidou et la collaboration du parti gaulliste avec Michel Bongrand, a posé les fondements (méconnus) d'une nouvelle théâtralité de la parole présidentielle après le général de Gaulle. Avec les années 1980 et la présidence de François Mitterrand, une autre étape va être franchie avec le concours de conseillers en communication tels que Jacques Séguéla et Jacques Pilhan. Le slogan "La force tranquille ", auquel l'imaginaire collectif attribue en grande partie la victoire de la gauche en 1981, cristallise l'avènement d'un autre marketing, politique celui-ci. Preuve de son succès, la paternité en est encore disputée notamment entre Séguéla, Pilhan (alors son collaborateur) et même par l'équipe de Bongrand - pourtant inscrit dans le camp adverse.

Jacques Pilhan, surnommé «le sorcier de l'Élysée ${ }^{21}$ », introduit une nouvelle dimension au sein de la présidence de la République. Venant, comme Jacques Séguéla et Michel Bongrand, du monde privé, il collabore étroitement à partir de 1983 avec Gérard Colé, conseiller en communication de François Mitterrand, pour finir par le remplacer en 1989. Tout en conservant ses activités privées, il devient ainsi officiellement conseiller à la présidence de la République (se faisant notamment l'aède de la «stratégie du désir »). Au service de François Mitterrand jusqu'en 1995, il passe à celui de Jacques Chirac, poursuivant ainsi sa mission élyséenne malgré l'alternance : il sera le mentor de Claude Chirac, la fille du président nouvellement élu qui tiendra les ficelles de la communication présidentielle.

Pour autant, la consécration du marketing politique dans ces décennies 1980 et 1990 ne suffit pas à embrasser tous les aspects de la communication présidentielle. En effet, un nouvel espace politique va s'affirmer à travers l'enjeu de la parole et des discours : celui de la «plume » présidentielle. Les collaborateurs sollicités, traditionnellement recherchés pour leur fibre littéraire, posent un paradigme: l'équilibre entre l'esprit (le souffle du discours) et la lettre (la dimension technique du métier de conseiller). François Mitterrand et Jacques Chirac se sont ainsi, tous deux, entourés d'écrivains : Érik Orsenna pour le premier, Denis Tillinac pour le second. Il est toutefois délicat d'évaluer leur influence exacte, face à la machinerie politique du secrétariat général de l'Élysée et des travaux des conseillers techniques en vue des prises de parole présidentielle. Ce sont donc plus des "écrivants", des «agrégés sachant écrire » que vont rechercher les présidents que des écrivains passés à leur service. Christine Albanel, sous Jacques Chirac, incarne cette première mutation : agrégée de lettres devenue haut fonctionnaire, elle offre un profil parfait pour prendre en charge dès 1995 l'écriture de la parole chiraquienne.

20. Arch. nat., 5 AG F, fonds Foccart. Partie inavouée de la campagne électorale, le recours à Michel Bongrand n'a laissé que peu de trace : c'est finalement dans le fonds Foccart, chargé d'aspects fort techniques et politiques de la campagne, que se retrouvent la documentation produite par "Services et Méthodes » et les échanges avec Michel Bongrand.

21. Sur ce personnage de l'ombre, central en communication politique dans les années quatre-vingts, se référer notamment à F. Bazin, Le Sorcier de l'Élysée. 
Dès le début du premier mandat, elle signe trois " grands discours » : le discours du Vel d'Hiv (16 juillet 1995), l'hommage à François Mitterrand (8 janvier $1996^{22}$ ) et l'annonce de la dissolution de l'Assemblée nationale (21 avril 1997). La communication reste toutefois sous la haute main du service de communication dirigé par Claude Chirac, tant pour des raisons politiques et personnelles qu'institutionnelles. Ces mandats chiraquiens fonctionnent pourtant comme une période d'incubation...

Avec l'élection de Nicolas Sarkozy et la banalisation du marketing politique, la figure de la «plume » présidentielle se trouve - paradoxalement - sortie de l'ombre et installée en pleine lumière tant elle incarne une dimension stratégique de la communication présidentielle. Si tout candidat peut avoir recours à des agences de communication, la distinction réside désormais dans le charisme. Qu'importe alors que les mots ne soient pas ceux du président en personne : il donne le souffle que met en lettres et en musique un de ses plus proches conseillers, érigé en véritable fondé de pouvoir intellectuel. Ceci justifie que la «plume » soit élevée au rang statutaire de «conseiller spécial » à partir de 2007. Dans les faits, elle répond directement de ses actes au président de la République, et non plus au secrétaire général comme tout conseiller ordinaire. Henri Guaino, gaulliste revendiqué passé par les cercles chiraquiens, inaugure cette fonction. Il signe les principaux discours du quinquennat de Nicolas Sarkozy, dont le discours d'investiture (16 mai 2007), le polémique discours de Dakar (26 juillet 2007) - qui met au jour son rôle dans l'opinion publique - ou encore le discours du Congrès de Versailles (22 juin 2009). Espace public stratégique de la politique élyséenne, la fonction de " plume » se décline au fil du mandat autour de trois individus, promus à des rangs protocolaires hiérarchisés. Après Henri Guaino, Camille Pascal est officiellement nommé en 2011 en qualité de conseiller pour l'audiovisuel, puis Marie de Gandt intègre les cercles UMP dès 2009 grâce à Laurent Wauquiez, son camarade de promotion à l'École normale supérieure: ils rejoignent la présidence de la République en qualité «d'agrégés sachant écrire ». Camille Pascal, promu au rang de "deuxième plume », devient alors le concurrent direct d'Henri Guaino, et assume sa posture de conseiller « cathodique et catholique ${ }^{23}$ » qui irrigue, en partie, ses discours.

Les premières années du mandat de François Hollande consacrent cette place spécifique de la «plume» comme conseiller spécial : Aquilino Morelle, l'un de ses plus proches collaborateurs lors de la campagne présidentielle de 2012, investit cette fonction sitôt le candidat socialiste élu. Il est également nommé «chef du pôle de communication » de l'Élysée, fusionnant in fine sur la figure de la «plume» l'enjeu de la communication présidentielle, éminemment liée à l'ethos du président de la $\mathrm{V}^{\mathrm{e}}$ République. Il démissionne de ses fonctions en avril 2014.

La $V^{\mathrm{e}}$ République a consacré l'avènement du verbe présidentiel, à l'aune du régime gaullien. Le verbe gaulliste, incarnation littéraire (supposée ou réelle suivant les observateurs) de la nation, se fait baromètre politique, sur l'héritage de l'appel du 18 juin tenu pour la parole originale - et nécessairement mythifiée - de la geste gaulliste ${ }^{24}$. Devenu président d'une République où l'exécutif s'affirme comme il n'osait plus le faire depuis 1870 par anti-bonapartisme fondateur de la République parlementaire (celle des avocats), le général de Gaulle pose les fondements d'une parole rare, et donc précieuse. Plus que tout autre prise de parole officielle, les discours constituent un témoignage qui répond à la double tension de l'immédiate action politique et de la postérité. En découle

22. Il est intéressant de signaler, dans ce cas, que la version de Christine Albanel - transcendant les personnalités pour valoriser la fonction présidentielle - l'emporte sur celle de Denis Tillinac qui avait également soumis un manuscrit. Se fait jour une forme de concurrence des " plumes » notamment dans leurs témoignages de la geste oratoire du président.

23. "Camille Pascal, un conseiller cathodique et catholique », La Croix, 24 janvier 2012. Ainsi, il est 1'auteur du discours du 6 janvier 2012 par lequel Nicolas Sarkozy, en visite en Lorraine, vient célébrer l'anniversaire de Jeanne d'Arc pour récupérer ce symbole national à la propagande Front national (Jeanne d'Arc « n'appartient à aucun parti »).

24. Ceci est tellement vrai que, dans la mémoire populaire, les mots célèbres résumant l'action du général de Gaulle et de la France libre («La France a perdu une bataille mais elle n'a pas perdu la guerre ») sont identifiés, à tort, à l'appel du 18 juin 1940. 
une double tension patrimoniale, entre "société de communication" et "société de conservation », dans laquelle les Archives nationales deviennent un enjeu, consacré par la création du service des archives au palais de l'Élysée en 1974.

Dès lors, la trace princeps de la main du prince, tenue pour le trésor patrimonial contemporain par excellence, devient l'observatoire de la fabrique de la pensée du chef de l'État, c'est-à-dire une voie intime pour toucher au cœur de sa pensée la plus personnelle (cet écho patrimonial prend tout son sens dans un régime politique extrêmement personnalisé tel que la $\mathrm{V}^{\mathrm{e}}$ République). Une double sacralisation se joue, plus ou moins consciemment, entre les palimpsestes du travail d'écriture (manuscrit, tapuscrit corrigé de la main du président, tapuscrit final) et leur conservation.

Simultanément, l'émergence de l'ère médiatique contraint ses successeurs à adapter les principes gaullistes de la parole présidentielle aux nécessités et aux évolutions des sociétés modernes, où les professionnels de la communication et du marketing politiques (trivialement surnommés spin doctors) s'imposent comme de nouveaux acteurs politiques. Or, malgré l'avènement des conseillers en communication au palais de l'Élysée, il apparaît que la maîtrise du verbe présidentiel, ce souffle politique qui unit le chef de l'État à la nation, se réaffirme sous une forme inédite.

Politiquement, par l'émergence de la "plume », s'est construit un double corps politicolittéraire du président, sur l'héritage institutionnel du verbe (fondateur) gaullien sous la $\mathrm{V}^{\mathrm{e}}$ République $^{25}$. Archivistiquement, la «topographie imaginaire de $\mathrm{l}^{\prime}$ histoire ${ }^{26}$ » entre en mouvement: les manuscrits des discours présidentiels quittent le secrétariat particulier du président pour les fonds des conseillers spéciaux - fonds devenus de nouveaux enjeux de collecte ${ }^{27} \ldots$

\begin{abstract}
Résumé
La parole présidentielle fait aujourd'hui l'objet de toutes les attentions et analyses médiatiques. Synthèse de l'homme et du politique, elle revêt une dimension nécessairement historique, se prêtant volontiers à la patrimonialisation et à l'anthologie des "grands discours qui ont marqué les Français ». À travers les traces manuscrites des discours conservées aux Archives nationales, apparaît, en filigrane, la fabrique du dire présidentiel. $\mathrm{C}^{\prime}$ est donc à une forme d'archéologie oratoire, communicationnelle et politique qu'invite cet article. Cette mise au jour pluridisciplinaire prend en compte différentes strates, de la $\mathrm{III}^{\mathrm{e}}$ à la $\mathrm{V}^{\mathrm{e}}$ République, depuis le mandat d'Albert Lebrun jusqu'à celui de François Hollande. Dans une appréhension diachronique, elle pose en regard l'émergence de la «société de communication » politique et la «société de conservation » en même temps qu'elle révèle les métamorphoses des pratiques et stratégies discursives élyséennes. La plume du président, sacrée et éminemment signifiante jusque dans ses ratures et hésitations, cède le pas aux "plumes» et autres « conseillers spéciaux». En ce sens, la «topographie imaginaire de l'histoire » que sont les archives s'en trouve profondément modifiée.
\end{abstract}

25. E. Kantorowicz, Les Deux Corps du roi.

26. Y. Potin, «L'historien en "ses" archives".

27. Henri Guaino, ardent défenseur du bilan de Nicolas Sarkozy, ne fait pas mystère (le jour même de l'investiture de François Hollande) de ses prétentions à écrire les chroniques du quinquennat... Et, à cette fin, auraient été conservés des documents à son départ de l'Élysée. 


\section{Bibliographie}

BARTHES Roland «Écrivains et écrivants », Essais critiques, Paris, Le Seuil, 1964, p. 147-154.

BAZIN François, Le Sorcier de l'Élysée, Paris, Plon, 2009.

ÉVEN Nicole, Inventaire des archives de la présidence du général de Gaulle (1959-1969), Paris, Archives nationales, 2012.

GENESTE Pascal (dir.) et Jean-Pierre BAT, Georges Pompidou, 1911-2011, catalogue d'exposition, Paris, Archives nationales, 2011.

GERMAIN Marie Odile et THIBAUlT Danièle (dir.), Brouillons d'écrivains, Paris, Bibliothèque nationale de France, 2001.

KANTOROWICZ Ernst, Les Deux corps du roi, Paris, Gallimard, 1989.

NORA Pierre, Les lieux de mémoires, Paris, Gallimard, 1984-1992.

PILHAN Jacques (entretien avec), «L'écriture médiatique », Le Débat, 87, 1995, p. 3-24.

POTIN Yann, «L'historien en "ses" archives », dans GRANGER Christophe (dir.), À quoi pensent les historiens, Paris, Autrement, 2013, p. 101-117.

SAUZAY Philippe, «La collecte exemplaire des archives présidentielles de Valéry Giscard d'Estaing ", dans Association des archivistes français, Les Archives des hommes politiques contemporains, Paris, Gallimard, 2007, p. 77-89.

SEIGNOBOS Émeline, «Les discours présidentiels aux Archives nationales : l'urgence de la postérité », Communication E langages, 177, septembre 2013, p. 135-154.

THEIS Laurent, « Le magnétophone d'Auriol », L'Histoire, 400, juin 2014, p. 21. 

Lieux 


\title{
Communiquer sur la citoyenneté et la latinité par le spectacle dans l'amphithéâtre de Nîmes (1900-1937)
}

\author{
Sabine TEULON LARDIC \\ CRD de Nîmes, \\ Académie de Nîmes
}

\begin{abstract}
Extrait de : Jean DuMA (dir.), Le Rituel des cérémonies, Paris,
Édition électronique du CTHS (Actes des congrès des sociétés historiques et scientifiques), 2015.
Cet article a été validé par le comité de lecture des Éditions du CTHS dans le cadre de la publication des actes du $139^{\circ}$ Congrès national des sociétés historiques et scientifiques tenu à Nîmes en 2014.
\end{abstract}

En ce $\mathrm{XIX}^{\mathrm{e}}$ siècle qui a sacralisé le théâtre en Europe, tant par ses créations que par l'édification de théâtres au cœur des villes, les instances politiques françaises de la III République tentent de décentraliser et démocratiser le théâtre, un puissant levier laïque pour former les citoyens. Pour conquérir de nouveaux publics, il s'agit de proposer le spectacle dans de vastes espaces de plein air. À cet effet, mobiliser les théâtres antiques a un double impact: celui d'accueillir un public de masse sur d'autres échelles qu'une salle de théâtre, celui de concevoir des spectacles renouant avec la grandeur de la civilisation gréco-romaine aux lendemains de la défaite de Sedan.

Forte de ces motivations, la naissance de spectacles théâtraux dans les sites antiques de la France méridionale, ex-colonie gallo-romaine, connaît un essor considérable : le théâtre antique d'Orange (1869) lancé par les Félibres, les arènes modernes de Béziers (1898) sous l'égide d'un mécène viticulteur, les amphithéâtres d'Arles et de Nîmes (1899), toutes villes desservies par le réseau ferré Paris-Lyon-Méditerranée qui communique sur la romanité du département du Gard par voie d'affiche (fig. 1 : Affiche du P.L.M. / Syndicat d'initiative des intérêts généraux de Nîmes et du Gard). Dans l'arc méridional de ces villes, le besoin de s'émanciper du centralisme parisien n'est pas étranger à cette activité. Effectivement, ces festivals sont concomitants du Théâtre du peuple à Bussang, puis du Théâtre National ambulant de F. Gémier.

À Nîmes, préfecture du Gard et principale ville du Bas-Languedoc, cité tranquille prospère, dont la population ouvrière est majoritaire à la Belle Époque, un cycle théâtral est progressivement instauré dans l'amphithéâtre à compter de 1900. Après nos deux premières études parues sur ce cycle ${ }^{1}$, nous proposons d'éclairer différemment ce champ inexploré sur la période précédant la Seconde Guerre mondiale. En premier lieu, notre recensement des productions de 1900 à 1937 présente la matière de notre investigation (documents d'archives de Nîmes et du Gard).

Ensuite, notre interrogation porte sur les processus de communication et de représentation des idéologies durant l'entre-deux-guerres. L'enceinte nîmoise antique anime en effet le projet citoyen d'un théâtre pour le peuple promu par R. Rolland, tandis que la réception des spectacles active la construction de l'identité latine. Nous souhaitons mettre en perspective l'ambivalence ou la convergence de cette double communication par le discours des acteurs (organisateur, édile, artiste) et celui de la réception (dépouillement de la presse). Notre recherche s'inscrit dans les enjeux de l'histoire culturelle.

1. S. Teulon Lardic "Mireille à Arles et Carmen à Nîmes: fabriquer l'évènement multiculturel dans l'amphithéâtre », p. 167-191; « Opéras et spectacles avec musique dans l'amphithéâtre de Nîmes (1900-1930) ». 


\section{Instaurer un cycle théâtral dans l'amphithéâtre de Nîmes}

C'est dans l'amphithéâtre romain que les initiatives d'acteurs nîmois et gardois, président à cette première vague de décentralisation culturelle. Restauré par l'architecte Henri Révoil en 1866, il renoue avec sa fonction de lieu de spectacle, abandonnée depuis le $\mathrm{V}^{\mathrm{e}}$ siècle. Jeux tauromachiques, concours équestres, cinématographe (après 1910) s'y déroulent durant la saison d'exploitation d'avril à octobre. Ses atouts résident dans ses espaces de circulation et sa capacité d'accueil, décrits par V. Lassalle :

«La structure intérieure du monument (...) a été conçue pour assurer de la façon la plus satisfaisante la circulation des spectateurs. Ceux-ci pouvaient accéder à des vomitoires proches de leur place grâce à 5 galeries concentriques situées à divers niveaux et reliées entre elles par de nombreuses galeries et escaliers rayonnants. $»^{2}$

Sa jauge d'environ 25000 spectateurs est démesurée ramenée à la population nîmoise de 74600 habitants en 1900, de 82000 en 1939³. Elle induit un meilleur ratio coût de production / billetterie et permet la tarification la plus accessible de tous les festivals méridionaux de plein air avant la Grande Guerre : 2 francs les places modestes, comparée à celle de 5 francs à Béziers, de 4 francs à Orange. Ce tarif nîmois est comparable au salaire moyen de journée d'un ouvrier, évalué à 2, 60 francs en 1900.

Dans cette sorte de compétition à laquelle se livrent les villes-ressources du Midi de la France, les instances tour à tour entrepreneuriales et publiques se relaient pour initier puis pérenniser un festival théâtral dont j'ai recensé les principales éditions (Tableau : les spectacles festivaliers dans l'amphithéâtre de Nîmes 1900-1930). Avant la Première Guerre, l'entrepreneur des arènes de Nîmes et d'Arles (A. Fayot), en est l'instigateur dès 1899. Puis, le Comité municipal des fêtes, le Syndicat d'initiative des intérêts régionaux lui succèdent avant le lancement du cycle "Théâtre antique des Arènes ", qui est délégué à un directeur artistique. Durant l'entre-deux-guerres, la direction du festival devient mixte, associant l'Association nîmoise de la Presse et le Syndicat d'initiative (1919). À compter de 1923, le retour au monopole de l'entrepreneur des arènes est entériné par le cahier des charges de l'adjudication de l'amphithéâtre.

Si ce cycle festivalier demeure quantitativement modeste - deux soirées estivales en moyenne - le faste des productions lui confère un aspect évènementiel et ses thématiques se démarquent de la scène parisienne. Les dégager brièvement permettra d'étudier par la suite les idées qu'elles véhiculent:

- l'axe prépondérant du théâtre antique (depuis CEdipe-roi de Sophocle en 1903) ou classique français (Corneille, Racine), plus rarement contemporain (A.-F. Hérold). Ces productions sont décentralisées depuis la Comédie-Française ou le théâtre de l'Odéon, un processus acté par l'administration municipale dans le cahier des charges :

«L'entrepreneur est tenu d'organiser dans la saison deux spectacles dramatiques au moins. Les œuvres qui seront représentées ou tout au moins leurs principaux interprètes, devront appartenir aux scènes de Paris, subventionnées par l'État. Deux créations devront être montées dans le cours des cinq années d'exercice. »"

- l'axe des opéras mobilise le répertoire quasi exclusivement français. Relevons la présence privilégiée de Mireille la Provençale et de Carmen de G. Bizet dès les premières éditions $(1899,1901)$, celle d'Enée dans Les Troyens de Berlioz lors des Fêtes de la victoire (1919), une production décentralisée depuis l'Opéra de Paris. Cependant, quelques

2. V. Lassalle, "L'amphithéâtre », Nîmes antique, p. 97. Le vomitoire est « un large passage donnant sur une précinction et où débouche un escalier radial donnant accès aux gradins » (ibid., p. 127).

3. Bulletin municipal de la ville de Nîmes, année 1900, année 1939.

4. Archives Départementales du Gard, série 8 T 12, Entreprise des spectacles dans les Arènes / saisons 1924 [à] 1928 /

Cahier des charges, article 20. 
Italiens sont consacrés (P. Mascagni, A. Boïto, G. Verdi), Ä̈da paraissant en 1920, soit sept ans après l'inauguration du festival Verdi dans l'amphithéâtre de Vérone. Remarquons la dominante latine : pour un Faust ou un Werther, les héros romains ou grecs, les héroïnes antiques (d'Aïda à Messaline) et celles contemporaines (précitées) surgissent du pourtour méditerranéen.

- peu de créations émergent des cycles, néanmoins celles tentées sont d'envergure telles Sémiramis de J. Péladan (1904), Dans la tourmente de M. Richard (1909). Leur réalisation suscite d'immenses décors de toile jouant de la hauteur de l'édifice ou bien de son antiquité en y incluant des colonnades (fig. 2 : décor antique pour la création du Jeune Dieu d'Hérold, 1911).

- de rares concerts sélectionnent La Damnation de Faust de Berlioz d'après Goethe (1902) ou Polyxène de T. Gouvy (1924), oratorio profane d'après les tragiques grecs. En esquivant le répertoire religieux, le spectacle nîmois demeure dans la filiation de ses rituels païens. Nous reviendrons sur cet aspect en interrogeant la réception.

Quant à l'édition 1937, sa particularité provient d'un évènement local : le transfert de la statue du Taureau d'Auguste Cain depuis le Trocadéro de Paris vers les Allées Jean Jaurès de Nîmes ${ }^{5}$. En comparaison de celui d'Orange, l'ADN de l'amphithéâtre nîmois semble donc plus diversifié en genre - drame avec ou sans musique de scène, opéra. En comparaison des arènes de Béziers, il s'oriente moins vers les commandes créations, ne bénéficiant pas ici du mécène viticulteur biterrois.

\section{Communiquer sur la citoyenneté}

«Le théâtre du peuple n'est pas un article de mode et un jeu de dilettantes. C'est l'expression impérieuse d'une société nouvelle, sa voix et sa pensée (...) Il ne s'agit pas d'ouvrir de nouveaux vieux théâtres. Il s'agit d'élever le Théâtre par et pour le Peuple. Il $\mathrm{s}^{\prime}$ agit de fonder un art nouveau pour un monde nouveau. ${ }^{6}$

L'injonction de Romain Rolland se concrétise en partie dans l'amphithéâtre nîmois. En partie car le mot d'ordre de "théâtre par et pour le peuple » s'incarne à Nîmes dans l'affirmation d'une culture de masse diffusée et accessible pour les citoyens dans le double sens du terme, soit «jouir des droits de la cité", soit «pratiquer les vertus nécessaires à la sauvegarde des libertés démocratiques ${ }^{7}$ ». Mais en sus, le spectacle nîmois s'inscrit dans le concept de latinité, propre au territoire méditerranéen, qui plus est dans l'enceinte gallo-romaine. Ces concepts entrent en convergence sur un territoire fortement marqué par le Félibrige, mais également par l'anti-jacobinisme des régions méridionales, d'autant que les mouvements ouvriers ont déclenché les récentes émeutes de la crise viticole languedocienne en $1907^{8}$. À ce propos, le plaidoyer du député Charles-Roux stigmatisant le pouvoir centralisateur de l'État-Nation dans sa monographie Nîmes, dévoile les « mentalités collectives » des méridionaux.

«Pourquoi faut-il que de récents évènements nous obligent à faire un triste retour en arrière et que notre cher peuple du Midi, donnant libre cours à sa colère, ait fait succéder les émeutes aux farandoles et arboré le signal de la révolte ? - La cause n'en est-elle pas dans la centralisation parisienne poussée à l'excès, dans l'ignorance des vrais besoins des populations placées loin de l'orbite de la capitale? (...) Ce n'est point sur le boulevard des Italiens ou dans les coulisses de l'Opéra qu'on apprend à gouverner un peuple, unifié sans doute, mais composé d'éléments divers, dont les mœurs, les caractères, l'état d'âme, varient suivant les régions qu'il habite et le soleil qui l'éclaire. »9

5. Les deux représentations précèdent l'inauguration du monument le 16 mai et la corrida de gala dans l'amphithéâtre.

6. R. Rolland, « Préface (1903) », Le Théâtre du peuple, p. 27.

7. Article « citoyen ", Grand Larousse de la langue française, vol. 2, p. 748.

8. Le 2 juin 1907, 200.000 à 300.000 manifestants défilent sur les boulevards nîmois qui convergent vers l'amphithéâtre, dont le maire, G. Crouzet. Cf. R. Huard, Histoire de Nîmes, p. 316.

9. J. Charles-Roux, Nîmes, p. 70. 


\section{Programmer, produire, instrumentaliser}

Reliées à ces mentalités collectives, les thématiques de programmation génèrent un discours militant de la part des acteurs nîmois. Le Comité des fêtes de la ville énonce son ambition culturelle :

«Faire revivre la cité dans sa gloire antique, travailler à augmenter le rayonnement de son nom, la servir fidèlement et pieusement dans ses intérêts matériels aussi bien que moraux (...), assurer la place prépondérante que notre ville doit avoir parmi les villes d'art célèbres, parmi les cités qui sont devenues ces temps derniers - telles Orange, ou Béziers - des centres d'attraction pour le monde des lettrés, des artistes, ou simplement des étrangers épris de beauté. ${ }^{10}$

En 1903, le Syndicat d'initiative des intérêts de Nîmes et du département du Gard (cf. fig. 1) mobilise le festival comme outil de communication territoriale sous la plume de son secrétaire qui souhaite fédérer ses concitoyens :

«Un âge nouveau commence pour les régions dont Nîmes est la capitale. Au-dessus de toutes les querelles politiques si ardentes chez nous, - et nous nous en faisons gloire, car chacun de nous est passionné par son idéal - le Syndicat d'Initiative est dès maintenant le champ d'action où toujours plus nombreux, nous nous trouverons tous unis pour donner à Nîmes et au Gard une des premières places parmi les plus belles régions de France. » ${ }^{11}$

L'année suivante, le Syndicat développe une rhétorique analogue à celle de R. Rolland lorsqu'il décide d'abaisser les places les plus modestes à 2 francs et s'inscrire par-là au cœur des enjeux du spectacle de masse :

«Des spectacles comme celui du 24 juillet qui constituent des fêtes d'art incomparables, doivent être accessibles aux travailleurs. L'âme populaire frissonne d'enthousiasme et de joie en présence de purs chefs-d'œuvre. C'est le peuple qui retire le plus grand bienfait de ces merveilleuses représentations données avec les plus grands acteurs des temps modernes. Le grand public sera profondément reconnaissant au Syndicat de l'avoir compris. $»^{12}$

L'accession en mairie des radicaux-socialistes (1909) permet de pérenniser cette tarification, d'autant que les visées de ce parti sont clairement de laïciser l'espace social. Dans L'Écho du Midi, les chorèges Nîmois sont comparés aux premiers militants de la décentralisation théâtrale, tels M. Pottecher à Bussang dans les Vosges :

«La foule doit être initiée, pour un prix modique, aux chefs-d'œuvre de l'antique, aux monuments de notre âge classique, aux productions des poètes d'aujourd'hui. Rares pourtant sont les théâtres de plein air où il est fait application de cette loi. On pouvait citer le théâtre du peuple de Bussang et le théâtre des arènes de Nîmes dont les chorèges ont la volonté nettement arrêtée de contribuer à l'éducation artistique de la foule en affirmant ce caractère nettement populaire des spectacles. $»^{13}$

Les acteurs ne dédaignent pas communiquer sur la personnalité politique qui préside l'édition 1903, soit le ministre d'origine gardoise G. Doumergue, futur président de la République. C'est dans les pages mêmes du programme d'CEdipe-roi que le prosélytisme s'affiche (cf. fig. 3: programme d'CEdipe-roi, 1903). Après une notice sur le tragédien Sophocle, c'est le portrait du héros contemporain qui y est décliné :

10. Archives municipales de Nîmes, série 2 R 180, liasse 1909, lettre du Comité des fêtes de la ville de Nîmes [été 1909].

11. Archives du Musée du Vieux Nîmes, Léon Baylet, «Le Syndicat d'Initiative de Nîmes et du Gard ", programme d'CEdipe-Roi de Sophocle (1903).

12. Archives municipales de Nîmes, série 2 R 181, liasse 1904, lettre ronéotypée du Syndicat d'initiative [1904].

13. L'Echo du Midi, $1^{\text {er }}$ au 7 juin 1912. 
«Mais nous pouvons bien dire que, s'il rencontre des adversaires à la Chambre, il ne compte pas d'ennemis. »

La presse locale et régionale, chroniquant abondamment chaque festival, n'est pas en reste dans sa manière de consigner les évènements. La décentralisation théâtrale est célébrée avec militantisme lors de la création de Sémiramis dont toutes les composantes font le «buzz» en 1904. L'auteur, J. Péladan, personnalité excentrique des lettres, a grandi à Nîmes; le rôle-titre est porté par la plus grande tragédienne de la ComédieFrançaise (Eugénie Second-Weber) et le décorateur A. Chambon (professeur à l'École de dessin de Nîmes) campe l'antiquité assyrienne avec le faste des futurs péplums.

«Sémiramis fut un éclatant succès de décentralisation artistique. On jouait une triple partie : représenter une œuvre nouvelle, verbe annonciateur d'un art original sortant absolument des vieux cadres et des habituelles formules, la faire jouer de nuit, dans un cadre gigantesque, effrayant à l'œil par sa masse et qu'il s'agissait d'incendier de lumière électrique sans nuire à la rayonnante beauté du monument découronné ; organiser dans une semaine une scène immense, un décor d'une originalité particulière où toutes les habitudes scéniques étaient renversées, où l'on jouait non plus en largeur, mais en hauteur, faire manœuvrer ainsi une foule de figurants, régler leurs mouvements et leurs rythmes en quelques hâtives séances et dans des conditions presque paradoxales. ${ }^{14}$

Comme à Athènes, la formation des citoyens peut s'accomplir sur les gradins (fig. 4). Ainsi la tragédie Antigone de Sophocle (1912) y est encensée pour :

«(sa) portée morale de haut enseignement esthétique, souvenons-nous de la devise :

"Mener le peuple au Bien par le chemin du Beau"

et encourageons les bons citoyens qui ont prix hardiment l'initiative d'une tâche éducative si féconde et si noble. ${ }^{15}$

Le patriotisme fonctionne de pair avec la citoyenneté dans les mentalités d'entre-guerres. En 1902, La Marseillaise jouée par l'orchestre Colonne annonce l'ouverture de l'audition $^{16}$ " de la Damnation de Faust: ne pas oublier que Berlioz est également l'orchestrateur de l'hymne national. À l'instar du Théâtre antique d'Orange, c'est la presse nationale qui baptise le cycle nîmois «Bayreuth français » en $1905^{17}$. Lors des fêtes de la Victoire de 1919, les représentations des Perses d'Eschyle et des Troyens de Berlioz suscitent une ferveur patriotique dont le chroniqueur restitue le solennel rituel profane.

«L'auditoire est recueilli (...) Ajoutons que cette musique pure et grave, tour à tour héroïque, passionnée, séduisante, convient à la grandeur des heures que nous vivons et ne pouvait manquer d'aller à l'âme des citoyens français. $»^{18}$

Quant à la rébellion sociale méridionale, à laquelle le député Charles-Roux faisait allusion, elle est mise en abyme dans l'amphithéâtre lors d'une création de M. Richard, Dans la Tourmente (1909). La didascalie introductive précise «La scène est à Nîmes, de 1790 à 1794 sur l'Esplanade ${ }^{19} »$. Ce drame sous la Terreur réactive la geste révolutionnaire initiée par Rolland (Quatorze Juillet) à travers l'agitation populaire de héros nîmois - Jean Dhombre, le pasteur Rabaud - ainsi que d' « hommes du peuple, ouvriers, campagnards, gardes nationaux, volontaires, soldats, administrateurs municipaux, femmes du peuple $^{20}{ }^{2}$. Le Journal du Midi célèbre cette fresque sociale du :

14. La Revue du Midi, 1904.

15. Le Petit Méridional, 21 juin 1912.

16. Journal du Midi, 30 juin 1902.

17. "Aux arènes de Nîmes - Inauguration du "Bayreuth français " ", Le Théâtre, septembre 1905, n 161, p. 5.

18. Le Petit Méridional, 7 juillet 1919.

19. M. Richard, Dans la tourmente / pièce historique en trois parties, p. 3.

20. Ibidem. 
«(...) peuple nîmois bien vivant, déchiré par les haines de partis. Nous le voyons tout frémissant de ferveur patriotique "La Patrie est en danger!" (...) C'est ensuite le Chant du départ hurlé par tout un peuple qui marche vers la gloire. $\gg^{21}$

En sus du verbe, cette rébellion passe par la réactivation d'authentiques chants révolutionnaires selon les rituels et répertoires propres à la $I^{\text {re }}$ République : les hymnes de Méhul, Gossec l'accompagnent ${ }^{22}$.

\section{Mobiliser les concitoyens nîmois autour du «temps de la fête »}

Au fil des éditions, les organisateurs élargissent le cercle des acteurs, qui ne sont pas seulement les organisateurs, professionnels et amateurs $\mathrm{du}$ spectacle vivant. Ces concitoyens sont harangués par le Comité d'organisation afin d'optimiser l'accueil des festivaliers en 1909.

«Le Comité qui multiplie depuis plusieurs mois ses efforts pour assurer à Nîmes des fêtes dignes de son renom glorieux, dignes de ses arènes incomparables, fait appel à nos concitoyens aimant fidèlement leur ville. Les étrangers qui viendront en foule dans nos murs (...) doivent emporter de Nîmes le souvenir agréable d'une cité riante et propre et de l'urbanité des Nîmois. C'est pour faire connaître au loin notre ville que le Comité y organise des spectacles de pure beauté, à l'exemple de quelques villes voisines. Les populations d'Orange, de Béziers, sont admirables de sens patriotique à l'occasion de ces manifestations (...) qu'elles encouragent de tous leurs efforts. Le Comité a la légitime prétention d'avoir fait ici mieux que ce qu'on peut faire partout ailleurs. Il espère trouver auprès des Nîmois le même sympathique concours que les organisateurs des spectacles d'Orange et de Béziers trouvent auprès de leurs concitoyens. ${ }^{23}$

Suivant l'interventionnisme du Comité, l'esprit fédérateur de la fête rejaillit dans l'espace social en tissant des liens entre les musiques locales. La veille des spectacles, une retraite aux flambeaux s'opère avec les musiques civiles et militaires qui fraternisent pour instaurer ce qui deviendra un rite festivalier :

« À l'occasion des grandes fêtes dramatiques, ce soir, vendredi à 9 heures, grande retraite aux flambeaux par le corps des Sapeurs-pompiers, la musique municipale, la fanfare $\mathrm{d}^{\prime}$ artillerie, les tambours et clairons du $40^{\mathrm{e}} \mathrm{d}^{\prime}$ infanterie. $»^{24}$

C'est néanmoins le colonel en garnison à Nîmes qui assure la protection de la manifestation pendant laquelle la ville est pavoisée de drapeaux tricolores :

« Pour éviter la cohue pendant la retraite organisée par le Comité des fêtes et à laquelle doit participer la garnison, un service d'ordre composé de 16 hommes à cheval et 20 hommes à pied sera commandé pour encadrer la musique et les tambours et clairons. ${ }^{25}$

Outre l'accompagnement festif des spectacles, la participation des chorales et harmonies locales s'avère opérante, non seulement au strict plan de la production, mais aussi comme ciment du corps social, à la manière citoyenne des chœurs du théâtre grec antique. Pour exemple, les deux Musiques de régiment gardois ${ }^{26}$ et les chorales nîmoises sont mutualisées pour interpréter les hymnes révolutionnaires et évoluer comme figurants Dans la tourmente (1909). Le compte-rendu les crédite "de redonner vie aux grandes heures de la République française ${ }^{27}$ ». Autre exemple, les chorales de tout quartier - et même des églises comme Saint-Charles - sont mobilisées pour la musique de scène de C. Saint-Saëns lors des représentations d'Antigone de Sophocle (1912).

21. Journal du Midi, 2 aout 1909.

22. Ces rituels sont précisément réactivés par R. Rolland dans les documents qu'il réunit en appendice de l'édition de son Théâtre du peuple, 1903.

23. Journal du Midi, 29 juillet 1909.

24. Journal du Midi, 30 juillet 1905.

25. Archives municipales de Nîmes, série 2 R 180, lettre du lieutenant-colonel Boyer au Maire de Nîmes, 28 juillet 1905 .

26. Musiques du $40^{\mathrm{e}} \mathrm{d}$ 'Infanterie et de l'École d'artillerie de Nîmes.

27. Le Petit Méridional, 3 aout 1909. 


\section{Mesures d'accessibilité, de sécurité}

Favoriser l'accès citoyen au spectacle de masse induit la mise en œuvre de mesures publiques. La tarification populaire, mise en place lors de l'accession des radicauxsocialistes (1909), génère en effet une affluence des publics que la mairie et les transports s'empressent de gérer. L'encadrement extérieur est organisé en amont, pendant et après le spectacle. Le rythme urbain se plie à celui-ci : ralentissement ou arrêt des transports privés et publics à compter de 1904 :

« Vu la loi du 5 avril 1884 (...) considérant que Sémiramis, donné dans l'Amphithéâtre des arènes le 24 juillet, attirera une foule considérable qui nécessitera des mesures d'ordre exceptionnelles (...) / Art. 1 - De 6 heures à minuit, la circulation des voitures et autres véhicules sera interdite entre l'angle du Palais de Justice et le Boulevard Victor Hugo. / Art. 2 - De 8 heures à minuit, la circulation des voitures non suspendues sera aussi interdite sur les voies publiques contournant la place des Arènes (...). Sur le même parcours et pendant le même temps, les voitures suspendues devront aller au pas et celle des tramways à une allure très modérée. Les Wattmans devront s'abstenir de clocher. $»^{28}$

À la sortie du spectacle, le flux des Nîmois est drainé par un service spécifique de la Compagnie des tramways :

«Départ : 1 - place des arènes au Chalet passant par le bd. Gambetta ; 2 - place des arènes à l'avenue de la Plate-forme passant par le chemin de Montpellier et le bd. de la République ; 3 - place des arènes à la gare des voyageurs ; 4 - place des arènes au mas Mathieu ; 5 - place des arènes à la gare des voyageurs en passant par le bd. Gambetta. Le tarif ne sera pas augmenté. $»^{29}$

Quant au flux des spectateurs allogènes, il est pris en charge par les réseaux ferrés :

«À l'occasion des représentations d'Amica et de Vénus et Adonis dans les Arènes de Nîmes, la Compagnie P.L.M. a organisé des trains spéciaux pour assurer le retour des voyageurs. La marche de ces trains est ainsi réglée : Nuit du 13 au 14 août: Nîmes-Montpellier (...) Nîmes Uzès (...) - Nîmes Aigues-mortes (...) - Nîmes Sommières. » ${ }^{30}$

À l'intérieur de l'amphithéâtre, la discipline est de rigueur, édictée par des arrêtés spécifiques nettement différenciés des cultures « chaudes » de la corrida :

«Sur le parcours intégré dans les articles précédents et dans les arènes, tout chant, tous cris, toute conversation de nature à troubler la représentation sont formellement interdites pendant la durée du spectacle. $»^{31}$

\section{Communiquer sur la latinité}

Si le Félibrige n'est pas ici directement aux commandes comme au Théâtre antique d'Orange, la latinité est cependant un mode d'appropriation de l'activité théâtrale à bien des égards. Le premier périodique taurin, Le Torero, consent à chroniquer les premiers spectacles d'opéra, tout en déplorant le manque de ferveur des publics et le choix trop intimiste de la Mireille inaugurale :

«De nombreux étrangers s'étaient rendus à Nîmes et ils ont emporté de cette fête une délicieuse impression; il manquait cependant l'enthousiasme, l'émotion, l'emballement fiévreux qui ne font jamais défaut aux corridas de muerte. Le cadre est trop vaste et trop

28. Archives municipales de Nîmes, série 2R 181, arrêté municipal du 21 juillet 1904.

29. Journal du Midi, 24 juillet 1904.

30. Journal du Midi, 11 aout 1905.

31. Archives municipales de Nîmes, série 2R 181, arrêté municipal du 21 juillet 1904. 
grandiose pour une pièce comme Mireille, où il y a des scènes parlées, et il n'y a guère que les grandes pièces du répertoire de grand opéra qui feraient un effet merveilleux. $»^{32}$

Comme à Orange, Arles ou Béziers, l'adjonction de pratiques culturelles régionales est une particularité incontournable. À Nîmes, inaugurer le monument d'A. Daudet (1899) ou celui de Bigot en amont d'un spectacle (1903) connecte le festival à ses ancrages territoriaux. Lorsque la première représentation de Mireille est placée sous les auspices de F. Mistral en 1899 et inclue les farandoleurs gardois et provençaux (fig. 5), sa reprise en 1930 s'opère à l'occasion des Fêtes mistraliennes devant cinquante félibres et la veuve du poète. Un chroniqueur rend compte de l'affluence exceptionnelle et de l'émotion collective :

«L'aspect de notre vieux cirque, dont le faîte même était couronné par une rangée d'auditeurs, et dont les coins les plus obscurs abritaient des groupes, donnait une émotion inoubliable. Les interprètes (...) donnent une interprétation irréprochable de l'œuvre de Mistral-Gounod (...). $»^{33}$

Dans l'inversion qui clôt cet énoncé, le compositeur parisien passe symboliquement au second plan, tandis que les librettistes passent à la trappe derrière la figure tutélaire du Félibrige. Un mode d'appropriation plus paradoxal surgit dès la première de Carmen en 1901. Une corrida est interpolée au $4^{\mathrm{e}}$ acte, transgressant la fiction d'Escamillo vainqueur des arènes de Séville en spectacle réel ${ }^{34}$. Ce fait $\mathrm{d}^{\prime}$ armes retentit dans toute la presse languedocienne et produit un discours enflammé dans les colonnes du Torero:

«Bizet est le Rouget de l'Isle de la corrida ; nous lui devons l'hymne de l'aficion sans lequel il ne saurait exister de parfait paseo, car il est avéré que nulle autre musique ne convient mieux à la marche triomphale de cuadrillas. Une telle affirmation peut susciter les sarcasmes de ceux qui, n'ayant jamais ouï l'ouverture de Carmen aux arènes, ignorent quel enthousiasme provoquent les premières mesures (...) Un frisson sacré s'empare des foules latines à ce moment. Ils semblent qu'elles reprennent conscience des lointaines origines et que, dans l'amphithéâtre reconquis après des siècles, à sa primitive splendeur, s'éveille l'âme rajeunie des ancêtres. ${ }^{35}$

Ce discours situe la réactivation des spectacles d'amphithéâtre en un "processus d'objectivation du passé en mémoire [contribuant] à façonner une identité collective ${ }^{36}$ ", celle de la latinité que le Félibrige a patiemment construite depuis sa fondation (1854). À rebours, le spectacle dans l'amphithéâtre peut générer certaines dynamiques dans le comportement des spectateurs. En 1930, lors du Congrès des viticulteurs du Sud-est à Nîmes, le félibre nîmois Pons s'échauffe après la représentation de Carmen de la veille :

«Assez de mots, de paroles vaines! / Le sang latin bout dans nos veines / Et l'heure de briser nos chaines / Naît avec l'aurore au levant. » ${ }^{37}$

Quant à la presse nationale, elle prend bien évidemment ses distances avec ses tentatives d'acculturation. En chroniquant l'adjonction d'une corrida à l'opéra, Le Monde illustré distingue la nature antinomique de chaque composante pour réfuter cette hybridation.

« Dans l'immense ruine moderne dont Nîmes se montre fière à juste titre, la représentation de Carmen a été un grand succès. Seule la corrida de toros nature faisait tache. Le théâtre tout de convention et la corrida toute de réalité ne sauraient s'accorder. ${ }^{38}$

32. « Représentation de Mireille », Le Torero, 25 juin 1899

33. Journal du Midi, 22 juillet 1930.

34. S. Teulon Lardic, "Arènes de Nîmes, lieu d'appropriation paradoxale de Carmen de Bizet avec tauromachie », p. 258 et sq.

35. Louis Feuillade, «Carmen aux Arènes de Nîmes », Le Torero, 12 mai 1901.

36. P. Poirrier, Les enjeux de l'histoire culturelle, p. 211.

37. Allocution de Michel Pons, citée par le Journal du Midi, 26 juin 1930.

38. F. Parent, « Une représentation de Carmen à Nîmes », Le Monde illustré, 18 mai 1901. 


\section{Des rituels et des héros aux festivals de Nîmes}

S'inscrivant dans les premières actions de décentralisation et démocratisation culturelle, Nîmes exploite sa romanité pour «faire revivre la cité dans sa gloire antique » selon les termes des acteurs nîmois. Durant l'entre-deux-guerres, communiquer sur le spectacle de l'amphithéâtre permet effectivement de s'inscrire dans les enjeux d'attractivité territoriale à l'heure du P.L.M., tout en accompagnant la nouvelle activité théâtrale, revendiquée comme une continuité des temps de la grandeur gallo-romains face aux héros de la civilisation méditerranéenne. Au fil des éditions, l'icône antique se dote d'un rituel profane : grâce à la tarification consentie, les publics allogènes et endogènes, socialement mixtes, convergent vers elle, tandis que le rythme urbain s'arrête. Au-delà du prosélytisme, communiquer est aussi l'occasion d'activer des mémoires collectives méridionales, transmises de manière souterraine au long de son histoire et affirmant sa différence (ou ses paradoxes) au sein de l'État-Nation.

C'est probablement ce dernier particularisme, boudé par R. Rolland, qui lui ôte l'opportunité de programmer ses fresques historiques in loco, lorsqu'il signale:

«(les) représentations de Nîmes, de Béziers et d'Orange, bien que gâtées par le double cabotinage provençal et parisien (...) servirent aussi la cause du théâtre populaire, qui $\mathrm{s}^{\prime}$ essayait de tous côtés en une multitude de tentatives. ${ }^{39}$

Aujourd'hui, si l'idéologie citoyenne semble en retrait du spectacle vivant nîmois, si l'identité latine y est éclipsée par l'hispanité des Ferias, communiquer sur la romanité demeure en revanche un concept plus que jamais opérant. Récemment, les édiles ont choisi d'édifier un Musée de la romanité pour leur nouveau mandat. Quant à l'activité de spectacles dans l'amphithéâtre, elle se doit d'être en 2014 plus que jamais attractive et singulière en terres festivalières. Orientée vers le rock, rap ou l'électro depuis une décennie, la $19^{\mathrm{e}}$ édition du Festival de Nîmes affiche Stromae et Chédid en 2014 alors que Metallica mettait le feu aux arènes en 2009 (fig. 6). En reléguant les héros Enée, Rabaud ou Carmen de la scène-amphithéâtre nîmoise, ces nouvelles idoles cristallisent d'autres représentations pour des spectacles, eux, toujours de masse. 


\begin{abstract}
Résumé
Proche du militantisme de R. Rolland, un cycle festivalier s'instaure dans l'amphithéâtre nîmois à compter de 1900. Initié par l'entrepreneur des arènes, puis acté par divers modes collectifs d'administration, ce cycle théâtral joue la carte de la décentralisation et de la démocratisation dans la compétition à laquelle se livrent les théâtres français de plein air du Midi.

À la faveur de représentations ambitieuses (drame antique, opéra et création recensés) et d'une fréquentation populaire due aux dispositifs de l'administration municipale, ce cycle devient un outil de communication territoriale au cœur des enjeux du spectacle de masse. En favorisant les échanges culturels et économiques entre Nîmes et Paris (ComédieFrançaise, Opéra de Paris), Nîmes et les grandes villes (orchestres de Marseille, de Lyon), il participe des processus de représentation et de structuration des idéologies marquantes durant l'entre-deux-guerres. En particulier, l'enceinte antique réanime le projet citoyen et patriotique du Théâtre pour le peuple (1903), tant par ses thématiques de programmation (cycles de théâtre grec antique de 1911 à 1914, Fêtes de la Victoire en 1919) que par les contributions musicales des chorales et musiques de régiment locales en musique de scène. Les organisateurs n'oublient pas de négocier la place des pratiques culturelles locales (corrida interpolée, centenaire de Mistral pour Mireille, etc.) pour connecter le cycle à son territoire. Cette communication surgit tant du discours des acteurs (organisateur, édile, artiste) que de celui de la réception, qui active l'identité latine sous les auspices du Félibrige. Le dépouillement des archives de Nîmes et du Gard nourrit cette investigation, inexplorée jusqu'à nos récentes publications.
\end{abstract}

\title{
Bibliographie
}

Bulletin municipal de la ville de Nîmes, Nîmes, Imprimerie Albin Pujolas et L. Méjan, année 1900, année 1939.

CHARLES-Roux Jules, Nîmes, $1^{\text {re }}$ édition 1908, réédition CPM, 1983.

HuARD Raymond, Histoire de Nîmes, Edisud, 1982.

LASSALLE Victor, «L'amphithéâtre », Nîmes antique, Paris, Monum, Éditions du patrimoine (collection Guides archéologiques de la France), 2005, p. 95-127.

POIRRIER Philippe, Les enjeux de l'histoire culturelle, Paris, Éditions du Seuil (PointsHistoire), 2004.

RICHARD Marius, Dans la tourmente / pièce historique en 3 parties / Représentée pour la première fois aux Arènes de Nîmes le $1^{\text {er }}$ août 1909, Nîmes, Imprimerie coopérative L'Ouvrière, 1909.

RollaND Romain, Le Théâtre du peuple, $1^{\text {re }}$ édition en 1903, Paris, Éditions Complexe, 2003.

TEULON LARDIC Sabine, «Mireille à Arles et Carmen à Nîmes : fabriquer l'évènement multiculturel dans l'amphithéâtre ", Mémoires de l'Académie de Nîmes / année 2012, Académie de Nîmes, 2013, p. 167-191.

TEUlON LARDIC Sabine, "Arènes de Nîmes (12 mai 1901), lieu d'appropriation paradoxale de Carmen de Bizet avec tauromachie », K. \& G. STÖCK (dir.), Musik-Stadt / Traditionen und Perspektiven urbaner Musikkulturen, actes du XIV ${ }^{\mathrm{e}}$ Congrès de la Gesellschaft für Musikforschung, Leipzig, septembre 2008 (Leipzig : Gudrun Schröder Verlag, 2012), vol. 4, p. 250-261.

TEULON LARDIC Sabine, "Opéras et spectacles avec musique dans l'amphithéâtre de Nîmes (1900-1930) : réactiver la culture antique ", Lieux de l'Opéra en Europe (XVII XXI siècles), actes du colloque international novembre 2013, Paris, École des Chartes, 2014 (à paraître). 
Tableau : les spectacles festivaliers dans l'amphithéâtre de Nîmes (1900-1930)

\begin{tabular}{|c|c|c|c|}
\hline Date & $\begin{array}{l}\text { Titre d'œuvre } d^{40} / \\
\text { auteur ou compositeur }\end{array}$ & Organisateur & Formation \\
\hline $\begin{array}{l}1899 \\
18 \mathrm{VI}\end{array}$ & $\begin{array}{l}\text { Mireille, opéra de C. } \\
\text { Gounod }\end{array}$ & $\begin{array}{l}\text { A. Fayot, } \\
\text { entrepreneur } \\
\text { des arènes d'Arles et } \\
\text { Nîmes }\end{array}$ & $\begin{array}{l}\text { Orchestre des } \\
\text { Concerts classiques } \\
\text { Marseille }\end{array}$ \\
\hline $\begin{array}{l}1901 \\
12 \text { et } 18 \mathrm{~V}\end{array}$ & Carmen, opéra de G. Bizet & A. Fayot (idem) & $\begin{array}{l}\text { Orchestre de Nîmes } \\
\text { et Montpellier }\end{array}$ \\
\hline $\begin{array}{l}1901 \\
22 \text { IX }\end{array}$ & $\begin{array}{l}\text { Guillaume Tell, opéra de } \\
\text { G. Rossini }\end{array}$ & A. Fayot (idem) & $\begin{array}{l}\text { Orchestre, dir. G. } \\
\text { Coste }\end{array}$ \\
\hline $\begin{array}{l}1902 \\
29 \mathrm{VI}\end{array}$ & $\begin{array}{l}\text { La Damnation de Faust } \\
\mathrm{d}^{\prime} \mathrm{H} \text {. Berlioz (version } \\
\text { concert) }\end{array}$ & A. Fayot (idem) & $\begin{array}{l}\text { Orchestre et chœurs } \\
\text { des Concerts } \\
\text { Colonne (Paris), dir. } \\
\text { E. Colonne }\end{array}$ \\
\hline $\begin{array}{l}1903 \\
26 \mathrm{VII}\end{array}$ & CEdipe-roi de Sophocle & $\begin{array}{l}\text { Syndicat d'initiative } \\
\text { des intérêts régionaux } \\
\text { de Nîmes et du Gard }\end{array}$ & $\begin{array}{l}\text { Comédie-Française } \\
\text { (Mounet-Sully, P. } \\
\text { Mounet) }\end{array}$ \\
\hline $\begin{array}{l}1904 \\
24 \mathrm{VII}\end{array}$ & Sémiramis* de J. Péladan & $\begin{array}{l}\text { Syndicat d'initiative } \\
\text { (...) de Nîmes et du } \\
\text { Gard }\end{array}$ & $\begin{array}{l}\text { Comédie-Française } \\
\text { (E. Segond-Weber) - } \\
\text { Musique } 40^{\mathrm{e}} \\
\text { Régiment d'artillerie } \\
\text { (musiques de scène) }\end{array}$ \\
\hline $\begin{array}{l}1905 \\
13 \text { VIII } \\
15 \text { VII } \\
\text { ? VIII }\end{array}$ & $\begin{array}{l}\text { Amica, opéra P. Mascagni } \\
\text { Vénus et Adonis opéra de } \\
\text { Leroux } \\
\text { Mefistofele, opéra d'A. } \\
\text { Boito }\end{array}$ & $\begin{array}{l}\text { Syndicat d'initiative } \\
\text { (...) de Nîmes et du } \\
\text { Gard }\end{array}$ & $\begin{array}{l}\text { Orchestre, } \\
\text { dir. Brunswick }\end{array}$ \\
\hline $\begin{array}{l}1909 \\
31 \mathrm{VII} \\
1^{\mathrm{er}} \mathrm{VIII}\end{array}$ & $\begin{array}{l}\text { Les Erinnyes d'Euripide } \\
\text { Dans la tourmente* de M. } \\
\text { Richard }\end{array}$ & $\begin{array}{l}\text { Comité des fêtes de la } \\
\text { Ville de Nîmes }\end{array}$ & $\begin{array}{l}\text { Orchestre Société des } \\
\text { concerts de Lyon, } \\
\text { dir. Witkovski } \\
\text { (musiques de scène) }\end{array}$ \\
\hline $\begin{array}{l}\mathbf{1 9 1 1} \\
24 \text { et } 25 \\
\text { VI }\end{array}$ & $\begin{array}{l}\text { Horace de Corneille } \\
\text { Le jeune Dieu * d'A.- F. } \\
\text { Hérold }\end{array}$ & $\begin{array}{l}1^{\text {er }} \text { cycle du Théâtre } \\
\text { antique, } \\
\text { A. Sauze directeur }\end{array}$ & $\begin{array}{l}\text { Comédie Française } \\
\text { (E. Segond-Weber) }\end{array}$ \\
\hline $\begin{array}{l}1912 \\
23 \mathrm{VI}\end{array}$ & $\begin{array}{l}\text { Botriocéphale de } \\
\text { C. Saint-Saëns } \\
\text { Antigone de Sophocle }\end{array}$ & $\begin{array}{l}2^{\mathrm{e}} \text { cycle du Théâtre } \\
\text { antique, } \\
\text { A. Sauze dir. }\end{array}$ & $\begin{array}{l}\text { Comédie-Française } \\
\text { (J. Bartet, J. Delvair) - } \\
\text { Orchestre de l'Opéra } \\
\text { de Marseille }\end{array}$ \\
\hline $\begin{array}{l}1913 \\
23,29 \mathrm{VI}\end{array}$ & $\begin{array}{l}\text { Esclarmonde de } \\
\text { Montségur* de } \\
\text { L. Larguier } \\
\text { Iphigénie en Aulide de } \\
\text { J. Racine }\end{array}$ & $\begin{array}{l}3^{\mathrm{e}} \text { cycle du Théâtre } \\
\text { antique }\end{array}$ & $\begin{array}{l}\text { Comédie-Française } \\
\text { (J. Bartet) }\end{array}$ \\
\hline $\begin{array}{l}1914 \\
13,14 \mathrm{VI}\end{array}$ & $\begin{array}{l}\text { Bérénice de J. Racine } \\
\text { Le Cid de P. Corneille }\end{array}$ & $\begin{array}{l}4^{\mathrm{e}} \text { cycle du Théâtre } \\
\text { antique }\end{array}$ & Comédie-Française \\
\hline
\end{tabular}

40. Légende : * après le titre désigne une création. 


\begin{tabular}{|c|c|c|c|}
\hline \multicolumn{4}{|c|}{ Interruption 1915-1918 (Grande Guerre) } \\
\hline $\begin{array}{l}1919 \\
5 \text { et } 7 \\
\text { VII } \\
6 \text { VII }\end{array}$ & $\begin{array}{l}\text { Les Troyens à Carthage, opéra } \\
\text { d'H. Berlioz } \\
\text { Les Perses d'Eschyle }\end{array}$ & $\begin{array}{l}\text { Association nîmoise de la } \\
\text { Presse et Syndicat } \\
\text { d'initiative. } \\
\text { "Fêtes de la victoire » }\end{array}$ & $\begin{array}{l}\text { Orchestre et } \\
\text { chœurs des } \\
\text { Théâtres de Paris, } \\
\text { dir. F. Ruhlmann } \\
\text { Comédie- } \\
\text { Française }\end{array}$ \\
\hline $\begin{array}{l}1920 \\
10 \text { VII } \\
11 \text { VII }\end{array}$ & $\begin{array}{l}\text { Aïda, opéra de G. Verdi } \\
\text { Sigurd, opéra d'E. Reyer }\end{array}$ & $\begin{array}{l}\text { Direction des Arènes, } \\
\text { Crémieux dir. }\end{array}$ & $\begin{array}{l}\text { Orchestre, dir. R. } \\
\text { Sonnier (Lyon) }\end{array}$ \\
\hline $\begin{array}{l}1921 \\
9 \text { VII } \\
10 \text { VII }\end{array}$ & $\begin{array}{l}\text { Messaline, opéra d'I. de Lara } \\
\text { Salammbô, opéra d' E. Reyer }\end{array}$ & Direction des Arènes & $\begin{array}{l}\text { Orchestre et } \\
\text { chœur, dir. X } \\
\text { (Nice) }\end{array}$ \\
\hline $\begin{array}{l}1922 \\
1,2 \text { VII }\end{array}$ & $\begin{array}{l}\text { CEdipe-roi de Sophocle } \\
\text { Les Phéniciennes de G. Rivollet }\end{array}$ & Direction des Arènes & $\begin{array}{l}\text { Comédie- } \\
\text { Française }\end{array}$ \\
\hline $\begin{array}{l}1923 \\
? \mathrm{VI}\end{array}$ & $\begin{array}{l}\text { Rome vaincue d'A. Parodi } \\
\text { Horace de P. Corneille }\end{array}$ & & \\
\hline $\begin{array}{l}1924 \\
21 \mathrm{VI} \\
22 \mathrm{VI}\end{array}$ & $\begin{array}{l}\text { Polyxène*, oratorio de T. } \\
\text { Gouvy } \\
\text { Werther, opéra de J. Massenet }\end{array}$ & $\begin{array}{l}\text { Gala de Schola Cantorum } \\
\text { de Nîmes (F. Gouvy dir.) } \\
\text { Direction des Arènes }\end{array}$ & $\begin{array}{l}\text { Orchestre et } \\
\text { chœurs de la } \\
\text { Schola Cantorum } \\
\text { Orchestre du } \\
\text { Grand-Théâtre } \\
\text { Marseille }\end{array}$ \\
\hline $\begin{array}{l}1925 \\
19 \mathrm{VII}\end{array}$ & $\begin{array}{l}\text { Les Burgraves, opéra de L. } \\
\text { Sachs }\end{array}$ & $\begin{array}{l}\text { Direction des Arènes, } \\
\text { Delort dir. }\end{array}$ & $\begin{array}{l}\text { Orchestre, dir. } \\
\text { S. Bovy (Nice) }\end{array}$ \\
\hline $\begin{array}{l}1930 \\
28 \mathrm{VI} \\
20 \mathrm{VII}\end{array}$ & $\begin{array}{l}\text { Carmen, opéra de G. Bizet } \\
\text { Mireille, opéra de C. Gounod }\end{array}$ & $\begin{array}{l}\text { Direction des Arènes } \\
\text { Comité du centenaire F. } \\
\text { Mistral }\end{array}$ & $\begin{array}{l}\text { Orchestre, } \\
\text { dir. Molinetti }\end{array}$ \\
\hline $\begin{array}{l}1937 \\
12 \mathrm{~V}\end{array}$ & $\begin{array}{l}\text { Britannicus de J. Racine } \\
\text { CEdipe-roi de Sophocle }\end{array}$ & $\begin{array}{l}\text { Association nîmoise de la } \\
\text { presse } \\
\text { «Fêtes du taureau » }\end{array}$ & $\begin{array}{l}\text { Comédie- } \\
\text { Française } \\
\text { (J. Hervé) - } \\
\text { Orchestre de la } \\
\text { Société du } \\
\text { conservatoire de } \\
\text { Nîmes, } \\
\text { dir. E. Carrière }\end{array}$ \\
\hline
\end{tabular}




\section{Illustrations}

Nous adressons nos remerciements à Mme le Conservateur du Musée du Vieux Nîmes pour la consultation du fonds.

Figure 1 : Affiche du P.L.M. et Syndicat d'initiative des intérêts généraux de Nîmes et du Gard, ca 1900 (Musée du Vieux Nîmes, n 999).

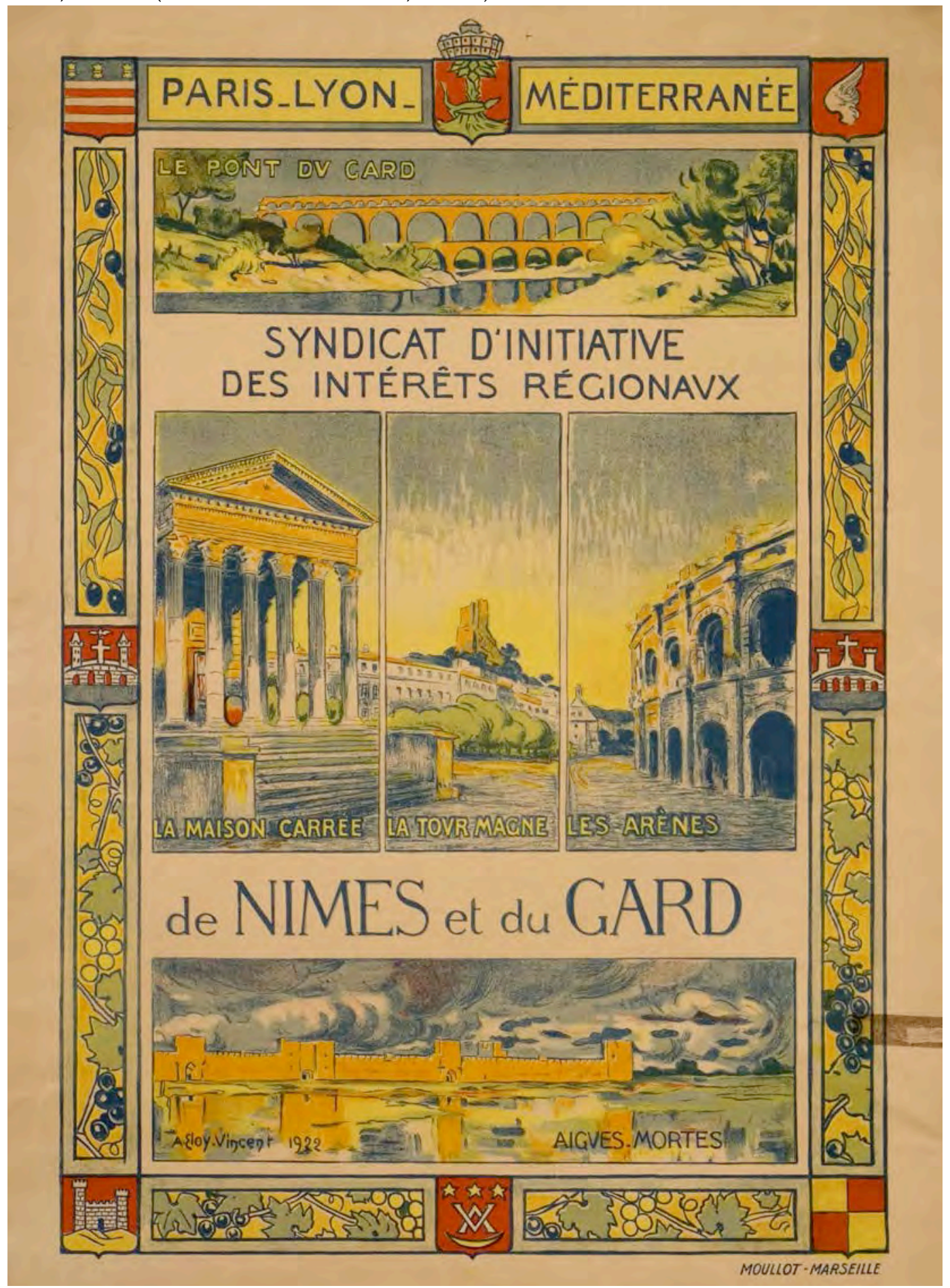


Figure 2 : Décor antique pour la création Le jeune Dieu d'Hérold, 1902 (Musée du Vieux Nîmes, fonds de l'amphithéâtre).

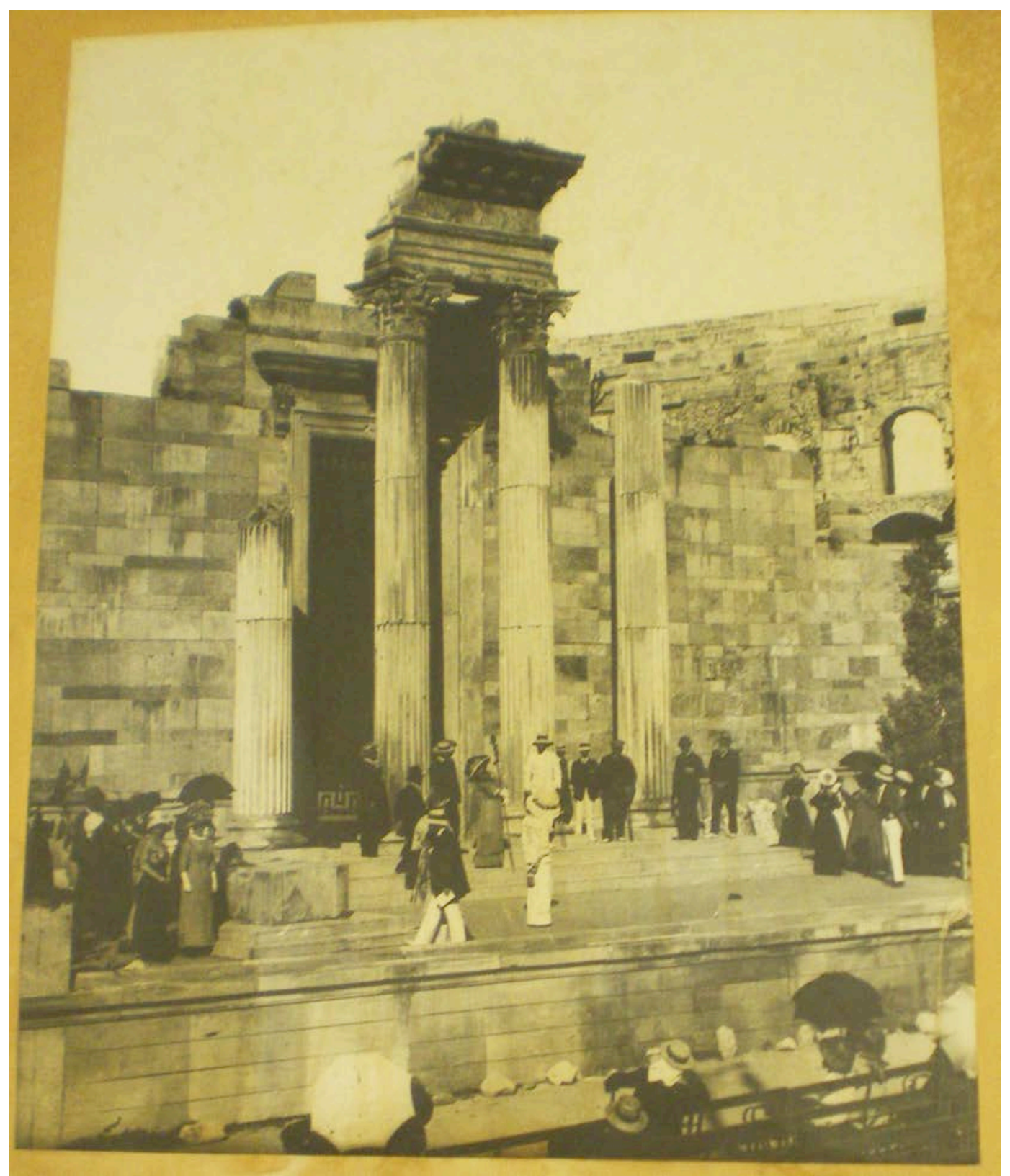


Figure 3: «G. Doumergue, ministre des Colonies », programme d'CEdipe-roi, juillet 1903 (Musée du Vieux Nîmes, fonds de l'amphithéâtre).

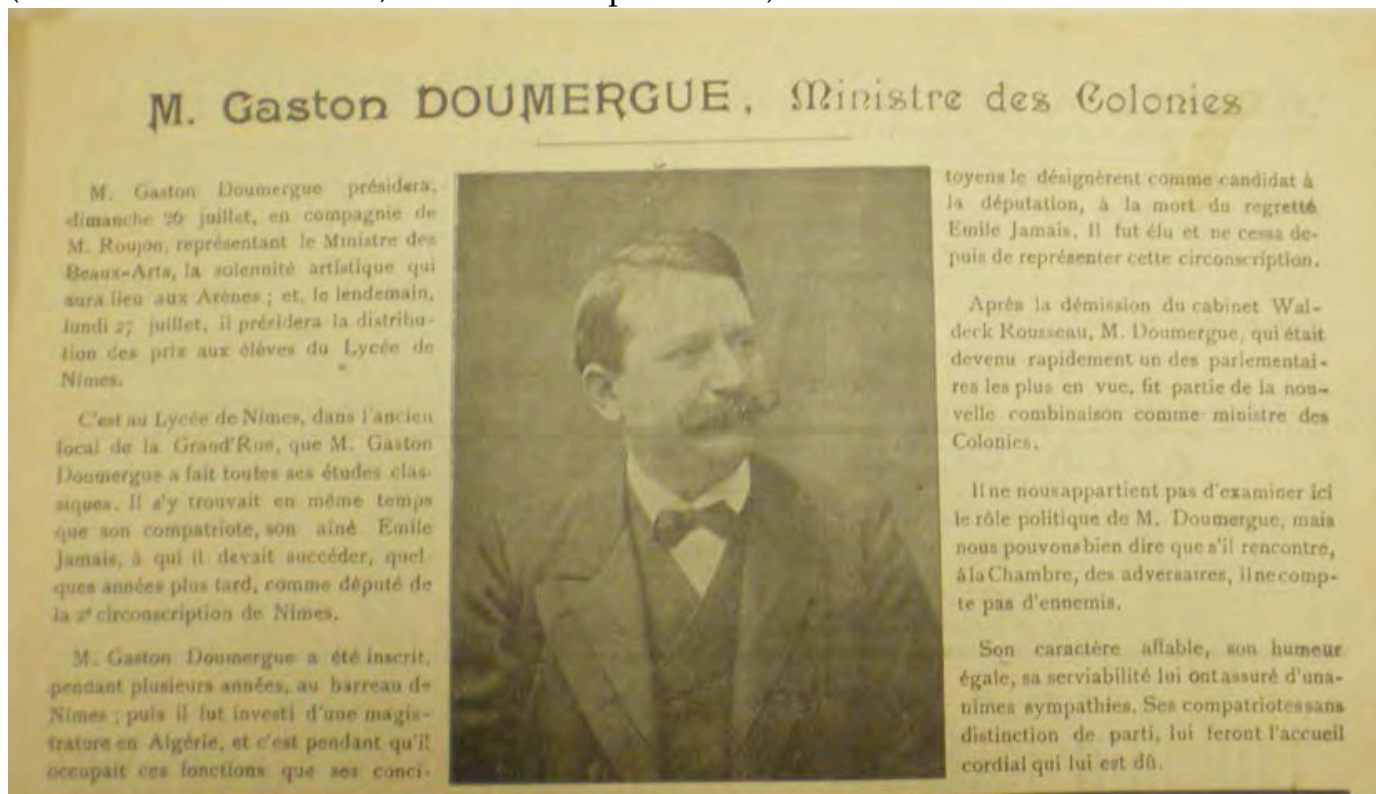

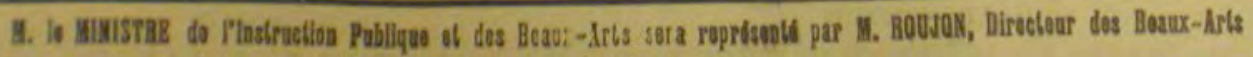

Figure 4 : le public et la loge municipale en 1903 (photo du Musée du Vieux Nîmes, fonds de l'amphithéâtre).

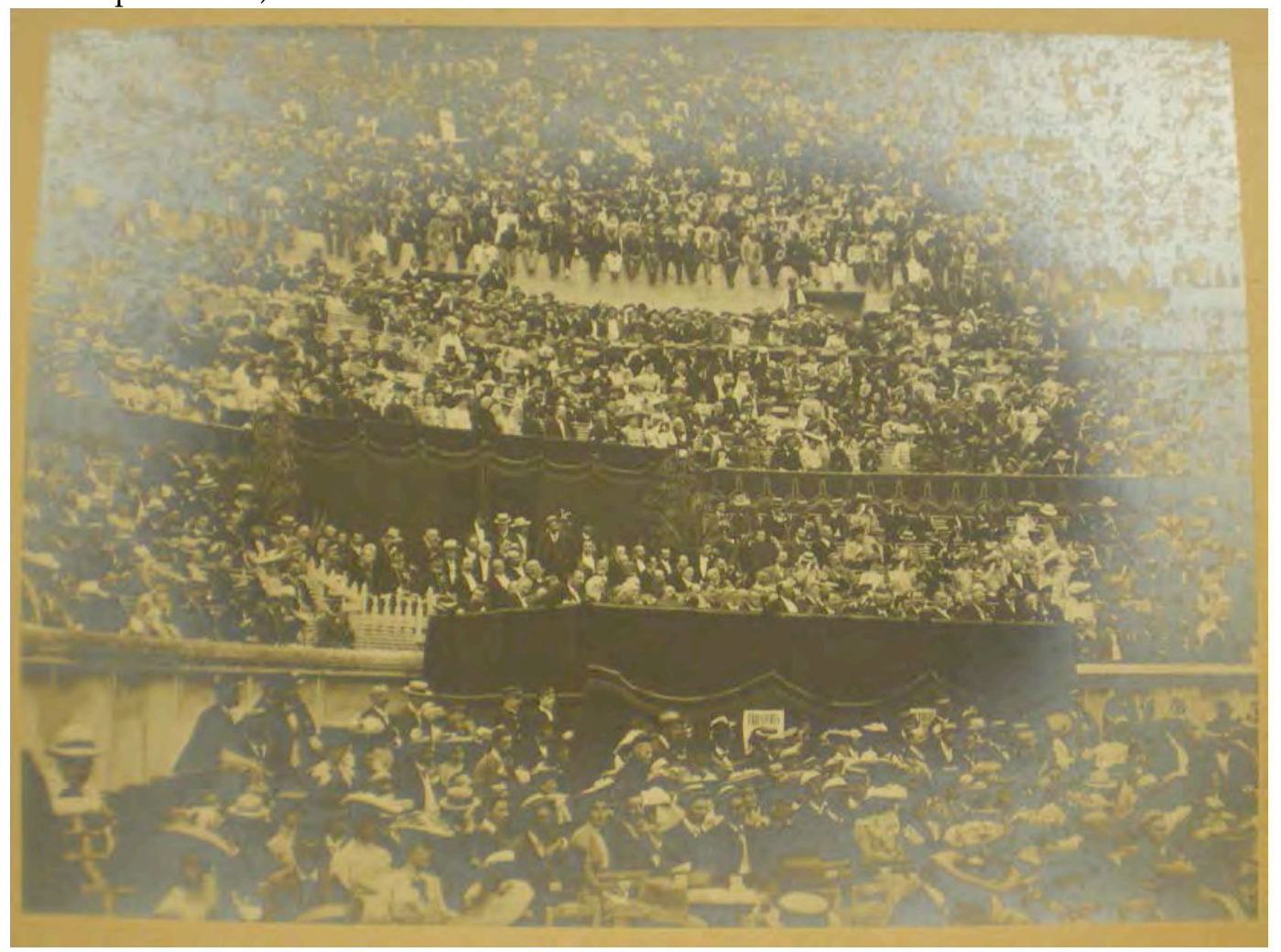


Figure 5 : Mireille, opéra de C. Gounod, représentation de 1899, acte II (photo du Musée du Vieux Nîmes, n999. 7.1).

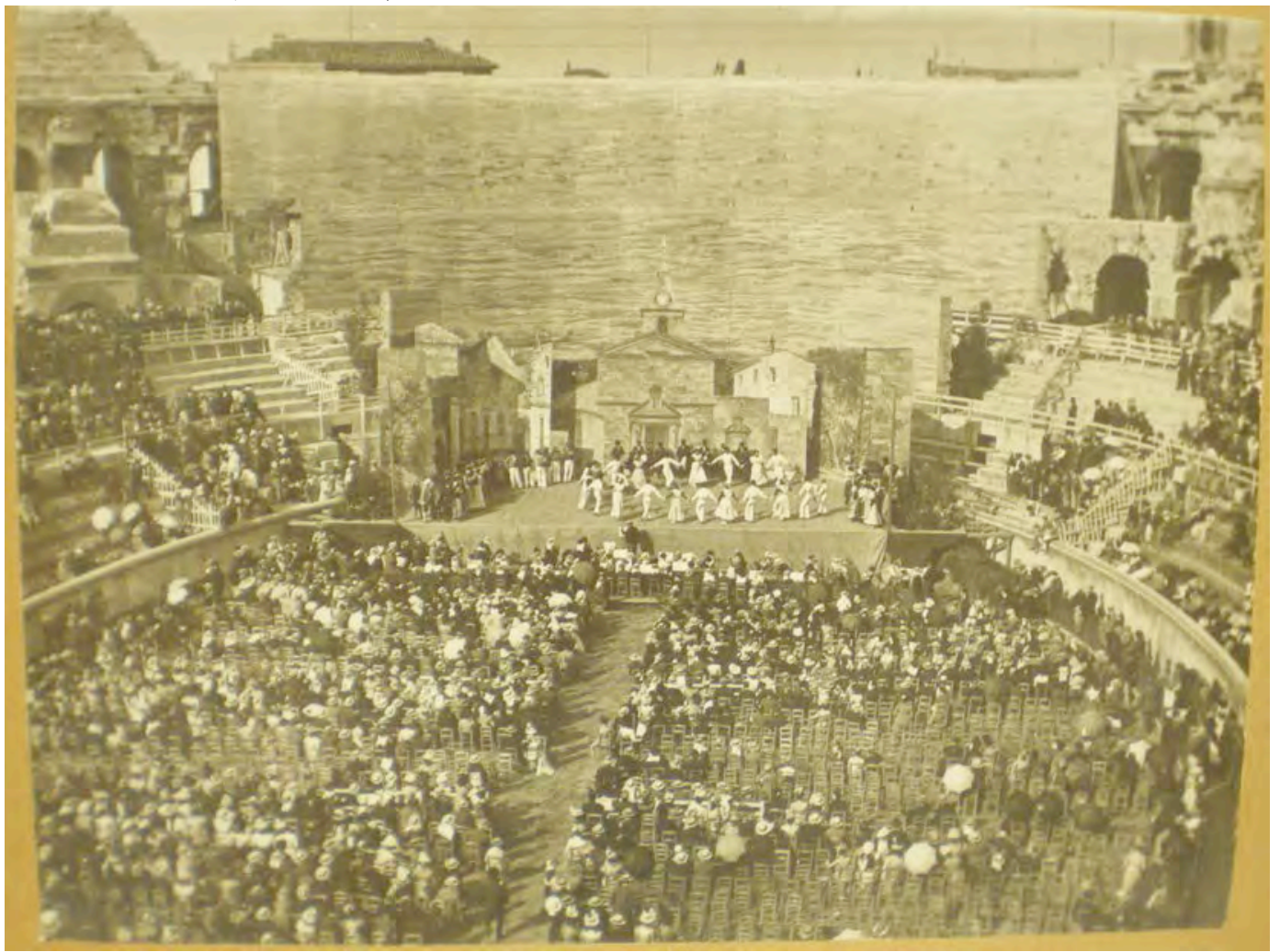

Figure 6 : affiche du Festival de Nîmes / Les arènes, 2009.

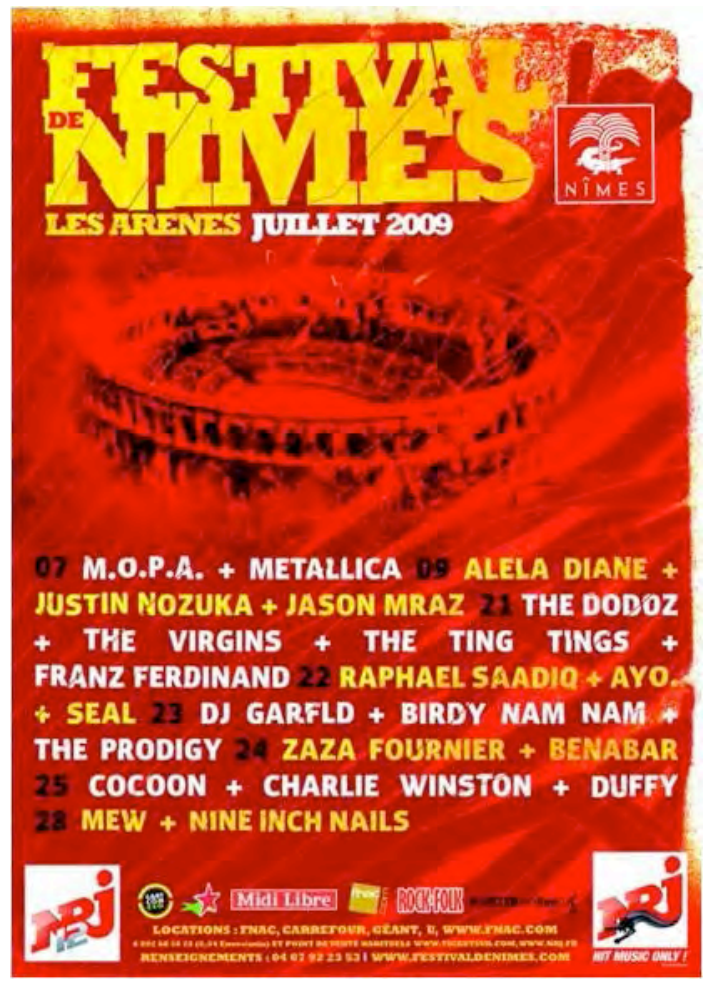




\title{
De l'apologie à l'apothéose médicéenne: le «Salon des Cinq Cents» et "San Lorenzo » (1564-1587)
}

\author{
Sonia ZERBIB \\ Doctorante en Histoire moderne \\ UMR 7303 TELEMME, Aix-Marseille Université/CNRS, \\ enseignante dans le secondaire \\ Extrait de : Jean DUMA (dir.), Le Rituel des cérémonies, Paris, \\ des congrès des sociétés historiques et scientifiques), 2015. \\ Cet article a été validé par le comité de lecture des Éditions du CTHS dans le cadre de la publication \\ des actes du $139^{\mathrm{e}}$ Congrès national des sociétés historiques et scientifiques tenu à Nîmes en 2014.
}

Si le Palazzo Vecchio voit l'identité du pouvoir se confondre avec celle du duc, San Lorenzo demeure le symbole de l'apothéose médicéenne. Ainsi comment ces lieux investis par le politique donnent-ils autorité à une dynastie en quête de légitimité ?

\section{Le "Salon des Cinq Cents ", théâtre d'une idéologie (1565-1567)}

Le caractère apologétique des événements de 1565 et de 1567, à la finalité politique commune, est rendu possible par la connotation politique du Salon des Cinq Cents.

Cosme $\mathrm{I}^{\mathrm{er}}$ manifeste en effet sa volonté de restructurer le Palazzo Vecchio où il s'installe avec sa cour à partir de 1540. La transformation de ce lieu en résidence princière commence à la fin de l'année 1554 et s'achève avec les fresques du Salon des Cinq Cents en 1571. Sa rénovation, véritable célébration des Médicis, correspond à un pouvoir ducal neuf et renforcé. Ainsi, ce lieu empreint de pouvoir voit se dérouler des événements privés au service d'une idéologie ducale en quête d'autorité. Lieu de réunion des membres de la République, il prend une place centrale dans le Palazzo Vecchio sous Cosme I ${ }^{\text {er }}$ et devient une salle de fêtes munie d'un théâtre provisoire réalisé par Giorgio Vasari.

Si 1565 marque une alliance qui s'annonce durable entre Francesco $\mathrm{I}^{\mathrm{er}}$ et Jeanne d'Autriche, le baptême de 1567 inscrit certes la première petite-fille de Cosme ${ }^{\text {er }}$ dans la communauté chrétienne, mais aussi sur la scène diplomatique. En effet, en associant cette fête à caractère privé à la sphère politique, les Médicis visent la conclusion d'une alliance matrimoniale future. Le rôle des femmes dans le rayonnement de la dynastie médicéenne s'avère par conséquent fondamental. En ce sens, je rejoins les propos de Dorothée Marciak qui fait remarquer qu'une des fonctions de la fête est d'anticiper «ce qui sera demain une réalité politique $»^{1}$.

Les noces, rendues officielles le 21 mars 1565, entre Francesco, fils aîné du duc Cosme I ${ }^{\mathrm{er}}$, élevé à la dignité de prince régent depuis le premier mai 1564, et Jeanne d'Autriche, fille de l'empereur Ferdinand et sœur de l'empereur Maximilien II, sont un moment fondamental de la politique et de la gloire des Médicis. En tissant une parenté impériale, elles scellent une légitimité de la dynastie au-delà de l'État toscan ${ }^{2}$ et renforcent l'image de monarchie autoritaire voulue par Cosme $\mathrm{I}^{\mathrm{er}}$. On apprend ainsi,

1. D. Marciak, La place du prince. Perspective et pouvoir dans le théâtre de cour des Médicis, Florence (1539-1600), p. 27.

2. C. Molinari, « Delle nozze medicee e dei loro cronisti », p. 23-24. 
«qu'étaient mandatés quelques gentilshommes de la ville à la porte principale du palais, qui reçurent et accompagnèrent à la salle les gentes dames florentines (...) invitées par son Excellence à un tel banquet (...) et ainsi dans l'ordre on récita d'abord la comédie puis on célébra le banquet. $»^{3}$

Pour honorer un tel événement, le théâtre était en effet privilégié car il permettait de servir l'idéologie médicéenne en la magnifiant. Le lieu de la fête s'inscrit dans un « espace vrai transfiguré $»^{4}$ ce qui lui donne une légitimité politique certaine. Plusieurs facteurs permettent d'avancer l'idée que ce lieu, à forte connotation politique, est certes métamorphosé mais demeure ancré dans la réalité. Cela est perceptible à la mise en place d'une véritable scène urbaine. Les descriptions de fêtes, commandées par les princes, permettent de reconstituer l'espace scénique. Domenico Mellini souligne ainsi que «la scène en perspective » fut recouverte par une "grande toile haute de seize bras et large de 22 » sur laquelle figurait « une très grande chasse faite en un très beau pays $»^{5}$. Cette scène était également entourée de façades sur lesquelles, selon Giovan Battista Cini, apparaissaient «toutes les places des villes du domaine de son Excellence » ${ }^{6}$, villes par ailleurs citées par Domenico Mellini : «Fiesole, Sienne, Pise, Arezzo, Cortone, Volterra, Pistoia, Borgo San Sepolcro, Montepulciano et Prato $»^{7}$. Cela révèle la puissance de Cosme I ${ }^{\text {er }}$ sur la Toscane et renforce l'idée d'un pouvoir établi. Il est en outre précisé par Giovan Battista Cini que «la scène représentait Florence » et notamment le quartier de Santa Trinità. La présence d'arcs triomphaux comme celui de la Vertu dans le quartier de San Giovanni est attestée dans cette chronique ${ }^{8}$. La réalité affichée par le lieu scénique rend la puissance souveraine plus transparente pour le spectateur.

Cette visibilité du pouvoir se confirme par la place centrale du couple princier soulignée par Giovan Battista Cini :

«Les très heureux époux dont les Altesses célébraient les noces, étaient au milieu de la salle. $»^{9}$

Le prince se donne en spectacle et assiste en même temps à la consolidation de son pouvoir mis en scène. Derrière son rôle d'acteur, il contrôle étroitement la représentation et joue dès le début un rôle déterminant, car c'est lui qui ordonne la levée du rideau qui dissimulait la scène. Ainsi, la réalité scénique et la place réservée au prince témoignent d'un discours politique clair.

Parallèlement à cette scène urbaine, la représentation théâtrale qui célèbre ces noces se compose de la Cofanaria, comédie de Francesco d'Ambra (1499-1558), auteur favorisé par Cosme, et des intermèdes de Giovan Battista Cini. Il semble important de préciser ici que

3. «Erano deputati alcuni gentilhuomini della città alla porta principale del palazzo i quali ricevessino, e accompagnassero per infino alle stanze (...) quelle gentil donne Fiorentine, che dall'Eccellenza del Principe erano state fatte invitare a tal convito (...) e cosi dar ordine si recitasse primeramente la comedia, e di poi si celebrassi il convito ", Cini, Giovan Battista, Descrizione dell'apparato della commedia e dell'intermedi di essa recitata in Firenze il giorno di S. Stefano l'anno 1565 nella Sala Grande del palazzo sua Ecc. Illust. nelle reali nozze dell'Illustriss. e Eccellentiss. il S. Don Francesco de'Medici e della regina Giovanna d'Austria, Florence, Giunti, 1566, p. 4.

4. A. Chastel, « Le lieu de la fête», p. 421.

5. «La scena e prospettiva », «La tela grande alta 16 braccia, e larga 22 », " una grandissima caccia fatta in un bellissimo paese », Mellini, Domenico, Descrizione dell'entrata della Serenissima Regina Giovanna d'Austria e l'apparato nella venuta, e per le felicissime nozze di S. Altezza e dell'Illustrissimo e Eccellentissimo S. Don Francesco de'Medici, Principe di Fiorenza e di Siena, Florence, Giunti, 1566, p. 135.

6. "Tutte le piazze della città del dominio di loro Eccellenze », Cini, Giovan Battista, Descrizione dell'apparato della commedia e dell'intermedi di essa recitata in Firenze il giorno di S. Stefano l'anno 1565 nella Sala Grande del palazzo sua Ecc. Illust. nelle reali nozze dell'Illustriss. e Eccellentiss. il S. Don Francesco de'Medici e della regina Giovanna d'Austria, Florence, Giunti, 1566, p. 8.

7. Mellini, Domenico, Descrizione dell'entrata della Serenissima Regina Giovanna d'Austria e l'apparato nella venuta, e per le felicissime nozze di S. Altezza e dell'Illustrissimo e Eccellentissimo S. Don Francesco de'Medici, Principe di Fiorenza e di Siena, Florence, Giunti, 1566, p. 124.

8. Cini, Giovan Battista, Descrizione dell'apparato della commedia e dell'intermedi di essa recitata in Firenze il giorno di S. Stefano l'anno 1565 nella Sala Grande del palazzo sua Ecc. Illust. nelle reali nozze dell'Illustriss. e Eccellentiss. il S. Don Francesco de'Medici e della regina Giovanna d'Austria, Florence, Giunti, 1566, p. 9.

9. « i felicissimi sposi delle cui Altezze celebravono le nozze, queste erano in mezzo della sale in coppia », ibid., p. 7. 
les descriptions relatives à ces noces donnent peu d'informations sur la pièce de théâtre elle-même. Celle de Giovan Battista Cini attache naturellement de l'importance aux seuls intermèdes. Cela s'explique entre autres par la place grandissante qu'ils occupaient depuis 1560 dans la représentation. Selon Bonner Mitchell, l'intermède correspond « à de petites représentations données avant ou après une comédie ou données entre deux actes ». Son origine remonte à la seconde moitié $\mathrm{du} \mathrm{XV}^{\mathrm{e}}$ siècle en Italie. Il est mis en espace sous différentes formes, plastiques, musicales et poétiques et reflète souvent une intention politique : il doit honorer et renforcer le pouvoir en place ${ }^{10}$. Roy Strong y voit également le moyen pour les Médicis de célébrer leur régime autoritaire ${ }^{11}$.

Par l'illusion scénique, ils suscitent en effet l'émerveillement du spectateur, renforcé par la place centrale de la mythologie dans les fêtes de l'époque maniériste. C'est par une association des princes aux dieux de l'Olympe que l'intermède permet de rendre compte de la puissance médicéenne. Ceux de Giovan Battista Cini mettent en scène Amour et Psyché qui célèbrent les thèmes de l'Amour, de ses tourments, de la beauté et de l'éternité, choix judicieux pour honorer ces noces.

La volonté de forger un État neuf, en associant fête privée et lieu politique, ressurgit avec le baptême de la première petite-fille de Cosme ${ }^{\mathrm{er}}$, née le $1^{\mathrm{er}}$ mars 1567 , qui eut lieu selon les écrits d'Agostino Lapini «le jour 29 de l'année 1567, un dimanche de carnaval ${ }^{12}$. Le Salon des Cinq Cents fut privilégié pour le banquet et la représentation théâtrale : Cosme I ${ }^{\mathrm{er}}$ manifestait à nouveau la volonté d'afficher sa politique absolutiste.

Une comédie de Lotto de Mazza, I Fabii, fut représentée avec ses intermèdes. Tout comme la comédie de la Cofanaria, elle fut approuvée par le régime. Ce contrôle étroit de la fête permettait l'affirmation d'un État moderne fort ${ }^{13}$. La réalité scénique et donc politique était également servie par des innovations scéniques majeures. Ici, le système des périactes qui participait au changement de perspective sur scène. Un conflit d'auteurs sur la première introduction de ce système est à préciser : Ludovico Zorzi pense qu'il a été inventé par Vasari seulement en 1569, date des festivités données à l'occasion de la venue à Florence de l'archiduc d'Autriche alors que, selon Gina Ianella, il a été inventé par Baldassare Lanci pour la représentation des Fabii en 1567.

La nouvelle perspective scénique qui en résulte peut d'une certaine manière correspondre à une nouvelle perspective du pouvoir. C'est par la transposition de la réalité de l'espace urbain sur scène que la réalité du pouvoir des Médicis est une nouvelle fois rendue visible. Ainsi Alessandro Ceccherelli précise qu'il est essentiel de présenter la scène :

«Il est nécessaire de raconter la façon dont la scène, conçue par Baldassare d'Urbino, était dite scène en perspective faite en certaine manière ; $(.$.$) on voyait le palais ducal (.$. plusieurs palais et des maisons ornées de balcons et de terrasses (...) cette dite scène restait ainsi jusqu'au quatrième acte, ensuite on chantait et on interprétait l'intermède. ${ }^{14}$

Tout comme pour les noces de 1565, il semble intéressant de mettre l'accent sur les intermèdes car ils constituent une allégorie du pouvoir absolu. Pour mettre en scène la puissance souveraine, la mythologie est une nouvelle fois privilégiée car elle sert à détourner l'interdiction d'assimiler le prince à Dieu. Le sixième et dernier intermède

10. M. Bonner, «Les intermèdes au service de l'État », p. 117 et 119.

11. R. Strong, Les fêtes de la Renaissance (1450-1650), art et pouvoir, p. 72.

12. "Al di 29 detto 1567, in domenica di carnavale ", Lapini, Agostino, Diario fiorentino dal 252 al 1596, Florence, Sansoni, 1900, XXVII, p. 158.

13. M. Plaisance, Florence, fêtes, spectacles et politique à l'époque de la Renaissance, p. 139.

14. «è necessario cantare il modo della scena, il quale era fatta, e fabricata per mano dell'Eccel. M. Baldassari da Urbino, era detta scena è prospettiva fatta in questa guisa; (...) si vedeva il Ducal Palazzo (...) vari palazzi e casamenti di diverse maniere con loggi, terrazzi in fuora (...) stette la detta scena cosi fino al quarto atto, si cantava e sonava l'intermedio ", Ceccherelli, Alessandro, Descrizione di tutte le feste, e mascherate fatte in Firenze per il carnavale questo anno 1567. E insieme l'ordine del Battesimo della Primogenia dell'Illustr. e Eccell. S. Principe di Firenze e di Siena, con gli intermedi della commedia e dell'apparato fatto per detto battesimo, p. 17. 
relatif au Banquet des dieux célébrant la naissance de Vénus qui renvoie au baptême d'Éléonore de Médicis et au banquet offert à l'ensemble des invités mérite une attention particulière. Ce thème de l'assemblée des dieux, récurrent à cette époque, permet à la cour de s'identifier et de reconnaître l'autorité médicéenne. C'est ainsi que les intermèdes donnent lieu à un somptueux banquet « dans la salle du Conseil (...) avec diverses sortes de ballets $»^{15}$.

Les noces de 1565 et le baptême d'Éléonore de Médicis résonnent dans la Sala Grande comme un éloge de la dynastie médicéenne et vont servir de tremplin à Cosme ${ }^{\mathrm{er}}$ pour acquérir le titre de grand-duc.

\section{"San Lorenzo ", théâtralisation à la louange de Michel-Ange}

Les funérailles sont en effet privilégiées pour confirmer le pouvoir de l'intérieur mais aussi assurer à la dynastie un rayonnement international. Pour ce faire, le spectacle reste le vecteur essentiel pour mettre en scène la mort et le sens qu'elle recouvre à cette époque.

Michel-Ange Buonarroti mourut à Rome le 17 février 1564, date controversée dans l'opuscule relatif aux funérailles du divin Michel-Ange mis en lumière par Giulio Piccini. En effet, il semblerait dans celui-ci que la mort de Michel-Ange soit survenue le 18 février 1564 :

«La glorieuse âme de Michel-Ange fut passée à meilleure vie le XVIII février 1563, en style florentin. $»^{16}$

La question du transfert du corps de Michel-Ange à Florence et l'organisation de ses funérailles se sont très vite imposées. Cosme $\mathrm{I}^{\mathrm{er}}$ exigea le rapatriement du corps de l'artiste dans la plus grande discrétion afin de «lui rendre les honneurs post-mortem avec toute la pompe possible ${ }^{17}$. De même, dès la nouvelle de sa mort, le représentant de l'Académie du dessin créée en 1563, Vincenzo Borghini, soumit un projet aux membres de celle-ci pour les funérailles de leur premier académicien et « leur rappela leur devoir statutaire $\mathrm{d}^{\prime}$ honorer leurs frères défunts ${ }^{18}$. Dans l'échange épistolaire entre Vincenzo Borghini et Cosme $\mathrm{I}^{\mathrm{er}}$, la question du lieu de la cérémonie était centrale comme le montre ce passage :

«Les membres de l'Académie du dessin (...) savent combien Votre Illustre Excellence était attachée à Michel-Ange, autant que celui-ci l'aimait, et ils vous supplient que dans votre générosité infinie vous leur accordiez de pouvoir célébrer les obsèques dans l'église SaintLaurent. ${ }^{19}$

L'accord ducal était en effet indispensable pour organiser une cérémonie publique et tout particulièrement dans la basilique San Lorenzo, lieu par excellence de la dynastie médicéenne. L'Académie reçut l'approbation de Cosme $\mathrm{I}^{\mathrm{er}}$ qui, ce faisant, rendait un hommage exceptionnel à Michel-Ange. Il est par ailleurs intéressant de préciser que dans la réédition des funérailles de ce dernier une lettre à laquelle fait référence Vasari est intégralement restituée. Elle est adressée aux commissaires par le secrétaire de Cosme $\mathrm{I}^{\mathrm{er}}$, Bernardino Grazzini, qui vient en quelque sorte renchérir la réponse du duc précédemment évoquée par ces quelques mots écrits de Pise le 10 mars 1563 (style florentin) : il évoque entre autres le «désir ardent » du duc d’honorer «la mémoire de

15. «Nella sala di consiglio, con diversi balli », ibid., p. 29.

16. G. Piccini (dir.), Esequie del divine Michelagnolo Buonarroti celebrate in Firenze dall'Accademia de'pittori, scultori, architettori, Florence, Tip. Gazetta d'Italia, 1875, p. 13.

17. G. Vasari (Vie de) Michel-Ange Buonarroti, Les vies des meilleurs peintres, sculpteurs et architectes, traduction et édition commentées sous la direction d'André Chastel, Arles, Actes Sud, 2005, 8, vol. II, livre IX, p. 318.

18. Ibid., p. 318

19. Ibid., p. $320-321$. 
Michel-Ange », il rappelle que le duc est favorable au déroulement des funérailles dans "l'Église de San Lorenzo, qu'il y participera financièrement (...) » ${ }^{20}$. Ainsi la prise en charge de la cérémonie et la réponse satisfaisante donnée à l'Académie confirment que le pouvoir, derrière l'hommage rendu au génie de l'artiste, contrôle pleinement la fête qui lui permet de s'affirmer.

Vasari et Borghini pouvaient alors commencer, avec les académiciens, à mettre en œuvre leur projet. C'est à ce moment-là que Lionardo Buonarroti, neveu de Michel-Ange, organisa le transfert du corps depuis Rome. Celui-ci arriva à Florence le 11 mars. Les

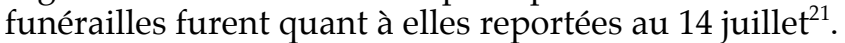

Il est important de rappeler ici que Michel-Ange, décédé à l'âge de 90 ans, fut non seulement témoin d'une affirmation progressive des Médicis mais encore acteur à part entière. Cela explique en partie que la cérémonie se soit déroulée dans le lieu symbolique de San Lorenzo. Ce dernier qui abrite à la fois les Médicis défunts et les œuvres florentines de Michel-Ange incarne donc la culture politique de la fête, initiée par Laurent le Magnifique. San Lorenzo fut par conséquent habillée d'un apparat exceptionnel pour rendre hommage au maître des trois arts. La théâtralisation opérait encore et l'organisation du décor correspondait remarquablement à la vie de Michel-Ange, partagée entre Rome et Florence. Le décor du catafalque, pièce maîtresse des funérailles, mérite une attention particulière. Ainsi, au centre de la basilique :

«On dressa comme prévu, un catafalque haut de vingt-huit brasses (...) à la base, on plaça deux superbes figures de fleuves étendus, l'Arno et le Tibre. »

La richesse des productions artistiques de la cité florentine était symbolisée par l'attribut que portait l'Arno à savoir :

«Une corne d'abondance pleine de fruits et de fleurs ». Le Tibre « avait les mains pleines de fleurs et de fruits reçus de la corne d'abondance de l'Arno étendu à ses côtés, ce qui rappelait que Michel-Ánge avait vécu une grande partie de sa vie à Rome et y avait créé les merveilles qui font l'admiration du monde. »

Ces deux œuvres avaient été respectivement réalisées par deux artistes de talent, Giovanni di Benedetto da Castello, élève de Bandinelli, et Battista de Benedetto, élève $\mathrm{d}^{\prime}$ Ammannatii ${ }^{22}$. Au-dessus de ce premier niveau, on pouvait voir quatre tableaux ${ }^{23}$ sur lesquels étaient représentées plusieurs scènes dont deux retiennent l'attention : celle où Laurent le Magnifique reçoit Michel-Ange dans son jardin, réalisée par Mirabello et Giovanni del Crucifissaio et celle où figurait :

«(une) Grande inscription épitaphe latine rédigée par le savant Pier Vettori, dont le sens était en italien : « l'Académie des peintres, sculpteurs et architectes, grâce à l'appui favorable du duc Cosme, leur chef et protecteur suprême de ces arts, a dédié en signe d'admiration pour le génie supérieur de Michel-Ange Buonarroti et en reconnaissance du bienfait de ses œuvres merveilleuses, ce mémorial issu de leurs mains et de leur affection au génie supérieur du plus grand peintre, sculpteur et architecte qui ait jamais été. »

Cette épitaphe, «soutenue par deux angelots en pleurs, éteignant une torche ${ }^{24}$, symbolisait la perte douloureuse de ce génie des arts. On voit à nouveau la mainmise du pouvoir sur la métamorphose du lieu où sont célébrées les funérailles.

20. "ardente desiderio », "memoria di Michelagnolo », "la chiesa di San Lorenzo, aiutarvi di denari», Piccini, Giulio (dir.), Esequie del divine Michelagnolo Buonarroti celebrate in Firenze dall'Accademia de'pittori, scultori, architettori, Florence, Tip. Gazetta d'Italia, 1875, p. 22.

21. Vasari, Giorgio, (Vie de) Michel-Ange Buonarroti, Les vies des meilleurs peintres, sculpteurs et architectes, traduction et édition commentées sous la direction d'André Chastel, Arles, Actes Sud, 2005, 8, vol. II, livre IX, p. 323.

22. Ibid., p. 326

23. Ibid., p. 326

24. Ibid., p. 327 
De riches œuvres ornaient encore le catafalque caractérisé par un «dégradé de plans successifs autour desquels on circulait, qui le faisait ressembler au mausolée d'Auguste à Rome ». On apprend aussi que «sur cette base reposait une pyramide de neuf brasses de haut ». La basilique de San Lorenzo était également décorée à la gloire de Michel-Ange ${ }^{25}$. On peut ainsi noter la présence d'un tableau réalisé par un élève de Bronzino, Stefano Pieri, représentant «Michel-Ange assis auprès de l'illustre Cosme dans une salle où ils bavardaient $»^{26}$. Les relations tissées par Cosme $\mathrm{I}^{\mathrm{er}}$ puis par le prince Francesco avec Michel-Ange laissaient présager d'un pouvoir stable. De même,

«l'intérieur des chapelles comportait des images, emblèmes (...) de la mort, différentes de l'ordinaire et d'une belle invention. (...) l'une reçut plus particulièrement des éloges ; l'Eternité une palme à la main maintenant son pied sur le cou de la mort qui gisait à terre, semblait d'un regard plein de dédain lui déclarer l'inanité de sa loi de nécessité, car MichelAnge vivrait de toute façon malgré elle. La devise était : Victoire de la vertu insigne. ${ }^{27}$

Cette image funéraire permettait encore de consacrer l'œuvre de Michel-Ange mais aussi de montrer que la création artistique devait perdurer sous son regard bienveillant.

Une codification de la cérémonie, en symbiose avec l'apparat, doit être également soulignée. Ainsi après l'installation de hautes personnalités comme le représentant de l'Académie, "commença une messe des morts des plus solennelles avec musique et tout le cérémonial ». Benedetto Varchi prononça une oraison funèbre dans laquelle «il développa les mérites, la vie, les œuvres du divin Michel-Ange Buonarroti ».

Ces obsèques célébrées à San Lorenzo avaient attiré une foule considérable, car «tous abandonnant toute autre préoccupation, étaient accourus à ce glorieux spectacle». Mais cet apparat de grande renommée n'ayant pas pu être vu par toute la ville, le duc prit la décision de le conserver "plusieurs semaines en état à la satisfaction de la foule et des étrangers qui vinrent le voir des régions voisines $»^{28}$.

Les funérailles célèbrent certes un génie de l'art mais aussi, de façon indirecte, le prestige d'une dynastie scellé par l'intemporalité de ce grand homme. Le pouvoir exalté par cette mise en scène de la mort annonce les fastes funéraires dynastiques de 1574 et de 1587.

\section{Lieux emblématiques et résonances funéraires dynastiques}

Les funérailles de Cosme $\mathrm{I}^{\mathrm{er}}$ devaient en effet résonner comme une véritable apothéose. Un moment clé de ce rituel funéraire est la reconnaissance du nouveau grand-duc au Palazzo Vecchio :

«Étaient convoqués tous les ambassadeurs du prince, tous les parents, tous les magistrats, tous les seigneurs (...) et finalement tous ceux qui dans la pompe devaient intervenir, le nouveau grand-duc, assis au milieu, occupait une place d'excellence, et l'image de la mort étant mise en scène sous un très riche baldaquin brodé $d^{\prime}$ 'or dans un splendide cercueil proche de la porte du même palais, M. Gio. Battista Adriani, orateur très savant et très spirituel de notre temps, monté en chaire, commença son oraison latine. ${ }^{29}$

25. Ibid., p. 329-330.

26. Ibid., p. 334

27. Ibid., p. 334

28. Ibid., p. 323

29. «stati convocati tutti gli imbasciatori de'Principi, tutti parenti, tutti i magistrati, tutti i signori (...) e finalmente tutti quelli, che nella pompa dovevano intervenire, sedendo in mezzo, $\mathcal{E}$ in luogo eminente il novello Gran Duca, $\mathcal{E}$ essendo stata messa l'imagine nel morto sotto un ricchissimo baldacchino di broccato d'oro in uno splendidissimo de'tempi nostri, salite nel preparato pulpito comincio la sua latina oratione", dans Descrzione della pompa funerale nelle esequie del Ser. Cosimo de'Medici granduca di Toscana, Florence, Giunti, 1608, p. 12-13. 
D'une part, la représentation de la mort évoquée dans la citation renvoie clairement à l'effigie du grand-duc qui symbolise la gloire du souverain défunt et l'affirmation officielle du nouveau grand-duc. Faite de cire, elle était l'œuvre du sculpteur Giambologna $^{30}$. Cette mise en scène de la mort illustre également la théorie des deux corps du roi exprimée ainsi « les deux corps du prince défunt et vivant » ${ }^{31}$. L'effigie, par essence, représentait le corps symbolique du grand-duc défunt et était assimilée à son immortalité. Cette tradition de l'effigie de cire revêtue d'habits royaux est attribuée aux deux grandes monarchies occidentales, l'Angleterre et la France, à partir des XIV $\mathrm{XV}^{\mathrm{e}}$ siècles $^{32}$. En quête de prestige, la dynastie des Médicis s'affranchit du pouvoir impérial ou du moins associe des traditions différentes afin de s'approprier un rituel et de consolider ainsi son pouvoir. D'autre part, le Palazzo Vecchio incarne la cérémonie du couronnement de Francesco $\mathrm{I}^{\mathrm{er}}$. Après les condoléances adressées au grand-duc et les félicitations pour sa nouvelle charge, les funérailles officielles purent commencer.

Le transfert de l'effigie eut donc lieu du centre politique de la cité à San Lorenzo. Ainsi on note dans la description officielle des funérailles que pour :

«Le meilleur Père de la Patrie», «les chevaliers de Saint-Étienne, placés en dernier, accompagnés par la garde allemande, par toute la cour du même grand-duc, et de nombreuses torches, le mettant sur un grand cercueil recouvert de broderies d'or le portèrent et le déposèrent dans la sacristie de San Lorenzo, chapelle privée de la maison Médicis construite par les Anciens avec une très grande dépense, \& avec des ornements \& une architecture singulière (...) où il fut enterré au dix-septième jour de mai afin qu'avec faste puissent être célébrées dignement les funérailles. ${ }^{33}$

San Lorenzo apparaît donc comme le lieu de sépulture réservé aux Médicis. Marcello Fantoni souligne en outre qu'aucune véritable tradition ne s'était imposée avant cette dynastie $^{34}$. Cela conforte l'idée de l'affirmation d'une tradition qui lui est propre et légitime un culte monarchique ${ }^{35}$, synonyme d'apothéose.

C'est en ce lieu que la pérennité du pouvoir s'exprime le plus intensément comme le montre l'expression « pouvoir maintenir en perpétuelle vie un corps si digne » ${ }^{36}$. Même si Giesey affirme que la «perpétuité c'était bien ce qu'aucun grand-duché ne pouvait jamais revendiquer $\gg{ }^{37}$ et explique que le pouvoir grand-ducal était délégué et n'émanait pas directement de Dieu, comme pour les monarchies occidentales, mais d'un pape et d'un Empereur, nous pouvons souligner l'ambition qu'a la dynastie des Médicis de se hisser au rang des grandes familles européennes. C'est donc à une lutte permanente contre le « caractère imparfait » de sa monarchie qu'elle œuvre.

La théâtralisation de l'événement s'exprimant par une théâtralisation de l'espace voit son apogée dans la basilique San Lorenzo. Dans ce lieu, on découvre des parois et des colonnes ornées, pour les premières, «d'images de la mort » et pour les secondes, des

30. E. Borsook, Art and politics at the Medici Court: the funeral of Cosimo I de'Medici, p. 38.

31. " $i$ due corpi del morto $\mathcal{E}$ del vivo principe", dans Descrzione della pompa funerale nelle esequie del Ser. Cosimo de'Medici granduca di Toscana, Florence, Giunti, 1608, p. 13.

32. Sabatier, Gérard, Hengerer, Mark, «Le grand théâtre de la mort », p. 7.

33. " ottimo Padre della PATRIA ", " i cavalieri di Santo Stefano in ultimo, accompagnati della guardia Tedescha, da tutta la corte di esso Gran Duca, E da buona quantità di torce, messolo sopra una grandissima bara tutta coperta di broccato d'oro lo portarono con sua mestitia, $\mathcal{E}$ deposero nella sagrestia di San Lorenzo, chiesa particolare della casa Medici fabbricata da suoi Antenati con grandissima spesa, $\mathcal{E}$ con ornamenti, $\mathcal{E}$ Architettura singolarissima (...) fu serbato insino al diciasettisimo giorno di Maggio, accioche con ordinate pompa se gli potessero celebrare Esequie degne", dans Descrzione della pompa funerale nelle esequie del Ser. Cosimo de'Medici granduca di Toscana, Florence, Giunti, 1608, p. 11.

34. M. Fantoni, «Les rituels funéraires comme fondement de la souveraineté chez les Médicis, XVI ${ }^{\mathrm{e}}$ XVIII ${ }^{\mathrm{e}}$ siècles », p. 194.

35. G. Sabatier et M. Hengerer, « Le grand théâtre de la mort », p. 11-12.

36. "di poter mantenere in perpetua vita corpo si degno", dans Descrzione della pompa funerale nelle esequie del Ser. Cosimo de'Medici granduca di Toscana, Florence, Giunti, 1608, p. 26.

37. M., Casini, I gesti del Principe. La festa politica a Firenze e Venezia in età rinascimentale, p. 92. 
"grandes armes du même grand-duc ${ }^{38}$. Parmi les divers décors, on peut retenir la présence de médailles qui «faisaient allusion aux plus glorieuses actions du même grand-duc ${ }^{39}$. L'adoption du modèle antique, dont témoignent ces médailles, s'inscrit ici dans une volonté d'apothéose du souverain à l'image des empereurs romains qui étaient en quelque sorte déifiés. Ainsi Cosme $\mathrm{I}^{\mathrm{er}}$ est assimilé à un « réel Auguste de nos temps »"

Ce lieu de valorisation des actions et des vertus du souverain défunt symbolise aussi l'intronisation du nouveau grand-duc comme ces passages le laissent entendre :

« À l'intérieur de la Tribune qui fut toute couverte de noir » était placé « le siège du nouveau grand-duc ${ }^{41}$ ou encore «Les pilastres étaient si hauts que sans empêcher la vue de ceux-ci (...) tout le restant de l'église puisse pleurer l'image du grand-duc mort et se réjouisse de celle du vivant. Au milieu de ces pilastres ensuite (...) devait être placé le cercueil. ${ }^{42}$

Le pouvoir, rendu visible, permet d'accélérer le processus de légitimation dynastique, central dans la cérémonie. Ainsi :

«La pompe entrée et le cercueil déposé sous la pyramide évoquée, une place étant attribuée à chacun, l'Archevêque César commença, avec l'assistance de quatre évêques et de hauts prélats, la cérémonie funéraire, à la fin de laquelle le très érudit et très cher Monsieur Pietro Vettori a récité le premier sa très élégante oraison. ${ }^{43}$

Tout en s'inscrivant dans la continuité des funérailles de Cosme $\mathrm{I}^{\mathrm{er}}$, celles de Francesco $\mathrm{I}^{\mathrm{er}}$, décédé le 19 octobre 1587, marquent par leur faste un ancrage politique certain dans la cité florentine. Elles furent organisées par son frère et successeur, le cardinal Ferdinand

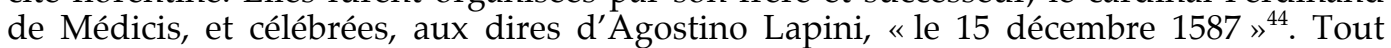
comme pour les funérailles du grand-duc Cosme $\mathrm{I}^{\mathrm{er}}$, l'intronisation du nouveau grandduc prit effet dans le Palazzo Vecchio : « le jour 25 du dit octobre 1587, qui fut un dimanche (...) dans le grand salon peint » où fut acclamé le nouveau "grand-duc Ferdinand de Médicis pour seigneur et maître avec grande joie ${ }^{45}$.

Si le Diario fiorentino d'Agostino Lapini permet d'attester de façon fiable le cadre spatiotemporel dans lequel ces funérailles se sont déroulées, je m'appuierai pour leur donner du sens sur la description laissée par Giovan Battista Strozzi qui est, à ma connaissance, une des plus fournies. Dans cette chronique, la glorification du défunt et l'intronisation du nouveau grand-duc sont également clairement affichées : " au Sérénissime Francesco Médicis G. duc de Toscane, son frère sérénissime et successeur ordonna que furent réalisées des funérailles adéquates à la réelle grandeur de l'un et de l'autre ${ }^{46}$. On peut en outre noter que se trouvait au Palazzo Vecchio:

"Sous un très riche baldaquin, l'effigie du grand-duc Francesco toute armée, recouverte d'un drap et avec la couronne sur la tête (...) dans un merveilleux cercueil. » ${ }^{47}$

38. "immagini della morte», "essendo ad ogni colonna un grand'arme di esso Gran Duca", dans Descrzione della pompa funerale nelle esequie del Ser. Cosimo de'Medici granduca di Toscana, Florence, Giunti, 1608, p. 26.

39. «alcune medaglie alludenti a parte de'piu gloriosi fatti di esso Gran duca, ibid., p. 27.

40. "il verace Augusto de'tempi nostri », ibid., p. 7.

41. «Dentro alla Tribuna poi, che tutta di nera era coperta (...) la sede del novello Gran Duca », ibid., p. 33.

42. "essendo $i$ pilastri di tanta altezza, che senza impedimento la vista di quelli (...) tutto il resto della chiesa potesse piangere l'immag. del morto G.D. E godersi quella del vivo. In mezzo a detti pilastri poi (...) doveva posarsi il feretro ", ibid., p. 35-36.

43. "entrata la pompa, $\mathcal{E}$ deposto il feretro sotto la Piramide predetta, essendo ordinatamente stato dato a ciascheduno il suo luogo, cominicio l'Arcivescovo di Cesare a predetto, con l'assistentia di quattro Vescovi e di alti Prelati la sua funerale cirimonia alla quale posto fine, havendo prima il dotiss. et chiariss. M. Pietro Vettori recitato in luogo eminente la sua elegantiss. oratione », ibid., p. 38.

44. Lapini, Agostino, Diario fiorentino dal 252 al 1596, Florence, Sansoni, 1900, XXVII, p. 262.

45. " A'di 25 di detto ottobre 1587, che fu in domenica (...) nel salone grande dipinto (...) gran duca Ferdinando Medici per loro signore e padrone, con allegrezza grandissima », ibid., p. 261.

46. "al Sereniss. suo fratello, e successore ordinasse che fussero fatte Essequie convenienti alla reale grandezza dell'uno, $e$ dell'altro", G. B. Strozzi, Essequie del serenissimo Don Francesco Medici Gran Duca di Toscana II, Florence, Sermartelli, 1587, p. 4.

47. "sotto il il ricchissimo baldachino l'immagine del G. Duca Francesco armata tutta, e di reale ammanto vestita, e con quella corona in testa (...) in un feretro mirabile », ibid., p. 11. 
Le rite médicéen de l'effigie est entretenu ce qui confirme une continuité certaine dans le pouvoir. San Lorenzo, autre lieu emblématique, apparaît central dans la transmission du pouvoir et l'apothéose du souverain défunt. Ici encore, l'espace est transformé en véritable lieu théâtral :

"Cavaliers et seigneurs à la porte de l'église de San Lorenzo, prenant le brancard, allèrent le poser dans ce lieu surélevé où brûlaient six cents bougies. »

C'est dans ce «même lieu » que «l'on érigea un très riche lit sur lequel (...) fut disposé le grand-duc. Il était recouvert d'un drap (...) similaire à celui que portait son père le jour de son couronnement par Pie V à Rome ${ }^{48}$. Ce spectacle de la mort, dont l'exposition du défunt fait partie, est décrit par Giovan Battista Strozzi comme «un spectacle générant horreur, étonnement et compassion ${ }^{49}$. Ce passage répond bien de la religion chrétienne mais aussi de la volonté de placer le défunt dans une position de gloire.

L'apparat extérieur et intérieur de la basilique témoigne également d'un spectacle de la mort. Ainsi Giovan Battista Strozzi évoque dans sa description les devises figurant sur la façade de San Lorenzo $0^{50}$ qui s'apparentent d'une certaine manière à l'affirmation publique de l'autorité médicéenne. En se prêtant à une réflexion sur la mort, elles renvoient à l'éternité du pouvoir.

Dans « l'espace majeur », on peut voir :

«Deux chaires en bronze qui avaient un tableau chacune; on reconnaît dans l'une des peintures l'ordre conservé dans la conduite de Poggio à Florence du grand-duc défunt ; l'autre (...) contenait la pompe des funérailles qui se célébraient. . ${ }^{51}$

Il est intéressant ici de remarquer que le thème de l'autocélébration du pouvoir est récurrent dans les cérémonies florentines. Cela est bien la preuve qu'il est en perpétuelle représentation et par conséquent en construction à travers ces festivités. Un parcours imagé était également conçu pour ces funérailles sous la forme de douze histoires qui évoquaient quelques moments de la vie du défunt, en particulier la cinquième et la onzième histoire, majeures dans la destinée politique de Francesco $\mathrm{I}^{\mathrm{er}}$. La première représente «la Prudence du père et la sienne, puisque le duc, connaissant bien le discernement du Prince, et parce qu'ayant vingt-trois ans » lui remet «en main le gouvernement $»^{52}$.

Cette peinture fait allusion à une étape très importante de la vie du Prince Francesco : Cosme Ir lui confie les rênes du pouvoir en 1564, tout en étant encore duc et très présent politiquement. La seconde montre Francesco I ${ }^{\mathrm{er}}$ devenant grand-duc de Toscane. Ce parcours historié, véritable illustration de l'apologie grand-ducale, est prolongé par des louanges.

Je terminerai en mettant l'accent sur quelques oraisons funèbres commandées par le futur souverain et qui font partie intégrante de la mise en scène de la mort. Ces panégyriques funéraires sont destinés à l'apothéose du grand-duc défunt. L'oraison s'assimile ainsi à un discours politique clair, visible à sa structure. D'une part, l'humilité de l'auteur,

48. « Cavalieri e Signori alla porta della chiesa di San Lorenzo predendo la lettiga, andarono a posarla in luogo rilevato da terra dove secento lumi ardevano » (...) «questo stesso luogo», "si eresse un ricchissimo letto e sopra esso (...) fu collocato il G. Duca. Era vestito di ammanto (...) simile à quello che haveva il suo Gran Padre il di che in Roma lo incorono Pio $V »$, p. 7-8.

49. « spettacolo, il quale il terrore, e maraviglia, e compassione generando », ibid., p. 9.

50. Ibid., p. 38.

51. «I due Pergami di Bronzo havevano (...) un quadro ciascuno; riconoscevasi nella pittura dell'uno l'ordine tenutosi nel condurre del Poggio a Firenze il Gran Duca morto; l'altro (...) conteneva la pompa dell'essequie che si celebravano", ibid., p. 42.

52. «la Prudenzia del Padre, e la sua, poiche il Duca molto ben conoscendo il senno del Principe, e percio in età di ventitre anni» $(. .$.$) « in mano il governo », ibid., p. 47$. 
nécessaire à l'éloge du défunt, est manifeste. Ainsi Pietro Vettori, dans son oraison prononcée à San Lorenzo à la louange de Cosme I ${ }^{\mathrm{er}}$, affirme " comment puis-je brièvement évoquer les nombreuses et grandes vertus d'un homme très savant? ${ }^{53}$. Cette question de l'humilité se lit dans la sobriété du discours de Giovan Battista Adriani, prononcé au Palazzo Vecchio, qui par ailleurs rend compte de l'assise du pouvoir médicéen. Ainsi les louanges à la vie de Cosme $\mathrm{I}^{\mathrm{er}}$ sont exprimées « sans beaucoup de mots et simplement ${ }^{54}$.

D'autre part, ces oraisons sont un éloge à la dynastie médicéenne. Pietro Vettori souligne la «clarté de la lignée " ${ }^{55}$ de Cosme I ${ }^{\text {er }}$ dont il fait les louanges par la suite. Giovan Battista Adriani s'appuie, quant à lui, sur les origines prestigieuses de Cosme $\mathrm{I}^{\mathrm{er}}$ afin de lui donner une légitimité politique : il le qualifie d'homme de " grand lignage » à qui fut confié «le pouvoir de gouverner» et insiste sur le fait que «dans la ville il n'y avait aucune mutation sinon la personne du prince $»^{56}$.

Enfin, évoquer les actions héroïques du grand-duc est un moyen d'en faire l'apothéose.

C'est dans ce cadre que des thèmes aussi variés que la transmission du pouvoir, la mémoire, l'éternité prennent tout leur sens et permettent de célébrer la gloire du grandduc défunt. Les discours funèbres relatifs aux funérailles du grand-duc Francesco ${ }^{\mathrm{er}}$ conservent la même structure que celle des oraisons dédiées à Cosme ${ }^{\text {er }}$, ce qui laisse penser que le pouvoir s'inscrit dans la durée. Si celui de Pietro Angeli da Barga, prononcé le 21 décembre 1587 au Palazzo Vecchio, marque le début de la glorification grand-ducale, celui de Lorenzo Giacomini achève le cycle funéraire et prend ainsi une dimension d'apothéose, perceptible dans un extrait de la lettre que ce dernier a adressée au grandduc Ferdinand $\mathrm{I}^{\mathrm{er}}$ au début de son oraison : " à lui donner une augmentation de grâce en présence de tous ${ }^{57}$. Son apothéose doit ainsi être affichée publiquement. La sublimité de l'oraison vient ainsi clore la magnificence funéraire et se veut en quelque sorte être un vernis funèbre : la mort sonne comme un triomphe.

L'emprise du pouvoir sur la métamorphose de ces lieux en véritables théâtres urbains ou théâtres de la mort renvoie ainsi à un État puissant.

53. "Come posso io brevemente raccontare tante, E cosi gran virtù di un'huomo sapientissimo ?», P. Vettori, Orazione recitata nell'esequie del sereniss. Cosimo de'Medici gran duca di Toscana nella chiesa di San Lorenzo, il di dicesette di maggio 1574. Et poscia da Francesco Boschi fiorentino della lingua latina tradotta nella favella fiorentina, Florence, Marescotti, 1574, p. 3.

54. «senza molte parole e semplicamente ", Adriani, Giovan Battista, Orazione di M. Gio. Battista Adriani all'essequie del sereniss.Cosimo de Medici, granduca di Toscana, p. 7.

55. «chiarezza del suo sangue "Vettori, Pietro, Orazione recitata nell'esequie del sereniss. Cosimo de'Medici gran duca di Toscana nella chiesa di San Lorenzo, il di dicesette di maggio 1574. Et poscia da Francesco Boschi fiorentino della lingua latina tradotta nella favella fiorentina, Florence, Marescotti, 1574, p. 4.

56. "alto legnaggio », " potere di governare e di reggere la Republica », "nella città non havea mutatione alcuna se non in quanto alla persona del principe », Adriani, Giovan Battista, Orazione di M. Gio. Battista Adriani all'essequie del sereniss.Cosimo de Medici, granduca di Toscana, Florence, Giunti, 1574, p. 12 et p. 15.

57. «darle accrescimento di grazia nel cospetto di tutti», Giacomini, Lorenzo, Oratione de le lodi di Francesco Medici granduca di Toscana, fatta per ordine dell'Accademia fiorentina nel tempio di San Lorenzo il di XXI dicembre, Florence, Sermartelli, 1587, p. 2. 


\section{Résumé}

L'ambition dynastique et le règne de la fête, transmis par Laurent le Magnifique, forgent progressivement la dynastie médicéenne. La fête de la Renaissance était ainsi conçue pour honorer différents événements, jalons de la vie florentine.

Je me propose d'analyser ici la politique festive mise en œuvre pour les noces de 1565, le baptême d'Éléonore de Médicis en 1567, les funérailles de Michel-Ange, de Cosme I ${ }^{\text {er }}$ et de Francesco $\mathrm{I}^{\mathrm{er}}$, en donnant du sens à des lieux bien particuliers et à leur métamorphose : le «Salon des Cinq Cents» et la basilique «San Lorenzo». Investis par le politique, ils deviennent des lieux de fête. Leur appropriation par les Médicis permet à l'autorité ducale puis grand-ducale de lutter contre le «caractère imparfait » de son régime autoritaire. Ces deux exemples attestent d'une théâtralisation de l'événement par une théâtralisation de l'espace. C'est bien parce qu'ils incarnent un «espace vrai transfiguré », pour reprendre une expression propre à André Chastel, que l'autorité médicéenne peut s'affirmer. En ce sens, l'apparat du centre politique de la cité et celui du lieu officiel des funérailles dynastiques résonnent comme un discours politique clair.

Je me suis appuyée pour donner du sens à ces lieux médicéens et à leur transformation par la fête, sur un corpus diversifié de sources imprimées mêlant chroniques et oraisons funèbres. Les chroniques de D. Mellini, de G.B. Cini, d'A. Ceccherelli, de G. Vasari, de G. Piccini ou encore de Giovan Battista Strozzi et les oraisons de P. Vettori, de G.B. Adriani ou encore celles de Pietro Angeli da Barga et de Lorenzo Giacomini sont au centre de mon travail.

\section{Bibliographie}

BONNER Mitchell, «Les intermèdes au service de l'État », dans JACQUOT Jean (dir.), Fêtes de la Renaissance III, Paris, CNRS, 1975, p. 117-131.

BORSOOK Ève, "Art and politics at the Medici Court : the funeral of Cosimo I de'Medici, Mitteilungen des Kunsthistorischen Institutes in Florenz, vol. 1/2, n¹2, 1965-1966, p. 95-114.

CASINI Matteo, I gesti del principe : la festa politica a Firenze e Venezia in età rinascimentale, Venise, Marsilio, 1996, 448 p.

CHASTEl André, "Le lieu de la fête », dans JACQUOT Jean (dir.), Fêtes de la Renaissance I, Paris, CNRS, 1956, p.419-423.

FANTONI Marcello, «Les rituels funéraires comme fondement de la souveraineté chez les Médicis, $\mathrm{XVI}^{\mathrm{e}}-\mathrm{XVIII}^{\mathrm{e}}$ siècle, dans CHROSCICKI Juliusz A., HENGERER Mark, SABATIER Gérard (dir.), Les funérailles princières $X V I^{e}-X V I I I^{e}$ siècle, Versailles, Édition de la Maison des sciences de l'homme, 2012, vol. 1, p. 193-200.

MARCIAK Dorothée, La place du prince. Perspective et pouvoir dans le théâtre de cour des Médicis, Florence (1539-1600), Paris, Honoré-Champion (Études et Essais de la Renaissance, 50), 2005, 381 p.

MOLINARI Cesare, " Delle nozze medicee e dei loro cronisti », Il teatro dei Medici, Quaderni di teatro, année II, n7, 1980, p.23-30.

PLAISANCE Michel, Florence, fêtes, spectacles et politique à l'époque de la Renaissance, Rome, Vecchiarelli, 2005, 310 p.

SABATIER Gérard, HENGERER, Mark, «Le grand théâtre de la mort », dans CHROSCICKI Juliusz A., HENGERER Mark, SABATIER Gérard (dir.), Les funérailles princières XVI XVIII ${ }^{e}$ siècle, Versailles, Édition de la Maison des sciences de l'homme, 2012, vol. 1, p. 7-13.

STRONG Roy, Les fêtes de la Renaissance (1450-1650), art et pouvoir, Arles, Solin, Le Méjan, 1991, 383 p. 


\title{
La salle des délibérations du Conseil général de Vaucluse: la représentation départementale en ses murs (1875-2014)
}

\author{
Blandine SILVESTRE \\ Archiviste, \\ Archives départementales de Vaucluse
}

\author{
Extrait de : Jean Duma (dir.), Le Rituel des cérémonies, Paris, \\ Édition électronique du CTHS (Actes des congrès des sociétés historiques et scientifiques), 2015. \\ Cet article a été validé par le comité de lecture des Éditions du CTHS dans le cadre de la publication \\ des actes du $139^{\mathrm{e}}$ Congrès national des sociétés historiques et scientifiques tenu à Nîmes en 2014.
}

Le cours de l'histoire institutionnelle de la France pourrait conférer à cette note un caractère d'urgence, par l'obsolescence programmée de son objet. L'analyse du lieu des débats du Conseil général en Vaucluse. L'existence de l'institution est, nous le savons, menacée par la réforme annoncée de l'organisation territoriale de la France.

À l'origine de cette étude, deux préoccupations se sont croisées. L'une, utilitaire, de la part des services en charge de l'entretien des bâtiments, l'autre politique et pédagogique, à l'initiative de l'un des conseillers généraux de Vaucluse. À celles-là, se sont joints les premiers effets - contradictoires - d'une réforme de la carte des cantons : l'accroissement du nombre des conseillers élus, à loger dans l'enceinte de l'hémicycle.

À moyen terme, il se pourrait bien que se pose à la collectivité la question du réemploi d'un bâtiment. Question prégnante à Avignon, dont le patrimoine est connu pour sa richesse, sa densité urbaine et la complexité de son réemploi, gage de pérennité. L'hémicycle du Conseil général de Vaucluse, non plus lieu des débats et de la prise de décision, mais cantonné à l'état de preuve et mémoire de la représentation départementale, issue de la Révolution française.

Dès à présent, la salle des délibérations du Conseil général de Vaucluse, cède régulièrement son rôle au profit de salles communales. La pratique de la décentralisation, au cœur de la Décentralisation, apparaissant comme un gage de démocratie participative et de proximité.

Pour l'historien, cette salle des délibérations fait figure d'exemplarité et d'exception, par son origine et par sa permanence. Combien d'hôtels de département conservent aujourd'hui ce témoignage de leurs débuts sur la scène administrative et politique de la France?

\section{L'institution départementale}

Les 83 départements français créés par la Constituante en 1790, furent dotés d'une assemblée représentative dont la mission était la gestion de tous les intérêts locaux. Ces premières ambitions démocratiques et décentralisatrices furent rapidement mises à mal, les conseils généraux étant placés sous tutelle dès 1793 et leur champ de compétence restreint. Pour des raisons historiques, le Vaucluse constitué de "pays " jusque-là séparés, dont Avignon et le Comtat-Venaissin, États du Saint-Siège réunis au royaume de France en 1791, fut créé par décret du 25 juin 1793 . C'est le $87^{\mathrm{e}}$ département français. 
La Troisième République fixa la forme actuelle du Conseil général. Dans chaque canton, un conseiller devait être élu au suffrage universel, pour un mandat de six ans. L'assemblée était renouvelable par moitié tous les trois ans ${ }^{1}$.

Le Conseil général reçut une compétence globale sur les affaires d'intérêt départemental : les hôpitaux et les hospices, l'instruction publique, les travaux publics et la police. Mais le préfet, seul titulaire du pouvoir exécutif, exerçait la tutelle de l'État, contrôlant les décisions adoptées par l'assemblée départementale, responsable de leur mise en application, ou de leur retrait.

Ce sont les lois de mars 1982, dites de décentralisation, qui accorderont aux départements français leur véritable autonomie, remettant le pouvoir exécutif aux présidents de Conseil général et donnant le coup d'envoi des transferts de compétences de l'État aux collectivités territoriales.

\section{L'hôtel du département}

En Vaucluse, l'émancipation, toute relative, du Conseil général, introduite par la loi du 10 août 1871, se traduisit dans les dispositions immobilières bientôt adoptées. Dans le cadre d'un programme d'aménagement foncier étendu, l'Assemblée départementale se dota d'un espace donnant à voir son indépendance, et particulièrement sa liberté de réunion sans approbation préalable du préfet.

Dès l'installation du premier préfet de Vaucluse, Jean Pelet de la Lozère, en 1800, à l'hôtel de Forbin, l'insuffisance des espaces affectés à ses appartements, au Conseil de Préfecture et au Conseil général d'administration, avait suscité de nombreuses et diverses études d'aménagement, de restauration, d'acquisition de bâtiments, voire de transfert du siège de la Préfecture.

Dans le même temps, le projet de percement de la rue de la Préfecture, inscrit au plan d'urbanisme de la ville, répondait à la nécessité, invoquée à partir des années 1820, de désenclaver l'hôtel de la préfecture pour des raisons de sécurité. Mais il rendait plus complexe l'établissement des bureaux et des archives de l'administration dans de nouveaux locaux. En effet, le tracé d'alignement impliquait la destruction partielle de l'hôtel des bureaux. (fig. 1)

Trois ans après le vote de la loi du 10 août 1871, l'assemblée départementale se prononça pour l'acquisition de l'hôtel Desmarets de Montdevergues, dit Joannis de Verclos - à l'époque qui nous occupe hôtel Foulc - du nom de ses derniers acquéreurs, sis place de la Préfecture, en vis-à-vis de l’hôtel de Forbin, siège de cette dernière.

Le 12 juin 1874, le préfet de Vaucluse, Scipion Doncieux, informé de l'intention des frères Foulc d'aliéner leur immeuble, enjoignait l'architecte du département, Auguste Tiers de s'en assurer et de dresser, en corollaire d'un éventuel accord, un projet pour y loger la salle du Conseil général, les bureaux des services de la Préfecture et les archives du département. La vente fut signée le 20 janvier 1876. Le Département de Vaucluse acquit l'hôtel Foulc pour une somme de 120000 francs.

Entre septembre 1875 et février 1876, plusieurs plans furent présentés par l'architecte Tiers, qui indiquent la progression des études soumises au préfet et à la commission départementale. Dès le 25 septembre 1875, un premier devis estimatif avait été dressé, enregistré seulement après l'acquisition effective. L'adjudication des travaux d'installation des bureaux et des salles du Conseil général et du Conseil de Préfecture fut donnée le 26 janvier 1876.

1. Loi du 10 août 1871 
L'implantation de la nouvelle salle du Conseil général est définie en lieu et place des cours, écuries et dépendances. L'architecte a conçu un petit pavillon indépendant dont la façade s'inscrira sur le fond de la cour et participera, via le vestibule, du caractère solennel de l'entrée de l'hôtel du Département. (Fig. 2-2b)

\section{La conception de la salle des délibérations}

\section{Le parti de l'architecte départemental... ou celui de son assistant?}

Les premiers plans dont nous disposons, datent du début de l'année 1876. Le devis estimatif initial définissait déjà l'implantation de ce bâtiment neuf «à l'extrémité du jardin, à l'emplacement des écuries et des remises » à démolir intégralement jusqu'aux fondations. Mais la correspondance échangée entre le préfet et le bureau de l'architecte du Département indique une révision du projet, à la demande de la Commission départementale.

Entre la fin de l'année 1875 et le mois de janvier 1876, l'architecte titulaire Auguste Tiers s'absente, en raison $\mathrm{d}^{\prime}$ « un malheureux événement » et délègue ses responsabilités à son adjoint Louis Valentin. Sur les observations de la commission départementale, et en l'absence de Tiers, Valentin est invité à produire un plan modifié, en forme d'hémicycle, pour la salle des délibérations. Le 7 janvier, il adresse au préfet les nouveaux plans demandés. Le montant de la dépense correspond au devis primitif. Il suffit de joindre ces plans au dossier communiqué aux entrepreneurs admis à concourir à l'adjudication. Une note du préfet, en bas de page, signale que ce courrier est renvoyé le lendemain «pour se conformer à nos dernières instructions ».

Le 18 janvier suivant, l'architecte adjoint adresse au préfet « le nouveau profil » demandé pour la construction de la salle du Conseil général. Il fait observer, d'une part l'excellente disposition adoptée du point de vue de l'ensemble de la distribution, d'autre part la délicate question de la limitation de la température dans la salle en période de grandes chaleurs, en raison de l'ouverture d'un ciel ouvert dans le plafond pour suppléer à l'insuffisance de la lumière naturelle dispensée par les baies latérales. Toutefois l'adoption d'une bonne ventilation devrait résoudre cette difficulté. À l'inverse, le chauffage sera distribué dans tous les espaces par un calorifère spécial. Le montant de cette nouvelle version du projet dépassera sensiblement les prévisions initiales.

Plusieurs plans, non datés, conservés dans le fonds Valentin aux Archives municipales d'Avignon, représentent la salle en hémicycle ${ }^{2}$; un autre plan, du 4 février 1876, conservé aux Archives départementales et signé par A. Tiers adopte un tracé différent ${ }^{3}$. Il accompagne les observations faites au préfet par l'architecte départemental, à son retour de congé.

En effet, Tiers désavoue le projet soumis par son adjoint, dans la précipitation et suggère des corrections. Il justifie celles-ci par des erreurs de composition et de distribution et par un coût excessif. Une première note manuscrite du préfet, le 2 février, prend le parti du plan «par terre » de Valentin, déjà approuvé par la commission. Le préfet le juge «très bien conçu » et exclut toute modification, hormis la décoration qui pourra subir quelques changements, à condition de ne pas en altérer l'harmonie.

La lettre de Tiers, en date du 4 février, illustrée du plan cité plus haut, livre le détail de ses critiques et des solutions qu'il recommande. Des économies seraient à faire : sur le décor de la façade sur le jardin; sur l'élévation de la salle, réduite de 2 mètres; sur

2. Archives municipales d'Avignon, 39 Z 1 Fonds Valentin.

3. Archives départementales de Vaucluse, 4 N Préfecture, Bâtiments départementaux, plan 35. 
l'abandon de l'hémicycle pour une forme polygonale offrant une réduction de $50 \%$ du coût des boiseries.

Dans une note du 28 février suivant, le préfet de Vaucluse maintient ses premières observations et n'accorde à l'architecte départemental qu'une simplification de l'ornementation intérieure, ou de façade, pour raison d'économie. (fig. 3 ; fig. 4)

\section{L'histoire du modèle : le symbole et l'efficience}

Les critères qui président à la conception d'une salle dévolue aux travaux de la représentation départementale répondent à des exigences fonctionnelles mais se conforment à des modèles historiques à forte charge symbolique.

À la fin de l'Ancien Régime, lors de la réunion des États généraux en mai 1789, PierreAdrien Pâris, architecte du roi, dut aménager, à l'hôtel des Menus-Plaisirs à Versailles, une salle capable d'accueillir les 1200 députés convoqués en assemblée. Il agrandit en ce sens une salle provisoire, destinée à l'assemblée des notables au cours des deux années précédentes. Selon l'usage, il avait repris le modèle de la basilique civile romaine, espace de référence capable de recevoir une foule, utilisé lors de la précédente réunion des Etats généraux en 1614-1615 : espace rectangulaire dont un petit côté recevait l'estrade royale et les trois autres des bancs destinés aux députés. Le quadrilatère était revêtu d'un ordre dorique, à la manière des temples de Pæstum. Afin d'augmenter la contenance de la salle, du côté de l'entrée, des bancs de députés avaient été ajoutés en arrière des colonnes.

Cette disposition traditionnelle n'emportait cependant pas l'adhésion unanime. On en trouve le témoignage dans les débats des représentants du Tiers État. ${ }^{4}$

Dès le 11 mai, alors que les trois ordres ne sont encore pas réunis, un membre des communes:

«A pris... occasion de remarquer que la salle étoit très incommode... que les bancs étant tous de niveau, et placés les uns derrière les autres, il y avait toujours une grande partie des Membres de l'Assemblée, qui ne pouvoit voir ni entendre celui qui portoit la parole. En conséquence, il a proposé qu'on envoyât au Grand Maître des cérémonies, pour lui demander que, sans aucun délai, les places fussent disposées dans une forme circulaire et amphithéâtrale. Cette nouvelle motion a été combattue. Pour l'écarter, on a opposé que la Salle n'étoit celle d'aucun des Ordres en particulier, mais des trois réunis ; que le Clergé et la Noblesse y avoient autant de droit que les Communes, et qu'ainsi la forme n'en devoit être changée que par la volonté générale. »

Si elle maintenait la référence à l'Antiquité, l'idée de l'amphithéâtre dépassait l'analogie de convenance et de contenance, assimilant toute salle d'assemblée à une basilique civile. Elle introduisait une dimension fonctionnelle, repérant l'amphithéâtre ${ }^{5}$ comme l'espace privilégié de la portée de la parole. L'architecte Pâris, fort de sa connaissance des monuments romains, adopta ce parti et adapta en conséquence les grandes lignes de la salle. Il disposa des bancs en gradins et une estrade au centre de la salle pour les orateurs. On trouve dans les « Leçons d'Histoire », données par Constantin-François de Volney en 1794 à l'École normale, une synthèse de la question architecturale dans son contexte politique et un programme pour les architectes de la République.

«Il serait à désirer que ce dernier art [1'architecture] s'occupât d'un genre de construction devenu le besoin le plus pressant de notre situation, la construction des salles d'assemblées, soit délibérantes, soit professantes. Novices à cet égard, nous n'avons encore obtenu depuis cinq ans que les essais les plus imparfaits, que les tâtonnements les plus vicieux ; je désigne ces salles où l'on voit l'ignorance de toutes les règles de l'art; où le local n'a aucune

4. Récit des séances des députés des communes, depuis le 5 mai jusqu'au 12 juin suivant, époque à laquelle la rédaction des procès-verbaux a commencé, p.15-16.

5. «Amphithéâtre» ou «théâtre», la confusion ou l'emploi équivalent des deux termes se fait encore de manière courante au XVIII ${ }^{\mathrm{e}}$ siècle. 
proportion avec le nombre des délibérants qu'il doit contenir; où ces délibérants sont disséminés sur une vaste surface, quand tout invite, quand tout impose la loi de les resserrer dans le plus petit espace; où les lois de l'acoustique sont tellement méconnues, que l'on a donné aux vaisseaux des formes carrées et barlongues, quand la forme circulaire se présentait comme la plus simple et la seule propre aux effets d'audition demandés; de manière que par une série de conséquences étroitement liées, la construction du vaisseau favorisant et même nécessitant le tumulte, et le tumulte empêchant la régularité et le calme de la délibération, il arrive que les lois qui dépendent de cette délibération, et que le sort d'un peuple qui dépend de ces lois, dépendent réellement de la disposition physique d'une salle. Il est donc d'une véritable importance de s'occuper activement de recherches à cet égard, et nous avons tout à gagner, en consultant, sur cette matière, l'histoire et les monuments de la Grèce et de l'Italie... ${ }^{6}$

Considérant l'importance du sujet, l'auteur insère en note ${ }^{7}$ les observations qu'il a retenues de son passage dans diverses salles:

«L'objet principal, même unique d'une salle délibérante est que les discutants se parlent avec aisance, s'entendent avec clarté ; décoration, construction, règles de l'art, tout doit être subordonné à ce point final. Pour l'obtenir, il faut :

$1^{\circ}$ Que les délibérants soient rapprochés les uns des autres, dans le plus petit espace conciliable avec la salubrité et la commodité ; sans cette condition ceux qui ont des voix faibles sont dépouillés de fait de leur droit de voter, et il s'établit une aristocratie de poumons qui n'est pas l'une des moins dangereuses.

$2^{\circ}$ Que les délibérants siègent dans l'ordre le plus propre à mettre en évidence tous leurs mouvements; car sans respect public, il n'y a point de dignité individuelle; ces deux premières conditions établissent la forme circulaire et amphithéâtrale.

$3^{\circ}$ Que les rangs des délibérants forment une masse continue, sans division matérielle qui en fasse des quartiers distincts ; car ces divisions matérielles favorisent et même fomentent des divisions morales de parti et de faction ;

$5^{\circ}$ Que les issues d'entrée et de sortie soient nombreuses, indépendantes les unes des autres, de manière que la salle puisse s'évacuer ou se remplir rapidement et sans confusion ;

$6^{\circ}$ Que l'auditoire soit placé de manière à ne gêner en rien les délibérants.

Comme ces dernières conditions pourraient sembler un problème, voici le plan que j'ai calculé sur ces diverses données, et qu'il n'appartient qu'à des architectes de rectifier dans l'exécution... »

La forme en hémicycle, déjà utilisée pour l'amphithéâtre de chirurgie (1773-1775) ${ }^{8}$, l'amphithéâtre du jardin des Plantes $(1787)^{9}$, pour la salle des machines aux Tuileries aménagée pour la Convention nationale (1792-1793 $)^{10}$, enfin pour la salle des séances du Palais Bourbon (1795-1798) ${ }^{11}$, enceinte du Conseil des Cinq-Cents, s'impose comme le modèle de la salle d'assemblée.

S'il existe une différence d'échelle entre la représentation nationale, pour laquelle Volney expose les dispositions architecturales, et les nécessités d'une assemblée départementale, les grandes lignes du parti seront retenues par les architectes vauclusiens.

L'an mil huit cent soixante-dix-huit et le huit avril, à deux heures de l'après-midi, le sénateur, président du Conseil général de Vaucluse, Régis Granier, ouvre la séance et son discours par ces mots :

«Messieurs et chers collègues,

Avant de passer à l'examen des affaires soumises à vos délibérations, permettez-moi de vous souhaiter la bienvenue dans la nouvelle salle de vos séances. Vous avez eu l'espoir, en imposant au Département les sacrifices de cette installation, que l'aménagement nouveau,

6. C.-F. de Volney, CEuvres complètes », p. 574-575.

7. Ibid., p. 575, n.1.

8. Jacques Gondoin de Folleville (1737-1818), auteur de la colonne Vendôme.

9. Edmé Verniquet (1727-1804), l'amphithéâtre fut agrandit en 1795 par Jacques-Guillaume Legrand (1743-1808) et Jacques Molinos (1743-1831).

10. Jacques-Pierre de Gisors (1755-1828), et Etienne-Chérubin Lecomte (vers 1760-66-1818), architecte en chef des Tuileries.

11. Par les deux mêmes architectes. 
en facilitant vos travaux, vous en permettrait l'exécution plus prompte. Il reste à désirer que cet espoir se réalise et que votre tâche soit, ainsi, rendue plus facile. »

Il ressort des premiers débats engagés dans l'hémicycle que des améliorations doivent lui être apportées. Le conseiller général Adrien Meynard en présente la requête lors de la reprise de la séance du 11 avril.

$1^{\circ}$ la correction $\mathrm{du}$ « défaut d'acoustique » de la nouvelle salle des séances ;

$2^{\circ} 1^{\prime}$ installation des salles nécessaires aux commissions en les rendant indépendantes les unes des autres;

$3^{\circ} 1^{\prime}$ aménagement $d^{\prime}$ « un cabinet pour M. le président. »

Un crédit suffisant, restant disponible sur la somme allouée à la construction des salles du Conseil général, le conseil adopte la proposition de M. Adrien Meynard. ${ }^{12}$

\section{La construction de la salle du Conseil général}

\section{Implantation et gros œuvre}

En lieu et place des bâtiments de services détruits, le pavillon qui abrite la salle des délibérations, flanquée de celles des commissions, s'inscrit au fond de la cour de l'hôtel du Département. (fig.5)

Partiellement enclavé dans le bâti ancien, il n'a de façade qu'à l'ouest le long de la rue Bouquerie et au nord sur la cour où s'ouvre son entrée principale. Trois salles, prenant jour au nord, précèdent l'hémicycle dont l'arc de cercle se développe vers le sud. À la périphérie de celui-ci sont logées d'autres petites pièces de dégagement et l'escalier d'accès à la tribune. Les différentes salles se commandent les unes les autres. L'alignement de la façade nord est rompu par l'avancée de la salle axiale formant perron de trois marches.

Les salles sont couvertes d'une toiture-terrasse au-dessus de laquelle s'élève le massif carré qui englobe le dôme de la salle des délibérations. Les moyens de construction mis en œuvre tirent parti des progrès de l'architecture à l'âge industriel, principalement par l'emploi d'une ossature métallique, encore dissimulée par une enveloppe d'apparence traditionnelle, conforme à la solennité de l'édifice. L'utilisation du fer est réservée à la confection des planchers porteurs. Entre les fers horizontaux sont tendus des voutains de brique, montés au mortier. L'ensemble du gros œuvre associe la maçonnerie de moellons, la brique, la pierre de taille pour les façades et encore le bois pour la charpente de l'hémicycle, prescrite en sapin suisse.

La pierre provient des carrières de pierre locale que l'on retrouve sur tous les chantiers avignonnais, carrières de Villeneuve, carrière de Saint-Rémy et de Fontvieille. Le lot de serrurerie est adjugé à la maison Biret, 5 rue Pétramale à Avignon. Le détail des travaux réalisés par cet atelier comprend les tirants de fer de la structure, les châssis ouvrants des croisées, jusqu'aux boulons de fixation, et l'exécution d'un " panneau en fer forgé, travail d'art » d'après les plans de l'architecte, sans plus de précision.

Le lot menuiserie revient à l'entreprise Ducret. Le mémoire dressé pour l'année 1877 détaille les ouvrages livrés. Les essences de bois employées varient selon la qualité des ouvrages, le sapin du nord pour des lambris, portes de placard, volets et persiennes; le chêne, réservé aux portes et chambranles, châssis vitrés, parquets à bâtons rompus, marches de l'estrade, pieds des bancs de la tribune; le noyer, utilisé pour la main courante de l'escalier de la tribune. Par mesure d'économie, certains matériaux sont de remploi. On le voit pour une partie des lambourdes des parquets en "chêne de barque » dans la grande salle et les parquets des salles annexes dits « de remploi » différenciés des 
«parquets neufs ». Le réemploi de parquet porte sur $7 \%$ de la surface totale parquetée soit plus de $230 \mathrm{~m}^{2}$. Il offre une réduction de plus de la moitié du prix du neuf. Suivant le même principe d'économie, des lambris ont été déposés du premier étage de l'hôtel Foulc pour être adaptés à la « salle à gauche de l'entrée ».

\section{La façade sur la cour}

L'architecte insère le pavillon dans le fond de la cour de l'hôtel, sans aligner ses lignes de niveaux sur les étages de celui-ci. Il lui donne une échelle légèrement supérieure. Le couronnement de la façade des salles de commissions atteint le premier tiers du deuxième niveau de l'immeuble qui en compte trois. Le dessin se démarque de la sobriété de l'ordonnancement des façades environnantes, mais il reprend comme élément d'unité l'encadrement des baies à crossette dont il dédouble la mouluration dans un traitement plus sec.

Il fait écho à la façade de l'hôtel, sur la place, en empruntant une ordonnance et des éléments significatifs, horizontaux ou verticaux: le socle à panneaux sous l'appui des fenêtres, le rang de denticules à la base des corniches, le bossage d'angle, la console à volute, et la mouluration des encadrements des baies.

Sept baies rectangulaires rythment la façade, groupées par paires, de part et d'autre des trois pans de la salle axiale. Le mur est réduit à l'encadrement des baies. La partition horizontale domine: les fenêtres s'ouvrent au-dessus d'un soubassement dont le bandeau est posé sur des consoles; le chaînage aux angles du perron est traité en sept sections à joints creux formant bossage, agrémenté d'une frise segmentée à décor de rosette ; le lourd entablement qui se déploie au-dessus des corniches des baies, couronné par un attique, n'est pas associé à un ordre classique de colonnes ou de piliers porteurs. Les lignes de forces verticales sont réduites aux arêtes des murs et aux chambranles des fenêtres. L'ornementation de la porte axiale est naturellement la plus développée. Son linteau est souligné d'une corniche portée par deux consoles en volutes.

Le massif de l'hémicycle, en retrait de la façade, reprend la structure générale. Le plan du mur rectiligne est rythmé par quatre faux piliers en bossage, qui reçoivent l'entablement et l'attique simplifiés. Au centre, une baie aveugle en plein cintre dont l'agrafe centrale rappelle les volutes de la porte, vient rompre la rigidité de l'ordonnance. On ne distingue pas, depuis la cour, les deux petites baies latérales, ouvertes au niveau de la toitureterrasse pour donner du jour à l’hémicycle.

L'ensemble des dessins sur calque, conservés dans le fonds Valentin ${ }^{13}$, illustre bien l'étude minutieuse des profils pour les façades sur cour et sur le plan de Lunel. Le sculpteur avignonnais, Arnaud, présente un mémoire, en novembre 1877, pour les travaux réalisés au cours de cette année. (fig.6)

\section{La mise en scène de la salle des délibérations}

Dans l'enceinte de l'hémicycle, le décor architectural se déploie. La sobriété des façades de pierre de taille est abandonnée au profit d'un programme élaboré, tirant parti de la technique des éléments de carton-pierre préfabriqués. Le carton pierre, appelé aussi pâte ou carton dans la correspondance, est une technique ancienne, industrialisée avec succès au XIX ${ }^{\mathrm{e}}$ siècle, en raison des larges possibilités qu'elle offre pour un prix modique. Son emploi est déjà attesté pour la corniche du grand salon de la préfecture en 1809. Il s'agit d'une technique de moulage d'une composition plastique dans laquelle entrent : de la pâte de carton, de la colle, de l'huile de lin, de la craie (carbonate de chaux) et de la terre bolaire, blanche, rouge et ferrugineuse selon les cas. ${ }^{14}$

13. Archives municipales d'Avignon, $39 \mathrm{Z} 1$ : fonds Valentin. Tous les mémoires et correspondances cités sont conservés dans ce dossier.

14. Sur ces techniques voir : M. Lebrun, Manuel complet du mouleur. 
La maison Édouard Lefèvre de Montpellier est désignée pour la réalisation du projet. Après en avoir indiqué les grandes lignes, l'architecte Tiers, se repose sur le talent et le savoir-faire de l'ornemaniste qui jouit d'une liberté de conception certaine.

Quelques pages de leur correspondance nous renseignent sur l'esprit et le détail du décor de la salle, dont cette réponse de Tiers, le 11 septembre 1876 à Lefèvre :

«Je désire que la salle du Conseil g. ${ }^{\text {al }}$ soit décorée dans le style Louis XIII mais en adoucissant les saillies de cette époque qui à l'intérieur sont généralement trop lourdes ; les chambranles des 4 portes qui donnent accès dans la salle seront en bois dans lesquels on pourra loger une moulure en carton pierre.

Le dessus de ces portes porte frise, corniche et motif.

Les arcades elliptiques auront une archivolte de 0,30 de hauteur comprenant un ove et une baguette perlée, au milieu une clef formée d'un mascaron avec accessoires. Les pilastres seront surmontés d'un chapiteau en carton.

Sur les grands pilastres régnera un entablement complet architrave frise et corniche. Dans ma première étude l'architrave avait de hauteur 0,22 la frise 0,25 et la corniche 0,38 , ayant relativement au style une saillie un peu faible.

Cet entablement sera ensuite surmonté d'une anse de panier de 1,05 de hauteur. La saillie des pilastres sera reproduite dans l'anse de panier et viendra buter contre le cercle du plafond.

Cette partie de l'anse de panier portera un motif de décoration particulier. Les compartiments faits dans l'anse de panier pour la prolongation des pilastres porteront chacun un motif avec cartouche médaillon \& c.

À l'extrémité de l'anse de panier un fort cadre de 0,25 portant un fort boudin de 0,08 couvert de feuilles de chêne et une baguette avec ruban et perles.

Si j'éclaire la salle par le ciel j'ouvre un fort cadre autour de la lanterne dans le même style que le précédent et un [ ] à jours dans la lanterne qui permette les courants d'air tout en masquant les orifices des soupiraux.

Dans le cas contraire je mettrai une forte et grande rosace Louis XIII. Quant aux murs de la salle vous devez avoir remarqué qu'il n'en reste pas tout est ouverture ou pilastre je ne crois pas qu'il y ait là un motif à décorations.

Quant aux salles des commissions qui sont autour j'aurais dans chaque salle un ornement aux 4 coins des plafonds et un trumeau au-dessus des portes et une rosace.

Je pense que ces renseignements qui ne sont que la description de ma première étude vous suffiront, mais il est bien entendu qu'ils ne doivent pas vous lier.

Il ne reste plus qu'à vous parler du tympan de la grande ouverture. C'est là que je compte mettre le buste de la République flanquée à droite et à gauche de l'Industrie et du Commerce avec les attributs de la richesse et de la prospérité de la force et de la gloire. »

Cette correspondance, accompagnée de croquis sur calque, se poursuit, entre la fin janvier et le mois de juin 1877. Elle porte sur des mises au point, relatives aux ornements de carton pierre, à des rectifications de cotes et au retard pris sur le chantier au cours de ce semestre. Cependant le 30 septembre suivant, les travaux de la maison Lefèvre sont facturés.

Le sculpteur avignonnais Arnaud, intervient aussi à l'intérieur de la salle, précisément pour les blasons des villes du département et la balustrade des tribunes.

La réalisation diffère du projet initial sur peu de points : la configuration et la hauteur réduite du plafond qui culmine à l'intérieur à $8 \mathrm{~m}$ 47. Ainsi que l'envisage Tiers, l'ouverture zénithale, sur le modèle de l'Assemblée nationale, est remplacée par un plafond plein à rosace. (fig. 7 ; fig.8)

On remarque aujourd'hui la tribune en débord sur le tracé semi-circulaire de la salle. Cette structure suspendue semble être une modification dont nous ignorons l'époque, dans l'intention évidente d'offrir plus d'espace au public et à la presse. Dans le « Mémoire des sculptures faites à la salle du Conseil général » que le sculpteur Arnaud présente le 23 novembre 1877, on lit, à la date du 5 octobre 1877 : « 5 balcons de tribunes dans l'intérieur en pierre ayant 18 culots chacun ... ».

Le reste du programme décoratif est en place, en partie caché par des tentures, derrières 
lesquelles on distingue au toucher les moulurations. Le demi-cercle est disposé en cinq travées, délimitées par de grands pilastres cannelés à chapiteau ionique orné d'une guirlande. Le sommet des arcs est souligné d'une guirlande rampante et d'un masque féminin ou masculin à la clef. Les chapiteaux reçoivent un entablement complet sur lequel se développe la voussure du couvrement, ce que Tiers désigne sous le terme d'anse de panier. Chacune des travées est habillée d'un cadre mouluré. Dans ces cadres prennent place les blasons des quatre grandes villes du département: Apt, Carpentras, Orange et Avignon.

Un traitement particulier est réservé au côté nord, derrière l'estrade de la présidence : « le tympan de la grande ouverture» ou l'architecte prévoit de «mettre le buste de la République flanquée à droite et à gauche de l'Industrie et du Commerce avec les attributs de la richesse et de la prospérité de la force et de la gloire »(fig. 9). Le programme a été réalisé conformément aux indications reçues par E. Lefèvre de l'architecte Tiers. Programme iconographique qui délivre un message économique et politique: sous l'autorité et la protection de la République, l'ordre du jour des conseillers généraux est énoncé par les allégories de l'Industrie et du Commerce. Celle-ci tient en main le caducée de Mercure, dieu du commerce et des voyages. À ses pieds une composition de tonneaux, colis, ancre marine et la silhouette d'un navire. L'Industrie pose la main gauche sur le manche d'une masse. Elle est entourée d'objets évocateurs tels que roue crantée, presse, scies, enclume. Au centre, sur un fût de colonne à chapiteau ionique, le buste de la République domine la composition. La tête de Marianne, ceinte d'une couronne de laurier, vient s'inscrire à la clef de l'arc.

En 1907, Les fenaisons en Provence, le tableau de Paul Vayson ${ }^{15}$ présenté au salon de 1867, fut offert au Conseil général et placé au-dessus de la tribune. Il complète le décor sculpté par l'évocation de la prospérité agricole et l'attachement des Vauclusiens à leur terre provençale. La scène peinte se situe au chemin des Trois Termes au nord de Gordes, d'où l'on distingue le Mont-Ventoux.

À la lecture du devis de peinture dressé en 1875, le revêtement pictural de la salle devait être limité au traitement des boiseries à quatre couches fines de peinture sans indication de coloris et à l'application du même nombre de couches mais «à trois tons » sur les parties non couvertes de boiseries. Aucune pièce des archives conservées ne laisse supposer la commande d'un décor mural ou d'un plafond peint tel celui de l'hôtel de ville d'Avignon. La dépense engagée, pour l'aménagement des services de la préfecture et de la salle du Conseil général, représentait un effort financier considérable dans une période d'austérité économique.

En plusieurs occasions l'architecte a émis des réserves sur le coût prévisible, l'a pondéré par une alternative plus modique. La conception du décor se veut classique, privilégiant une sobre élégance et un caractère solennel, en accord avec le sérieux des travaux du Conseil. Le seul développement figuratif, hormis les blasons des quatre villes, est cantonné au tympan du grand arc dont les allégories délivrent le message volontariste des élus pour la prospérité de Vaucluse. Par convenance, la tête de Marianne est laurée. Ce détail a son importance dans l'histoire de la III ${ }^{\mathrm{e}}$ République. (fig.10)

\section{Les symboles du gouvernement de la République ou l'histoire d'un bonnet rouge}

Le choix de la coiffure de la République nommée "Marianne" donna lieu à des discussions passionnées. Au cours de la quatorzième séance de l'année 1871, le 13 novembre, le conseiller Varène dénonça devant l'assemblée un excès de pouvoir imputé au sous-préfet Petiton dans la commune de Bollène : l'ordre donné au maire de « faire

15. Paul Hippolyte Vayson (Gordes 1841 - Paris 1911). Élève de Jules Laurens et de Charles Gleyre. Médaillé de troisième classe au Salon de 1875, de 2e classe en 1879, il reçut la médaille d'or aux expositions universelles de 1889 et 1900. Paul Vayson fut maire de la commune de Murs de 1896 à 1911. Son ami, le préfet de Vaucluse (1906-1910), historien et critique d'art, Jules Belleudy, lui rendit hommage dans les Mémoires de l'Académie de Vaucluse. 
disparaître la couche en rouge du bonnet phrygien surmonté d'une cocarde tricolore ». ${ }^{16}$ Il s'ensuivit un débat enflammé entre le préfet et les plus ardents républicains de l'assemblée départementale. Au fil de la dispute, imagée par des anecdotes locales, argumentée sur un précédent au conseil général de l'Hérault qui motiva la consultation $\mathrm{du}$ chef $\mathrm{du}$ gouvernement, Thiers soi-même, est abordé le fond du problème: l'incertitude, quant à la nature du régime depuis la proclamation du 4 septembre 1870, et l'impatience des élus locaux à voir le gouvernement définir le(s) symbole(s) propre(s) à la République.

Sept ans plus tard, la controverse vauclusienne figurait dans le réquisitoire prononcé par le représentant du ministère public, au cours du procès intenté au gérant de La Lanterne, quotidien politique parisien :

«En 1871, M. Thiers, à propos du conflit qui s'est élevé dans le conseil général de Vaucluse sur l'apposition d'un buste de la République coiffé du bonnet phrygien, donnait à qui de droit les instructions suivantes :

"Faites, disparaître une image inconvenante : la majorité ne doit pas blesser les sentiments de la minorité."

Enfin, une circulaire récente de la préfecture de police enjoint la saisie des emblèmes séditieux, surtout du bonnet phrygien. En résumé, pour nous, la République se couronne d'étoiles et d'épis et non de ce triste bonnet. »

On se souvient de la prudence $\mathrm{d}^{\prime}$ Adolphe Thiers, dans sa détermination à donner à la France un régime de liberté et de stabilité. Il rappelait le 8 juin 1871, devant l'Assemblée, que la forme du futur régime pourrait être la monarchie, mais déclarait dans le même temps que la République devait bénéficier d'un " essai loyal » dont il faisait le devoir présent. Les élections partielles de juillet 1871 virent la victoire des républicains modérés, confirmée aux élections des conseils généraux à l'automne. Il faudrait encore attendre la «Constitution de 1875 » pour que s'affirme cette république parlementaire dont l'effigie allait présider les séances du Conseil général de Vaucluse, coiffée de la couronne de lauriers. Cet aspect de l'affirmation républicaine dans son contexte méridional a retenu l'attention de Maurice Agulhon qui lui consacre un passage de son ouvrage Marianne au combat $^{17}$ sous le titre « En province, la petite guerre des Mariannes ».

\section{De l'inventaire à la mise en valeur}

Le pavillon de l'hémicycle du Conseil général de Vaucluse a sa place dans l'inventaire de «l'architecture républicaine» de la Troisième République. Le programme n'a pas l'ampleur et l'ambition des magnifiques hôtels de préfecture bâtis par les architectes les plus en vue. Il s'inscrit dans le mouvement majoritaire des travaux exécutés par les architectes départementaux, sous le contrôle du Conseil des bâtiments civils.

En Vaucluse, l'appropriation de bâtiments anciens à l'usage de préfecture a prévalu. Des raisons d'économie et de topographie urbaine ont présidé au choix de l'hôtel de Forbin. Cependant l'inadéquation de cet ensemble immobilier à sa destination se révéla rapidement. L'acquisition de l'hôtel Desmarets de Montdevergues permit de pallier l'exiguiité des locaux administratifs. De surcroît, par le choix d'y implanter la salle des délibérations du Conseil général, en vis-à-vis de l'hôtel du préfet, l'assemblée départementale se distinguait du représentant du gouvernement.

Plutôt que d'aménager une salle dans le bâtiment existant, le parti de la construction d'un véritable édifice, dans l'enceinte des dépendances de l'hôtel particulier, fut adopté. Certes, son implantation limite sa visibilité dans l'espace urbain. Aucune inscription de façade, pas plus que de signe distinctif, ne délivre de façon explicite le message de la 
République. Mais la proclamation est implicite, par le biais de la qualité de la construction, plus que par ses dimensions. La composition est néo-classique, modérée dans ses effets et dans ses moyens, encore loin des hardiesses du style $\mathrm{III}^{\mathrm{e}}$ République ou Beaux-Arts, tant pour ses lignes que pour son décor intérieur.

Le contexte historique, la situation urbaine, l'inspiration et la composition architecturale de l'hémicycle du Conseil général de Vaucluse, sa conservation et son emploi pérenne, se conjuguent pour lui conférer une valeur patrimoniale étendue. Formons le vœu que la présente étude contribue à sa mise en valeur.

\begin{abstract}
Résumé
La salle des délibérations du Conseil général de Vaucluse fut construite au lendemain de la loi du 10 août 1871 marquant le premier pas de l'émancipation du département dans l'organisation territoriale de la France. La conception de cette salle s'inscrit dans la suite des expériences architecturales conduites depuis la fin $\mathrm{du} X \mathrm{XVII}{ }^{\mathrm{e}}$ siècle, tant pour les espaces de la représentation politique que de la transmission des savoirs. Le programme ornemental emprunte au vocabulaire néoclassique et signifie, sous l'égide de la République, les objectifs des travaux de l'assemblée départementale. Ce décor fut confié à un ornemaniste de renom, Édouard Lefèvre, de Montpellier. L'exemplarité et la qualité formelle de l'hémicycle de Vaucluse, plaidaient en faveur de mesures de protection et de mise en valeur. Les fonds d'archives de l'administration et de l'architecte départemental ont été exploités dans la présente étude préalable au projet de rénovation.
\end{abstract}

\title{
Bibliographie
}

Procès-verbal des séances de l'Assemblée nationale de France, tenues en l'année 1789 et suivantes; précédé du "Récit des séances des députés des communes, depuis le 5 mai jusqu'au 12 juin suivant"; du procès-verbal des conférences pour la vérification des pouvoirs; et du procès-verbal des séances des députés des communes, depuis le 12 jusqu'au 17 juin 1789, tome premier, Impr. nationale, Paris, 1791.

Procès-verbal des séances du Conseil général de Vaucluse - Session de 1871, Avignon, impr. administrative de Seguin frères, 1871.

Procès-verbal des séances du Conseil général de Vaucluse - Session d'avril 1878, Avignon, impr. administrative de Seguin frères, 1878.

AGUlHON Maurice, Marianne au combat. L'imagerie et la symbolique républicaines de 1789 à 1880, Paris, Flammarion, 1979.

LEBRUN M., Manuel complet du mouleur, ou l'Art de mouler en plâtre, carton, carton-pierre, carton-cuir, cire, plomb, argile, bois, écaille, corne, etc.: contenant tout ce qui est relatif au moulage sur la nature morte et vivante etc., Paris, Librairie encyclopédique de Roret, 1829.

VOLNEY Constantin-François de, CEuvres complètes, précédées d'une notice sur la vie et les écrits de l'auteur, Paris, Firmin Didot, 1837. 


\section{Illustrations}

figure 1 : Plan d'alignement de 1855, Archives municipales d'Avignon, 1 O 11

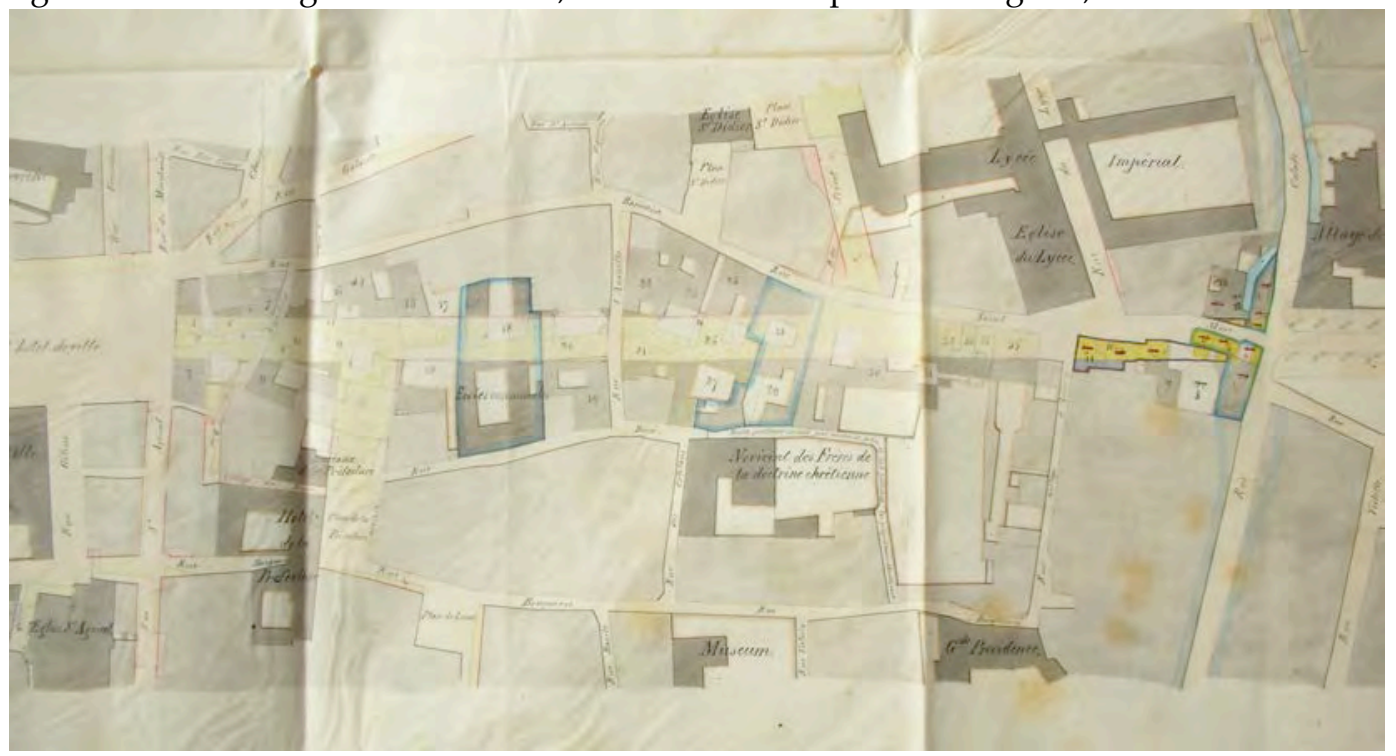

figure 2 : Plan de l'immeuble Foulc, Archives départementales de Vaucluse, 4 N plan 34

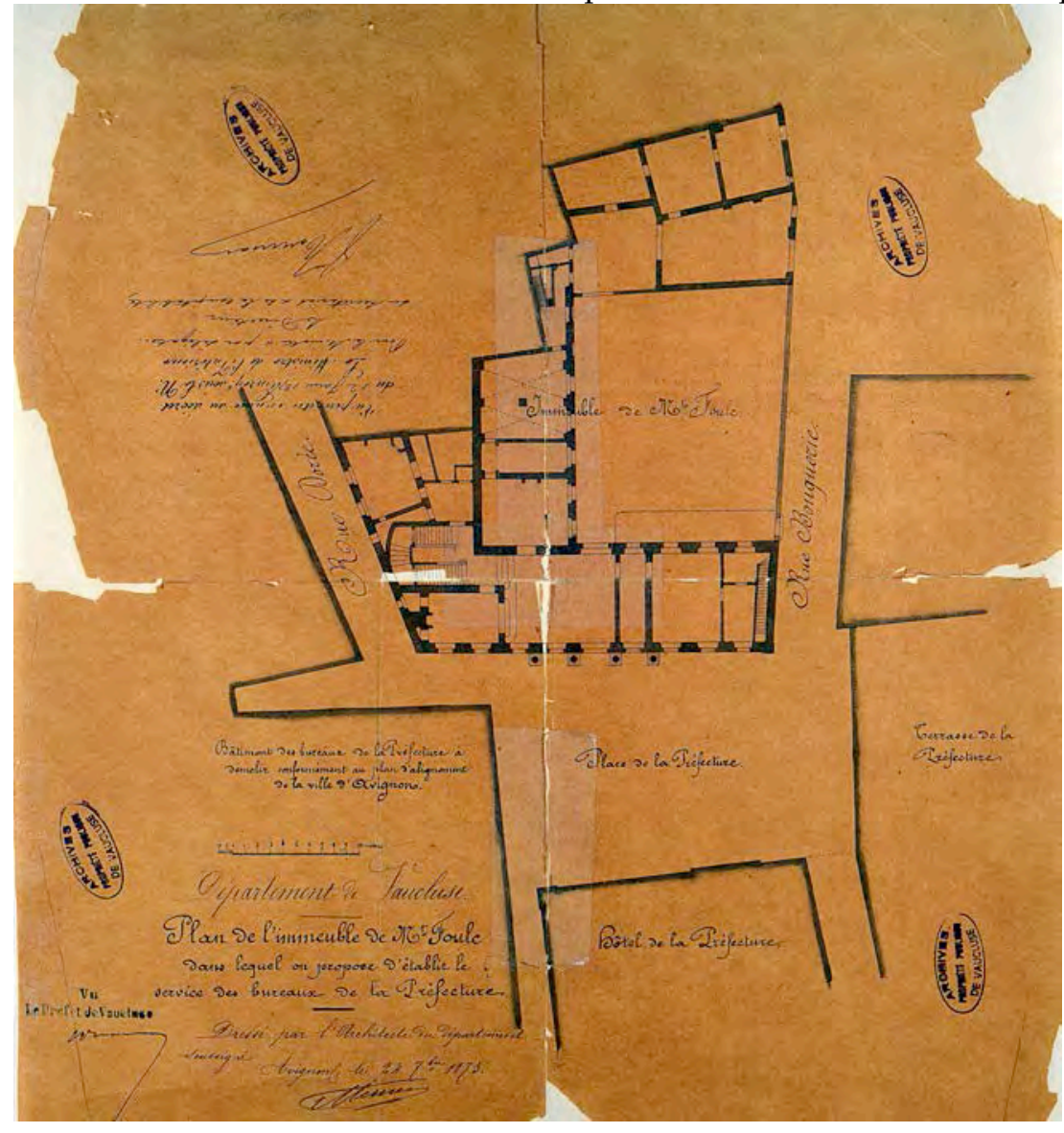


figure $2 b$ : Implantation de la salle des délibérations sur fond de plan de l'immeuble Foulc, Archives départementales de Vaucluse, 4 N plan 34

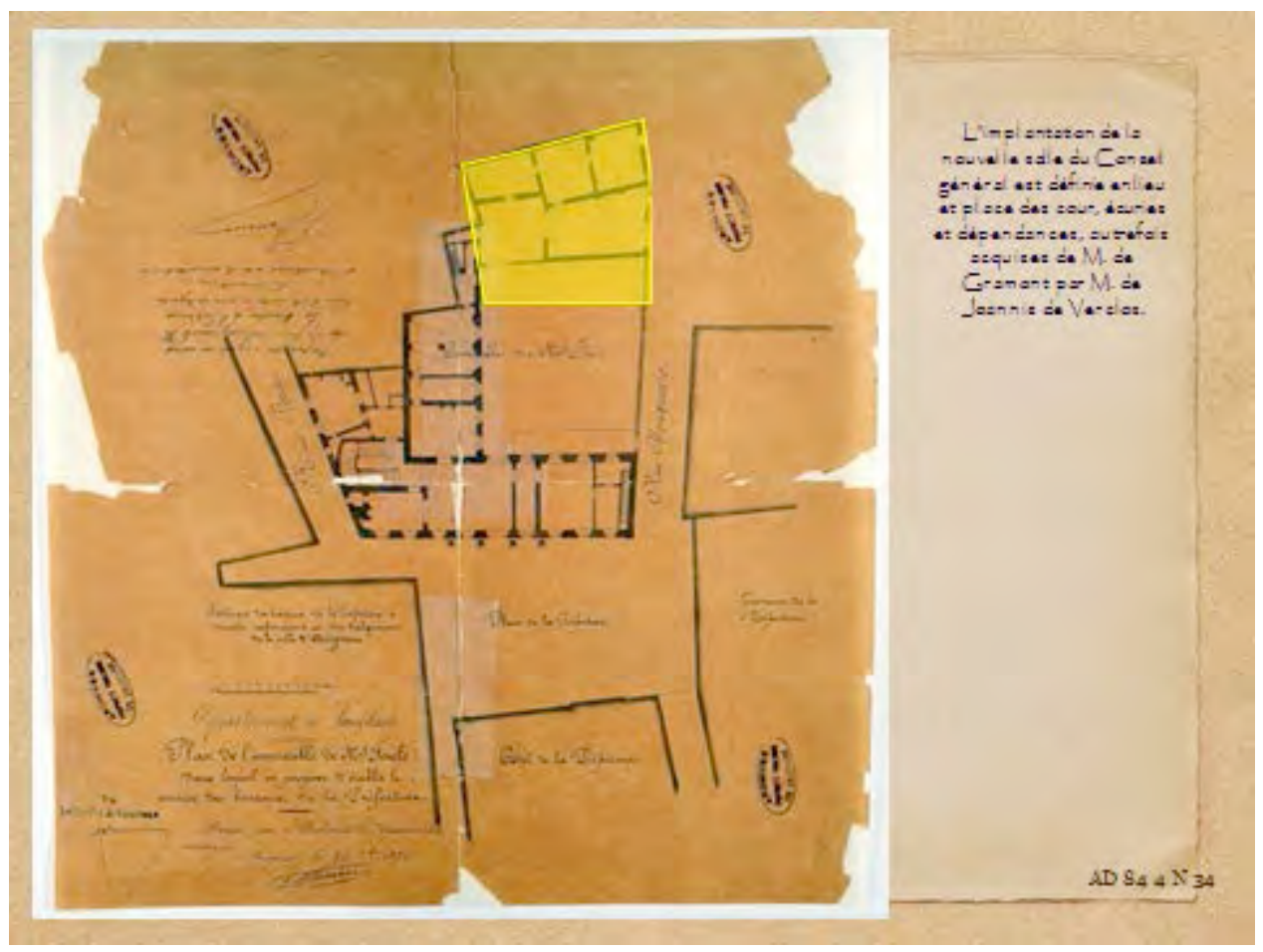


figure 3 : Plan de l'hémicycle, fonds Valentin, Archives municipales d'Avignon, 39 Z 1

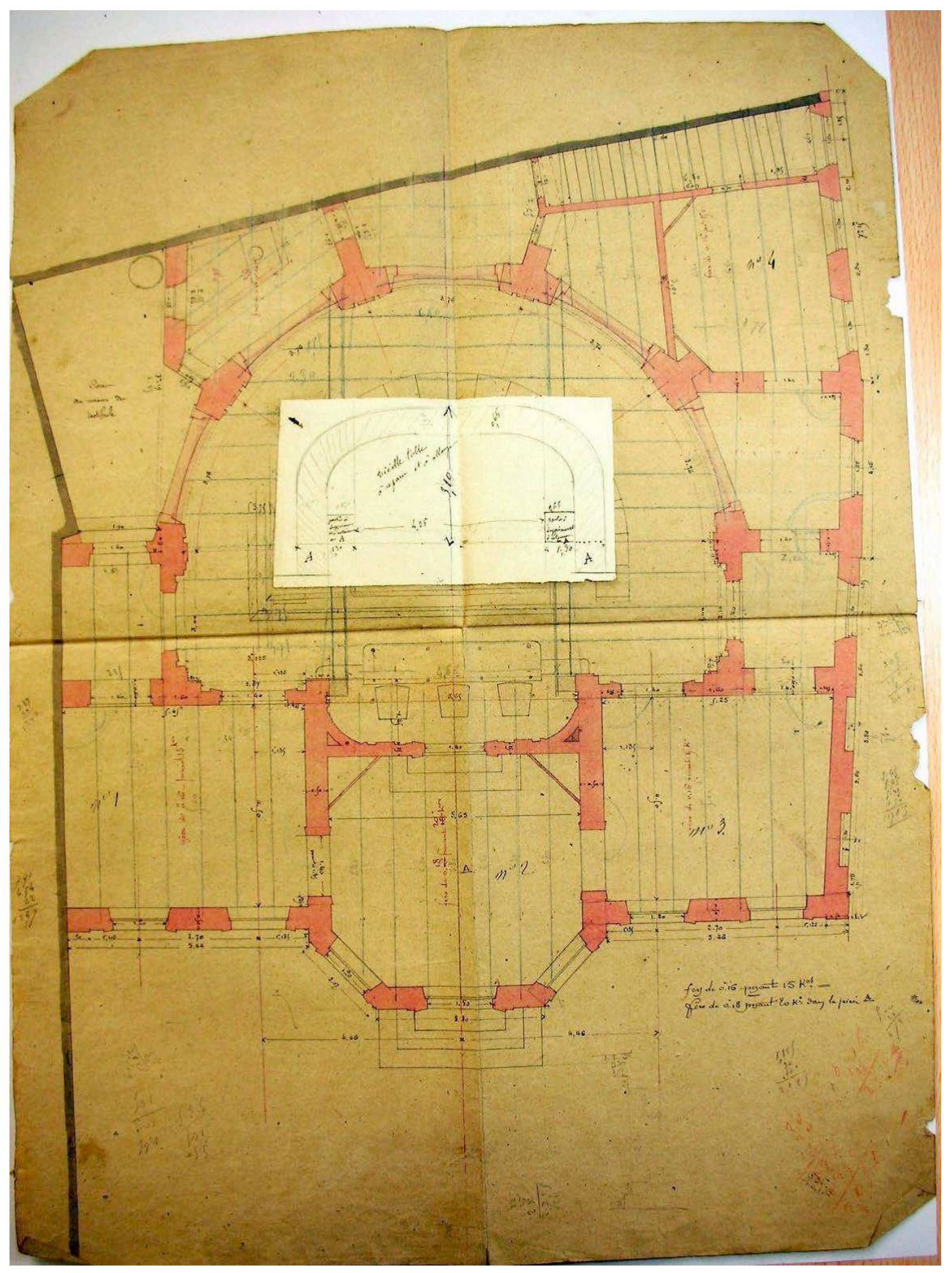


figure 4: Plan de l'hémicycle, signé Thiers, daté du 4 février 1876, Archives départementales de Vaucluse, 4 N plan 35

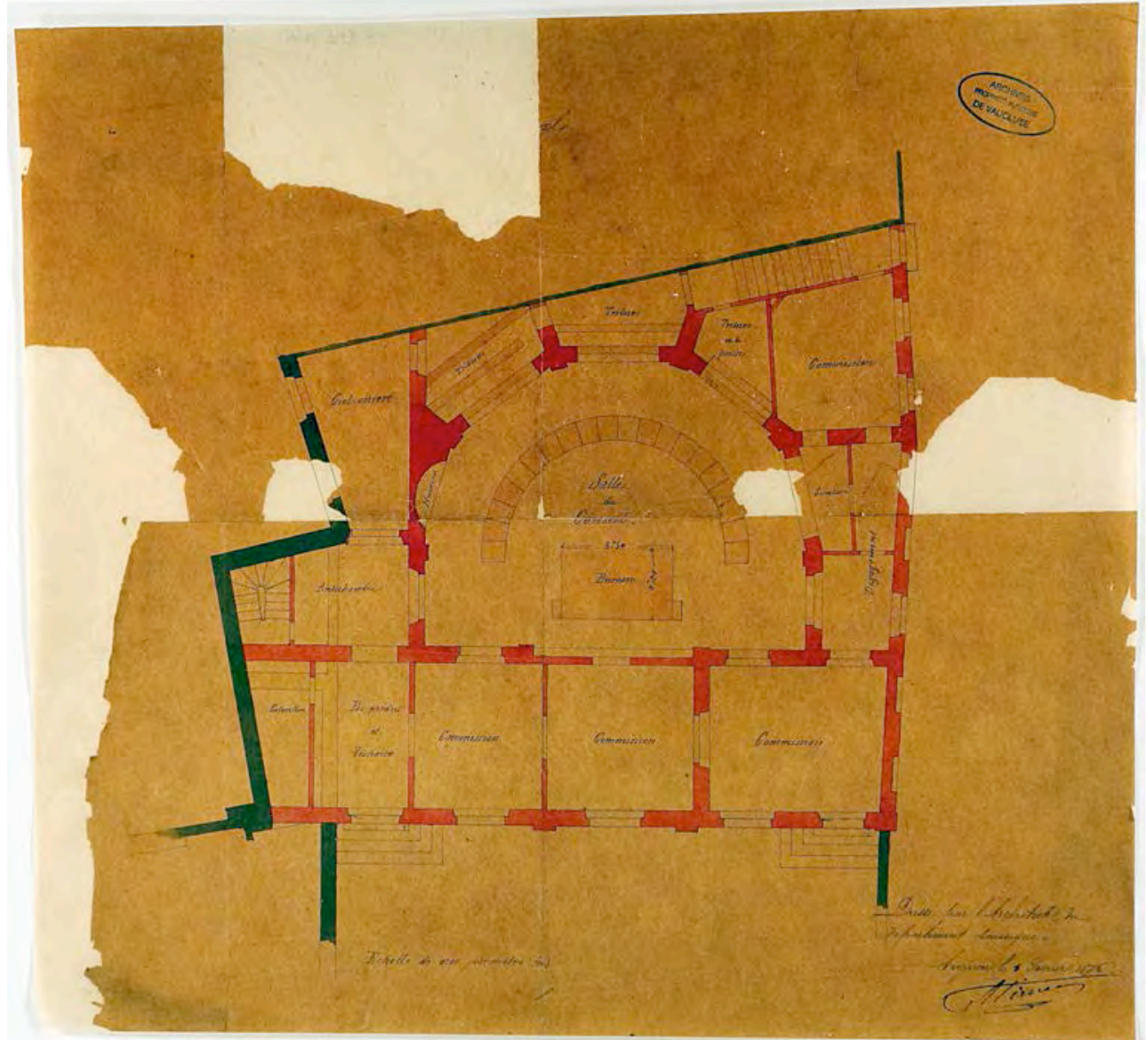

figure 5 : Vue de la façade sur cour, Archives départementales de Vaucluse, cliché J.-M Picasso, 2014

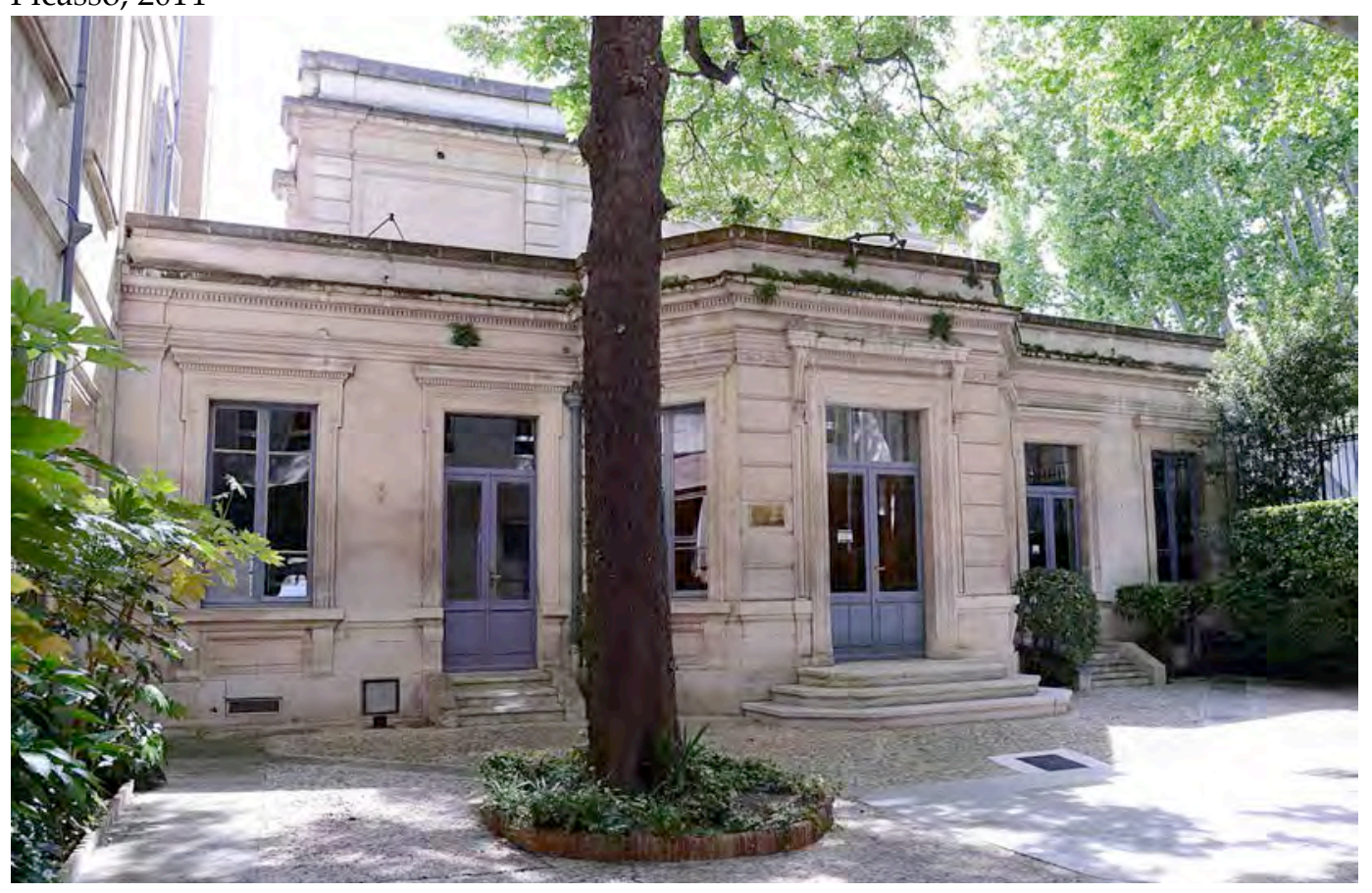


figure 6: Frise segmentée à décor de rosettes, fonds Valentin, Archives municipales d'Avignon, $39 \mathrm{Z} 1$

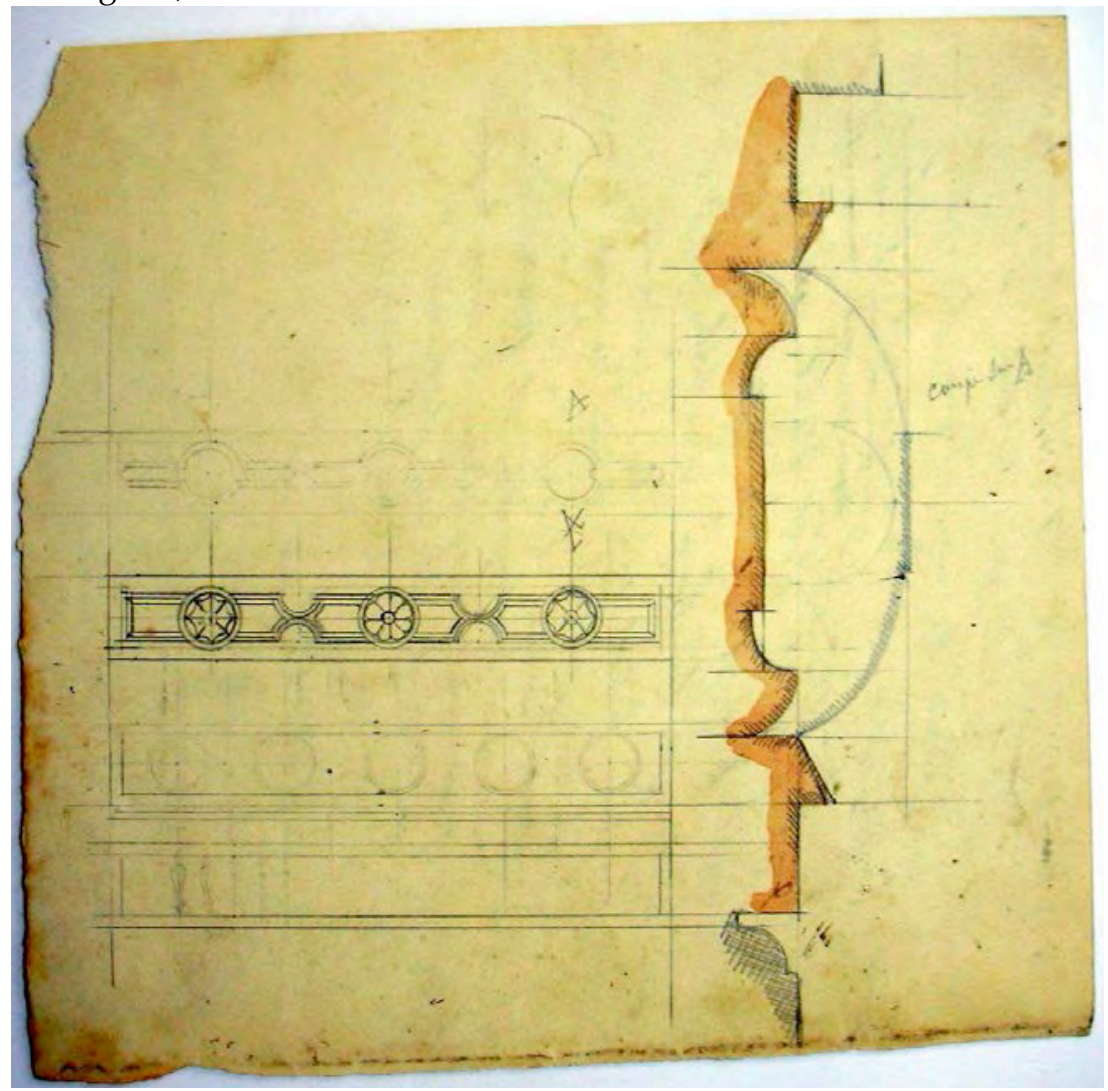

figure 7 : Plafond de la salle des délibérations, Archives départementales de Vaucluse, cliché J.-M Picasso, 2014

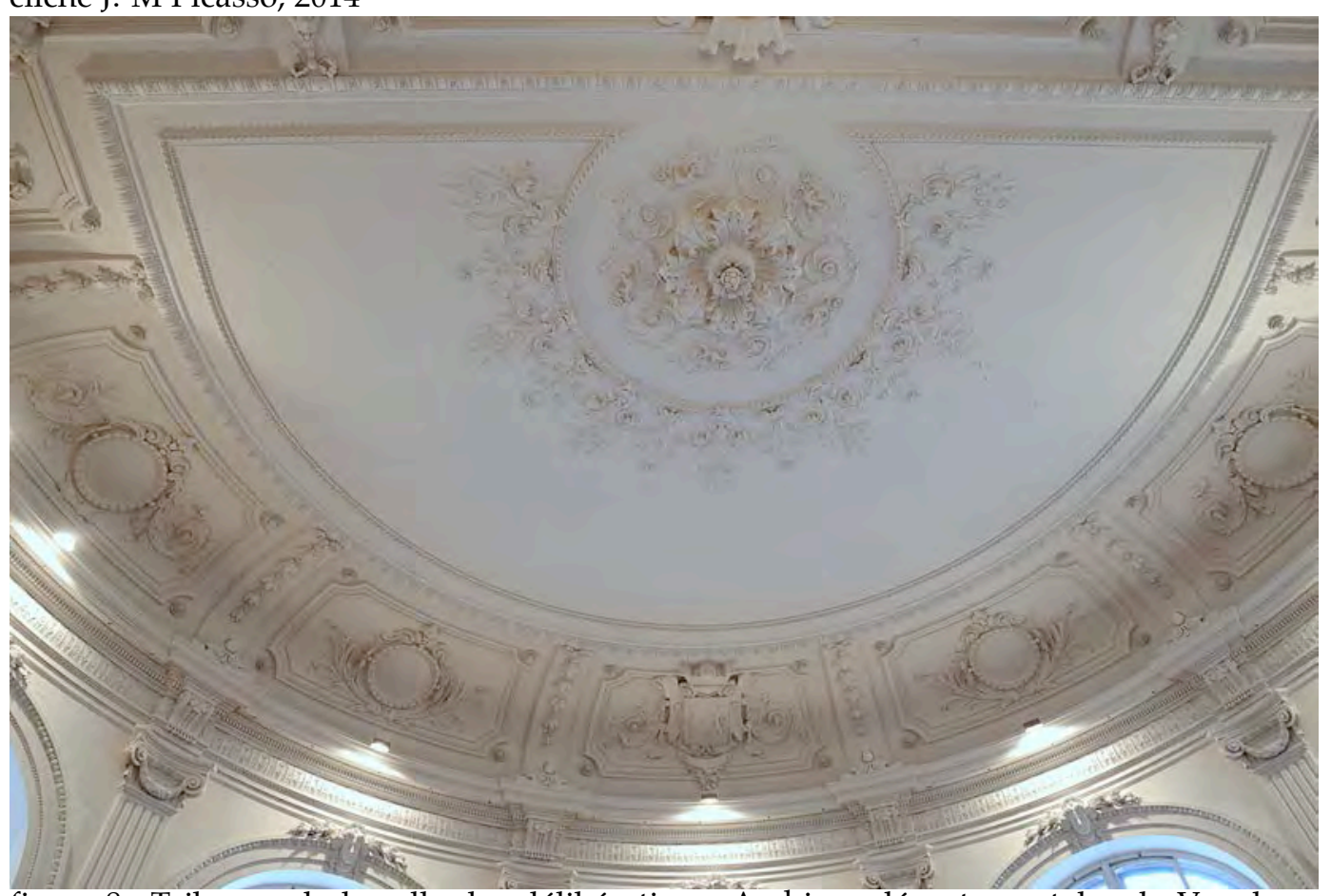

figure 8 : Tribunes de la salle des délibérations, Archives départementales de Vaucluse, 
cliché J.-M Picasso, 2014

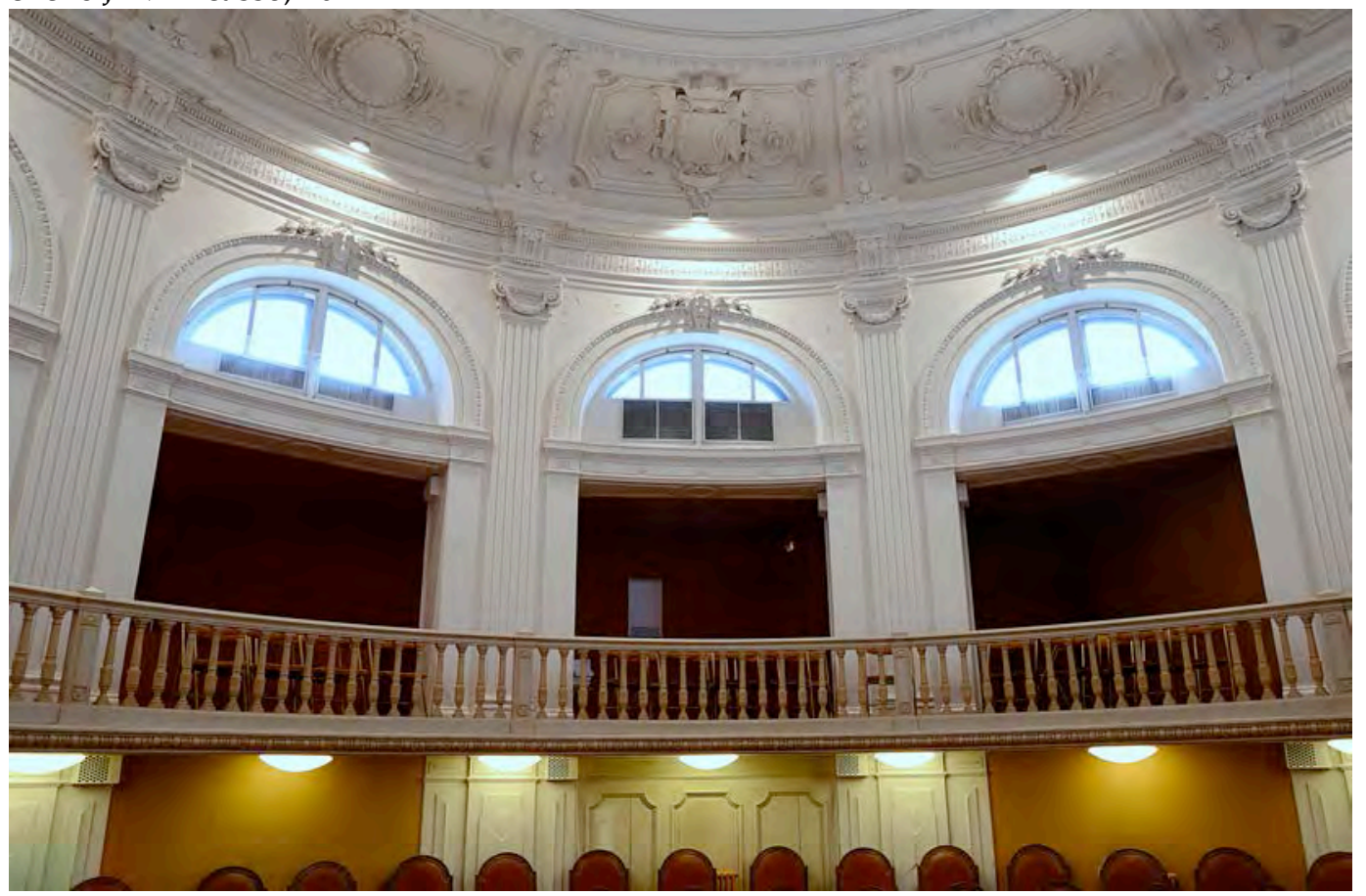

figure 9: Mur de fond de la salle des délibérations, Archives départementales de Vaucluse, cliché J.-M Picasso, 2014

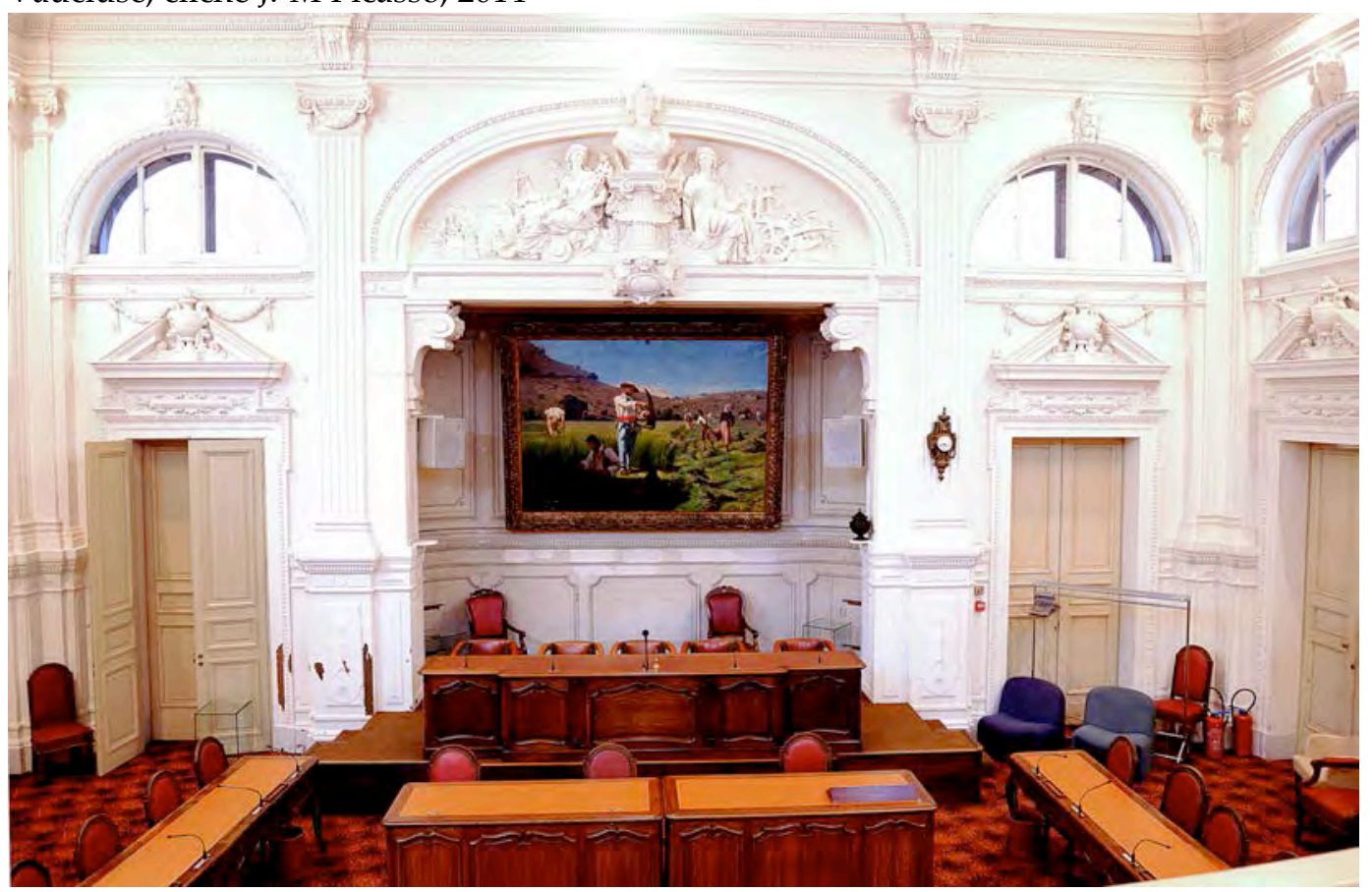


figure 10: Marianne, détail du «tympan de la grande ouverture » de la salle des délibérations, Archives départementales de Vaucluse, cliché J.-M Picasso, 2014

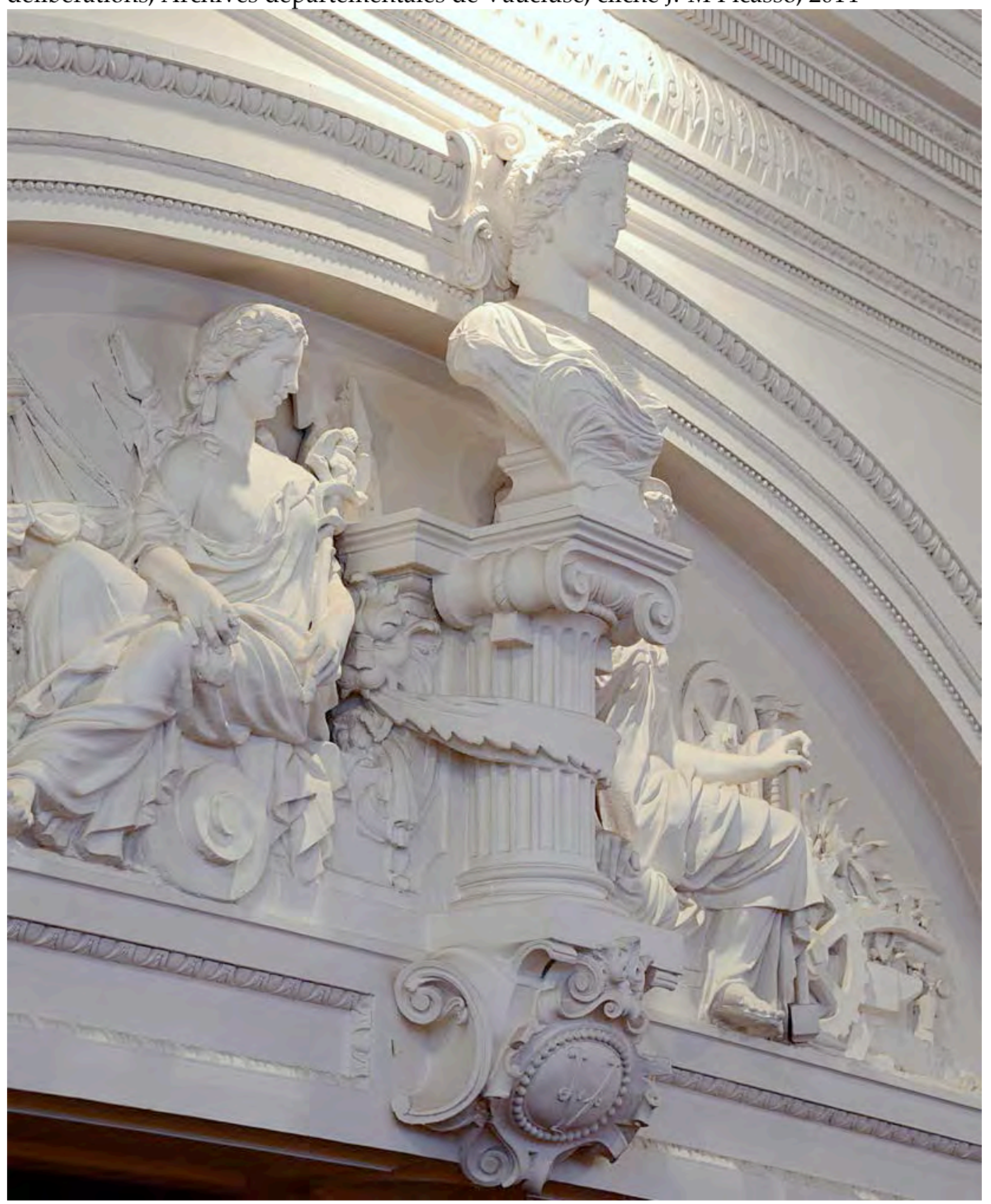

